\title{
Interventions to increase apolipoprotein A-I transcription in HepG2 cells
}

Citation for published version (APA):

van der Krieken, S. E. (2017). Interventions to increase apolipoprotein A-I transcription in HepG2 cells. [Doctoral Thesis, Maastricht University]. Uitgeverij BOXPress. https://doi.org/10.26481/dis.20170330svdk

Document status and date:

Published: 01/01/2017

DOI:

10.26481/dis.20170330svdk

Document Version:

Publisher's PDF, also known as Version of record

\section{Please check the document version of this publication:}

- A submitted manuscript is the version of the article upon submission and before peer-review. There can be important differences between the submitted version and the official published version of record.

People interested in the research are advised to contact the author for the final version of the publication, or visit the DOI to the publisher's website.

- The final author version and the galley proof are versions of the publication after peer review.

- The final published version features the final layout of the paper including the volume, issue and page numbers.

Link to publication

\footnotetext{
General rights rights.

- You may freely distribute the URL identifying the publication in the public portal. please follow below link for the End User Agreement:

www.umlib.nl/taverne-license

Take down policy

If you believe that this document breaches copyright please contact us at:

repository@maastrichtuniversity.nl

providing details and we will investigate your claim.
}

Copyright and moral rights for the publications made accessible in the public portal are retained by the authors and/or other copyright owners and it is a condition of accessing publications that users recognise and abide by the legal requirements associated with these

- Users may download and print one copy of any publication from the public portal for the purpose of private study or research.

- You may not further distribute the material or use it for any profit-making activity or commercial gain

If the publication is distributed under the terms of Article $25 \mathrm{fa}$ of the Dutch Copyright Act, indicated by the "Taverne" license above, 
Interventions to increase apolipoprotein A-I transcription in HepG2 cells 


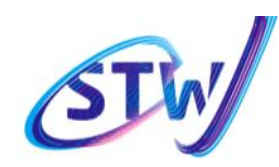

Enabling new technology
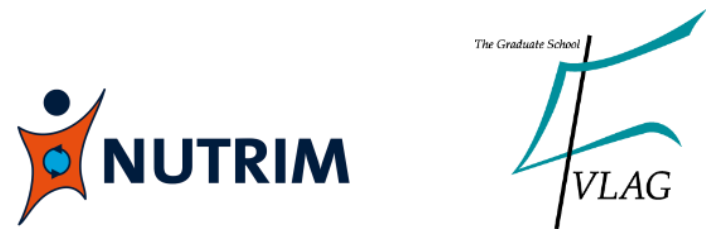

This research was supported by the Dutch Technology Foundation STW, which is part of the Netherlands Organisation for Scientific Research (NWO), and which is partly funded by the Ministry of Economic Affairs (project number 11349). The research was performed within NUTRIM School of Nutrition and Translational Research in Metabolism, which participates in the Graduate School VLAG (Food Technology, Agrobiotechnology, Nutrition and Health Sciences), accredited by the Royal Netherlands Academy of Arts and Sciences.

Cover design: ProefschriftMaken

Layout: Sophie. E. van der Krieken

Printed by: Proefschriftmaken II Uitgeverij BOXPress

(C) Copyright Sophie E. van der Krieken, Maastricht 2017

ISBN 9789462955684 


\title{
Interventions to increase apolipoprotein A-I transcription in HepG2 cells
}

\author{
PROEFSCHRIFT \\ ter verkrijging van de graad van doctor \\ aan de Universiteit Maastricht \\ op gezag van de Rector Magnificus, \\ Prof. dr. Rianne M. Letschert \\ volgens het besluit van het College van Decanen, \\ in het openbaar te verdedigen \\ op donderdag 30 maart 2017 om 16:00 uur
}

door

Sophie Elise van der Krieken

geboren te Eindhoven op 8 april 1989 


\section{Promotores}

Prof. dr. J. Plat

Prof. dr. ir. R. P. Mensink

\section{Co-promotor}

Dr. H.E. Popeijus

\section{Beoordelingscommissie}

Prof. dr. E.C.M. Mariman

(voorzitter)

Prof. dr. A.K. Groen

(Academisch Medisch Centrum, Amsterdam)

Prof. dr. S.A.H. Kersten

(Wageningen UR, Wageningen)

Dr. S. Rensen

Prof. dr. R. Shiri-Sverdlov 
Table of Contents

Chapter 1 General introduction

Chapter 2 CCAAT/enhancer binding protein $\beta$ in relation to ER-stress, inflammation, and metabolic disturbances

Chapter 3 C/EBP- $\beta$ is differentially affected by PPAR agonists Fenofibric acid and GW7647, but does not change apolipoprotein A-I production during ER-stress and inflammation

Chapter 4 Identification of natural PPARa transactivating compounds and their effects on apolipoprotein A-I transcription 85 in HepG2 cells

Chapter 5 Link between ER-stress, PPAR $\alpha$ activation and BET inhibition in relation to apolipoprotein A-I transcription 105 in HepG2 cells

Chapter 6 Fatty acid chain length and saturation influences PPAR a transcriptional activation and repression in HepG2 cells

Chapter 7 Structure similarity search for natural compounds that increase apolipoprotein A-I transcription in HepG2 cells: a focus on BRD4 inhibition

Chapter 8 General discussion

Summary

Samenvatting

Valorisation

Dankwoord

Curriculum vitae 213

List of publications 



\section{CHAPTER 1}

General introduction 


\section{CHAPTER 1}

\section{General introduction}

Despite remarkable improvements in prevention and treatment, cardiovascular diseases (CVDs) are still the leading cause of mortality worldwide [1]. Besides genetic factors, particularly behavioral risk factors such as an unhealthy diet, physical inactivity, cigarette smoking, obesity and excessive use of alcohol, contribute to CVD development [2]. CVDs can be classified as coronary heart diseases (CHDs), cerebrovascular diseases and peripheral arterial diseases and are all strongly related to dyslipidemia. Dyslipidemia is characterized by aberrant plasma lipid and lipoprotein concentrations and the unfavorable distribution of lipids over the different lipoprotein classes, and is defined by a Low Density Lipoprotein cholesterol (LDL-C) concentration above $2.6 \mathrm{mmol} / \mathrm{l}$ (or $100 \mathrm{mg} / \mathrm{dl}$ ) and/or a High Density Lipoprotein cholesterol (HDL-C) concentration under $1 \mathrm{mmol} / \mathrm{l}$ (or 40 $\mathrm{mg} / \mathrm{dl}$ ), and circulating triacylglycerol (TGs) of more than $1.7 \mathrm{mmol} / \mathrm{l}(150 \mathrm{mg} / \mathrm{dl})$. This disturbed lipid and lipoprotein profile, often seen in the metabolic syndrome, is highly associated with the development of atherosclerotic lesions in the artery walls (figure 1).

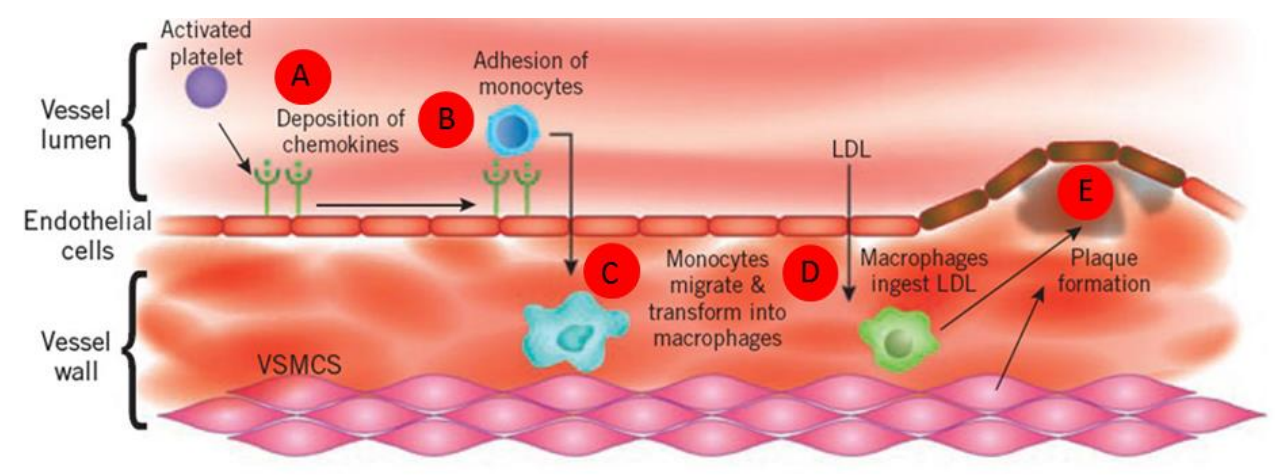

Figure 1. The development of atherosclerotic lesions, a process that is driven by inflammation. This figure was adapted from Fulmer et al. [3]. The development of atherosclerosis is a process that is already initiated during infancy. The onset of atherosclerosis may involve a response to injury of the endothelial wall [4] and the retention of small dense LDL particles from the circulation into the vessel wall [5] and is an inflammatory induced process. When LDL becomes trapped in the subendothelial space, it may undergo oxidative modification, forming oxy-LDL. The presence of oxy-LDL triggers the production of adhesion molecules $(A)$ and recruitment of monocytes (B) into the artery wall, where they differentiate into macrophages $(C)$. Oxidized LDL is then engulfed by the macrophages in such high amounts that they form lipid laden foam cells (D). Eventually, the accumulation of foam cells, smooth muscle cells and cell debris, covered by a fibrous cap, will give rise to a mature atherosclerotic plaque $(E)$ [6]. At this stage the plaque is prone to rupture, thereby causing myocardial infarction or stroke. 


\section{GENERAL INTRODUCTION}

The most successful example of a therapy to improve dyslipidemia is the use of statins that lower the atherogenic LDL-C concentrations. Statin treatment inhibits the enzyme HMG-CoA reductase, thereby lowering the production of cholesterol in virtually every single cell in the body. Particularly the inhibition of endogenous cholesterol synthesis in the liver contributes to a reduction in circulating LDL-C concentrations. In response to this lower endogenous cholesterol production, the hepatocytes increase their expression of the LDL-receptor, and as such enhance plasma cholesterol uptake. Currently, also the effects of PCSK9 inhibitors are tested in human studies [7]. PCSK9 inhibition decreased plasma LDL-C concentrations even further as it prevents degradation of the LDL-receptor, which further increases the uptake of LDL particles in the liver. Although the use of statins has clearly led to a reduction in CVD events [8], CVDs still occurred in a large portion of patients who already received statin treatment. Thus, in order to further reduce the CVD-related economic and societal burden, it is of major importance to discover additional interventions to further decrease this risk for CVD development. A promising strategy to decrease the detrimental effects of dyslipidemia related to atherosclerosis development is increasing the cholesterol efflux capacity, via increased transcription of apolipoprotein A-I (apoA-I), leading to the production of more functional HDL particles.

\section{HDL metabolism}

After transcription in the human hepatocytes or the small intestinal cells, apoA-I is produced as a pre-pro-protein, which is cleaved in the endoplasmic reticulum by the action of a signal peptidase [9]. This cleavage results in the formation of intracellular pro-apoA-I, which is secreted by the cell into the extracellular space. Subsequently, the pro-segment is removed by the action of Bone Morphogenetic Protein-1 (BMP-1) and Procollagen C-proteinase Enhancer-2 Protein (PCPE2) $[10,11]$. At this stage, the C-terminal domain of the lipid free or lipid poor apoA-I particle can interact with the adenosine triphosphate-binding cassette $A 1$ (ABCA1) transporter on the surface of macrophages, endothelial cells, hepatocytes and small intestinal cells, facilitating cholesterol, sphingomyelin and phospholipid uptake $[12,13]$. Besides formation of apoA-I in the small intestine and hepatocytes, apoA-I can also be released from LPL mediated lipolysis of VLDL and chylomicrons [14]. The initial lipidation of apoA-I already takes place in the endoplasmic reticulum of the apoA-I producing cell and occurs independent of $A B C A 1$ [15]. Likewise, in the Golgi and the plasma membrane, by using a dimeric form of $A B C A 1$, apoA-I already gains some lipids $[16,17]$. By the uptake of free cholesterol and phospholipids, first pre- $\beta 2 \mathrm{HDL}$ is formed. Next a discoid pre- $\beta 3$ HDL particle is formed that can take up cholesterol and store it in the lipid bilayer [18]. The enzyme lecithin-cholesterol acyl transferase (LCAT) facilitates the conversion into HDL3 by transforming the cholesterol in the bilayer into hydrophobic cholesterol esters. These cholesterol esters can be exchanged for TGs from very low-density lipoprotein (VLDL), LDL and intermediate low-density lipoprotein (IDL)-particles. This process is facilitated by cholesteryl ester transfer protein (CETP). The HDL3 particle can bind to the ABCG1 receptor on the macrophages of the vessel wall, thereby increasing reverse cholesterol transport (RCT), and converting the HDL3 particles into HDL2 particles [18]. The HDL2 


\section{CHAPTER 1}

particle can be converted into lipid poor apoA-I again by binding to SR-B1 receptor. Alternatively, the entire particle can be taken up via the holo-receptor in the liver. HDL2 could also be transferred into HDL3 again by the action of lipases such as hepatic lipase (HL) and endothelial lipase (EL) or phospholipid transfer protein (PLTP), which hydrolyze triglycerides (TG) and phospholipids, or phospholipids [14].

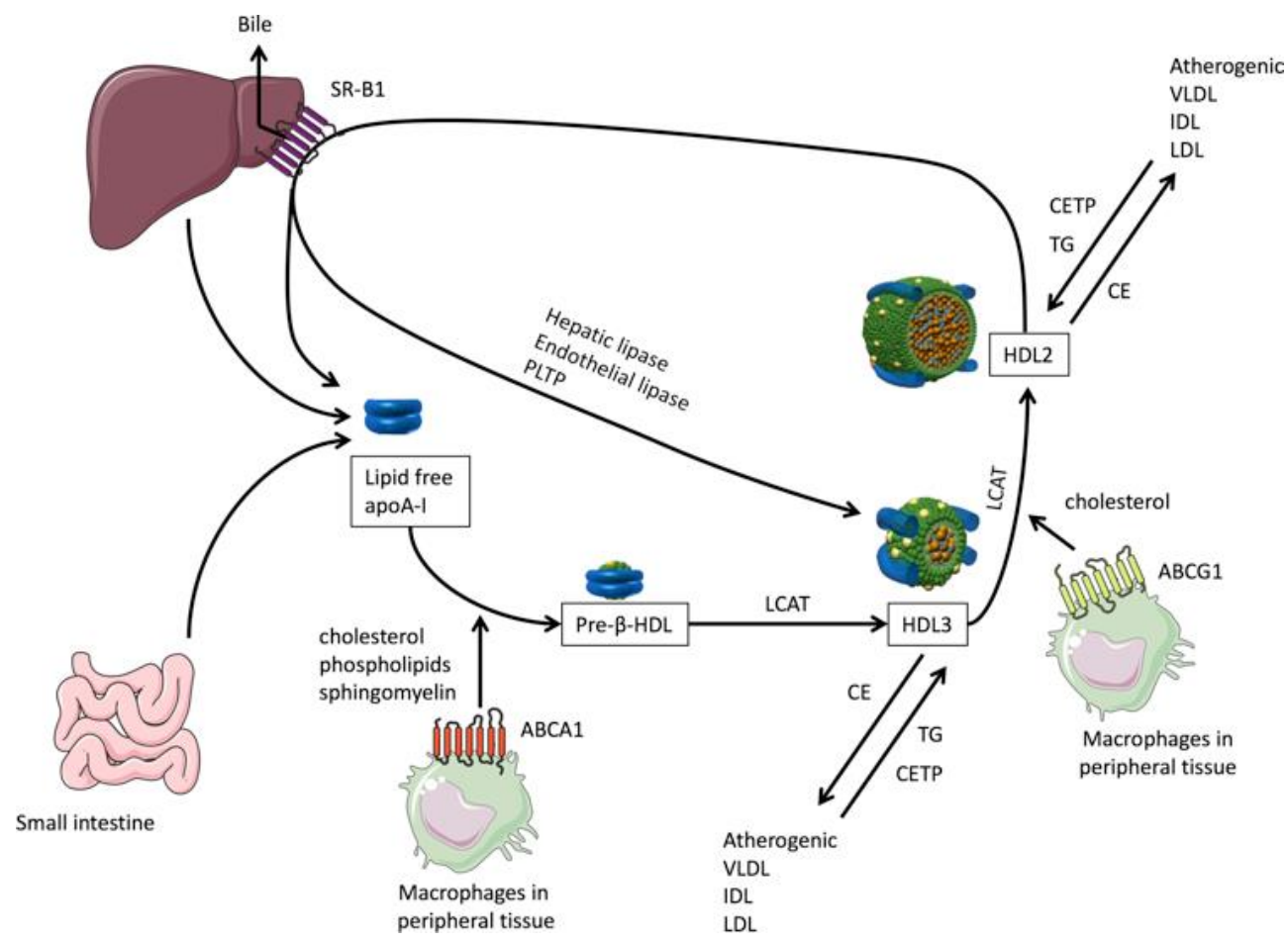

Figure 2. HDL metabolism and reverse cholesterol transport (RCT). ApoA-I, which is produced in the human intestine and liver, obtains cholesterol, phospholipids and sphingomyelin, via the $A B C A 1$ and $A B C G 1$ transporters in the atherosclerotic lesion or peripheral tissue. HDL particles can bind to the SR-B1 transporter to bring the obtained cholesterol to the liver for the production of bile acids. The HDL particles can become lipid free apoA-I or HDL3 particles again which enables them to participate in the RCT process again, or it can be cleared by the kidneys.

\section{Interventions strategies to increase HDL-C}

Previous large-scale prospective and epidemiological studies [19-25] have shown an inverse relationship between serum HDL-C concentrations and CVD events, even after LDL-C reductions. Additionally, it was stated that every $1 \%$ increase in HDL-C might reduce CVD risk by 2 to $3 \%$ [26]. The HDL particle indeed possesses antithrombotic [27], anti-inflammatory [28,29] and anti-oxidative properties [30]. Furthermore, HDL is an important player in the RCT pathway [31]. During RCT the 


\section{GENERAL INTRODUCTION}

HDL particle accepts cholesterol from the cholesterol-loaded macrophages in the atherosclerotic plaque and transports this back to the liver. In the liver the cholesterol can be used for the production of bile acid or the incorporation into VLDL. Therefore, increasing HDL-C was believed to reduce the risk for CVD development, independent of LDL-C reductions.

Interestingly, the hypothesis that HDL-C is causally related to CVD development has been seriously challenged by recent trials, as several interventions that increased HDL-C, failed to reduce CVD risk. One example of such an intervention is niacin treatment $[32,33]$. Niacin modulates plasma lipid concentrations, as it increases HDL-C and decreases LDL-C and triglyceride concentrations, but it did not reduce CVD risk and even showed severe side-effects like bleeding, flushing and itching, which made early trial termination necessary [32,34]. Another method to raise HDL-C is by CETP inhibition [35]. As explained earlier, CETP is involved in the transfer of cholesterol esters from HDL-C to the more atherogenic lipoproteins (VLDL, IDL, LDL). A study using CETP inhibitor torcetrapib was even terminated in 2006 due to higher mortality rates in the treatment group [36] and an off-target effect on blood pressure via its influence on the renin-angiotensin-aldosterone system [37]. Despite of increasing effects on HDL-C, additional studies using the CETP inhibitors evacetrapib [38] and dalcetrapib [39] failed to show clinically meaningful efficacy. Currently, studies with anacetrapib (REVEAL) and TA-8995 are ongoing [40]. These studies should give a definite answer on the question if CETP inhibition is a promising method for CVD risk management. Another HDLtargeted therapy is the use of fibrates. Fibrates are activators of peroxisome proliferator-activated receptor alpha (PPAR $\alpha$ ), a known transcription factor involved in HDL production. The effects of fibrates are multifactorial, as they may lower plasma VLDL-C, LDL-C, increase HDL-C and reduce triglyceride concentrations. Clearly, these effects contribute to a reduction in CVD risk. However, the clinical use of for example gemfibrozil is decreasing, because of concerns for adverse effects and limited data in reducing CVD related morbidity and mortality [41]. An earlier meta-analysis on fibrates concluded that although fibrates increase HDL-C, they did not decrease the incidence of CVD in patients treated with statins [42].

Next to several HDL-targeted therapies that failed to show a direct link between HDL-C and CVDs, the HDL-C hypothesis was questioned due to genetic polymorphism studies, as in these studies raised human plasma HDL-C did not reduce the risk for myocardial infarctions [43]. Therefore, a new focus is currently developing, which stresses the importance of increasing HDL particle functionality, rather than the absolute concentration of HDL-C in the blood plasma $[44,45]$.

\section{HDL particle functionality}

Recent evidence suggests that increased cholesterol- efflux capacity protects against development of CVD [46] and recurrence of CVD [47]. HDL particle functionality is determined by measuring cholesterol-efflux capacity, which is the capacity of HDL to accept cholesterol from cholesterol-loaded macrophages [48]. The ABCA1 transporter is the mediator of cholesterol efflux. HDL particles vary in their size and molecular composition. It is the difference in the functional activity of these sub-fractions of HDL that determines their cholesterol efflux capacity. Especially the small dense HDL particles (pre- $\beta-H D L, H D L 3$ ) interact with the 


\section{CHAPTER 1}

ABCA1 transporter, thereby mediating cholesterol efflux from the macrophages. This is why increasing large HDL particles via decreased HDL catabolism or clearance is probably not beneficial and the focus should be on production of the small dense HDL particles such as pre- $\beta$-HDL [49]. Also, this provides a possible explanation for the inability of clinical trials using HDL-C increasing agents such as CETP inhibitors, to reduce cardiovascular events [12]. Therefore, studies should focus on increasing the amount of HDL particles that are highly capable of promoting cholesterol efflux.

\section{Apolipoprotein A-I as a target for CHD risk reduction}

Approximately $70 \%$ of a HDL particle consists of apolipoprotein A-I (apoA-I) [50]. As mentioned, evidence suggests that not an increased HDL-C, but elevated serum apoA-I concentrations should be the target for CVD reduction [51]. Many atheroprotective properties have been ascribed to apoA-I [52], in particularly its role in increasing cholesterol efflux from macrophages in the artery wall. The importance of increasing apoA-I production in order to form functional HDL is highlighted by studies concerning genetic variations in genes encoding for proteins involved in HDL metabolism [53,54]. Also, mutations in the gene for apoA-I might impair HDL particle function [55]. The anti-atheroprotective properties of apoA-I have been confirmed in in vivo studies. Mice that were transfected with the human gene for apoA-I were protected against CVD development, as they were protected against lesion formation [56,57]. Furthermore, apoA-I mimetics may be a beneficial strategy to decrease atherosclerosis [58], as the infusion of recombinant apoA-I reduced lesion size in patients with acute coronary syndromes [59]. Moreover, intravenous infusion of a novel formulation of apoA-I CSL112 in subjects with stable atherosclerosis caused a three-fold increase in total cholesterol efflux capacity [60]. Together, this evidence illustrates that increasing apoA-I transcription may be a promising strategy for CVD prevention. Thus, in order to increase HDL functionality we need to discover factors that increase apoA-I transcription, which will be the main focus of this thesis. In addition, several features of the metabolic syndrome, such as inflammation and ER-stress decrease apoA-I transcription. Previous studies have discovered the presence of ER-stress especially in the vulnerable atherosclerotic plaque [61]. Also inflammation is a key feature in the development of atherosclerosis [62]. Therefore, in this thesis also the effects of these detrimental metabolic effects on apoA-I were studied. 


\section{GENERAL INTRODUCTION}

\section{Apolipoprotein A-I transcription}

ApoA-I comprises a total of 243 amino acids and is mainly produced in the human hepatocytes and enterocytes from the small intestine. The apoA-I gene is located at chromosome 11 of the human genome. Transcription of apoA-I is the result of a complex interplay between transcription factors, inhibitors and activators, and only occurs in the presence of the apoA-I enhancer, the apoA-I promoter and the apoCIII enhancer. Especially in the intestine, apoA-I transcription is regulated via aforementioned regions, while in hepatocytes the presence of the apoA-I promoter is sufficient for apoA-I transcription [63].

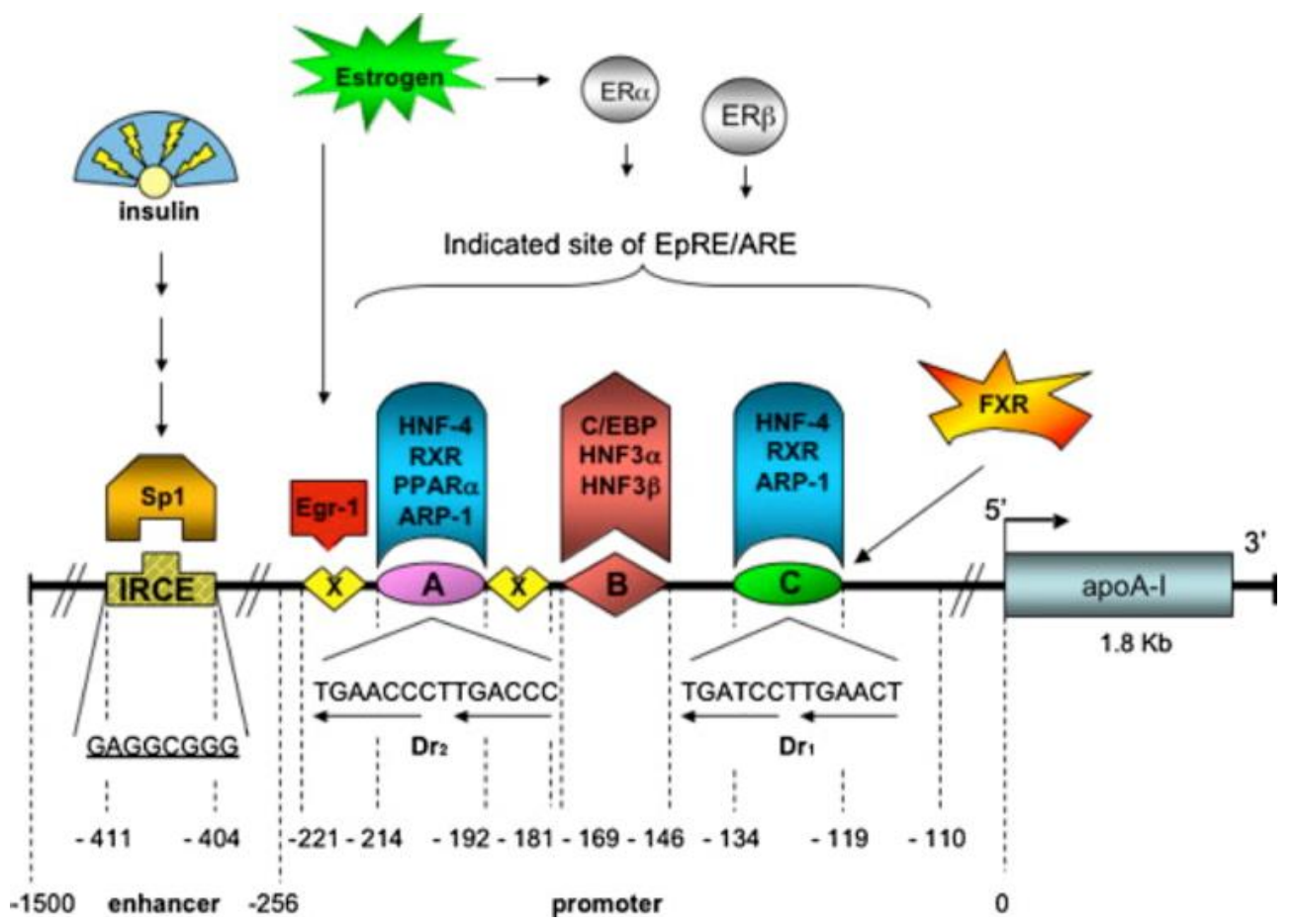

Figure 3. Model of the apoA-I promoter/enhancer region. Image retrieved from Dullens et al. [64].

From the apoA-I promoter/enhancer region (figure 3), the elements " $A$ ", "B" and "C" are essential for apoA-I gene expression. Both the elements $A$ and $C$ contain a hormone response element (HRE), which is a binding site for several nuclear receptors, amongst others HNF-4 [65]. Moreover, the presence of antioxidant response elements (AREs) was described in the promoter of apoA-I [66,67]. In addition, element $A$ has a PPAR response element (PPRE) which can bind for example to transcription factor peroxisome proliferator-activated receptor alpha (PPARa), a transcription factor involved in the transcription of apoA-I [68]. Thus, although both element $A$ and $C$ contain a HRE binding place, the retinoid $X$ receptor (RXR)/PPARa heterodimer exclusively binds to element $A$ [69]. Element $B$ of the promoter region can bind CCAAT-enhancer binding proteins (C/EBP) [70], 


\section{CHAPTER 1}

Hepatic Nuclear Factor alpha (HNF3 $\alpha$ ) and beta (HNF3 $\beta$ ) [71]. Moreover, some compounds are known to activate the elements in the apoA-I promoter/enhancer region. For example, insulin is able to activate $\mathrm{Sp} 1$, thereby activating the insulin response core element (IRCE). IRCE activation was shown to enhance apoA-I production [72]. Furthermore, the estrogen pathway may induce apoA-I promoter activation, as the promoter contains several response elements, which are activated by estrogen receptor alpha (Era) and estrogen receptor beta $(\operatorname{Er} \beta)$. FXR, on the other hand, can reduce apoA-I promoter activation in mice [73] and is therefore suggested to decrease apoA-I gene activity. As stated earlier, intestinal apoA-I gene expression is also regulated by the apoC-III promoter/enhancer region [74]. Both the promoter and enhancer regions contain HRE binding sites, whereas the apoC-III enhancer provides binding places for Sp1.

\section{Strategies to increase apoA-I production}

Increasing apoA-I is a promising strategy to enhance HDL particle functionality, which may subsequently decrease the risk for CVD development and recurrent CVD [46,48]. ApoA-I concentrations in plasma can be increased using different strategies. Next to the beneficial effects of apoA-I mimetics or intravenous infusion of apoA-I particles, another promising strategy is to focus on enhancing transcription of de novo apoA-I.

Several PPAR $\alpha$ activators such as GW7647 and/or PPAR activating fibrates have been reported to increase apoA-I transcription. The fibrates gemfibrozil and fenofibric acid have been proposed as agents to respectively increase apoA-I or to increase the cholesterol efflux capacity towards apoA-I [75,76]. Also PPARa agonist GW7647 is known to increase apoA-I production [77] and GW7647 enables enhanced cholesterol efflux to apoA-I in hypercholesterolemic mice expressing the human apoA-I gene [78]. Probably fenofibric acid exerts its actions via increased $A B C A 1$ transporter production, rather than via increased production of apoA-I.

Recently, a group of compounds called Bromodomain and Extra-Terminal (BET) inhibitors was discovered that clearly increased apoA-I production, as shown in in vitro and in vivo studies with monkeys and humans [79]. In humans, the BET proteins BRD2, BRD3, BRD4 and testes specific BRD-T are found. The BET proteins are involved in the activation of the transcription machinery by binding to the acetylated histone residues in the DNA, making it accessible to transcription factors. Although the exact mechanism is not known, BET inhibitors act through an epigenetic mechanism in which they inhibit the BET family of proteins from binding to the acetylated histone residues, thereby increasing apoA-I transcription. BET inhibitors with a favorable effect on apoA-I transcription are for example RVX-208 [80], JQ1(+) [81], I-BET151 [82] and GW841819X [83]. In a recent study, it was shown that RVX-208 decreased also pro-atherosclerotic, pro-inflammatory, proatherogenic and pro-thrombotic pathways that might contribute to CVD risk [84]. However, the exact mechanism behind the process of BET inhibition is not completely understood.

To summarize, although aforementioned strategies are promising to increase apoA-I transcription and consequently HDL functionality, there is an urgent need to identify novel compounds that increase apoA-I transcription and to understand the 


\section{GENERAL INTRODUCTION}

processes involved in apoA-I transcription. Moreover, until now the focus has been mainly on the identification of synthetic agents to increase apoA-I transcription. Therefore, it is of interest to discover natural compounds with comparable effects on apoA-I transcription.

\section{Endoplasmic reticulum stress in relation to CVD}

Next to the involvement of inflammation in the onset of atherosclerosis, also endoplasmic reticulum (ER)- stress is involved in disturbed HDL metabolism [85] and atherosclerosis development $[61,86,87]$. In the atherosclerotic lesion, the presence of ER-stress was specifically found in lesions that were unstable, and thus were prone to rupture $[88,89]$. Furthermore, ER-stress is also involved in the onset of other metabolic syndrome related diseases such as diabetes, as ERstress in the pancreatic cells leads to damage, which could influence insulin secretion and prevent glucose homeostasis [90]. Markers of ER-stress are increased during obesity in mice, and artificial induction of ER-stress by the addition of thapsigargin or tunicamycin has been shown to reduce apoA-I production [91] and insulin signaling [92,93], via disruption of calcium levels and inhibition of protein glycosylation, respectively.

The ER normally ensures the folding of newly synthesized proteins. During cellular stress conditions, such as hyperglycemia or alterations in cellular calcium level, poorly folded proteins accumulate in the ER, which is detected by the ER-resident trans membrane sensors ATF6, PERK and IRE1 [94,95] (figure 4). First, GRP78 senses unfolded proteins in the ER, after which it dissociates from the three main ER-stress sensors and binds to proteins that are accumulated in the ER. This step is the trigger for the onset of the unfolded protein response (UPR) response [96]. Initially, the UPR attempts to cope with ER-stress by the attenuation of protein translation to stop formation of new proteins, or the induction of chaperone genes that promote protein folding and induce the ER-associated degradation (ERAD) system, thereby inducing proteasome-dependent protein degradation. If these pathways fail to restore cellular homeostasis, for example when there is prolonged ER-stress, this UPR response will eventually trigger apoptosis [94]. 


\section{CHAPTER 1}

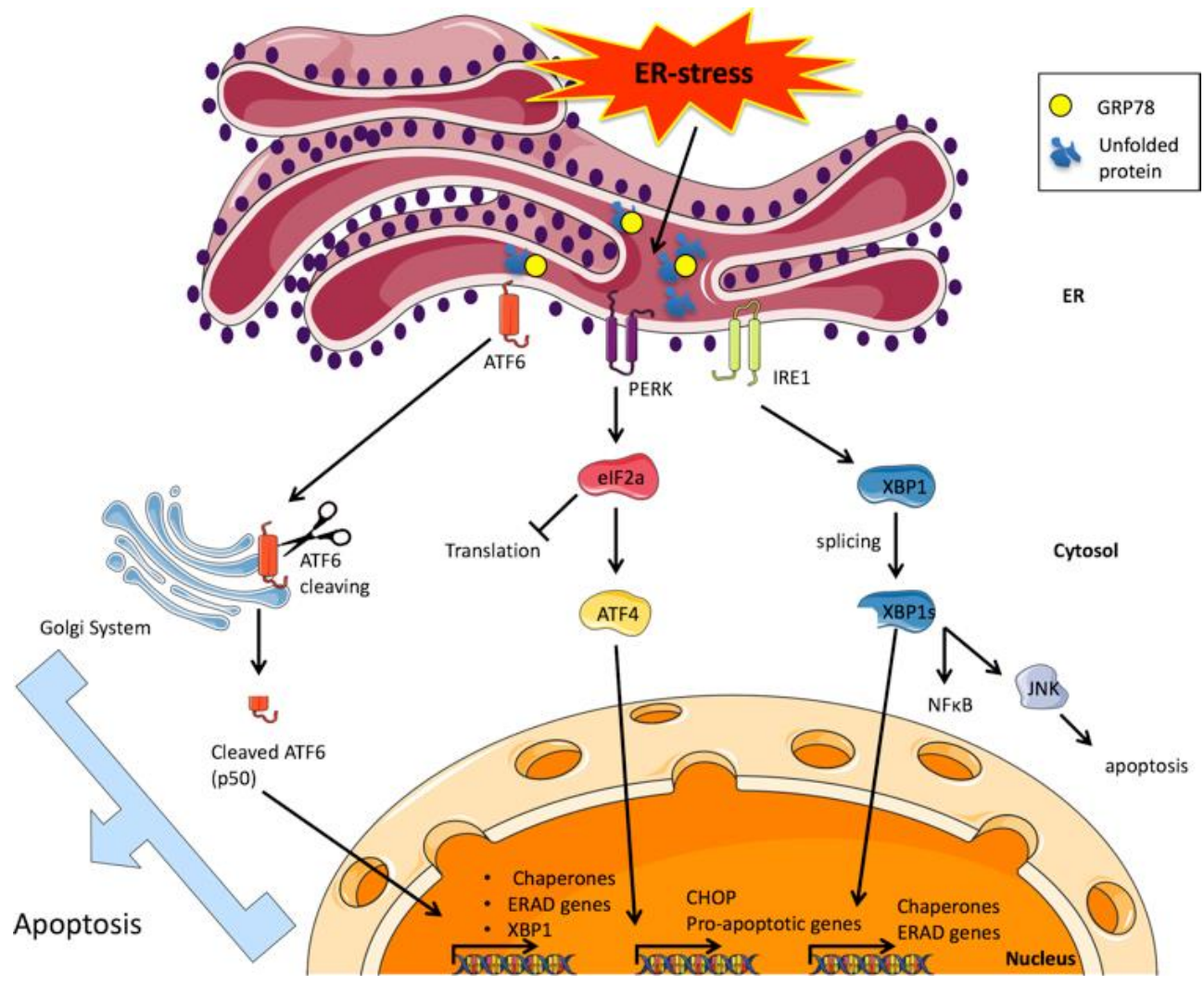

Figure 4. Schematic representation of the ER-stress induced UPR pathway, in a situation of prolonged ER-stress. In a situation of ER-stress, GRP78 proteins that are normally bound to the three ER-resident trans membrane sensors ATF6, PERK and IRE1, dissociate and bind to the unfolded proteins. This initiates the unfolded protein response (UPR). After activation, ATF6 is cleaved in the cytosol and is translocated to the nucleus, where it induces chaperone production to aid in protein folding and ERAD related genes. PERK induces elF2a, which leads to a block of initial translation, and ATF4 production. In the nucleus ATF4 initiates the transcription of CHOP. In the IRE1 pathway, activation results in XBP1 splicing and the production of chaperones and ERAD genes, while JNK activation induces apoptosis. 


\section{Outline of the thesis}

In this thesis, we focused on the identification and description of the effects of several (natural) compounds and cellular metabolic syndrome related pathways, such as ER-stress or inflammation, on the transcription of apoA-I. Furthermore we aimed to discover strategies to increase the transcription of apoA-I. In chapter 2 of this thesis we reviewed the involvement of the C/EBP- $\beta$ gene in the metabolic syndrome. The choice to investigate the C/EBP- $\beta$ gene was based on preliminary data of Dullens et al. [77]. Although generally accepted that PPARa is involved in increasing apoA-I production, Dullens et al. showed that two PPARa agonists fenofibric acid (FeAc) and GW7647 exerted different effects on apoA-I production in a human carcinoma liver cell line (HepG2) and human intestinal cell line (CaCo2). Using a microarray approach, we aimed to identify genes that might be responsible for the different effects of these two PPARa agonists on apoA-I production. C/EBP- $\beta$ was one of the genes that were differentially expressed in the FeAc vs GW7647 conditions. Furthermore, in the apoA-I gene a binding place for $\mathrm{C} / \mathrm{EBP}$ is found. Therefore, in chapter 3 of this thesis we aimed to identify, based on the microarray of Dullens et al., the effects of C/EBP- $\beta$ on apoA-I production. We focused on C/EBP- $\beta$ in particular, as in the promoter of the apoA-I gene a C/EBP binding place is found. C/EBP- $\beta$ overexpression and gene silencing experiments were performed and effects on apoA-I production were measured. In chapter 4 we aimed to discover natural compounds that are able to increase apoAI transcription via a PPARa approach. Natural compounds from a database of the company DSM were screened for PPARa transactivation and tested for their ability to activate PPARa target gene CPT1 $\alpha$. Twenty-three resulting compounds were tested in vitro for their ability to increase apoA-I transcription. Chapter 5 focused on a possible link between three processes that are known to influence apoA-I transcription: endoplasmic reticulum (ER) stress, bromodomain and extra terminal (BET) protein inhibition and PPARa activation. In chapter 6 we examined doseresponse relationships between several fatty acids and PPARa transactivation in HepG2 cells. Many studies have only evaluated only the binding of fatty acids to the PPARa promoter. However, this does not necessarily lead to PPARa transactivation. Apparently, also other factors next to PPARa are involved in increasing apoA-I production. Furthermore, we showed that the effects on PPARa transactivation are dose-dependent. Recent evidence also showed that bromodomain inhibition increases apoA-I production. Therefore, in chapter 7 in silico compound similarity searches were performed to discover, if apoA-I increasing compounds and/or bromodomain inhibitors showed structural overlap. In addition, the structure of apoA-I increasing compounds and/or bromodomain inhibitors was compared with the compounds in two natural databases. Finally, in chapter $\mathbf{8}$ the main outcomes of all studies are discussed and placed into broader perspective. 


\section{CHAPTER 1}

\section{References}

1. Organization WH (June 2016) Cardiovascular diseases (CVDs) fact sheet Available from: http://wwwwhoint/mediacentre/factsheets/fs317/en/.

2. Dahlof B (2010) Cardiovascular disease risk factors: epidemiology and risk assessment. Am J Cardiol 105: 3A-9A.

3. Fulmer (2009) Disrupting atherosclerosis. Institute for molecular cardiovascular research available from: $\quad$ http://www.imcar.rwth-aachen.de/news/2009/03-03-carolus-therapeuticsscibx/index.php, September 2016.

4. Ross R, Glomset JA (1973) Atherosclerosis and the arterial smooth muscle cell: Proliferation of smooth muscle is a key event in the genesis of the lesions of atherosclerosis. Science 180: 1332-1339.

5. Simionescu M, Simionescu N (1993) Proatherosclerotic events: pathobiochemical changes occurring in the arterial wall before monocyte migration. FASEB J 7: 1359-1366.

6. Jonasson L, Holm J, Skalli O, Bondjers G, Hansson GK (1986) Regional accumulations of T cells, macrophages, and smooth muscle cells in the human atherosclerotic plaque. Arteriosclerosis 6: $131-138$.

7. Blom DJ, Dent R, Castro RC, Toth PP (2016) PCSK9 inhibition in the management of hyperlipidemia: focus on evolocumab. Vasc Health Risk Manag 12: 185-197.

8. Stone NJ, Robinson JG, Lichtenstein AH, Bairey Merz CN, Blum CB, et al. (2014) 2013 ACC/AHA guideline on the treatment of blood cholesterol to reduce atherosclerotic cardiovascular risk in adults: a report of the American College of Cardiology/American Heart Association Task Force on Practice Guidelines. J Am Coll Cardiol 63: 2889-2934.

9. Stoffel W, Kruger E, Deutzmann R (1983) Cell-free translation of human liver apolipoprotein Al and All mRNA. Processing of primary translation products. Hoppe Seylers Z Physiol Chem 364: 227-237.

10. Chau P, Fielding PE, Fielding CJ (2007) Bone morphogenetic protein-1 (BMP-1) cleaves human proapolipoprotein $A 1$ and regulates its activation for lipid binding. Biochemistry 46: 84458450.

11. Zhu J, Gardner J, Pullinger CR, Kane JP, Thompson JF, et al. (2009) Regulation of apoAl processing by procollagen $\mathrm{C}$-proteinase enhancer-2 and bone morphogenetic protein-1. J Lipid Res 50: 1330-1339.

12. Rye KA, Barter PJ (2014) Cardioprotective functions of HDLs. J Lipid Res 55: 168-179.

13. Basso F, Freeman L, Knapper CL, Remaley A, Stonik J, et al. (2003) Role of the hepatic ABCA1 transporter in modulating intrahepatic cholesterol and plasma HDL cholesterol concentrations. J Lipid Res 44: 296-302.

14. von Eckardstein A, Nofer JR, Assmann G (2001) High density lipoproteins and arteriosclerosis. Role of cholesterol efflux and reverse cholesterol transport. Arterioscler Thromb Vasc Biol 21: 1327.

15. Gillard BK, Lin HY, Massey JB, Pownall HJ (2009) Apolipoproteins A-I, A-II and E are independently distributed among intracellular and newly secreted HDL of human hepatoma cells. Biochim Biophys Acta 1791: 1125-1132.

16. Maric J, Kiss RS, Franklin V, Marcel YL (2005) Intracellular lipidation of newly synthesized apolipoprotein A-I in primary murine hepatocytes. J Biol Chem 280: 39942-39949.

17. Nagata KO, Nakada C, Kasai RS, Kusumi A, Ueda K (2013) ABCA1 dimer-monomer interconversion during $\mathrm{HDL}$ generation revealed by single-molecule imaging. Proc Natl Acad Sci U S A 110: 5034-5039.

18. Wang N, Lan D, Chen W, Matsuura F, Tall AR (2004) ATP-binding cassette transporters G1 and G4 mediate cellular cholesterol efflux to high-density lipoproteins. Proc Natl Acad Sci U S A 101: 9774-9779.

19. Gordon DJ, Knoke J, Probstfield JL, Superko R, Tyroler HA (1986) High-density lipoprotein cholesterol and coronary heart disease in hypercholesterolemic men: the Lipid Research Clinics Coronary Primary Prevention Trial. Circulation 74: 1217-1225.

20. Enger SC, Hjermann I, Foss OP, Helgeland A, Holme I, et al. (1979) High density lipoprotein cholesterol and myocardial infarction or sudden coronary death: a prospective case-control study in middle-aged men of the Oslo study. Artery 5: 170-181.

21. Miller NE, Thelle DS, Forde OH, Mjos OD (1977) The Tromso heart-study. High-density lipoprotein and coronary heart-disease: a prospective case-control study. Lancet 1: 965-968.

22. Gordon T, Castelli WP, Hjortland MC, Kannel WB, Dawber TR (1977) High density lipoprotein as a protective factor against coronary heart disease. The Framingham Study. Am J Med 62: 707714. 


\section{GENERAL INTRODUCTION}

23. Jacobs DR, Jr., Mebane IL, Bangdiwala SI, Criqui MH, Tyroler HA (1990) High density lipoprotein cholesterol as a predictor of cardiovascular disease mortality in men and women: the followup study of the Lipid Research Clinics Prevalence Study. Am J Epidemiol 131: 32-47.

24. Pekkanen J, Linn S, Heiss G, Suchindran CM, Leon A, et al. (1990) Ten-year mortality from cardiovascular disease in relation to cholesterol level among men with and without preexisting cardiovascular disease. N Engl J Med 322: 1700-1707.

25. Luc G, Bard JM, Ferrieres J, Evans A, Amouyel P, et al. (2002) Value of HDL cholesterol, apolipoprotein A-I, lipoprotein A-I, and lipoprotein A-I/A-II in prediction of coronary heart disease: the PRIME Study. Prospective Epidemiological Study of Myocardial Infarction. Arterioscler Thromb Vasc Biol 22: 1155-1161.

26. Gordon DJ, Probstfield JL, Garrison RJ, Neaton JD, Castelli WP, et al. (1989) High-density lipoprotein cholesterol and cardiovascular disease. Four prospective American studies. Circulation 79: 8-15.

27. Mineo C, Deguchi H, Griffin JH, Shaul PW (2006) Endothelial and antithrombotic actions of HDL. Circ Res 98: 1352-1364.

28. Cockerill GW, Saklatvala J, Ridley SH, Yarwood H, Miller NE, et al. (1999) High-density lipoproteins differentially modulate cytokine-induced expression of E-selectin and cyclooxygenase-2. Arterioscler Thromb Vasc Biol 19: 910-917.

29. Umemoto T, Han CY, Mitra P, Averill MM, Tang C, et al. (2013) Apolipoprotein Al and high-density lipoprotein have anti-inflammatory effects on adipocytes via cholesterol transporters: ATPbinding cassette A-1, ATP-binding cassette G-1, and scavenger receptor B-1. Circ Res 112: 1345-1354.

30. Navab M, Ananthramaiah GM, Reddy ST, Van Lenten BJ, Ansell BJ, et al. (2004) The oxidation hypothesis of atherogenesis: the role of oxidized phospholipids and HDL. J Lipid Res 45: 9931007.

31. Tall AR (1998) An overview of reverse cholesterol transport. Eur Heart J 19 Suppl A: A31-35.

32. Group HTC, Landray MJ, Haynes R, Hopewell JC, Parish S, et al. (2014) Effects of extendedrelease niacin with laropiprant in high-risk patients. N Engl J Med 371: 203-212.

33. Investigators A-H, Boden WE, Probstfield JL, Anderson T, Chaitman BR, et al. (2011) Niacin in patients with low HDL cholesterol levels receiving intensive statin therapy. N Engl J Med 365: 2255-2267.

34. Group HTC (2013) HPS2-THRIVE randomized placebo-controlled trial in 25673 high-risk patients of ER niacin/laropiprant: trial design, pre-specified muscle and liver outcomes, and reasons for stopping study treatment. Eur Heart J 34: 1279-1291.

35. Ray KK, Ditmarsch M, Kallend D, Niesor EJ, Suchankova G, et al. (2014) The effect of cholesteryl ester transfer protein inhibition on lipids, lipoproteins, and markers of HDL function after an acute coronary syndrome: the dal-ACUTE randomized trial. Eur Heart J 35: 1792-1800.

36. Barter PJ, Caulfield M, Eriksson M, Grundy SM, Kastelein JJ, et al. (2007) Effects of torcetrapib in patients at high risk for coronary events. N Engl J Med 357: 2109-2122.

37. Vergeer M, Stroes ES (2009) The pharmacology and off-target effects of some cholesterol ester transfer protein inhibitors. Am J Cardiol 104: 32E-38E.

38. Nicholls SJ, Brewer HB, Kastelein JJ, Krueger KA, Wang MD, et al. (2011) Effects of the CETP inhibitor evacetrapib administered as monotherapy or in combination with statins on HDL and LDL cholesterol: a randomized controlled trial. JAMA 306: 2099-2109.

39. Schwartz GG, Olsson AG, Abt M, Ballantyne CM, Barter PJ, et al. (2012) Effects of dalcetrapib in patients with a recent acute coronary syndrome. N Engl J Med 367: 2089-2099.

40. Hovingh GK, Kastelein JJ, van Deventer SJ, Round P, Ford J, et al. (2015) Cholesterol ester transfer protein inhibition by TA-8995 in patients with mild dyslipidaemia (TULIP): a randomised, double-blind, placebo-controlled phase 2 trial. Lancet 386: 452-460.

41. Wiggins BS, Saseen JJ, Morris PB (2016) Gemfibrozil in Combination with Statins-Is It Really Contraindicated? Curr Atheroscler Rep 18: 18.

42. Keene D, Price C, Shun-Shin MJ, Francis DP (2014) Effect on cardiovascular risk of high density lipoprotein targeted drug treatments niacin, fibrates, and CETP inhibitors: meta-analysis of randomised controlled trials including 117,411 patients. BMJ 349: g4379.

43. Voight BF, Peloso GM, Orho-Melander M, Frikke-Schmidt R, Barbalic M, et al. (2012) Plasma HDL cholesterol and risk of myocardial infarction: a mendelian randomisation study. Lancet 380: 572-580.

44. Kingwell BA, Chapman MJ, Kontush A, Miller NE (2014) HDL-targeted therapies: progress, failures and future. Nat Rev Drug Discov 13: 445-464.

45. Kosmas CE, Christodoulidis G, Cheng JW, Vittorio TJ, Lerakis S (2014) High-density lipoprotein functionality in coronary artery disease. Am J Med Sci 347: 504-508. 


\section{CHAPTER 1}

46. Rohatgi A, de Lemos JA, Shaul PW (2015) HDL cholesterol efflux capacity and cardiovascular events. N Engl J Med 372: 1871-1872.

47. Ishikawa T, Ayaori M, Uto-Kondo H, Nakajima T, Mutoh M, et al. (2015) High-density lipoprotein cholesterol efflux capacity as a relevant predictor of atherosclerotic coronary disease. Atherosclerosis 242: 318-322.

48. Borja MS, Ng KF, Irwin A, Hong J, Wu X, et al. (2015) HDL-apolipoprotein A-I exchange is independently associated with cholesterol efflux capacity. J Lipid Res 56: 2002-2009.

49. Du XM, Kim MJ, Hou L, Le Goff W, Chapman MJ, et al. (2015) HDL particle size is a critical determinant of ABCA1-mediated macrophage cellular cholesterol export. Circ Res 116: 11331142.

50. Lewis GF, Rader DJ (2005) New insights into the regulation of HDL metabolism and reverse cholesterol transport. Circ Res 96: 1221-1232.

51. Smits LP, Kootte RS, Stroes ES (2014) Reversal of atherosclerosis with apolipoprotein A1: back to basics. Atherosclerosis 232: 217-219.

52. Boekholdt SM, Arsenault BJ, Hovingh GK, Mora S, Pedersen TR, et al. (2013) Levels and changes of $\mathrm{HDL}$ cholesterol and apolipoprotein A-I in relation to risk of cardiovascular events among statin-treated patients: a meta-analysis. Circulation 128: 1504-1512.

53. Hovingh GK, de Groot E, van der Steeg W, Boekholdt SM, Hutten BA, et al. (2005) Inherited disorders of HDL metabolism and atherosclerosis. Curr Opin Lipidol 16: 139-145.

54. Anthanont P, Polisecki E, Asztalos BF, Diffenderfer MR, Barrett PH, et al. (2014) A novel ApoA-I truncation (ApoA-IMytilene) associated with decreased ApoA-I production. Atherosclerosis 235: 470-476.

55. Hovingh GK, Brownlie A, Bisoendial RJ, Dube MP, Levels JH, et al. (2004) A novel apoA-I mutation (L178P) leads to endothelial dysfunction, increased arterial wall thickness, and premature coronary artery disease. J Am Coll Cardiol 44: 1429-1435.

56. Rubin EM, Krauss RM, Spangler EA, Verstuyft JG, Clift SM (1991) Inhibition of early atherogenesis in transgenic mice by human apolipoprotein Al. Nature 353: 265-267.

57. Tangirala RK, Tsukamoto K, Chun SH, Usher D, Pure E, et al. (1999) Regression of atherosclerosis induced by liver-directed gene transfer of apolipoprotein A-I in mice. Circulation 100: 18161822.

58. Leman LJ, Maryanoff BE, Ghadiri MR (2014) Molecules that mimic apolipoprotein A-I: potential agents for treating atherosclerosis. J Med Chem 57: 2169-2196.

59. Nissen SE, Tsunoda T, Tuzcu EM, Schoenhagen P, Cooper CJ, et al. (2003) Effect of recombinant ApoA-I Milano on coronary atherosclerosis in patients with acute coronary syndromes: a randomized controlled trial. JAMA 290: 2292-2300.

60. Tricoci P, D'Andrea DM, Gurbel PA, Yao Z, Cuchel M, et al. (2015) Infusion of Reconstituted HighDensity Lipoprotein, CSL112, in Patients With Atherosclerosis: Safety and Pharmacokinetic Results From a Phase 2a Randomized Clinical Trial. J Am Heart Assoc 4: e002171.

61. Chistiakov DA, Sobenin IA, Orekhov AN, Bobryshev YV (2014) Role of endoplasmic reticulum stress in atherosclerosis and diabetic macrovascular complications. Biomed Res Int 2014: 610140.

62. Manduteanu I, Simionescu M (2012) Inflammation in atherosclerosis: a cause or a result of vascular disorders? J Cell Mol Med 16: 1978-1990.

63. Zannis VI, Kan HY, Kritis A, Zanni EE, Kardassis D (2001) Transcriptional regulatory mechanisms of the human apolipoprotein genes in vitro and in vivo. Curr Opin Lipidol 12: 181-207.

64. Dullens SP, Plat J, Mensink RP (2007) Increasing apoA-I production as a target for CHD risk reduction. Nutr Metab Cardiovasc Dis 17: 616-628.

65. Tzameli I, Zannis VI (1996) Binding specificity and modulation of the ApoA-I promoter activity by homo- and heterodimers of nuclear receptors. J Biol Chem 271: 8402-8415.

66. Tam SP, Zhang X, Cuthbert C, Wang Z, Ellis T (1997) Effects of dimethyl sulfoxide on apolipoprotein A-I in the human hepatoma cell line, HepG2. J Lipid Res 38: 2090-2102.

67. Cuthbert C, Wang Z, Zhang X, Tam SP (1997) Regulation of human apolipoprotein A-I gene expression by gramoxone. J Biol Chem 272: 14954-14960.

68. Duez H, Lefebvre B, Poulain P, Torra IP, Percevault F, et al. (2005) Regulation of human apoA-I by gemfibrozil and fenofibrate through selective peroxisome proliferator-activated receptor alpha modulation. Arterioscler Thromb Vasc Biol 25: 585-591.

69. Vu-Dac N, Schoonjans K, Laine B, Fruchart JC, Auwerx J, et al. (1994) Negative regulation of the human apolipoprotein A-I promoter by fibrates can be attenuated by the interaction of the peroxisome proliferator-activated receptor with its response element. J Biol Chem 269: 31012-31018. 


\section{GENERAL INTRODUCTION}

70. Harnish DC, Malik S, Karathanasis SK (1994) Activation of apolipoprotein Al gene transcription by the liver-enriched factor HNF-3. J Biol Chem 269: 28220-28226.

71. Kan HY, Georgopoulos S, Zanni M, Shkodrani A, Tzatsos A, et al. (2004) Contribution of the hormone-response elements of the proximal ApoA-I promoter, ApoClll enhancer, and C/EBP binding site of the proximal ApoA-I promoter to the hepatic and intestinal expression of the ApoA-I and ApoCIII genes in transgenic mice. Biochemistry 43: 5084-5093.

72. Lam JK, Matsubara S, Mihara K, Zheng XL, Mooradian AD, et al. (2003) Insulin induction of apolipoprotein Al, role of Sp1. Biochemistry 42: 2680-2690.

73. Claudel T, Sturm E, Duez H, Torra IP, Sirvent A, et al. (2002) Bile acid-activated nuclear receptor FXR suppresses apolipoprotein A-I transcription via a negative FXR response element. J Clin Invest 109: 961-971.

74. Zannis VI, Liu T, Zanni M, Kan HY, Kardassis D (2003) Regulatory gene mutations affecting apolipoprotein gene expression: functions and regulatory behavior of known genes may guide future pharmacogenomic approaches to therapy. Clin Chem Lab Med 41: 411-424.

75. Jin FY, Kamanna VS, Chuang MY, Morgan K, Kashyap ML (1996) Gemfibrozil stimulates apolipoprotein A-I synthesis and secretion by stabilization of mRNA transcripts in human hepatoblastoma cell line (Hep G2). Arterioscler Thromb Vasc Biol 16: 1052-1062.

76. Arakawa R, Tamehiro N, Nishimaki-Mogami T, Ueda K, Yokoyama S (2005) Fenofibric acid, an active form of fenofibrate, increases apolipoprotein A-I-mediated high-density lipoprotein biogenesis by enhancing transcription of ATP-binding cassette transporter A1 gene in a liver $X$ receptor-dependent manner. Arterioscler Thromb Vasc Biol 25: 1193-1197.

77. Dullens SP, Mensink RP, Mariman EC, Plat J (2009) Differentiated CaCo-2 cells as an in-vitro model to evaluate de-novo apolipoprotein A-I production in the small intestine. Eur $\mathrm{J}$ Gastroenterol Hepatol 21: 642-649.

78. Nakaya K, Tohyama J, Naik SU, Tanigawa H, MacPhee C, et al. (2011) Peroxisome proliferatoractivated receptor-alpha activation promotes macrophage reverse cholesterol transport through a liver X receptor-dependent pathway. Arterioscler Thromb Vasc Biol 31: 1276-1282.

79. Bailey D, Jahagirdar R, Gordon A, Hafiane A, Campbell S, et al. (2010) RVX-208: a small molecule that increases apolipoprotein $\mathrm{A}-\mathrm{I}$ and high-density lipoprotein cholesterol in vitro and in vivo. J Am Coll Cardiol 55: 2580-2589.

80. McLure KG, Gesner EM, Tsujikawa L, Kharenko OA, Attwell S, et al. (2013) RVX-208, an inducer of ApoA-I in humans, is a BET bromodomain antagonist. PLoS One 8: e83190.

81. Kempen HJ, Bellus D, Fedorov O, Nicklisch S, Filippakopoulos P, et al. (2013) Stimulation of Hepatic Apolipoprotein A-I Production by Novel Thieno-Triazolodiazepines: Roles of the Classical Benzodiazepine Receptor, PAF Receptor, and Bromodomain Binding. Lipid Insights 6: 47-54.

82. Seal J, Lamotte Y, Donche F, Bouillot A, Mirguet O, et al. (2012) Identification of a novel series of BET family bromodomain inhibitors: binding mode and profile of I-BET151 (GSK1210151A). Bioorg Med Chem Lett 22: 2968-2972.

83. Nicodeme E, Jeffrey KL, Schaefer U, Beinke S, Dewell S, et al. (2010) Suppression of inflammation by a synthetic histone mimic. Nature 468: 1119-1123.

84. Gilham D, Wasiak S, Tsujikawa LM, Halliday C, Norek K, et al. (2016) RVX-208, a BET-inhibitor for treating atherosclerotic cardiovascular disease, raises $A p O A-1 / \mathrm{HDL}$ and represses pathways that contribute to cardiovascular disease. Atherosclerosis 247: 48-57.

85. Zhou H, Liu R (2014) ER stress and hepatic lipid metabolism. Front Genet 5: 112.

86. Tabas I (2010) The role of endoplasmic reticulum stress in the progression of atherosclerosis. Circ Res 107: 839-850.

87. Ivanova EA, Orekhov AN (2016) The Role of Endoplasmic Reticulum Stress and Unfolded Protein Response in Atherosclerosis. Int J Mol Sci 17.

88. Bjorkerud S, Bjorkerud B (1996) Apoptosis is abundant in human atherosclerotic lesions, especially in inflammatory cells (macrophages and T cells), and may contribute to the accumulation of gruel and plaque instability. Am J Pathol 149: 367-380.

89. Myoishi M, Hao H, Minamino T, Watanabe K, Nishihira K, et al. (2007) Increased endoplasmic reticulum stress in atherosclerotic plaques associated with acute coronary syndrome. Circulation 116: 1226-1233.

90. Back SH, Kang SW, Han J, Chung HT (2012) Endoplasmic reticulum stress in the beta-cell pathogenesis of type 2 diabetes. Exp Diabetes Res 2012: 618396.

91. Naem E, Haas MJ, Wong NC, Mooradian AD (2013) Endoplasmic reticulum stress in HepG2 cells inhibits apolipoprotein A-I secretion. Life Sci 92: 72-80.

92. Wang Y, Vera L, Fischer WH, Montminy M (2009) The CREB coactivator CRTC2 links hepatic ER stress and fasting gluconeogenesis. Nature 460: 534-537. 


\section{CHAPTER 1}

93. Ozcan U, Cao Q, Yilmaz E, Lee AH, Iwakoshi NN, et al. (2004) Endoplasmic reticulum stress links obesity, insulin action, and type 2 diabetes. Science 306: 457-461.

94. Kim I, Xu W, Reed JC (2008) Cell death and endoplasmic reticulum stress: disease relevance and therapeutic opportunities. Nat Rev Drug Discov 7: 1013-1030.

95. Li Y, Guo Y, Tang J, Jiang J, Chen Z (2014) New insights into the roles of CHOP-induced apoptosis in ER stress. Acta Biochim Biophys Sin (Shanghai) 46: 629-640.

96. Banerjee S, Zhao Y, Sarkar PS, Rosenblatt KP, Tilton RG, et al. (2013) Klotho ameliorates chemically induced endoplasmic reticulum (ER) stress signaling. Cell Physiol Biochem 31: 659-672. 


\section{CHAPTER 2}

CCAAT/enhancer binding protein $\beta$ in relation to ER-stress, inflammation, and metabolic disturbances

Sophie E. van der Krieken*, Herman E. Popeijus*, Ronald P. Mensink, and Jogchum Plat

Biomed Res Int. 2015; 2015: 324815.

${ }^{*}$ Authors contributed equally 


\section{CHAPTER 2}

\section{Abstract}

The prevalence of the metabolic syndrome and underlying metabolic disturbances increase rapidly in developed countries. Various molecular targets are currently under investigation to unravel the molecular mechanisms that cause these disturbances. This is done in attempt to counter or prevent the negative health consequences of the metabolic disturbances. Here, we reviewed the current knowledge on the role of C/EBP- $\beta$ in these metabolic disturbances. C/EBP- $\beta$ deletion in mice resulted in downregulation of hepatic lipogenic genes and increased expression of $\beta$-oxidation genes in brown adipose tissue. Furthermore, C/EBP- $\beta$ is important in the differentiation and maturation of adipocytes and is increased during ER-stress and pro-inflammatory conditions. So far, studies were only conducted in animals and in cell systems. The results found indicate that C/EBP- $\beta$ is an important transcription factor within the metabolic disturbances of the metabolic system. Therefore, it is interesting to examine the potential role of C/EBP- $\beta$ at molecular and physiological level in humans. 


\section{C/EBP- $\beta$ IN RELATION TO METABOLIC DISTURBANCES}

\section{Introduction}

The prevalence of obesity is increasing worldwide. This is worrisome regarding the known association of obesity with the development of the metabolic syndrome. The metabolic syndrome comprises a cluster of disturbances in metabolism such as an impaired glucose- and lipid metabolism, high blood pressure, dyslipidemia and a pro-inflammatory state [1]. Eventually, these disturbances might result in the development of type II diabetes mellitus and cardiovascular diseases [2].

Nowadays it is acknowledged that adipose tissue is a highly endocrine organ that secretes several adipokines, including a variety of pro-inflammatory cytokines [3]. As a consequence, there is a constant exposure to low-grade systemic inflammation. Typically, elevated concentrations of C-reactive protein, various cytokines, pro-thrombotic molecules and adhesion molecules are present in this inflammatory state [4-6] which play an essential role in the development of atherosclerosis and insulin resistance $[7,8]$.

It is intriguing to consider the variety and number of processes that are differentially regulated between metabolic syndrome patients and healthy subjects. Many of these processes are regulated at the level of gene expression, which is controlled by downstream processes and factors, such as RNA processing, mRNA translation, mRNA degradation and interaction with other proteins. Probably the most influential step in regulating gene expression is the rate of transcriptional regulation. Transcription factors are able to interact with regulatory sequences of target genes, thereby influencing their expression level and consequently influence metabolism in a direct and/or indirect manner [9].

Next to transcription factors such as PPARs, NFKB and chREBP [10-12], there are strong indications that also the transcription factor CCAAT/enhancer binding protein $(\mathrm{C} / \mathrm{EBP}-\beta)$ is involved in processes related to the metabolic syndrome. C/EBP- $\beta$ knockout mice fed a high fat diet showed a decreased fat mass, decreased serum triacylglycerols and cholesterol concentrations, and lower hepatic triacylglycerol concentrations compared to their wild type littermates [13]. Moreover, expression of hepatic lipogenic genes was downregulated, while the expression of $\beta$-oxidation genes in brown adipose tissue was increased [13]. These effects are in line with earlier observations that the beta variant of C/EBP is important in the differentiation and maturation of adipocytes [13]. Finally, since C/EBP- $\beta$ is activated in pro-inflammatory conditions [14], there might also be a link between C/EBP- $\beta$ and low-grade systemic inflammation. Therefore, in this review we will focus on the influence of $\mathrm{C} / \mathrm{EBP}-\beta$ and its isoforms on metabolic disturbances related to the metabolic syndrome.

\section{CCAAT/ enhancer binding proteins}

\section{The C/EBP family of transcription factors}

CCAAT/enhancer binding proteins (C/EBPs) are a six-member family ( $\alpha$ to $\zeta$ ) of transcription factors. They are involved in the regulation and expression of numerous genes. C/EBPs affect gene expression by binding to a DNA binding site (consensus sequence "CCAAT"), which is present in many gene promoter- and 


\section{CHAPTER 2}

enhancer regions. All members of the C/EBP family contain a basic leucine zipper (bZIP) domain at the carboxyl-terminus (c-terminus), which is involved in dimerization and binding to the DNA [9]. Specifically, in all isoforms of C/EBP, an extension of the zipper dimerization domain, the tail sequence, acts as a motif for protein-protein interactions. For a detailed description of the structure of CCAAT/ enhancer binding family members, we refer to two earlier reviews $[9,15]$.

\section{Tissue specific C/EBP expression of variants a to $\zeta$}

$\mathrm{C} / \mathrm{EBP}$ protein variants are differentially expressed in various tissues. C/EBP- $\alpha$ is expressed predominantly in liver and adipose tissue and at lower level in lungs, intestine, adrenal gland, placenta and peripheral-blood mononuclear cells [16-19]. $\mathrm{C} / \mathrm{EBP}-\beta$ is highly expressed in the intestine, liver, kidney, lungs, spleen, adipose tissue, pancreatic $\beta$-cells [20], and monocytes and granulocytes [9,16,17,21-26]. The expression of the $\delta$-member of the C/EBP family is restricted to adipose tissue, intestine and lungs, whereas $\mathrm{C} / \mathrm{EBP}-\varepsilon$ expression is found primarily in myeloid and lymphoid cells $[9,18,27,28]$. Finally, C/EBP-Y and C/EBP- $\zeta$ are ubiquitously expressed in most tissues [9,29,30].

\section{A focus on the CCAAT/enhancer binding proteins family member C/EBP- $\beta$}

Given the large number of publications describing a link between the $\beta$ isoform of $\mathrm{C} / \mathrm{EBP}$ and one or more characteristics of the metabolic syndrome, we decided to focus in more detail on the C/EBP- $\beta$ isoform. In the literature, C/EBP- $\beta$ is known under various names: NF-IL6 (Nuclear factor for IL-6), TCF5 (Transcription factor 5), LAP (Liver enriched activator protein), IL-6DBP (IL-6 dependent DNA binding protein), CRP2 (C/EBP-related protein 2), AGP/EBP (Alpha-1-acid glycoprotein enhancer binding protein), NF-M, SF-B (Silencer factor) or ApC/EBP [9]. C/EBP- $\beta$ forms hetero- and homo dimers, thereby altering its preferential DNA binding to initiate transcription of target genes involved in various cellular processes $[9,14,19,31-34]$.

\section{C/EBP- $\beta$ isoforms}

C/EBP- $\beta$ is an intronless gene that codes for the production of a single mRNA $[16,35]$. The mouse C/EBP- $\beta$ mRNA transcript can translate into four different protein isoforms: full length C/EBP- $\beta$ or LAP* (liver-enriched transcriptional activating protein star) with an atomic mass of $38 \mathrm{kDa}$, LAP (liver-enriched transcriptional activating protein), which has an atomic mass of $35 \mathrm{kDa}$, the $20 \mathrm{kDa}$ isoform LIP (liver-enriched transcriptional inhibitory protein) and a smaller $16 \mathrm{kDa}$ isoform (figure 1). The isoform LAP is a transcriptional activator, while the isoform LIP, which lacks the transactivation domain, is a transcriptional inhibitor (figure 2). This results in isoform specific transcriptional activation potential [16,36,37]. Already in 1991, Descombes and Schibler [35] have shown that the isoforms LIP and LAP have antagonistic activities. Also in heterodimerized form with other family members, LIP inhibits the transcriptional activation activity of its partner $[9,36]$. Together, these data suggests that LIP acts as a dominant negative regulator of other C/EBP family members. 


\section{C/EBP- $\beta$ IN RELATION TO METABOLIC DISTURBANCES}

In some articles authors use the term "LIP/LAP ratio" to refer to changes in the amount of LAP*, LAP or LIP protein that is produced. In our perception, one should also refer to exact concentrations of LAP*, LAP or LIP, since a ratio does not give information on the amount of each isoform that is produced. For example there is a difference between a LIP/LAP ratio of for example $8 / 2$ or $100 / 25$, while both ratio's seem equal: 4. At high amounts of the transcription factors the biological effects are likely to differ when compared to lower concentrations e.g. at high dose (one of) the heterodimeric partners of LIP/LAP might become limiting or all binding places might become fully occupied.

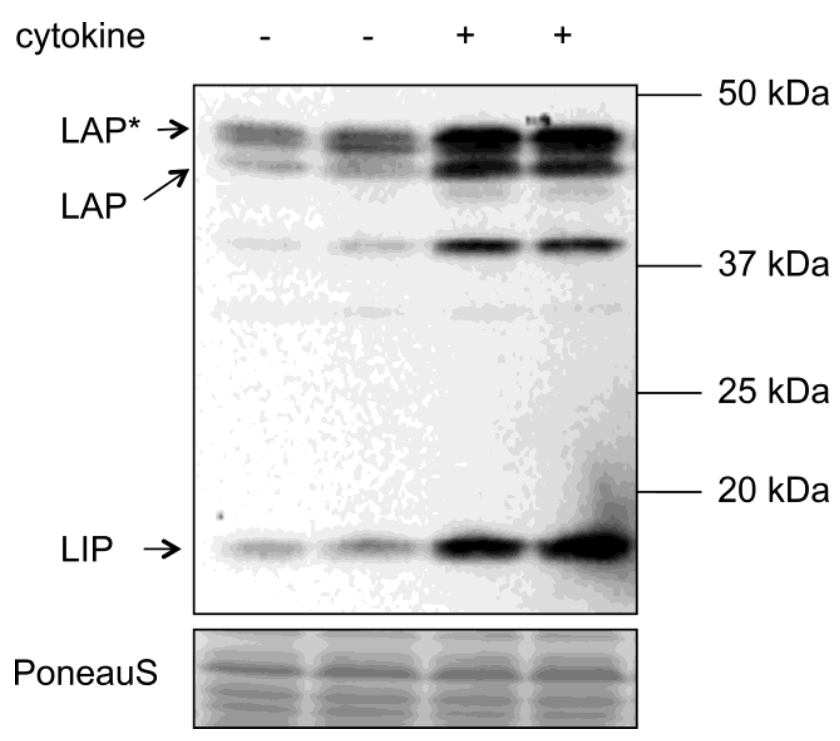

Figure 1. Human C/EBP- $\beta$ protein expression in human liver carcinoma cells (HepG2 cells) under normal and after inflammation induced C/EBP- $\beta$ activation by the addition of a cytokine cocktail for $48 \mathrm{~h}$ (IL-6, IL-1 $\beta$, TNF- $\alpha$ ), detected by western blotting. Human C/EBP- $\beta$ isoforms LAP*, LAP and LIP are indicated using the arrows (note: they run at different size as the mouse isoforms (Santa Cruz Biotechnology, C/EBP- $\beta$ (C-19): sc-150). Just above $37 \mathrm{kDa}$ and below the $37 \mathrm{kDa}$ breakdown fragments of the larger human isoforms are detected.

\section{Transcription of C/EBP- $\beta$}

\section{Activation of $C / E B P-\beta$ transcription}

In the $\mathrm{C} / \mathrm{EBP}-\beta$ promoter various binding sites allow binding of transcription factors that directly influence transcription of C/EBP- $\beta$ mRNA (table 1). Furthermore, there are two cAMP-like responsive elements (CRE-like sites) in the region close to the TATA box of the C/EBP- $\beta$ gene. The PKA/CREB pathway targets these two CRE- 


\section{CHAPTER 2}

binding sites and thereby regulates the transcription of C/EBP $-\beta$ [38]. In addition, $\mathrm{C} / \mathrm{EBP}-\beta$ is able to stimulate its own transcription [38].

\section{Isoform specific translation}

A possible model to explain the production of the various C/EBP- $\beta$ isoforms involves a "leaky ribosome scanning mechanism" [39]. In this model, the first AUG codon is ignored by the ribosomes that are scanning the C/EBP- $\beta$ mRNA, resulting in translation initiation starting from the next AUG codon (figure 2) [39]. As an alternative, Timchenko et al. [40] proposed another pathway for LIP production named "proteolytic cleavage", which is regulated by another member of the C/EBP family; C/EBP-a [41]. Since low proteolytic activity was found in cultured cells, they also concluded that the generation of LIP is predominantly depending on translational regulation [40].

TAD1

TAD2

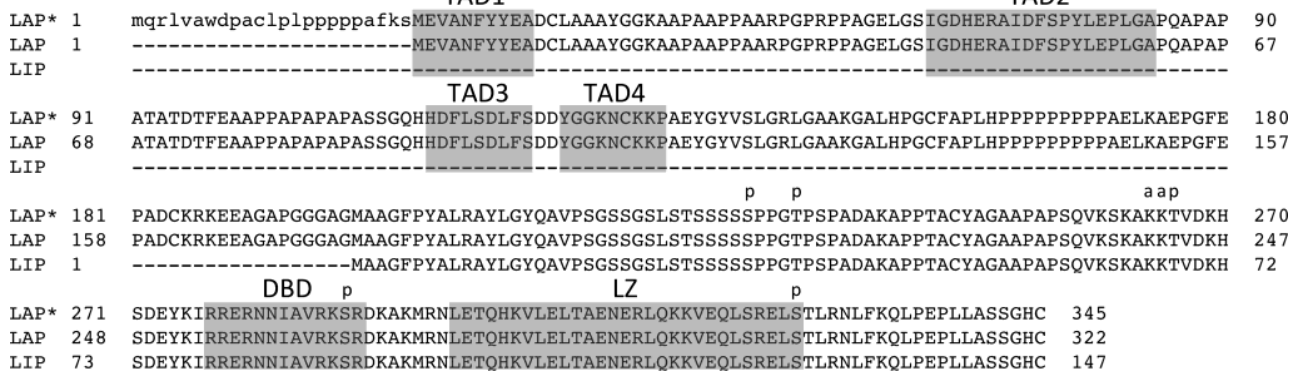

Figure 2. Alignment of C/EBP- $\beta$ isoforms LAP*, LAP, and LIP created and annotated using reference sequence (LAP*: NP_005185; LAP: NP_001272807; LIP: NP 001272808) [42,43]. Transactivation domain (TAD) 1-4, the DNA binding domain (DBD), and the leucine zipper domain (LZ) are indicated with the shaded boxes. Phosphorylation sites are indicated using the letter " $p$ " and acetylation sites with the letter "a".

\section{C/EBP- $\beta$ target genes}

Although C/EBP- $\beta$ increases the expression of a wide variety of target genes that regulate numerous metabolic processes (table 1), C/EBP- $\beta$ binding sites are particularly found in regulatory sequences of genes that are associated with i.e. the inflammatory response [21], or the ER-stress pathway [44]. In addition, several $\mathrm{C} / \mathrm{EBP}-\beta$ protein interactions and regulatory factors that are involved in C/EBP- $\beta$ transcription have been reported (table 1). 


\section{C/EBP- $\beta$ IN RELATION TO METABOLIC DISTURBANCES}

Table 1. Regulatory factors for C/EBP- $\beta$-production, C/EBP- $\beta$-target genes and protein interactions (Please note that this list is not exhaustive, for a more extensive list also visit the GenCards website [45]).

\begin{tabular}{l|l|l}
$\begin{array}{l}\text { Regulatory factors in C/EBP- } \beta \\
\text { transcription }\end{array}$ & C/EBP- $\beta$ target genes & C/EBP- $\beta$ protein interactions \\
\hline Sp1 [46] & IL-6 [47] & CREB1 [48] \\
CREB/ ATF [46] & TNF- $\alpha$ [21] & CRSP3 [49] \\
SREBP1c [50] & IL1- $\beta$ [21] & DDIT3/CHOP [51] \\
RARa [52] & IL-8 [53] & EP300 [54] \\
Myb [55] & IL-12 [21] & HMG-I/HMG-Y [56] \\
Fra-2 [57] & G-CSF or CSF3 [21] & HSF-1 [58] \\
EGR2 or KROX20 [59] & Receptors for G-CSF, GM- & SWI/SNF complex [60] \\
STAT-3 [61] & CSF, M-CSF [21] & Sp1 [56] \\
NFkB [62] & MIP1- $[47]$ & TRIM28/ KAP1 [63] \\
C/EBP- $\beta$ [38] & Osteoponin [47] & EGR-1/ zif268/ NGFI-A [64] \\
& CD14 [47] & Smad-3 and Smad-4 [65] \\
& MIP1- $\beta$ [15] & ATF2 [66] \\
& CRP [21] & ATF4 [67] \\
& Hemopexin [21] & C/EBP- $\alpha, \beta, \gamma, \delta, \zeta[9]$ \\
& Haptoglobin [15] & FKHR [68] \\
& AGP-a1 [21] & \\
& NFkB, P50 subunit [62] & \\
& NR3C1 [69] & \\
& C-FOS [70] & \\
& PPAR-y [71,72] & \\
& C/EBP- $\alpha, \beta, \gamma, \delta, \zeta ~[9]$ & \\
cAMP [73] & Albumin [74] & \\
MDR1 [75] &
\end{tabular}

\section{The role of C/EBP- $\beta$ in metabolic regulation}

Numerous studies suggest a role for C/EBP- $\beta$ in pathways related to the metabolic syndrome. Current insights regarding the involvement of C/EBP- $\beta$ in adipose tissue differentiation, glucose- and insulin metabolism, triacylglycerol metabolism, hepatic steatosis, endoplasmic reticulum stress, inflammation and HDL production will be described in the following sections (figure 3). When discussing the influence of C/EBP- $\beta$ on metabolic aberrations, it is important to consider the effects of C/EBP$\beta$ on weight- or adipose tissue loss, as weight loss might consequently induce positive effects on the features of the metabolic syndrome [76,77]. 


\section{CHAPTER 2}

Glucose- \& Insulin metabolism

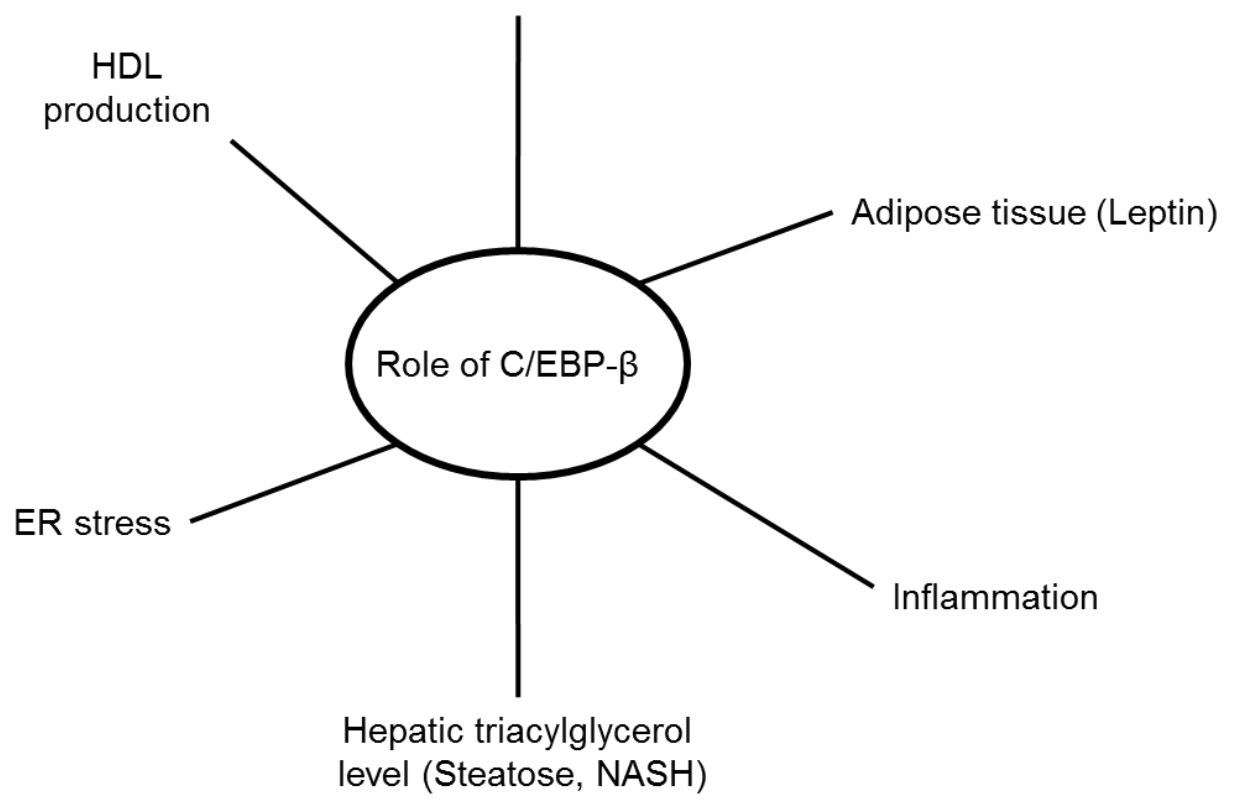

Figure 3. Simplified scheme of the involvement of C/EBP- $\beta$ in factors related to the metabolic syndrome as described in literature.

\section{The role of $C / E B P-\beta$ in adipose tissue mass and adipocyte differentiation}

C/EBP- $\beta$, as well as other members of the C/EBP family, plays a role in adipocyte differentiation and maturation, suggesting involvement in the etiology of overweight and obesity. When wild type and C/EBP- $\beta$ deficient mice were fed a high-fat diet (60 en\%) for 12 weeks, the wild type mice gained weight, while the knockouts did not and even lost body fat. Also on a low-fat diet, the C/EBP- $\beta$ knockouts had less total body fat [13]. Similar findings were reported by Staiger et al. [78]. Although we can certainly not rule out that weight loss itself contributed considerably to the observed healthier metabolic profile, the C/EBP- $\beta$ deletion resulted in decreased expression of hepatic lipogenic genes and lowered expression of acetyl-CoA carboxylase and reduced fatty acid synthase, suggestive for a reduced hepatic fatty acid production and increased lipolysis [13]. In addition, after the high-fat diet, energy expenditure, which was measured by $\mathrm{CO} 2$ production, was increased in the C/EBP- $\beta$ knockouts, while the amount of brown adipose tissue was not increased. However, although brown adipose tissue was not elevated, the explanation for the increased energy expenditure in the C/EBP- $\beta$ knockout mice was explained by elevated gene expression in brown adipose tissue $\beta$-oxidation (LCAD and AOX). Although UCP1 and UCP3 in the muscle was clearly increased, the change in UCP expression in BAT did not reach statistical significance [13].

C/EBP- $\beta$ and $-\alpha$ are postulated as transcriptional activators for the mouse UCP gene, as two binding places for C/EBP were detected in the UCP gene promoter. 


\section{C/EBP- $\beta$ IN RELATION TO METABOLIC DISTURBANCES}

Co-transfection of the UCP-CAT vector with C/EBP- $\beta$ resulted in increased transactivation of the UCP promoter in primary brown adipocytes of rats [79]. Furthermore, when exposed to cold, which is a stimulus for development of brown fat and UCP expression, specifically C/EBP- $\beta$ expression showed a time dependent increase in brown adipose tissue of adult rats. Here, LIP protein production increased rapidly after 12 to 24 hours of cold exposure. Additionally, C/EBP- $\beta$ mRNA expression and LIP protein production was higher during fetal development of brown adipose tissue compared to adult brown adipose tissue, and during BAT development in the fetus the amount of LIP decreased gradually [80]. These data suggest a role for C/EBP- $\beta$ and particularly its isoform LIP in the (fetal to adult) development of brown adipose tissue BAT and in increasing brown adipose tissue activity.

As described in table 1, C/EBP- $\beta$ can induce both PPAR- $y$ and C/EBP- $\alpha$ gene expression, since both genes contain $\mathrm{C} / \mathrm{EBP}$ binding sites in their proximal promoters [71,72]. Especially, during the first two days of white adipocyte differentiation, C/EBP- $\beta$ and C/EBP- $\delta$ levels are increased, after which levels decrease sharply before C/EBP- $\alpha$ levels increase [16]. During the early stage of adipogenesis, C/EBP- $\beta$ and C/EBP- $\delta$ mRNA activate transcription of PPAR- $\gamma$ [81]. Mice deprived of the C/EBP- $\beta$ gene did show white adipocyte development, e.g. they could not store lipids inside the adipocytes, regardless the presence of C/EBP- $\alpha$ and PPAR- $\gamma$ [81]. In addition, Chung et al., 2012 [82] suggested that activation of Wnt- $\beta$ inhibits activations of PPAR- $\gamma$ and C/EBP- $\alpha$ that are controlled by $\mathrm{C} / \mathrm{EBP}-\beta$. When adipogenic inducers (such as insulin) were added, knockdown of $\mathrm{C} / \mathrm{EBP}-\beta$ inhibited adipogenesis, while activated signaling of Wnt $\beta$ was maintained. When the C/EBP- $\beta$ gene was overexpressed, signaling of Wnt $\beta$ was inhibited. These findings suggest that C/EBP- $\beta$ can inhibit Wnt- $\beta$ signaling and that $\mathrm{C} / \mathrm{EBP}-\beta$ is necessary to stimulate the expression of genes responsible for adipogenesis [82]. Zuo et al. have also evaluated the role of C/EBP- $\beta$ in the activation of C/EBP- $\alpha$ [71]. In an earlier study it was shown that after inhibition of C/EBP- $\beta$ activity by ectopic expression of the protein LIP, the expression of C/EBP$\alpha$ and PPAR- $\gamma$ were blocked [83]. This suggests that C/EBP- $\beta$ isoform LIP modulates the expression of C/EBP- $\alpha$. In the past, the role of C/EBP- $\beta$ in inducing adipogenesis via PPAR- $\gamma$ was already extensively investigated $[84,85]$. For example, the truncated isoform LIP inhibited adipocyte differentiation in 3T3-L1 cells [84]. However, these studies could not examine effects on C/EBP- $\alpha$ induction, since NIH-3T3 fibroblasts were used, which do not produce C/EBP- $\alpha[71,86]$. Zuo et al. now suggested that $\mathrm{C} / \mathrm{EBP}-\beta$ is able to activate adipogenesis through the stimulation of PPAR- $\gamma$, which activates C/EBP- $\alpha$ expression [71].

The role of the adipokine leptin as a mediator of energy balance is well known in humans $[87,88]$. ChIP analysis suggested that leptin levels are decreased by C/EBP- $\beta$ via association with the promoter of leptin. This finding is confirmed with observations showing that the leptin promoter contains a C/EBP motif binding site [20], to which C/EBP- $\alpha$ can bind [89]. In C/EBP- $\beta$ knockout mice a reduction in leptin but also a decrease in fat mass was observed [78]. However, as leptin is produced by white adipose tissue, it is also possible that the observed decrease in leptin simply results from the decrease in the amount of body fat.

In summary, in vitro and animal studies suggest that C/EBP- $\beta$ plays an important role in the promoting the development and differentiation of both white- and brown 


\section{CHAPTER 2}

adipose tissue. In addition, C/EBP- $\beta$ plays a role in increasing brown adipose tissue activity, via elevated UCP expression in brown adipose tissue. Furthermore, the $\mathrm{C} / \mathrm{EBP}$ family might be involved in the production of leptin.

\section{The role of $C / E B P-\beta$ in glucose- and insulin metabolism}

Besides a potential indirect effect of $C / E B P-\beta$ on metabolism via a reduced adipocyte mass, there are indications that C/EBP- $\beta$ directly affects glucose and insulin metabolism (figure 4). A decreased hepatic C/EBP- $\beta$ expression coincides with increased insulin production [20,90,91]. Rats and mice fed a highcarbohydrate diet ( $81 \%$ sucrose), thereby increasing insulin secretion 5 -fold, showed an $80 \%$ decreased hepatic C/EBP- $\beta$ mRNA production compared to animals fed a standard diet (41\% starch) [90]. Matsuda et al. found that pancreatic $\beta$-cell specific C/EBP- $\beta$ knockout mice were characterized by increased insulin secretion, while they did not differ in body weight compared to controls [92]. Furthermore, C/EBP- $\beta$ expression was increased in hepatocytes of (streptozotocintreated) type I diabetic rats [90]. However, when these animals were treated with insulin or with the insulin mimetic vanadate, C/EBP- $\beta$ expression decreased again [90]. Altogether, these findings not only indicate that C/EBP- $\beta$ plays a role in regulating pancreatic insulin secretion, but also that insulin relates to lower hepatic expression of C/EBP- $\beta$ [90]. These effects may also translate into differences in glucose metabolism. Fifty percent of all C/EBP- $\beta$ knockout mice die early due to disturbances in glycogen mobilization and consequent hypoglycemia [93]. After an 18 hour fast, surviving mice clearly suffered from severe hypoglycemia, decreased hepatic glucose production ( $40 \%$ reduction) and low plasma free fatty acid (FFA) concentrations compared to wild type mice. However, plasma insulin levels were comparable between the knockout and wild type mice. After correction for the amount of DNA per gram of adipose tissue the overnight fasted knockouts showed reduced lipid content per cell. The authors state that the decrease in fat mass might have accounted for the decreased FFA concentrations in C/EBP- $\beta$ knockout mice. Moreover, hepatic cyclic adenosine monophosphate (cAMP) was reduced in C/EBP- $\beta$ knockout mice during basal and glucagon stimulated conditions [93], and administration of CAMP increased glycogen mobilization, resulting in normal blood glucose concentrations [93,94]. cAMP is an important contributor to whole body glucose homeostasis, as it is involved in the insulin-signaling cascade by activating PKA (Madsen, 2010). In relation to this, it has been shown that C/EBP- $\beta$ is required in maintaining appropriate CAMP concentrations in liver and adipose tissue [94].

Besides an effect on glucose homeostasis via affecting insulin and glucagon directly, the C/EBP gene family may also affect the uptake of glucose, as the promoter of the GLUT-4 gene contains a C/EBP binding site [95]. This might explain partly why adipocytes of C/EBP $-\beta$ and $-\delta$ deficient mouse embryonic fibroblasts (MEFs) have reduced GLUT-4 mRNA expression [96]. In addition, the insulin receptor substrate-2 (IRS-2) was decreased in these mice compared to their control littermates, which could be another explanation for reduced GLUT-4 expression. Furthermore, in HepG2 cells, transcription of the human insulin receptor (IR) is controlled by a transcriptionally active multi-protein-DNA complex. This complex is composed of nuclear protein HMGI-Y, transcription factors Sp1 


\section{C/EBP- $\beta$ IN RELATION TO METABOLIC DISTURBANCES}

and $\mathrm{C} / \mathrm{EBP}-\beta$ [56]. Although IR expression was not changed in adipocytes of $\mathrm{C} / \mathrm{EBP}-\beta / \delta$ deficient mouse MEFs [96], the findings of Foti et al. suggest that C/EBP- $\beta$ is involved in a transcriptional network needed for the transcription of human insulin receptors [56]. In contrast, deleting C/EBP- $\beta$ in mice increased IRS1 levels as well as skeletal muscle insulin sensitivity [97]. Moreover, despite the decreased amount of adipose tissue, which could explain (part of) the favourable metabolic effects, mice with a C/EBP- $\beta$ gene deletion showed reduced plasma free fatty acid concentrations and increased insulin-signal transduction in skeletal muscle, indicating improved whole-body insulin sensitivity [97]. This was supported by findings that C/EBP- $\beta$ suppression in palmitate-treated 3T3L1 cells improved Akt phosphorylation in response to insulin [98]. Furthermore, in mice, the accumulation of C/EBP- $\beta$ leads to failure of pancreatic $\beta$-cells, due to increased vulnerability to ER-stress. These findings suggest that C/EBP- $\beta$ is also involved in the onset of insulin resistance and type II diabetes [92].

In conclusion, animal and cell studies suggest that C/EBP- $\beta$ influences insulin and glucose metabolism. However, in most cases the effect of C/EBP- $\beta$ knockout resulted in decreased body weight or adipose tissue loss, which might have caused the reduction of blood glucose and free fatty acids. Since the accumulation of C/EBP- $\beta$ in the pancreatic $\beta$-cells may increase the risk for type II diabetes in animals, it might be interesting to investigate the contribution of C/EBP- $\beta$ in the onset of type II diabetes in humans.
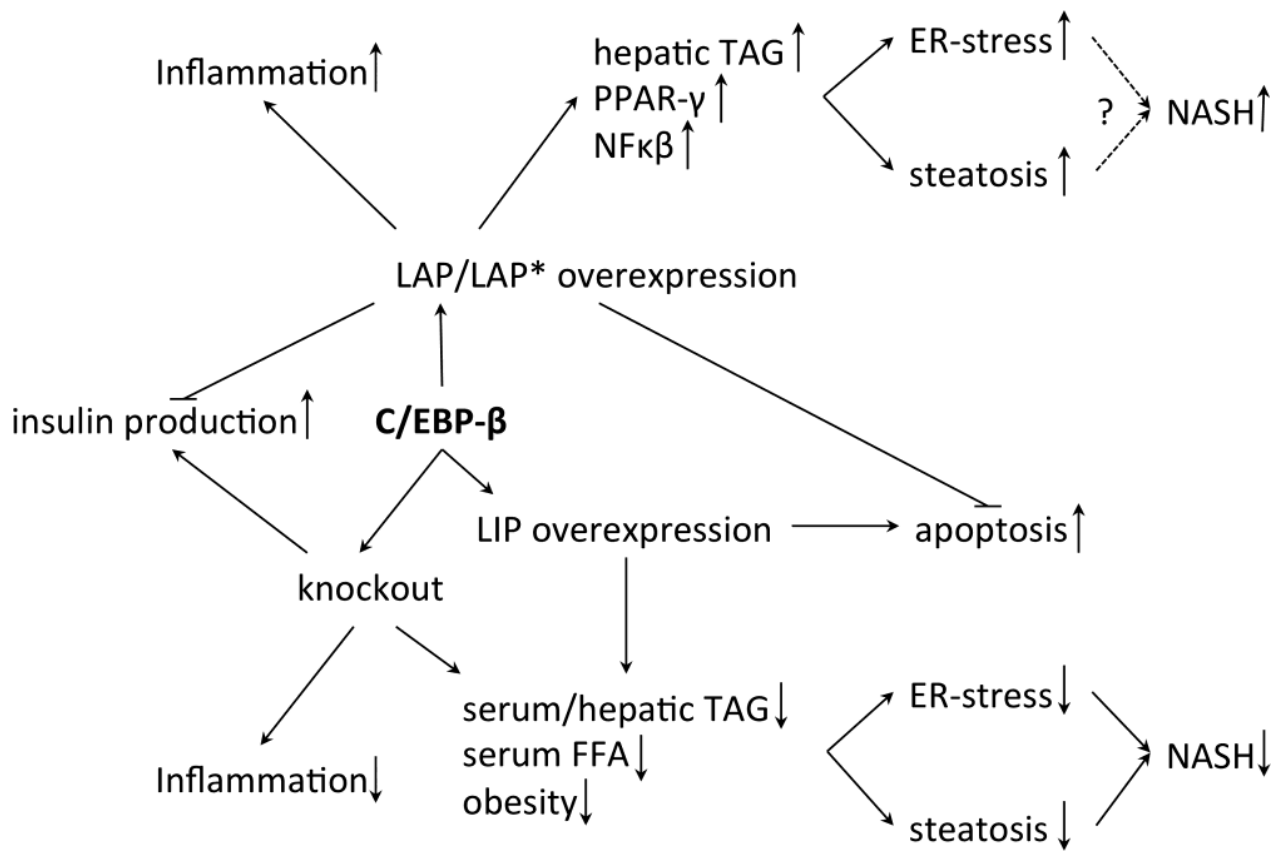

Figure 4. C/EBP- $\beta$ in metabolic processes related to the metabolic syndrome. 
The role of $C / E B P-\beta$ in triacylglycerol metabolism and hepatic steatosis

Although we can not rule out the beneficial metabolic effects of subsequent weight loss, C/EBP- $\beta$ knockout mice showed lower serum and triacylglycerol concentrations and a decreased hepatic triacylglycerol content, when compared to their wild type littermates on the same high-fat diet (figure 4) [13]. In addition, in Lepr $(\mathrm{db} / \mathrm{db})$ mice, where no weight loss could be detected, the deletion of C/EBP- $\beta$ reduced hepatic fat content, and thereby the risk to develop diabetes and obesity [99]. Moreover, hepatic triacylglycerol content as well as lipogenic enzyme activity of C/EBP- $\beta(-/-) \times \operatorname{Lepr}(\mathrm{db} / \mathrm{db})$ mice was dramatically decreased in comparison to wild type mice. However, in the same study, overexpression of C/EBP- $\beta$ isoform LIP in wild type mice resulted in a $50 \%$ reduction of hepatic triacylglycerol concentrations. This might be explained by the fact that LIP is a dominant negative protein, which might inhibit other C/EBP- $\beta$ isoforms that seem to cause steatosis [99]. Non Alcoholic Steatohepatitis (NASH) is strongly associated with obesity, type II diabetes and the metabolic syndrome [100]. The first step in development of $\mathrm{NASH}$ is the increased accumulation of triacylglycerol in the liver caused by lipid overflow. Next, inflammation is induced which can eventually result in development of fibrosis and ultimately liver cell death. Rahman et al. have shown that C/EBP- $\beta$ knockout mice, in which NASH was induced using a methionine-choline deficient diet (MCDD), were partly protected from the development of steatosis, although the results on weight loss in MCDD fed C/EBP- $\beta$ knockout mice were not shown [101]. The authors also mention the possibility of C/EBP- $\beta$ deletion leading to reduced accumulation of lipids in the liver. They ascribe the decreased steatosis development to decreased lipogenesis, resulting in decreased hepatic triacylglycerol content and a decreased activation of inflammation [101]. Similar to the phenotypic response in MCDD fed mice, C/EBP- $\beta$ overexpression in hepatocytes of wild-type mice increased PPAR- $\gamma$ activation, NFKB, hepatic triacylglycerol level, steatosis and ER-stress. These data suggest that high C/EBP$\beta$ levels contribute to the development of NASH and that C/EBP- $\beta$ inhibition is potentially beneficial in preventing hepatic steatosis.

\section{The role of $C / E B P-\beta$ in endoplasmic reticulum stress}

The endoplasmic reticulum (ER) plays a role in folding newly synthesized proteins [102]. In conditions of ER-stress, poorly folded proteins accumulate in the ER, which is detected by the three main ER-stress sensors IRE1 $\alpha / \beta$, PERK and ATF6 [103-105]. The master regulator of ER-stress is GRP78 or BiP protein. When GRP78 detects ER-stress, it dissociates from the ER-stress sensors to activate the unfolded protein response (UPR) [103]. Initially, the UPR copes with ER-stress by introducing chaperones and by attenuation of protein translation. However, persistent ER-stress will eventually trigger cell death or apoptosis [104].

In cultured HepG2 cells, C6 cells and mouse insulinoma cells, C/EBP- $\beta$ (especially the C/EBP- $\beta$ isoform LAP) was activated during ER-stress (figure 4) $[44,59,106]$. This increased LAP production was followed in time by an increase of the isoform LIP. Meir et al. have shown that LAP overexpression decreased, whereas LIP overexpression increased ER-stress triggered cell death [44]. These findings were confirmed by $\mathrm{Li}$ et al, who furthermore showed that C/EBP- $\beta$ binds to ATF4 and CHOP (also named C/EBP- $\zeta$ ), which are both induced during the UPR [106]. LIP 


\section{C/EBP- $\beta$ IN RELATION TO METABOLIC DISTURBANCES}

lowered the expression of pro-survival ATF-4 target genes, and C/EBP- $\beta$ was found to increase the production of CHOP and its downstream cell death related proteins [106]. Besides hepatocytes, also other tissues such as adipocytes, macrophages and $\beta$-cells are targeted by C/EBP- $\beta$ induced ER-stress. For example, Matsuda et al. showed that accumulation of C/EBP- $\beta$ in the $\beta$-cells of the pancreas of diabetic mice induced loss of $\beta$-cell mass and insulin production [92]. The explanation for this finding was the accumulation of C/EBP- $\beta$ blocking ATF6mediated GRP78 transcription, which makes cells more vulnerable for ER-stress and ultimately to the onset of type II diabetes [92].

Together, these results show a link between C/EBP- $\beta$ and ER-stress. C/EBP- $\beta$ isoform LIP appears important in the switch from a protective to an apoptotic pathway in cells that are exposed to ER-stress related UPR. This makes C/EBP- $\beta$ and its isoforms interesting for further research in the prevention of ER-stress in humans, in which reduction of isoform LIP seems beneficial to reduce ER-stress triggered cell death.

\section{The role of $C / E B P-\beta$ in the inflammatory cascade}

Evidence for a role of the different members of the C/EBP family in the inflammatory response rapidly increases $[98,107]$. Many studies have shown that C/EBP- $\beta$ is transcriptionally activated by inflammatory stimuli such as turpentine oil, cytokines such as IL-6, IL-1 and TNF- $\alpha$, and bacterial LPS [107]. When the transactivation domain of C/EBP- $\beta$ becomes phosphorylated due to the presence of inflammatory stimuli, transcription of the C/EBP- $\beta$ gene increases [108]. C/EBP$\beta$ on its turn elevates expression of various pro-inflammatory genes. It is generally accepted that C/EBP- $\beta$ is a key regulator of IL- 6 signaling and is important in transcriptional regulation of the IL-6 gene [31,109]. IL-6 is a key player in various characteristics of the metabolic syndrome, since it is an important contributor to the low-grade pro-inflammatory state [110]. IL-6 on the other hand suppresses the production of insulin in subjects with type II diabetes, which indicates increased insulin sensitivity [111]. One question is whether all C/EBP- $\beta$ isoforms are equally important in its effects on inflammation. After treatment of BALB/c mice with LPS, particularly the expression of the LIP isoform was strongly increased whereas the expression of isoform LAP did not change [112]. This could indicate that particularly an increase in isoform LIP is important in regulating the inflammatory state.

In macrophages, C/EBP- $\beta$ is involved in coordinating the expression of IL-1, IL-6, IL-8, TNF- $\alpha$, granulocyte colony-stimulating factor (G-CSF), nitric oxide synthase, neutrophil elastase, myeloperoxidase, and lysozyme- and the macrophage granulocyte and granulocyte-macrophage receptor genes [113]. C/EBP- $\beta$ is also able to increase the gene expression of macrophage inflammatory protein 1 (MIP$1 \alpha$ ), osteopontin and CD14 in a monocytic cell line (M1 cells) [113]. In addition, C/EBP- $\beta$ knockout mice showed an impaired ability to activate macrophages, pointing towards a distorted immune response [94]. Moreover, C/EBP- $\beta$ knockout mice suffered from defects in their innate, humoral and cellular immunity, which is due to a deficiency in the activation of splenic macrophages, an impaired IL-12 production (involved in activation of natural killer cells and T-cells), and an altered T-helper function. These data reveal that C/EBP- $\beta$ is crucial for the accurate 


\section{CHAPTER 2}

functioning of the immune response, in particular of haemopoietic and lymphoid compartments. Further, Yan et al. showed in macrophages that C/EBP- $\beta$ and $-\delta$ activated the inflammatory response even more when overexpressed together, suggesting that $C / E B P-\beta-C / E B P-\delta$ heterodimers are more potent activators [114].

There is also a link between C/EBP- $\beta$ expression and inflammation in high fat treated RAW 264.7 macrophage cells, 3T3-L1 adipocytes [98]. C/EBP- $\beta$ deletion completely blunted the high-fat diet-induced development of inflammation [98]. Moreover, IL-10 and LXRa gene expression as well as its targets (SCD1 and DGAT2) was largely increased in peritoneal C/EBP- $\beta$ knock out macrophages. Even more, they showed suppressed expression of the NLRP3 gene, which is necessary for the activation of the inflammasome [98]. In the macrophage cell line RAW 264.7 or in 3T3-L1 adipocytes, knock down of C/EBP- $\beta$ also blocked the onset of inflammation after palmitate addition, probably via a decreased activation of p65-NFKB [98]. The latter finding was confirmed by performing a C/EBP- $\beta$ overexpression experiment in which NFKB binding, pro-inflammatory cytokine gene expression and JNK activation were indeed increased [98]. Finally, Screpanti et al. showed diminished NO production after $C$. ablicans infection by macrophages from C/EBP- $\beta$ knockout mice, while wild type macrophages were perfectly capable of producing the vasodilator NO [31].

These results suggest that C/EBP- $\beta$ is an important contributor in the onset of the inflammatory response. It would be interesting to evaluate the effects of C/EBP- $\beta$ inhibition in the prevention of obesity induced systemic inflammation. Evaluation of the most important isoform within this context also deserves attention.

\section{The role of $C / E B P-\beta$ in $H D L$ metabolism}

Large-scale epidemiological studies suggest that increased high-density lipoprotein cholesterol (HDL-C) concentrations protect against the development of cardiovascular diseases [115,116]. However, recent studies failed to show that an increase in serum HDL-C levels translates into a lower CVD risk [117]. Nowadays, the emphasis is on increasing HDL functionality [118] and there is growing evidence that the protective effects of HDL-C depend on apoA-I, the main protein constituent of an HDL particle $[119,120]$. The apoA-I promoter has a C/EBP binding site, which suggests C/EBP- $\beta$ could be involved in the production of apoA-I. However, available data for a possible role of C/EBP- $\beta$ in regulating apoA-I production is not conclusive. Although Kan and colleagues [121] concluded that C/EBP- $\beta$ was not involved in apoA-I production, this was not explored during inflammatory conditions. Testing this hypothesis during inflammatory conditions might be interesting since inflammation is a prominent feature of the metabolic syndrome, and apoA-I is a negative acute phase protein. Moreover, effects of different isoforms were not explored by Kan. Given the potential differences in regulatory effects, it is possible that specific C/EBP- $\beta$ isoforms influence apoA-I production differently. 


\section{C/EBP- $\beta$ IN RELATION TO METABOLIC DISTURBANCES}

\section{Conclusions}

We have evaluated a possible role for C/EBP- $\beta$ and its isoforms in the etiology and progression of the metabolic syndrome (table 2 and figure 4). Currently, all data available regarding the role of C/EBP- $\beta$ arise from animal and in vitro experiments whereas data from human studies is lacking. There is evidence that C/EBP- $\beta$, in particular its isoform LIP, plays a role in the development of white- and brown adipose tissue and in increase activity of brown adipose tissue. Furthermore, animal studies showed that C/EBP- $\beta$ knockout results in weight loss, lower plasma free fatty acids and decreased plasma glucose concentrations. However, one should be aware that C/EBP- $\beta$ deletion coincides with a strong reduction in body weight and fat mass. This decline in fat mass can be ascribed to the prominent role of C/EBP- $\beta$ in adipogenesis. Therefore, it is questionable whether the metabolic effects described are due to C/EBP- $\beta$ itself or are actually indirect effects due to an inability to increase in body weight and in fat mass. Besides these metabolic effects there is a vast amount of evidence showing a role of C/EBP- $\beta$ in increased inflammatory response and ER-stress. In conclusion, in light of these results it is also important to examine the potential role of C/EBP- $\beta$ in humans with and without the metabolic syndrome. 


\section{CHAPTER 2}

Table 2. The involvement of C/EBP- $\beta$ in metabolic processes

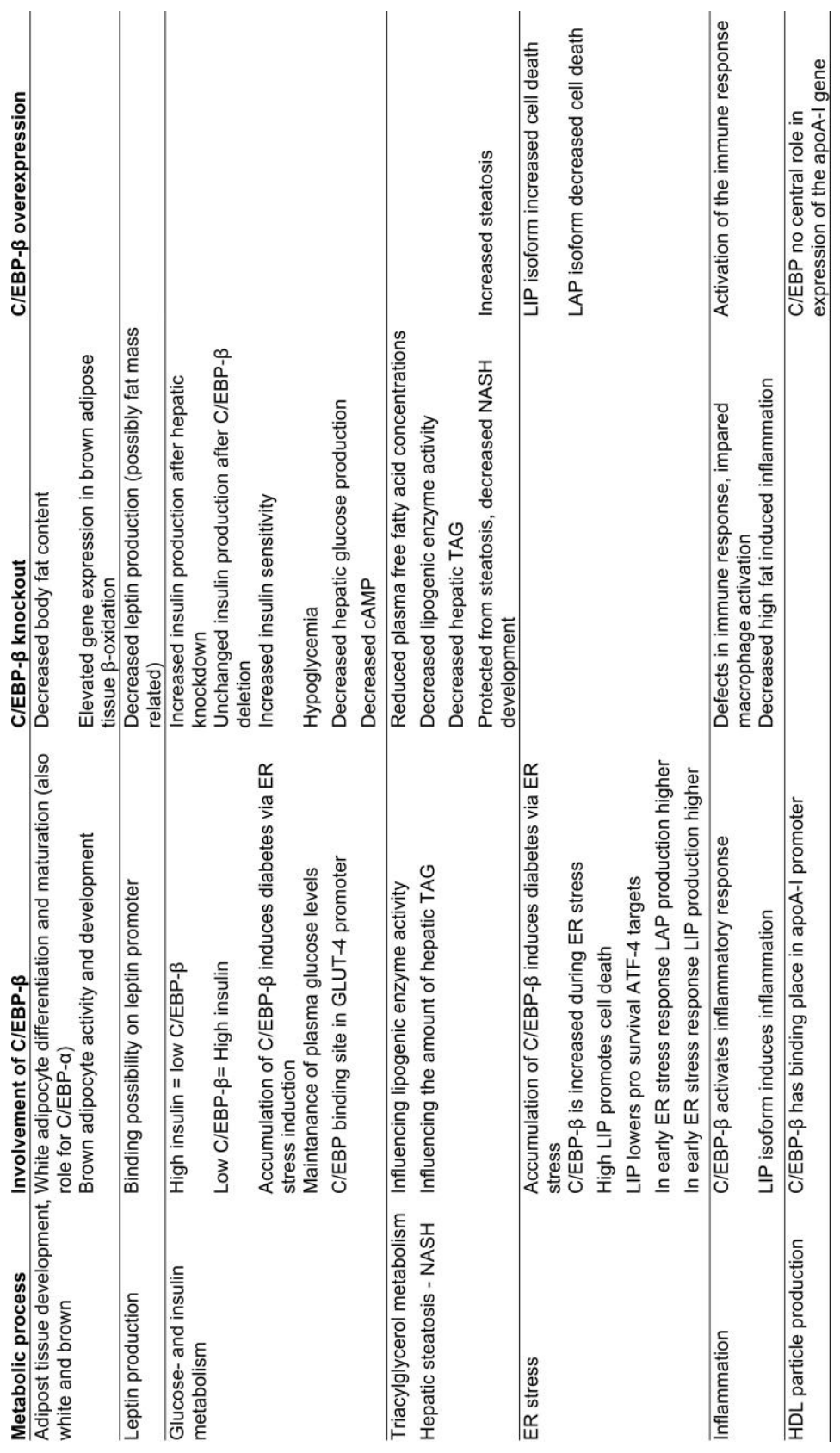




\section{C/EBP- $\beta$ IN RELATION TO METABOLIC DISTURBANCES}

\section{References}

1. Salmenniemi U, Ruotsalainen E, Pihlajamaki J, Vauhkonen I, Kainulainen S, et al. (2004) Multiple abnormalities in glucose and energy metabolism and coordinated changes in levels of adiponectin, cytokines, and adhesion molecules in subjects with metabolic syndrome. Circulation 110: 3842-3848.

2. James PT, Rigby N, Leach R (2004) The obesity epidemic, metabolic syndrome and future prevention strategies. European Journal of Cardiovascular Prevention \& Rehabilitation 11: 3 8.

3. Ahima RS (2006) Adipose tissue as an endocrine organ. Obesity (Silver Spring) 14 Suppl 5: 242S$249 S$.

4. Visser M, Bouter LM, McQuillan GM, Wener MH, Harris TB (1999) Elevated C-reactive protein levels in overweight and obese adults. JAMA 282: 2131-2135

5. Juhan-Vague I, Alessi MC, Mavri A, Morange PE (2003) Plasminogen activator inhibitor-1, inflammation, obesity, insulin resistance and vascular risk. J Thromb Haemost 1: 1575-1579.

6. Yudkin JS (2003) Adipose tissue, insulin action and vascular disease: inflammatory signals. Int J Obes Relat Metab Disord 27 Suppl 3: S25-28.

7. Ross R (1999) Atherosclerosis is an inflammatory disease. Am Heart J 138: S419-420.

8. Haffner SM (2003) Insulin resistance, inflammation, and the prediabetic state. Am J Cardiol 92: 18J26J.

9. Ramji DP, Foka P (2002) CCAAT/enhancer-binding proteins: structure, function and regulation. Biochem J 365: 561-575

10. Bragt MC, Popeijus HE (2008) Peroxisome proliferator-activated receptors and the metabolic syndrome. Physiol Behav 94: 187-197.

11. Baker RG, Hayden MS, Ghosh S (2011) NF-kappaB, inflammation, and metabolic disease. Cell Metab 13: 11-22.

12. lizuka K, Horikawa $Y$ (2008) ChREBP: a glucose-activated transcription factor involved in the development of metabolic syndrome. Endocr J 55: 617-624.

13. Millward CA, Heaney JD, Sinasac DS, Chu EC, Bederman IR, et al. (2007) Mice with a deletion in the gene for CCAAT/enhancer-binding protein beta are protected against diet-induced obesity. Diabetes 56: 161-167.

14. Sato Y, Nishio Y, Sekine O, Kodama K, Nagai Y, et al. (2007) Increased expression of CCAAT/enhancer binding protein-beta and -delta and monocyte chemoattractant protein-1 genes in aortas from hyperinsulinaemic rats. Diabetologia 50: 481-489.

15. Tsukada J, Yoshida Y, Kominato Y, Auron PE (2011) The CCAAT/enhancer (C/EBP) family of basic-leucine zipper (bZIP) transcription factors is a multifaceted highly-regulated system for gene regulation. Cytokine 54: 6-19.

16. Cao Z, Umek RM, McKnight SL (1991) Regulated expression of three C/EBP isoforms during adipose conversion of 3T3-L1 cells. Genes Dev 5: 1538-1552.

17. Williams SC, Cantwell CA, Johnson PF (1991) A family of C/EBP-related proteins capable of forming covalently linked leucine zipper dimers in vitro. Genes Dev 5: 1553-1567.

18. Antonson P, Xanthopoulos KG (1995) Molecular cloning, sequence, and expression patterns of the human gene encoding CCAAT/enhancer binding protein alpha (C/EBP alpha). Biochem Biophys Res Commun 215: 106-113.

19. Lekstrom-Himes J, Xanthopoulos KG (1998) Biological role of the CCAAT/enhancer-binding protein family of transcription factors. J Biol Chem 273: 28545-28548.

20. Lu M, Seufert J, Habener JF (1997) Pancreatic beta-cell-specific repression of insulin gene transcription by CCAAT/enhancer-binding protein beta. Inhibitory interactions with basic helixloop-helix transcription factor E47. J Biol Chem 272: 28349-28359.

21. Akira S, Isshiki H, Sugita T, Tanabe O, Kinoshita S, et al. (1990) A nuclear factor for IL-6 expression (NF-IL6) is a member of a C/EBP family. EMBO J 9: 1897-1906.

22. Poli V, Mancini FP, Cortese R (1990) IL-6DBP, a nuclear protein involved in interleukin-6 signal transduction, defines a new family of leucine zipper proteins related to C/EBP. Cell 63: 643653.

23. Descombes P, Chojkier M, Lichtsteiner S, Falvey E, Schibler U (1990) LAP, a novel member of the C/EBP gene family, encodes a liver-enriched transcriptional activator protein. Genes Dev 4 1541-1551.

24. Chang CJ, Chen TT, Lei HY, Chen DS, Lee SC (1990) Molecular cloning of a transcription factor, AGP/EBP, that belongs to members of the C/EBP family. Mol Cell Biol 10: 6642-6653.

25. Katz S, Kowenz-Leutz E, Muller C, Meese K, Ness SA, et al. (1993) The NF-M transcription factor is related to $\mathrm{C} / \mathrm{EBP}$ beta and plays a role in signal transduction, differentiation and 


\section{CHAPTER 2}

leukemogenesis of avian myelomonocytic cells. EMBO J 12: 1321-1332.

26. Kinoshita S, Akira S, Kishimoto T (1992) A member of the C/EBP family, NF-IL6 beta, forms a heterodimer and transcriptionally synergizes with NF-IL6. Proc Natl Acad Sci U S A 89: 14731476.

27. Chumakov AM, Grillier I, Chumakova E, Chih D, Slater J, et al. (1997) Cloning of the novel human myeloid-cell-specific C/EBP-epsilon transcription factor. Mol Cell Biol 17: 1375-1386.

28. Yamanaka R, Kim GD, Radomska HS, Lekstrom-Himes J, Smith LT, et al. (1997) CCAAT/enhancer binding protein epsilon is preferentially up-regulated during granulocytic differentiation and its functional versatility is determined by alternative use of promoters and differential splicing. Proc Natl Acad Sci U S A 94: 6462-6467.

29. Roman C, Platero JS, Shuman J, Calame K (1990) Ig/EBP-1: a ubiquitously expressed immunoglobulin enhancer binding protein that is similar to $\mathrm{C} / \mathrm{EBP}$ and heterodimerizes with C/EBP. Genes Dev 4: 1404-1415.

30. Ron D, Habener JF (1992) CHOP, a novel developmentally regulated nuclear protein that dimerizes with transcription factors C/EBP and LAP and functions as a dominant-negative inhibitor of gene transcription. Genes Dev 6: 439-453.

31. Screpanti I, Romani L, Musiani P, Modesti A, Fattori E, et al. (1995) Lymphoproliferative disorder and imbalanced T-helper response in C/EBP beta-deficient mice. EMBO J 14: 1932-1941.

32. Tanaka T, Akira S, Yoshida K, Umemoto M, Yoneda Y, et al. (1995) Targeted disruption of the NFIL6 gene discloses its essential role in bacteria killing and tumor cytotoxicity by macrophages. Cell 80: 353-361.

33. Greenbaum LE, Li W, Cressman DE, Peng Y, Ciliberto G, et al. (1998) CCAAT enhancer- binding protein beta is required for normal hepatocyte proliferation in mice after partial hepatectomy. $J$ Clin Invest 102: 996-1007.

34. Welm AL, Mackey SL, Timchenko LT, Darlington GJ, Timchenko NA (2000) Translational induction of liver-enriched transcriptional inhibitory protein during acute phase response leads to repression of CCAAT/enhancer binding protein alpha mRNA. J Biol Chem 275: 27406-27413.

35. Descombes P, Schibler U (1991) A liver-enriched transcriptional activator protein, LAP, and a transcriptional inhibitory protein, LIP, are translated from the same mRNA. Cell 67: 569-579.

36. Ossipow V, Descombes P, Schibler U (1993) CCAAT/enhancer-binding protein mRNA is translated into multiple proteins with different transcription activation potentials. Proc Natl Acad Sci U S A 90: 8219-8223.

37. Lin FT, MacDougald OA, Diehl AM, Lane MD (1993) A 30-kDa alternative translation product of the CCAAT/enhancer binding protein alpha message: transcriptional activator lacking antimitotic activity. Proc Natl Acad Sci U S A 90: 9606-9610.

38. Niehof M, Kubicka S, Zender L, Manns MP, Trautwein C (2001) Autoregulation enables different pathways to control CCAAT/enhancer binding protein beta (C/EBP beta) transcription. J Mol Biol 309: 855-868.

39. Kozak M (1989) The scanning model for translation: an update. J Cell Biol 108: 229-241.

40. Timchenko NA, Welm AL, Lu X, Timchenko LT (1999) CUG repeat binding protein (CUGBP1) interacts with the $5^{\prime}$ region of C/EBPbeta mRNA and regulates translation of C/EBPbeta isoforms. Nucleic Acids Res 27: 4517-4525.

41. Welm AL, Timchenko NA, Darlington GJ (1999) C/EBPalpha regulates generation of C/EBPbeta isoforms through activation of specific proteolytic cleavage. Mol Cell Biol 19: 1695-1704.

42. Tatusova T, Ciufo S, Fedorov B, O'Neill K, Tolstoy I (2014) RefSeq microbial genomes database: new representation and annotation strategy. Nucleic Acids Res 42: D553-559.

43. Williams SC, Baer M, Dillner AJ, Johnson PF (1995) CRP2 (C/EBP beta) contains a bipartite regulatory domain that controls transcriptional activation, DNA binding and cell specificity. EMBO J 14: 3170-3183.

44. Meir O, Dvash E, Werman A, Rubinstein M (2010) C/EBP-beta regulates endoplasmic reticulum stress-triggered cell death in mouse and human models. PLoS One 5: e9516.

45. Rebhan M, Chalifa-Caspi V, Prilusky J, Lancet D (1997) GeneCards: integrating information about genes, proteins and diseases. Trends Genet 13: 163.

46. Berrier A, Siu G, Calame K (1998) Transcription of a minimal promoter from the NF-IL6 gene is regulated by CREB/ATF and SP1 proteins in U937 promonocytic cells. J Immunol 161: 22672275 .

47. Matsumoto M, Sakao Y, Akira S (1998) Inducible expression of nuclear factor IL-6 increases endogenous gene expression of macrophage inflammatory protein-1 alpha, osteopontin and CD14 in a monocytic leukemia cell line. Int Immunol 10: 1825-1835.

48. Chen Y, Zhuang S, Cassenaer S, Casteel DE, Gudi T, et al. (2003) Synergism between calcium and cyclic GMP in cyclic AMP response element-dependent transcriptional regulation requires 


\section{C/EBP- $\beta$ IN RELATION TO METABOLIC DISTURBANCES}

cooperation between CREB and C/EBP-beta. Mol Cell Biol 23: 4066-4082.

49. Mo X, Kowenz-Leutz E, Xu H, Leutz A (2004) Ras induces mediator complex exchange on C/EBP beta. Mol Cell 13: 241-250.

50. Le Lay S, Lefrere I, Trautwein C, Dugail I, Krief S (2002) Insulin and sterol-regulatory elementbinding protein-1C (SREBP-1C) regulation of gene expression in 3T3-L1 adipocytes. Identification of CCAAT/enhancer-binding protein beta as an SREBP-1C target. J Biol Chem 277: 35625-35634.

51. Hattori T, Ohoka N, Hayashi H, Onozaki K (2003) C/EBP homologous protein (CHOP) up-regulates IL-6 transcription by trapping negative regulating NF-IL6 isoform. FEBS Lett 541: 33-39.

52. Duprez E, Wagner K, Koch H, Tenen DG (2003) C/EBPbeta: a major PML-RARA-responsive gene in retinoic acid-induced differentiation of APL cells. EMBO J 22: 5806-5816.

53. Kuilman T, Michaloglou C, Vredeveld LC, Douma S, van Doorn R, et al. (2008) Oncogene-induced senescence relayed by an interleukin-dependent inflammatory network. Cell 133: 1019-1031.

54. Mink S, Haenig B, Klempnauer KH (1997) Interaction and functional collaboration of p300 and C/EBPbeta. Mol Cell Biol 17: 6609-6617.

55. Mink S, Jaswal S, Burk O, Klempnauer KH (1999) The v-Myb oncoprotein activates C/EBPbeta expression by stimulating an autoregulatory loop at the C/EBPbeta promoter. Biochim Biophys Acta 1447: 175-184.

56. Foti D, luliano R, Chiefari E, Brunetti A (2003) A nucleoprotein complex containing Sp1, C/EBP beta, and HMGI-Y controls human insulin receptor gene transcription. Mol Cell Biol 23: 27202732.

57. Chang W, Rewari A, Centrella M, McCarthy TL (2004) Fos-related antigen 2 controls protein kinase A-induced CCAAT/enhancer-binding protein beta expression in osteoblasts. J Biol Chem 279: $42438-42444$.

58. Xie Y, Chen C, Stevenson MA, Auron PE, Calderwood SK (2002) Heat shock factor 1 represses transcription of the $\mathrm{IL}-1$ beta gene through physical interaction with the nuclear factor of interleukin 6. J Biol Chem 277: 11802-11810.

59. Chen Z, Torrens JI, Anand A, Spiegelman BM, Friedman JM (2005) Krox20 stimulates adipogenesis via C/EBPbeta-dependent and -independent mechanisms. Cell Metab 1: 93-106.

60. Kowenz-Leutz E, Leutz A (1999) A C/EBP beta isoform recruits the SWI/SNF complex to activate myeloid genes. Mol Cell 4: 735-743.

61. Niehof M, Streetz K, Rakemann T, Bischoff SC, Manns MP, et al. (2001) Interleukin-6-induced tethering of STAT3 to the LAP/C/EBPbeta promoter suggests a new mechanism of transcriptional regulation by STAT3. J Biol Chem 276: 9016-9027.

62. LeClair KP, Blanar MA, Sharp PA (1992) The p50 subunit of NF-kappa B associates with the NF-IL6 transcription factor. Proc Natl Acad Sci U S A 89: 8145-8149.

63. Chang CJ, Chen YL, Lee SC (1998) Coactivator TIF1beta interacts with transcription factor $\mathrm{C} /$ EBPbeta and glucocorticoid receptor to induce alpha1-acid glycoprotein gene expression. Mol Cell Biol 18: 5880-5887.

64. Zhang F, Lin M, Abidi P, Thiel G, Liu J (2003) Specific interaction of Egr1 and c/EBPbeta leads to the transcriptional activation of the human low density lipoprotein receptor gene. J Biol Chem 278: 44246-44254.

65. Coyle-Rink J, Sweet T, Abraham S, Sawaya B, Batuman O, et al. (2002) Interaction between TGFbeta signaling proteins and C/EBP controls basal and Tat-mediated transcription of HIV-1 LTR in astrocytes. Virology 299: 240-247.

66. Shuman JD, Cheong J, Coligan JE (1997) ATF-2 and C/EBPalpha can form a heterodimeric DNA binding complex in vitro. Functional implications for transcriptional regulation. J Biol Chem 272: $12793-12800$.

67. Podust LM, Krezel AM, Kim Y (2001) Crystal structure of the CCAAT box/enhancer-binding protein beta activating transcription factor-4 basic leucine zipper heterodimer in the absence of DNA. J Biol Chem 276: 505-513.

68. Christian M, Zhang X, Schneider-Merck T, Unterman TG, Gellersen B, et al. (2002) Cyclic AMPinduced forkhead transcription factor, FKHR, cooperates with CCAAT/enhancer-binding protein beta in differentiating human endometrial stromal cells. J Biol Chem 277: 2082520832.

69. Boruk M, Savory JG, Hache RJ (1998) AF-2-dependent potentiation of CCAAT enhancer binding protein beta-mediated transcriptional activation by glucocorticoid receptor. Mol Endocrinol 12: 1749-1763.

70. Metz R, Ziff E (1991) cAMP stimulates the C/EBP-related transcription factor rNFIL-6 to trans-locate to the nucleus and induce c-fos transcription. Genes Dev 5: 1754-1766.

71. Zuo Y, Qiang L, Farmer SR (2006) Activation of CCAAT/enhancer-binding protein (C/EBP) alpha 


\section{CHAPTER 2}

expression by $\mathrm{C} / \mathrm{EBP}$ beta during adipogenesis requires a peroxisome proliferator-activated receptor-gamma-associated repression of HDAC1 at the C/ebp alpha gene promoter. J Biol Chem 281: 7960-7967.

72. Wu Z, Xie Y, Bucher NL, Farmer SR (1995) Conditional ectopic expression of C/EBP beta in NIH3T3 cells induces PPAR gamma and stimulates adipogenesis. Genes Dev 9: 2350-2363.

73. Park EA, Gurney AL, Nizielski SE, Hakimi P, Cao Z, et al. (1993) Relative roles of CCAAT/enhancer-binding protein beta and CAMP regulatory element-binding protein in controlling transcription of the gene for phosphoenolpyruvate carboxykinase (GTP). J Biol Chem 268: 613-619.

74. Trautwein C, Rakemann T, Pietrangelo A, Plumpe J, Montosi G, et al. (1996) C/EBP-beta/LAP controls down-regulation of albumin gene transcription during liver regeneration. $\mathrm{J}$ Biol Chem 271: 22262-22270.

75. Chen GK, Sale S, Tan T, Ermoian RP, Sikic BI (2004) CCAAT/enhancer-binding protein beta (nuclear factor for interleukin 6) transactivates the human MDR1 gene by interaction with an inverted CCAAT box in human cancer cells. Mol Pharmacol 65: 906-916.

76. Busetto L (2001) Visceral obesity and the metabolic syndrome: effects of weight loss. Nutr Metab Cardiovasc Dis 11: 195-204.

77. Clifton PM, Keogh JB, Foster PR, Noakes M (2005) Effect of weight loss on inflammatory and endothelial markers and FMD using two low-fat diets. Int J Obes (Lond) 29: 1445-1451.

78. Staiger J, Lueben MJ, Berrigan D, Malik R, Perkins SN, et al. (2009) C/EBPbeta regulates body composition, energy balance-related hormones and tumor growth. Carcinogenesis 30: 832840.

79. Yubero P, Manchado C, Cassard-Doulcier AM, Mampel T, Vinas O, et al. (1994) CCAAT/enhancer binding proteins alpha and beta are transcriptional activators of the brown fat uncoupling protein gene promoter. Biochem Biophys Res Commun 198: 653-659.

80. Manchado C, Yubero P, Vinas O, Iglesias R, Villarroya F, et al. (1994) CCAAT/enhancer-binding proteins alpha and beta in brown adipose tissue: evidence for a tissue-specific pattern of expression during development. Biochem J 302 ( Pt 3): 695-700.

81. Tanaka T, Yoshida N, Kishimoto T, Akira S (1997) Defective adipocyte differentiation in mice lacking the C/EBPbeta and/or C/EBPdelta gene. EMBO J 16: 7432-7443.

82. Chung SS, Lee JS, Kim M, Ahn BY, Jung HS, et al. (2012) Regulation of Wnt/beta-catenin signaling by CCAAT/enhancer binding protein beta during adipogenesis. Obesity (Silver Spring) 20: 482-487.

83. Hamm JK, Park BH, Farmer SR (2001) A role for C/EBPbeta in regulating peroxisome proliferatoractivated receptor gamma activity during adipogenesis in 3T3-L1 preadipocytes. J Biol Chem 276: 18464-18471.

84. Yeh WC, Cao Z, Classon M, McKnight SL (1995) Cascade regulation of terminal adipocyte differentiation by three members of the C/EBP family of leucine zipper proteins. Genes Dev 9: 168-181.

85. Wu Z, Xie Y, Morrison RF, Bucher NL, Farmer SR (1998) PPARgamma induces the insulindependent glucose transporter GLUT4 in the absence of C/EBPalpha during the conversion of 3T3 fibroblasts into adipocytes. J Clin Invest 101: 22-32.

86. Shao HY, Hsu HY, Wu KS, Hee SW, Chuang LM, et al. (2013) Prolonged induction activates Cebpalpha independent adipogenesis in NIH/3T3 cells. PLoS One 8: e51459.

87. Klok MD, Jakobsdottir S, Drent ML (2007) The role of leptin and ghrelin in the regulation of food intake and body weight in humans: a review. Obes Rev 8: 21-34.

88. Chedraui P, Perez-Lopez FR, Escobar GS, Palla G, Montt-Guevara M, et al. (2014) Circulating leptin, resistin, adiponectin, visfatin, adipsin and ghrelin levels and insulin resistance in postmenopausal women with and without the metabolic syndrome. Maturitas 79: 86-90.

89. Mason MM, He Y, Chen H, Quon MJ, Reitman M (1998) Regulation of leptin promoter function by Sp1, C/EBP, and a novel factor. Endocrinology 139: 1013-1022.

90. Bosch F, Sabater J, Valera A (1995) Insulin inhibits liver expression of the CCAAT/enhancer-binding protein beta. Diabetes 44: 267-271.

91. Seufert J, Weir GC, Habener JF (1998) Differential expression of the insulin gene transcriptional repressor CCAAT/enhancer-binding protein beta and transactivator islet duodenum homeobox-1 in rat pancreatic beta cells during the development of diabetes mellitus. J Clin Invest 101: 2528-2539.

92. Matsuda T, Kido Y, Asahara S, Kaisho T, Tanaka T, et al. (2010) Ablation of C/EBPbeta alleviates ER stress and pancreatic beta cell failure through the GRP78 chaperone in mice. J Clin Invest 120: 115-126.

93. Liu S, Croniger C, Arizmendi C, Harada-Shiba M, Ren J, et al. (1999) Hypoglycemia and impaired 


\section{C/EBP- $\beta$ IN RELATION TO METABOLIC DISTURBANCES}

hepatic glucose production in mice with a deletion of the C/EBPbeta gene. J Clin Invest 103: 207-213.

94. Croniger CM, Millward C, Yang J, Kawai Y, Arinze IJ, et al. (2001) Mice with a deletion in the gene for CCAAT/enhancer-binding protein beta have an attenuated response to cAMP and impaired carbohydrate metabolism. J Biol Chem 276: 629-638.

95. Kaestner KH, Christy RJ, Lane MD (1990) Mouse insulin-responsive glucose transporter gene: characterization of the gene and trans-activation by the CCAAT/enhancer binding protein. Proc Natl Acad Sci U S A 87: 251-255.

96. Yamamoto H, Kurebayashi S, Hirose T, Kouhara H, Kasayama S (2002) Reduced IRS-2 and GLUT4 expression in PPARgamma2-induced adipocytes derived from C/EBPbeta and C/EBPdelta-deficient mouse embryonic fibroblasts. J Cell Sci 115: 3601-3607.

97. Wang L, Shao J, Muhlenkamp P, Liu S, Klepcyk P, et al. (2000) Increased insulin receptor substrate-1 and enhanced skeletal muscle insulin sensitivity in mice lacking CCAAT/enhancer-binding protein beta. J Biol Chem 275: 14173-14181.

98. Rahman SM, Janssen RC, Choudhury M, Baquero KC, Aikens RM, et al. (2012) CCAAT/enhancerbinding protein beta (C/EBPbeta) expression regulates dietary-induced inflammation in macrophages and adipose tissue in mice. J Biol Chem 287: 34349-34360.

99. Schroeder-Gloeckler JM, Rahman SM, Janssen RC, Qiao L, Shao J, et al. (2007) CCAAT/enhancer-binding protein beta deletion reduces adiposity, hepatic steatosis, and diabetes in Lepr(db/db) mice. J Biol Chem 282: 15717-15729.

100. Angulo $P$ (2002) Nonalcoholic fatty liver disease. N Engl J Med 346: 1221-1231.

101. Rahman SM, Schroeder-Gloeckler JM, Janssen RC, Jiang H, Qadri I, et al. (2007) CCAAT/enhancing binding protein beta deletion in mice attenuates inflammation, endoplasmic reticulum stress, and lipid accumulation in diet-induced nonalcoholic steatohepatitis. Hepatology 45: 1108-1117.

102. Vitale A, Denecke J (1999) The endoplasmic reticulum-gateway of the secretory pathway. Plant Cell 11: 615-628.

103. Banerjee S, Zhao Y, Sarkar PS, Rosenblatt KP, Tilton RG, et al. (2013) Klotho ameliorates chemically induced endoplasmic reticulum (ER) stress signaling. Cell Physiol Biochem 31: 659-672.

104. Kim I, Xu W, Reed JC (2008) Cell death and endoplasmic reticulum stress: disease relevance and therapeutic opportunities. Nat Rev Drug Discov 7: 1013-1030.

105. Yiming Li YG, Juan Tang, Jianli Jiang and Zhinan Chen (2014) New insights into the roles of CHOP-induced apoptosis in ER stress. Acta Biochim Biophys Sin.

106. Li Y, Bevilacqua E, Chiribau CB, Majumder M, Wang C, et al. (2008) Differential control of the CCAAT/enhancer-binding protein beta (C/EBPbeta) products liver-enriched transcriptional activating protein (LAP) and liver-enriched transcriptional inhibitory protein (LIP) and the regulation of gene expression during the response to endoplasmic reticulum stress. J Biol Chem 283: 22443-22456.

107. Cloutier A, Guindi C, Larivee P, Dubois CM, Amrani A, et al. (2009) Inflammatory cytokine production by human neutrophils involves C/EBP transcription factors. J Immunol 182: 563571.

108. Trautwein C, Caelles C, van der Geer P, Hunter T, Karin M, et al. (1993) Transactivation by NFIL6/LAP is enhanced by phosphorylation of its activation domain. Nature 364: 544-547.

109. Hungness ES, Luo GJ, Pritts TA, Sun X, Robb BW, et al. (2002) Transcription factors C/EBP-beta and -delta regulate IL-6 production in IL-1beta-stimulated human enterocytes. J Cell Physiol 192: 64-70.

110. Wannamethee SG, Whincup PH, Rumley A, Lowe GD (2007) Inter-relationships of interleukin-6, cardiovascular risk factors and the metabolic syndrome among older men. $\mathrm{J}$ Thromb Haemost 5: 1637-1643.

111. Harder-Lauridsen NM, Krogh-Madsen R, Holst JJ, Plomgaard P, Leick L, et al. (2014) Effect of IL-6 on the insulin sensitivity in patients with type 2 diabetes. Am J Physiol Endocrinol Metab 306: E769-778.

112. An MR, Hsieh CC, Reisner PD, Rabek JP, Scott SG, et al. (1996) Evidence for posttranscriptional regulation of $\mathrm{C} / \mathrm{EBP}$ alpha and $\mathrm{C} / \mathrm{EBPbeta}$ isoform expression during the lipopolysaccharidemediated acute-phase response. Mol Cell Biol 16: 2295-2306.

113. Poli V (1998) The role of C/EBP isoforms in the control of inflammatory and native immunity functions. J Biol Chem 273: 29279-29282.

114. Yan C, Zhu M, Staiger J, Johnson PF, Gao H (2012) C5a-regulated CCAAT/enhancer-binding proteins beta and delta are essential in Fcgamma receptor-mediated inflammatory cytokine and chemokine production in macrophages. J Biol Chem 287: 3217-3230. 


\section{CHAPTER 2}

115. Luc G, Bard JM, Ferrieres J, Evans A, Amouyel P, et al. (2002) Value of HDL cholesterol, apolipoprotein A-I, lipoprotein A-I, and lipoprotein A-I/A-II in prediction of coronary heart disease: the PRIME Study. Prospective Epidemiological Study of Myocardial Infarction. Arterioscler Thromb Vasc Biol 22: 1155-1161.

116. Barter PJ, Rye KA (2006) Relationship between the concentration and antiatherogenic activity of high-density lipoproteins. Curr Opin Lipidol 17: 399-403.

117. Rader DJ, Tall AR (2012) The not-so-simple HDL story: Is it time to revise the HDL cholesterol hypothesis? Nat Med 18: 1344-1346.

118. Boekholdt SM, Arsenault BJ, Hovingh GK, Mora S, Pedersen TR, et al. (2013) Levels and changes of $\mathrm{HDL}$ cholesterol and apolipoprotein A-I in relation to risk of cardiovascular events among statin-treated patients: a meta-analysis. Circulation 128: 1504-1512.

119. Nissen SE, Tsunoda T, Tuzcu EM, Schoenhagen P, Cooper CJ, et al. (2003) Effect of recombinant ApoA-I Milano on coronary atherosclerosis in patients with acute coronary syndromes: a randomized controlled trial. JAMA 290: 2292-2300.

120. Leman LJ, Maryanoff BE, Ghadiri MR (2014) Molecules that mimic apolipoprotein A-I: potential agents for treating atherosclerosis. J Med Chem 57: 2169-2196.

121. Kan HY, Georgopoulos S, Zanni M, Shkodrani A, Tzatsos A, et al. (2004) Contribution of the hormone-response elements of the proximal ApoA-I promoter, ApoCIII enhancer, and C/EBP binding site of the proximal ApoA-I promoter to the hepatic and intestinal expression of the ApoA-I and ApoCIII genes in transgenic mice. Biochemistry 43: 5084-5093. 


\section{CHAPTER 3}

C/EBP- $\beta$ is differentially affected by PPAR $\alpha$ agonists fenofibric acid and GW7647, but does not change apolipoprotein A-I production during ER-stress and inflammation

Sophie E. van der Krieken, Herman E. Popeijus, Maurice Konings, Stefan P.J. Dullens, Ronald P. Mensink and Jogchum Plat

J. Cell. Biochem. 2016 Sep 12. doi: 10.1002/jcb.25731 


\section{CHAPTER 3}

\section{Abstract}

Increasing apolipoproteinA-I (apoA-I) production may be anti-atherogenic. Thus, there is a need to identify regulatory factors involved. Transcription of apoA-I involves peroxisome-proliferator-activated-receptor-alpha (PPARa) activation, but endoplasmic reticulum (ER) -stress and inflammation also influence apoA-I production. To unravel why PPARa agonist GW7647 increased apoA-I production compared to PPARa agonist fenofibric acid (FeAc) in human hepatocellular carcinoma (HepG2) and colorectal adenocarcinoma (CaCo-2) cells, gene expression profiles were compared. Microarray analyses suggested CCAAT/enhancer-binding-protein-beta (C/EBP- $\beta)$ involvement in the FeAc condition. Therefore, C/EBP- $\beta$ silencing and isoform-specific overexpression experiments were performed under ER-stressed, inflammatory and noninflammatory conditions. mRNA expression of C/EBP- $\beta$, ATF3, NF-IL3 and GDF15 were upregulated by FeAc compared to GW7647 in both cell lines, while DDIT3 and DDIT4 mRNA were only upregulated in HepG2 cells. This ER-stress related signature was associated with decreased apoA-I secretion. After ER-stress induction by thapsigargin or FeAc addition, intracellular apoA-I concentrations decreased, while ER-stress marker expression (CHOP, XBP1s, C/EBP- $\beta$ ) increased. Cytokine addition increased intracellular C/EBP- $\beta$ levels and lowered apoA-I concentrations. Although a C/EBP binding place is present in the apoA-I promoter, C/EBP- $\beta$ silencing or isoform-specific overexpression did not affect apoA-I production in inflammatory, non-inflammatory and ER-stressed conditions. Therefore, $\mathrm{C} / \mathrm{EBP}-\beta$ is not a target to influence hepatic apoA-I production. 


\section{NATURAL PPAR $\alpha$ TRANSACTIVATING COMPOUNDS}

\section{Introduction}

Many large-scale prospective epidemiological studies have shown an inverse relationship between serum HDL-cholesterol (HDL-C) concentrations and cardiovascular disease (CVD) risk, most likely due to the role of HDL-C in reverse cholesterol transport [1]. Interestingly, increasing HDL concentrations per se did not lower CVD risk. Therefore, the focus has shifted towards increasing HDL functionality [2]. In this respect, accumulating evidence shows that in particular elevated serum apolipoprotein A-I (apoA-I) concentrations are athero-protective [3] and should be the target for CVD prevention [4]. ApoA-I is the most abundant apolipoprotein in HDL and is produced mainly in the human liver and intestine. It is well known that human apoA-I transgenic mice are protected against atherosclerotic lesion development [5]. Additionally, apoA-I mimetics are potential agents to prevent atherosclerosis [6]. For example, intravenous infusion of recombinant apoA-I was protective in the context of CVD development by reducing atheroma size in patients with acute coronary syndromes [7]. The importance of apoA-I production in the formation of functional HDL is also shown in studies with patients suffering from familial hypoalphalipoproteinemia [8] and analphalipoprotenemia [9]. Moreover, mutations in the apoA-I gene might result in impaired HDL particle function [10]. Finally, apoA-I was shown to be involved in regulating insulin secretion and glucose metabolism in smooth muscle cells, which may also contribute to a reduced CVD risk [2]. These data emphasize the need to better understand the regulatory processes of apoA-I transcription, translation and secretion, when the ultimate aim is to elevate apoA-I production and consequently $\mathrm{HDL}$ functionality. The production of apoA-I is mediated via the activation of transcription factor peroxisome proliferator-activated receptor alpha (PPARa) [11]. However, PPARa activation alone is not always sufficient to enhance apoA-I production, as apoA-I production might also be influenced by other factors like HNF4, HNF3b [12,13] or BET proteins [14]. We observed that PPARa agonists FeAc and GW7647 exerted different effects on apoA-I production in HepG2 and CaCo-2 cells, which was also found in a previous study of Dullens et al [15]. The aims of this study were to identify via a micro-array approach, which (transcription) factors are causing the differences in apoA-I production in HepG2 and $\mathrm{CaCo}-2$ after addition of the PPARa agonists (FeAc or GW7647), and to find additional targets that are part of the regulatory network of apoA-I transcription in HepG2 cells. Since conditions like endoplasmic reticulum (ER) -stress and inflammation are associated with decreased serum apoA-I concentrations [16] we specifically investigated possibilities to change apoA-I production under these conditions.

\section{Materials \& Methods}

\section{HepG2 and CaCo-2 cell culture}

HepG2 cells (kindly provided by Sten Braesch-Andersen, PhD, Mabtech, Nacka Strand, Sweden) were maintained in Minimum Essential Medium (MEM) plus Lglutamine (5.5mM low glucose, Invitrogen Life Technologies, Carlsbad, CA, USA) and $\mathrm{CaCo}-2$ cells (European Collection of Cell Cultures (ECACC)) were cultured in Dulbecco's Modified Eagle Medium (DMEM, 25mM glucose). Both MEM and 


\section{CHAPTER 3}

DMEM were supplemented with $10 \%$ Fetal Bovine Serum (FBS, v/v), 1\% Non Essential Amino Acids (NEAA, v/v), 1\% penicillin/streptomycin ( $\mathrm{v} / \mathrm{v})$, and $1 \%$ sodium pyruvate $(1 \mathrm{mM} v / \mathrm{v})$. Medium supplements were obtained from Invitrogen Life Technologies, Carlsbad, CA, USA. Cells were grown in a humid atmosphere, with $5 \% \mathrm{CO} 2$ at $37^{\circ} \mathrm{C}$.

$\mathrm{CaCo} 2$ cells undergo spontaneous differentiation when a monolayer of polarized cells is cultured for two to three weeks [17] and after differentiation they produce apoA-I. Therefore, CaCo- 2 cells were seeded in 6 -well plates $\left(5 \times 10^{\wedge} 5\right.$ cells per $\mathrm{ml}$, $2 \mathrm{ml} /$ well), and culture medium was refreshed every two to three days. To ensure that the CaCo-2 cell monolayer remained confluent they were microscopically followed over time. HepG2 cells were cultured in 6 -well plates $\left(5 \times 10^{\wedge} 5\right.$ cells per $\mathrm{ml}$, $2 \mathrm{ml} / \mathrm{well}$ ) to a confluency of \pm 90 percent. Three hours prior determination of the gene expression profiles, the cells were exposed in triplicate to $0.6 \mathrm{mM}$ fenofibric acid (FeAc) (sonificated for 30 minutes at $47 \mathrm{kHz}$ in medium; Fournier, Dijon, France) or $100 \mathrm{nM}$ GW7647 dissolved in medium (Sigma St. Louis, MO, USA). Changes in the gene expression profile were measured 3 hours post-drug exposure [18]. Moreover, we aimed to measure gene expression in an early phase, before changes in apoA-I expression were evident.

\section{Search for potential regulatory factors in apoA-I production via micro-array}

Using twelve 22K Agilent Human 1A micro-arrays, genes that were differentially expressed following treatment of HepG2 or CaCo-2 cells with FeAc or GW7647, were identified according to manufacturers' protocol. Hybridization and image scanning was performed at the Microarray Facility, Leuven University, Leuven, Belgium.

\section{RNA isolation and Agilent hybridization}

In order to perform the micro-arrays, RNA was isolated using the ABI Prism 6100 Nucleic Acid Prep Station according to manufacturer's protocol (Applied Biosystems, Warrington, UK). RNA of FeAc-treated cells was Cy5-labeled and RNA of GW7647-treated cells was Cy3-labeled. FeAc- and GW7647-labeled total RNA was paired and hybridized on a 22K Agilent Human 1A oligo nucleotide V2 micro-arrays (Agilent Technologies, Santa Clara, CA, USA). In addition, a dye-flip was performed on a second micro-array.

\section{Micro-array Image and Data analysis}

Agilent images were scored with the Agilent G2567AA Feature Extraction Software v8.5 (Agilent Technologies, Santa Clara, CA, USA) using the default parameters, as defined by the Agilent Human 1Av2 protocol and statistically analyzed with the Bioconductor "limma" package build 2.8.1 [19]. Only values that met our quality criteria were used. The quality criteria were: 1 ) each fluorescent spot had to consist of at least 55 pixels, 2) the background-corrected spot intensity (MeanSignal BGUsed) had to be greater than $2.6 \times \mathrm{SD}$ of the measured background, and 3) the 


\section{NATURAL PPAR $\alpha$ TRANSACTIVATING COMPOUNDS}

fluorescent spot intensity was unsaturated for both channels. The intensities corrected for background were normalized for all micro-arrays by the LOESS algorithm (within-array) and a quantile normalization step (between-array) [20]. Verification for consistency of the signal intensity was done by subtracting the corrected signal of the red (Cy5-labeled) channel with the green (Cy3-labeled) signal of its dye-flip counterpart and vice versa. The result was plotted (supplemental figures S1 and S2) and expected to center around 0. For one micro-array this spread was too large and therefore this micro-array was excluded.

A gene list for each cell line was generated for the remaining micro-arrays using the "limma" functions Imfit and eBayes. Next, the gene lists were filtered (filter criteria: $P$-values $(P \leq 0.05)$ and absolute fold changes $(|F C| \geq 1.2)$ ) following: a) manually comparison to each other, b) used for pathway- and GO analysis (GenMAPP v2.1/GO-elite v1.17 beta) for pathway analysis and controlled for reporter specificity (31). A pathway was considered differentially regulated when the $z$-score was $\geq 1$ in one of the cell lines.

\section{Real-time quantitative RT-PCR analysis}

Real-time quantitative PCR (RTq-PCR) analysis was performed to verify the differential expression of genes as identified in the micro-array experiments. Hereto, the following Taqman gene expression assays were applied and analyzed on a Taqman ABI7000 (Applied Biosystems, Warrington, UK); ApoA-I (Hs00163641_m1), ATF3 (Hs00231069_m1), C/EBP- $\beta$ (Hs00942496_s1), DDIT3 (Hs99999172_m1), DDIT4 (Hs01111686_g1), GDF15 (Hs00171132_m1), NFIL3 (Hs00993282_m1) PPARa (Hs00231882_m1), CPT1a (Hs00912671_m1), the housekeeping gene Cyclophilin A (Hs99999904_m1), and quantified as described by Livak et al [21].

\section{ApoA-I protein concentrations}

Cell culture medium from treated HepG2 and differentiated CaCo-2 cells was collected after 48 hours of incubation and human apoA-I protein concentrations were determined with a sandwich ELISA (Mabtech, Nacka Strand, Sweden) in combination with the apoA-I calibration curve using purified human apoA-I (Sigma, St. Louis, MO, USA).

\section{Activation of C/EBP- $\beta$ in HepG2 cells}

To activate C/EBP- $\beta$, 8-bromo-CAMP [22] $(0.5 \mathrm{mM}$; Calbiochem) or a cytokine cocktail (comprised of human IL-6 $100 \mathrm{ng} / \mathrm{ml}$ (kindly provided by Prof. W.A. Buurman, Maastricht University, The Netherlands) TNF- $\alpha$ (100 ng/mL; Sigma), and IL-1 $\beta$ (5 $\mathrm{ng} / \mathrm{mL}$; Sigma)) was used alone or in combination with the PPAR $\alpha$ agonist GW7647.

Induction of ER-stress in HepG2 cells 


\section{CHAPTER 3}

To induce ER-stress in HepG2 cells, four different concentrations $(0.001 \mu \mathrm{M}$, $0.01 \mu \mathrm{M}, 0.1 \mu \mathrm{M}$, or $0.5 \mu \mathrm{M}$ ) of thapsigargin, obtained from Sigma Aldrich (St. Louis, MO, USA) were incubated for 48 hours. ER-stress was monitored via expression analysis of ER-stress markers XBP1s and CHOP by western blotting as described later.

\section{Inhibition of C/EBP- $\beta$ expression in HepG2 cells}

To inhibit C/EBP- $\beta$, HepG2 cells were transfected with C/EBP- $\beta$ siRNA sc-29229 (h) or sc-44251 (h2) (Santa Cruz Biotechnology, Inc.). siRNA-A sc-37007 was used as a control (Santa Cruz Biotechnology, Inc.). Transfections were performed in quadruplicate using Lipofectamine (Roche Diagnostics, Basel, Switzerland) according to the manufacturers' instruction for 48 hours.

\section{Transient transfection of $C / E B P-\beta$ isoforms $L A P^{*}, L A P$ and $L I P$}

Isoform specific overexpression of C/EBP- $\beta$ in HepG2 or Caco2 cells was achieved through transfection of $0.25 \mu \mathrm{g}$ of the specific isoform of C/EBP- $\beta$ cloned into the pcDNA 3.1 plasmid: liver-enriched transcriptional activating protein star $\left(\mathrm{LAP}^{*}\right)$, liver-enriched transcriptional activating protein (LAP), and liver-enriched transcriptional inhibitory protein (LIP) (Invitrogen Life Technologies, Carlsbad, CA, USA). Transfections were performed according to the manufacturer's instructions, for 48 hours, using XtremeGENE9 or Lipofectamine LTX PLUS from Roche and Invitrogen respectively. A Histon-GFP expression vector was used to control for successful transfection. A transfection efficiency of at least $75 \%$ green cells was considered to be sufficient, which was estimated visually by fluorescence microscopy.

\section{Preparation of cell lysates and protein quantification}

To prepare cell lysates, cells were washed twice with a PBS solution and lysed on ice for 20 minutes in 100 $\mu$ l Radioimmunoprecipitation assay buffer (RIPA) buffer (RIPA buffer, Sigma-Aldrich), containing a protease inhibitor cocktail (Complete, Mini Protease inhibitor Cocktail Tablets, Roche) and a phosphatase inhibitor cocktail (PhosSTOP, Phosphatase Inhibitor Cocktail Tablets, Roche). Protein content was determined using the Pierce BCA assay kit according to the manufacturers' manual (Pierce ${ }^{\circledR}$ BCA Protein Assay Kit).

\section{Western blotting}

Typically, $15 \mu$ g protein of each cell lysate was loaded on a $12 \%$ running and $4 \%$ stacking SDS-PAGE gel. The Precision Plus Protein ${ }^{\mathrm{TM}}$ All Blue marker (Biorad) was used to determine protein size. After the samples were separated and blotted overnight on a PVDF membrane the transfer and equal loading of proteins was checked using PonceauS staining. At each occasion the primary antibody was 


\section{NATURAL PPARa TRANSACTIVATING COMPOUNDS}

incubated overnight at $4^{\circ} \mathrm{C}$, washed with TRIS buffered saline containing $0.2 \%$ tween (TBS-T), incubated with a proper secondary antibody coupled to horse radish peroxidase (Stabilized Conjugated Goat anti-rabbit HRP) for 4 hours at $4^{\circ} \mathrm{C}$ and visualized using either the SuperSignal West Femto kit or SuperSignal West DURA kit (Pierce) and the ChemiDoc XRS imaging system (Biorad). Antibodies to XBP1s (\#647501, mouse), CHOP (\#1649, mouse), apoA-I (\#0650180, sheep) and C/EBP- $\beta$ (\#A2109 c-19, rabbit) were purchased from Biolegend (ITK diagnostics, San Diego, CA), Cell Signaling, Select Science (MorphoSys UK Ltd) and Santa Cruz Biotechnology Inc. (Heidelberg, Germany), respectively. Secondary antibodies used were donkey-anti-sheep-HRP (Abcam), goat- anti-mouse (Pierce) and goat-anti-sheep HRP (Pierce).

\section{Statistical analysis}

All data are shown as mean \pm standard deviations. Differences between treatments were tested by Kruskall Wallis nonparametric test, following Dunn's test for multiple comparison, unless indicated otherwise. Statistical analyses were performed Graphpad Prism 7 (GraphPad Software, Inc., CA, USA).

\section{Results}

Search for potential regulatory factors in apoA-I production via micro-array

Despite the fact that FeAc and GW7647 are both accepted PPARa agonists and both induced CPT1 $\alpha$ at a dose dependent manner in HepG2, HepG2 cells treated with GW7647 showed a significantly higher apoA-I secretion in cell culture medium as compared to FeAc (figure $\mathbf{1}$ and S3A). The concentration of the PPARa agonists, was based on the previous studie of Dullens et al. To explain this differential apoA-I production by FeAc and GW7647, gene expression profiles of FeAc- and GW7647-treated HepG2 and CaCo-2 cells were compared using microarrays (for the rationale of the study see figure 1B). 


\section{CHAPTER 3}
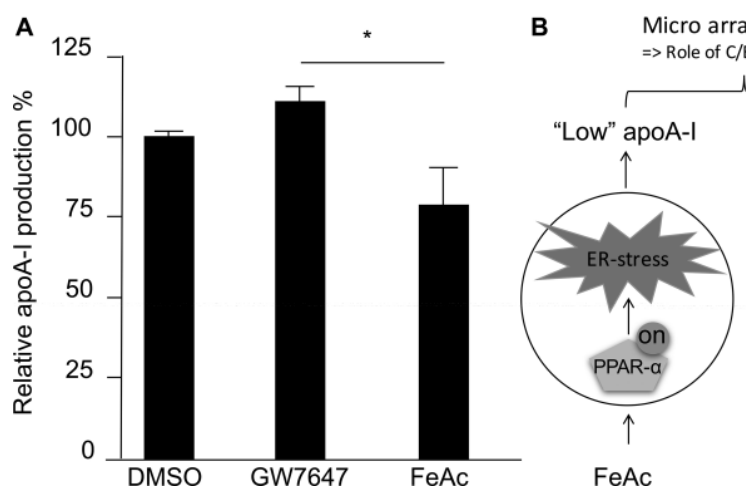

C/EBP- $\beta$ overexpression

C/EBP- $\beta$ silencing

(+/- ER-stress or inflammation)

Figure 1. (a) Relative effect of GW7647 and FeAc on apoA-I secretion in HepG2 cells; ApoA-I production of HepG2 cells incubated with PPARa activators FeAc $(0.6 \mathrm{mM})$ or GW7647 (100nM) for 48 hours. DMSO was used as control condition. (b) Schematic presentation of the study rationale. To explain the differential effect of FeAc and GW7647 on apoA-I production, gene expression profiles of FeAc- and GW7647- treated HepG2 and CaCo-2 cells were compared using micro-arrays. One of the differentially expressed genes was C/EBP- $\beta$. The effect of C/EBP- $\beta$ on apoA-I production was investigated via silencing and overexpression experiments, during normal, ER-stressed and cytokine treated conditions.

Micro-array data analysis resulted in a differentially regulated gene set for FeAc versus GW7647 treated cells that consisted of 473 up-regulated genes and 396 down-regulated genes in HepG2 cells, and 238 up-regulated genes and 222 downregulated genes in differentiated $\mathrm{CaCo}-2$ cells. From these genes, 63 were differentially expressed in both cell lines, as presented in the Venn diagrams (figure 2A) and listed in supplemental table 1. These 63 genes were considered as candidate genes responsible for the differential regulation of apoA-I production following treatment with $\mathrm{FeAc}$ versus GW7647 both in HepG2 and CaCo-2 cells. Pathway analysis of the FeAc versus GW7647 treated HepG2 and CaCo-2 cells showed that the MAPK signalling pathway (KEGG), adipogenesis, and hypertrophy were differentially regulated (for the affected GenMAPP v2.1 pathway list see supplemental table 2). The extended list of affected genes within these pathways is presented in supplemental table 3. In the MAPK signalling pathway (KEGG) for example the genes for DDIT1, ATF4 and MOS were upregulated in HepG2, but not in CaCo-2 cells, whereas the genes for NDN, SOCS3 and BMP2 were increased from the adipogenesis pathway in HepG2 only. Moreover, of the hypertrophy related genes, IFRD1 and VEGF were increasingly expressed in HepG2 or CaCo-2 and HepG2 respectively.

Interestingly, when focusing on the complete set of data, especially the transcription factors ATF3, GDF15, NF-IL3 and C/EBP- $\beta$ were strongly upregulated after FeAc compared to GW7647 treatment in both cell lines (supplemental table 4 and figure 2B and 2C). Gene expression of DDIT3 and DDIT4 were only differentially expressed in HepG2 cells (supplemental table 4 and figure 2C). PPARY or PPARa expression both did not differ between the FeAc and the GW7647 treated cells. Furthermore, to verify that PPARa activity was increased 


\section{NATURAL PPARa TRANSACTIVATING COMPOUNDS}

after exposure to both PPAR agonists, CPT1 $\alpha$ mRNA expression was measured. The PPAR $\alpha$ target CPT1 $\alpha$ was indeed dose dependently increased for in both FeAc and GW7647 conditions (supplemental figure S3A). In addition, PPARa transactivation increased after GW7647 as well as FeAc addition (supplemental figure S3B). A dose response curve for apoA-I production after GW7647 and FeAc addition in HepG2 cells can be found in supplemental figure S4A and S4B.
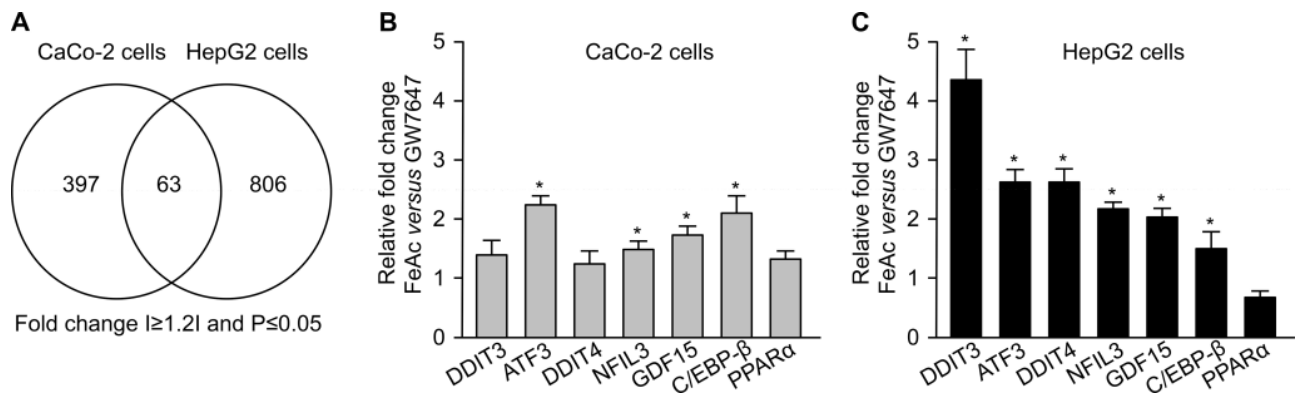

Figure 2. Microarray results of GW7647 and FeAc treated CaCo-2 and HepG2 cells; (a) Venn diagram, indicating that 63 genes are differentially expressed in the FeAc vs GW7647 condition, after three hours of incubation; (b) Relative fold changes of gene expression in the FeAc compared to GW7647 condition in CaCo2 cells after three hours of incubation or $2 \mathrm{C}$ : Relative fold changes of gene expression in the FeAc compared to GW7647 condition in HepG2 cells after three hours of incubation. $\mathrm{N}=2$. ${ }^{*} \mathrm{P} \leq 0.05$ : Statistically different between $\mathrm{FeAc}$ and GW7647.

Subsequent analysis of the list of all regulated transcription factors revealed abundance of factors associated with ER-stress (supplemental table 4). Since ERstress is associated with decreased apoA-I production [16], this observation was explored into more detail. Increased production of the ER-stress markers (supplemental table 4) was also confirmed at the protein level and showed a clear increase in the production of CHOP, XBP1s and C/EBP- $\beta$ in the FeAc condition as compared to GW7647 (figure 3). 


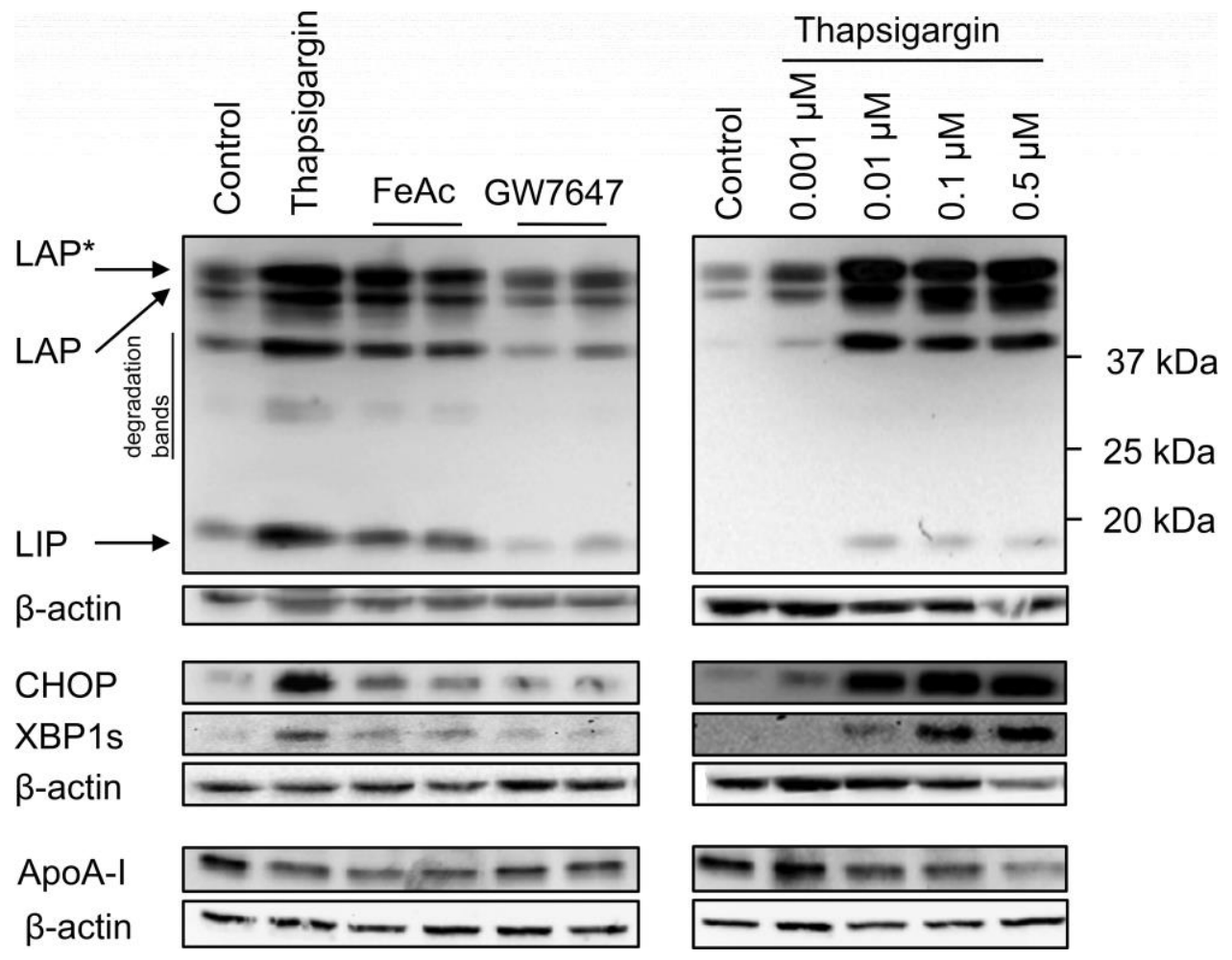

Figure 3. Protein expression of C/EBP- $\beta$, CHOP, XBP1s, apoA-I in FeAc-, GW7647- and thapsigargin treated HepG2 cells; HepG2 cells were incubated with $0.6 \mathrm{mM}$ FeAc, $100 \mathrm{nM}$ GW7647 or $0.01 \mu \mathrm{M}$ thapsigargin for 48 hours. Using western blotting the protein expression of the proteins C/EBP- $\beta$, CHOP, XBP1s and apoA-I was determined. $\beta$-actin was used as a control for equal protein loading. Protein degradation bands are indicated accordingly.

\section{Activation of ER-stress via thapsigargin lowers apoA-I production}

Activation of ER-stress by thapsigargin dose-dependently increased intracellular levels of the ER-stress related proteins CHOP, XBP1s and C/EBP- $\beta$ (figure 3). The observed effects after FeAc treatment are in line with the effects seen after thapsigargin addition. Thapsigargin also clearly decreased intracellular apoA-I protein content (figure 3 ) and apoA-I protein production in culture supernatant (figure 4A). 


\section{NATURAL PPARa TRANSACTIVATING COMPOUNDS}

Induction of inflammation lowers apoA-I production

To induce inflammation, HepG2 cells were treated with IL-6 or a cytokine cocktail composed of IL1- $\beta$, TNF- $\alpha$ and IL-6. This resulted in reduced production of apoA-I, while $\mathrm{C} / \mathrm{EBP}-\beta$ mRNA production and C/EBP- $\beta$ protein production increased (figure 4B).

A

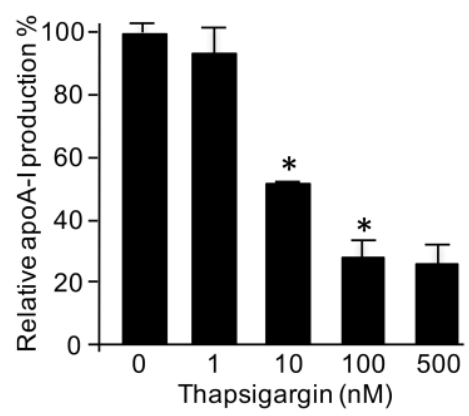

C

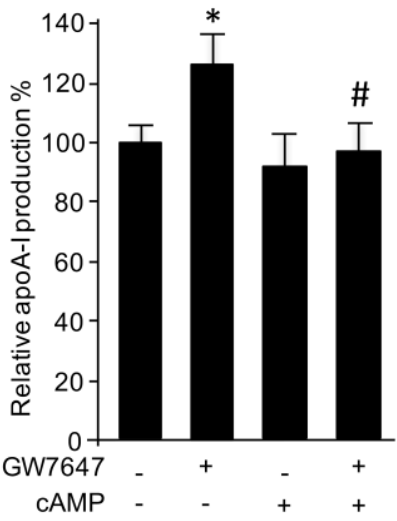

B

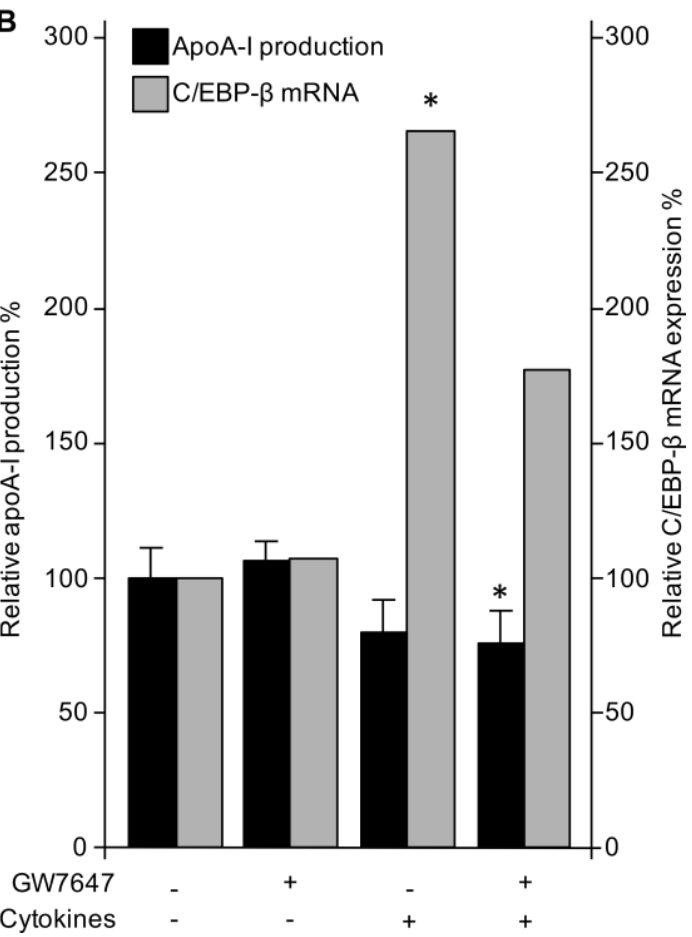

Figure 4. Relative apoA-I protein or C/EBP- $\beta$ mRNA production after GW7647 addition and stress induction using cytokines or thapsigargin in HepG2 cells; (a) The effect of a cytokine cocktail composed of TNF- $\alpha$, IL- 6 and IL-1 $\beta$, and/or GW7647 addition on apoA-I protein and C/EBP- $\beta$ mRNA in HepG2 cells, after 48 hours of incubation; (b) The effect of several doses of thapsigargin $(0 ; 1 ; 10 ; 100$ and $500 \mathrm{nM}$ ) on apoA-I production in HepG2 cells, after 48 hours of incubation; (c) The effect of C/EBP- $\beta$ activator cAMP on apoA-I production in HepG2 cells, after 48 hours of incubation. Changes are indicated with a * when significantly different $(p \leq 0.05)$ compared to the control condition or with a \# when the CAMP condition is significantly different $(p \leq 0.05)$ from the cAMP plus GW7647 treated condition. 


\section{CHAPTER 3}

Effect of biochemical C/EBP- $\beta$ activation, $C / E B P-\beta$ overexpression or $C / E B P-\beta$ inhibition on apoA-I production

The addition of C/EBP- $\beta$ activator cAMP clearly prevented the increase in apoA-I secretion by GW7647 in HepG2 cells (figure 4C). To evaluate the role of C/EBP- $\beta$ on the decreased apoA-I production in the experiments described above, all C/EBP- $\beta$ isoforms were silenced at once at protein level for 72 hours by C/EBP- $\beta$ RNAi. Approximately $90 \%$ of C/EBP- $\beta$ was silenced (figure $5 \mathrm{~A}$ ) in our silencing experiments. Furthermore, transfections clearly resulted in succesfull overexpression of the three individual C/EBP- $\beta$ isoforms (figure 5B). Interestingly, silencing of all C/EBP- $\beta$ isoforms during ER-stress, inflammation or in nonstressed conditions or overexpression of the three individual C/EBP- $\beta$ isoforms, did not alter apoA-I production in HepG2 cells (figure 5C and 5D), also not during ERstress (figure 6A), inflammation (figure 6B) or in non-stressed conditions (figure $\mathbf{5}$ and 6).

A

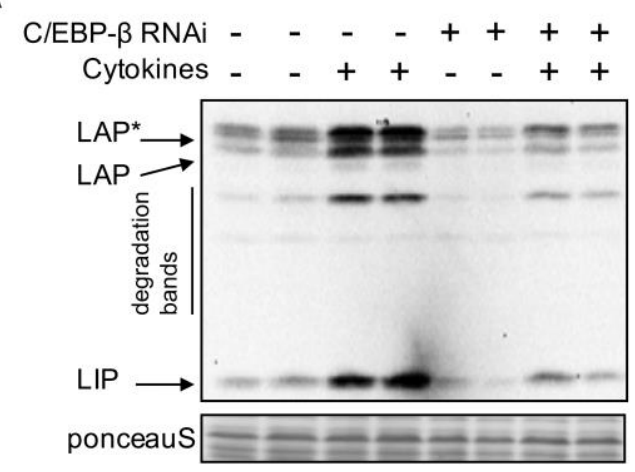

C

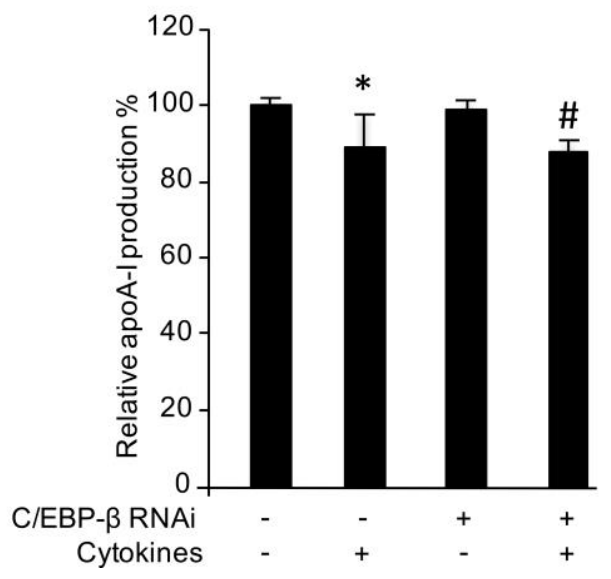

B

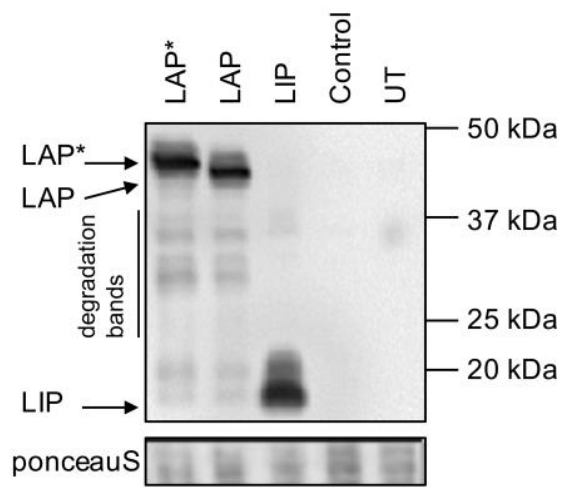

D

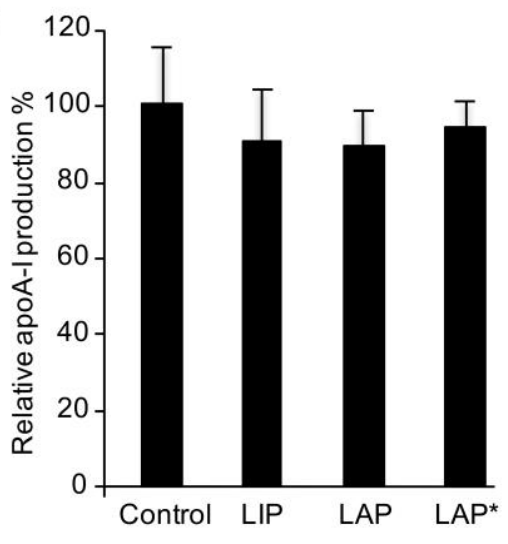

Figure 5. Effect of C/EBP- $\beta$ silencing and overexpression on apoA-I production in HepG2 cells; (a) Western blot results of C/EBP- $\beta$ silencing using RNAi, with or without the addition of a cytokine cocktail, after 48 hours of incubation; (b) Protein expression of specific C/EBP- $\beta$ isoforms determined after 48 hours of C/EBP- $\beta$ isoform overexpression. UT= untreated HepG2 cells; (c) The effects of C/EBP- $\beta$ 


\section{NATURAL PPARa TRANSACTIVATING COMPOUNDS}

silencing on apoA-I production, with or without addition of a cytokine cocktail, after 48 hours of incubation; (d) The effect of C/EBP- $\beta$ isoform specific overexpression on apoA-I production in HepG2 cells, after 48 hours of incubation. Protein degradation bands are indicated accordingly. Changes are indicated with a * when significantly different $(p \leq 0.05)$ compared to the control condition or with a \# when the RNAi treated condition is significantly different $(p \leq 0.05)$ from the RNAi plus cytokine condition.

A

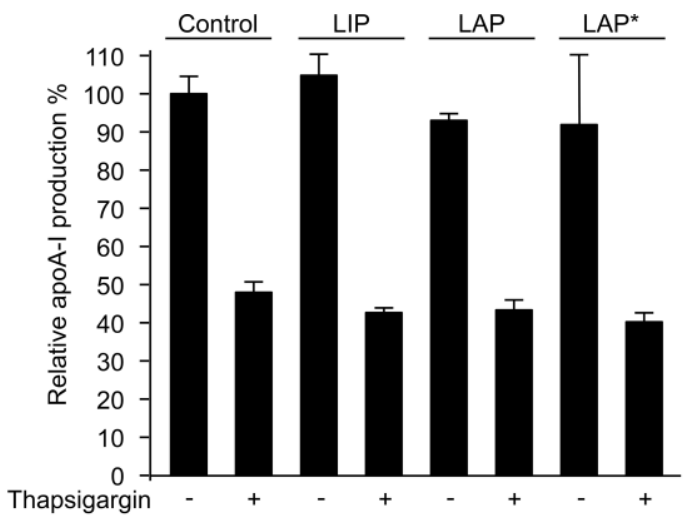

B

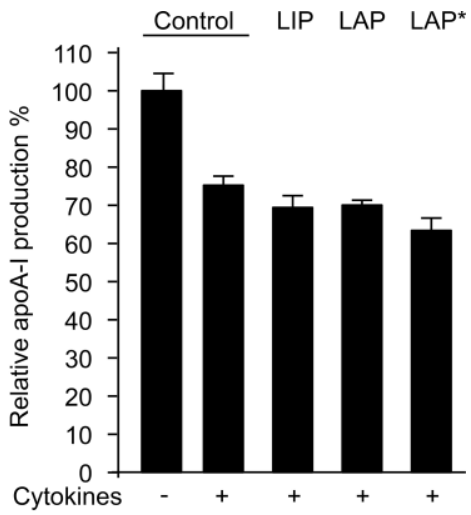

C

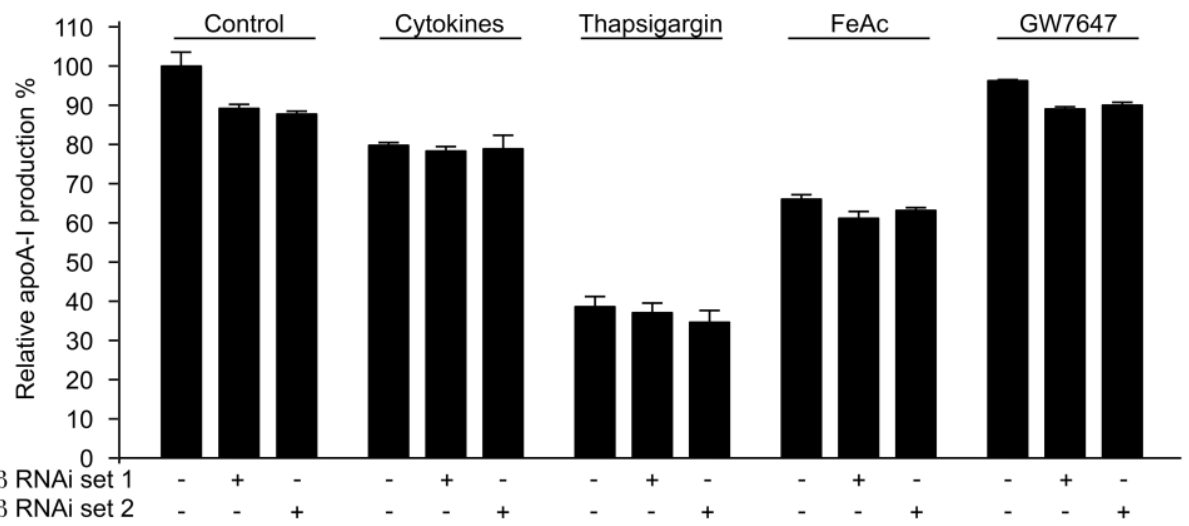

Figure 6. The effect of C/EBP- $\beta$ silencing or overexpression on apoA-I production during ER-stress, inflammatory conditions or after FeAc or GW7647 addition; (a) Relative apoA-I production in HepG2 cells that are transfected with C/EBP- $\beta$ isoforms with or without the addition of Thapsigargin, after 48 hours of incubation; (b) Relative apoA-I production in HepG2 cells that are transfected with C/EBP- $\beta$ isoforms with or without the addition of a cytokine cocktail, after 48 hours of incubation; (c) Relative apoA-I production in HepG2 cells treated with siRNA against $\mathrm{C} / \mathrm{EBP}-\beta$, with or without the addition of either a cytokine cocktail, thapsigargin, FeAc or GW7647, for 48 hours. 


\section{CHAPTER 3}

\section{Discussion}

Obesity and type II diabetes, both part of the metabolic syndrome, are associated with low-grade systemic inflammation, resulting in lower serum HDL-C and apoA-I concentrations [23-25]. Besides obesity, type II diabetes and inflammation, hyperglycemia is associated with the metabolic syndrome and is known to induce endoplasmatic reticulum (ER) stress [16]. ER-stress is described to decrease apoA-I concentrations [16]. In this study we searched for targets that play a role in the regulatory network of apoA-I transcription. In the regulation of apoA-I protein synthesis it is generally accepted that PPARa is involved [11]. Although fibrates are known to increase apoA-I concentrations mediated through PPARa activation, individual fibrates may exert different effects on apoA-I production [11]. Indeed, our results showed that in HepG2 cells, exposure to the PPARa activator FeAc resulted in a $21.5 \%$ lower apoA-I production compared with the PPARa activator GW7647. PPARa expression was equal in the HepG2 and CaCo-2 cells treated with both agonists. Also confirmative qPCRs showed in both conditions an increased expression of the specific PPAR $\alpha$ target CPT1 $\alpha$ [26]. In agreement with earlier observations [15], these results suggest that PPARa activation alone is not sufficient to increase apoA-I production which implies that additional (co)factors, and/or transcription factors, all part of the yet not fully identified transcription factor network, also participate in this complex mechanism leading to increased apoA-I production.

We showed that in both HepG2s and CaCo-2 cells the genes ATF3, C/EBP- $\beta$, GDF15 and NF-IL3 were consistently increased after treatment with FeAc compared to GW7647. Our micro-array analysis also showed that a reduced apoAI production as seen in the FeAc condition was associated with increased expression of a panel of genes that are typically upregulated during cellular stress or ER-stress. This indicates that there is a remarkable similarity between our results and biochemically-induced ER-stress signatures [27-29].

Furthermore, exposure of HepG2 cells to FeAc not only decreased apoA-I production, but simultaneously increased intracellular production of several ERstress markers such as CHOP and XBP1s. Therefore it is tempting to suggest that the FeAc-induced decrease in apoA-I secretion could be the result of increased activation of the ER-stress pathway. Further experiments, in which HepG2 cells were exposed to thapsigargin-induced ER-stress, showed that intracellular C/EBP$\beta$ protein expression was increased, which supported earlier findings that $C / E B P-\beta$ is part of the ER-stress signature $[27,28,30]$. As C/EBP- $\beta$ was also one of the candidate genes on the list of the micro-array experiment, we next explored the role of C/EBP- $\beta$ on apoA-I production. Another rationale for focusing on C/EBP- $\beta$ is the presence of a C/EBP binding site in the promoter region of apoA-I [31] and the known association of C/EBP- $\beta$ with inflammation [32-35].

Indeed, we showed that ER-stress and inflammatory conditions clearly decreased apoA-I production and simultaneously increased C/EBP- $\beta$ production. However, $\mathrm{C} / \mathrm{EBP}-\beta$ silencing in inflammatory-, non-inflammatory and ER-stress conditions did not influence hepatic apoA-I production. As the various C/EBP- $\beta$ isoforms have different transcriptional activation potentials [36-38], we next evaluated their individual effects on apoA-I production. LAP is known as a transcriptional activator, 


\section{NATURAL PPARa TRANSACTIVATING COMPOUNDS}

while isoform LIP is known as a transcriptional inhibitor $[36,39]$. Until now, the role of these two different C/EBP- $\beta$ isoforms, or the role of full length C/EBP- $\beta$ isoform $\mathrm{LAP}^{*}$ on apoA-I production during non-inflammatory-, inflammatory and ER-stress conditions has never been explored. Remarkably, isoform specific C/EBP- $\beta$ overexpression did not change apoA-I production and secretion in HepG2 cells during ER-stress, and the inflammatory- and non- inflammatory condition. Our data therefore extend the findings of Kan et al. [40], who found that in unstressed conditions C/EBP was not involved in apoA-I production. Unfortunately, isoform specific knockdown experiments to further examine the role of the various C/EBP- $\beta$ isoforms on apoA-I production is impossible due to the structural overlap of the three different isoforms.

As was previously reviewed by our group [41], C/EBP- $\beta$ is able to bind to the promoter of IL-6 [42] and IL1 $\beta$ [43]. Although the addition of the cytokine cocktail clearly induced C/EBP- $\beta$ mRNA expression, we should keep in mind that C/EBP- $\beta$ is involved in inflammation onset. However, here we aimed to show that a (cytokine-induced) decrease in apoA-I production, leads to an increased production of $C / E B P-\beta$. A binding place in the promoter region of apoA-I and the increase in C/EBP- $\beta$ mRNA after cytokine addition made C/EBP- $\beta$ a likely candidate for our study. Nowadays, identification of components to increase apoA-I production receives more and more attention. One of these components is RVX-208, which has been shown to increase production of apoA-I and HDL-C concentrations in in vitro and in vivo studies [14]. RVX-208 is an inhibitor of the bromo- and extra terminal (BET) family of transcription factors, which mediates apoA-I production [44-46]. Whether RVX-208 also acts via inhibition of ER-stress and thereby influences apoA-I production has not been investigated. In this respect, however, Hart et al. [47] have found that specifically the expression of genes from the UPR response were downregulated upon treatment with the bromodomain inhibitor JQ1. Possibly, BET inhibitors are potentially interesting compounds for down regulation of the ER-stress pathway. In differentiated CaCo-2 cells, oxidized fatty acids (OxFA) increased apoA-I production [48], possibly because oxFA are ligands for PPAR $\gamma$. There may be a link between ER-stress and PPARy, as PPARy is able to restore the function of the islets of diabetic mice by reducing ER-stress [49]. Interestingly, literature suggests that FeAc addition could also induce PPARY, however, we did not find a significant difference in PPARy between our FeAc and GW7647 treated HepG2 or Caco2 cells. This is also in line with the expected expression profile of PPARy which is the predominant PPAR in fat tissue instead of liver of colon [50]. Therefore, we did not consider PPARY a candidate responsible for this difference in apoA-I production. Thus, mechanisms underlying the effects of compounds that enhance apoA-I production such as RVX208 and oxidized fatty acids may involve ER-stress, which suggests that ER-stress inhibition might indeed be an important target in conditions of low endogenous apoA-I production.

In a study of Arakawa et al. [51], ABCA1 mRNA expression increased after treatment of immune cells with FeAc. Indeed, an increased ABCA1 production might be beneficial regarding CVD risk reduction, as it could lead to increased cholesterol efflux to apoA-I. On the other hand, in the DAIS study [52] no effect of FeAc on apoA-I production was found. The combination of our data, data of Arakawa and the DAIS study, show that FeAc may exert beneficial effects on CVD development in vivo, probably independent of a change in apoA-I production. 


\section{CHAPTER 3}

In conclusion, ER-stress and inflammatory conditions lower apoA-I production and increase the expression of the ER-stress parameter C/EBP- $\beta$. Despite the fact that there is a C/EBP binding place in the apoA-I promoter, neither overexpression nor silencing of $\mathrm{C} / \mathrm{EBP}-\beta$ in inflammatory, non-inflammatory or ER-stress conditions, influenced hepatic apoA-I production. Therefore, C/EBP- $\beta$ is not a target to rescue the attenuated apoA-I production during ER-stress and inflammation. Additional research is needed to elucidate factors that link ER-stress and inflammation to reduced apoA-I production, which is often seen in the metabolic syndrome.

\section{Acknowledgments}

We would like to thank K. Serbonij for his contribution to cell culture experiments.

This research was supported by the Dutch Technology Foundation STW, which is part of the Netherlands Organization for Scientific Research (NWO), and which is partly funded by the Ministry of Economic Affairs. 


\section{NATURAL PPAR $\alpha$ TRANSACTIVATING COMPOUNDS}

\section{References}

1. Duffy D, Rader DJ (2009) Update on strategies to increase HDL quantity and function. Nat Rev Cardiol 6: 455-463.

2. Kingwell BA, Chapman MJ, Kontush A, Miller NE (2014) HDL-targeted therapies: progress, failures and future. Nat Rev Drug Discov 13: 445-464.

3. Boekholdt SM, Arsenault BJ, Hovingh GK, Mora S, Pedersen TR, et al. (2013) Levels and changes of $\mathrm{HDL}$ cholesterol and apolipoprotein A-I in relation to risk of cardiovascular events among statin-treated patients: a meta-analysis. Circulation 128: 1504-1512.

4. Smits LP, Kootte RS, Stroes ES (2014) Reversal of atherosclerosis with apolipoprotein A1: back to basics. Atherosclerosis 232: 217-219.

5. Rubin EM, Krauss RM, Spangler EA, Verstuyft JG, Clift SM (1991) Inhibition of early atherogenesis in transgenic mice by human apolipoprotein AI. Nature 353: 265-267.

6. Leman LJ, Maryanoff BE, Ghadiri MR (2014) Molecules that mimic apolipoprotein A-I: potential agents for treating atherosclerosis. J Med Chem 57: 2169-2196.

7. Nissen SE, Tsunoda T, Tuzcu EM, Schoenhagen P, Cooper CJ, et al. (2003) Effect of recombinant ApoA-I Milano on coronary atherosclerosis in patients with acute coronary syndromes: a randomized controlled trial. JAMA 290: 2292-2300.

8. Brooks-Wilson A, Marcil M, Clee SM, Zhang LH, Roomp K, et al. (1999) Mutations in ABC1 in Tangier disease and familial high-density lipoprotein deficiency. Nat Genet 22: 336-345.

9. Moriyama K, Sasaki J, Takada Y, Matsunaga A, Fukui J, et al. (1996) A cysteine-containing truncated apo A-I variant associated with HDL deficiency. Arterioscler Thromb Vasc Biol 16: 1416-1423.

10. Hovingh GK, Brownlie A, Bisoendial RJ, Dube MP, Levels JH, et al. (2004) A novel apoA-I mutation (L178P) leads to endothelial dysfunction, increased arterial wall thickness, and premature coronary artery disease. J Am Coll Cardiol 44: 1429-1435.

11. Duez H, Lefebvre B, Poulain P, Torra IP, Percevault F, et al. (2005) Regulation of human apoA-I by gemfibrozil and fenofibrate through selective peroxisome proliferator-activated receptor alpha modulation. Arterioscler Thromb Vasc Biol 25: 585-591.

12. Tzameli I, Zannis VI (1996) Binding specificity and modulation of the ApoA-I promoter activity by homo- and heterodimers of nuclear receptors. J Biol Chem 271: 8402-8415.

13. Harnish DC, Malik S, Karathanasis SK (1994) Activation of apolipoprotein Al gene transcription by the liver-enriched factor HNF-3. J Biol Chem 269: 28220-28226.

14. Bailey D, Jahagirdar R, Gordon A, Hafiane A, Campbell S, et al. (2010) RVX-208: a small molecule that increases apolipoprotein A-I and high-density lipoprotein cholesterol in vitro and in vivo. J Am Coll Cardiol 55: 2580-2589.

15. Dullens SP, Mensink RP, Mariman EC, Plat J (2009) Differentiated CaCo-2 cells as an in-vitro model to evaluate de-novo apolipoprotein A-I production in the small intestine. Eur $\mathrm{J}$ Gastroenterol Hepatol 21: 642-649.

16. Naem E, Haas MJ, Wong NC, Mooradian AD (2013) Endoplasmic reticulum stress in HepG2 cells inhibits apolipoprotein A-I secretion. Life Sci 92: 72-80.

17. Ferruzza S, Rossi C, Scarino ML, Sambuy Y (2012) A protocol for differentiation of human intestinal Caco-2 cells in asymmetric serum-containing medium. Toxicol In Vitro 26: 1252-1255.

18. Iyer VR, Eisen MB, Ross DT, Schuler G, Moore T, et al. (1999) The transcriptional program in the response of human fibroblasts to serum. Science 283: 83-87.

19. Gentleman RC, Carey VJ, Bates DM, Bolstad B, Dettling M, et al. (2004) Bioconductor: open software development for computational biology and bioinformatics. Genome Biol 5: R80. 


\section{CHAPTER 3}

20. Bolstad BM, Irizarry RA, Astrand M, Speed TP (2003) A comparison of normalization methods for high density oligonucleotide array data based on variance and bias. Bioinformatics 19: 185193.

21. Livak KJ, Schmittgen TD (2001) Analysis of relative gene expression data using real-time quantitative PCR and the 2(-Delta Delta C(T)) Method. Methods 25: 402-408.

22. Metz R, Ziff E (1991) CAMP stimulates the C/EBP-related transcription factor rNFIL-6 to trans-locate to the nucleus and induce c-fos transcription. Genes Dev 5: 1754-1766.

23. Orlov SV, Mogilenko DA, Shavva VS, Dizhe EB, Ignatovich IA, et al. (2010) Effect of TNFalpha on activities of different promoters of human apolipoprotein A-I gene. Biochem Biophys Res Commun 398: 224-230.

24. Bausserman LL, Bernier DN, McAdam KP, Herbert PN (1988) Serum amyloid A and high density lipoproteins during the acute phase response. Eur J Clin Invest 18: 619-626.

25. Tietge UJ, Maugeais C, Lund-Katz S, Grass D, deBeer FC, et al. (2002) Human secretory phospholipase A2 mediates decreased plasma levels of HDL cholesterol and apoA-I in response to inflammation in human apoA-I transgenic mice. Arterioscler Thromb Vasc Biol 22: 1213-1218.

26. Mandard S, Muller M, Kersten S (2004) Peroxisome proliferator-activated receptor alpha target genes. Cell Mol Life Sci 61: 393-416.

27. Meir O, Dvash E, Werman A, Rubinstein M (2010) C/EBP-beta regulates endoplasmic reticulum stress-triggered cell death in mouse and human models. PLoS One 5: e9516.

28. Sok J, Wang XZ, Batchvarova N, Kuroda M, Harding H, et al. (1999) CHOP-Dependent stressinducible expression of a novel form of carbonic anhydrase VI. Mol Cell Biol 19: 495-504.

29. Dombroski BA, Nayak RR, Ewens KG, Ankener W, Cheung VG, et al. (2010) Gene expression and genetic variation in response to endoplasmic reticulum stress in human cells. Am $\mathrm{J}$ Hum Genet 86: 719-729.

30. Li Y, Bevilacqua E, Chiribau CB, Majumder M, Wang C, et al. (2008) Differential control of the CCAAT/enhancer-binding protein beta (C/EBPbeta) products liver-enriched transcriptional activating protein (LAP) and liver-enriched transcriptional inhibitory protein (LIP) and the regulation of gene expression during the response to endoplasmic reticulum stress. J Biol Chem 283: 22443-22456.

31. Dullens SP, Plat J, Mensink RP (2007) Increasing apoA-I production as a target for CHD risk reduction. Nutr Metab Cardiovasc Dis 17: 616-628.

32. Cloutier A, Guindi C, Larivee P, Dubois CM, Amrani A, et al. (2009) Inflammatory cytokine production by human neutrophils involves C/EBP transcription factors. J Immunol 182: 563571.

33. Trautwein C, Caelles C, van der Geer P, Hunter T, Karin M, et al. (1993) Transactivation by NFIL6/LAP is enhanced by phosphorylation of its activation domain. Nature 364: 544-547.

34. Nakajima K, Kusafuka T, Takeda T, Fujitani Y, Nakae K, et al. (1993) Identification of a novel interleukin-6 response element containing an Ets-binding site and a CRE-like site in the junB promoter. Mol Cell Biol 13: 3027-3041.

35. Screpanti I, Romani L, Musiani P, Modesti A, Fattori E, et al. (1995) Lymphoproliferative disorder and imbalanced T-helper response in C/EBP beta-deficient mice. EMBO J 14: 1932-1941.

36. Ramji DP, Foka P (2002) CCAAT/enhancer-binding proteins: structure, function and regulation. Biochem J 365: 561-575.

37. Cao Z, Umek RM, McKnight SL (1991) Regulated expression of three C/EBP isoforms during adipose conversion of 3T3-L1 cells. Genes Dev 5: 1538-1552. 


\section{NATURAL PPAR $\alpha$ TRANSACTIVATING COMPOUNDS}

38. Ossipow V, Descombes P, Schibler U (1993) CCAAT/enhancer-binding protein mRNA is translated into multiple proteins with different transcription activation potentials. Proc Natl Acad Sci U S A 90: 8219-8223.

39. Descombes P, Chojkier M, Lichtsteiner S, Falvey E, Schibler U (1990) LAP, a novel member of the C/EBP gene family, encodes a liver-enriched transcriptional activator protein. Genes Dev 4: 1541-1551.

40. Kan HY, Georgopoulos S, Zanni M, Shkodrani A, Tzatsos A, et al. (2004) Contribution of the hormone-response elements of the proximal ApoA-I promoter, ApoCIII enhancer, and C/EBP binding site of the proximal ApoA-I promoter to the hepatic and intestinal expression of the ApoA-I and ApoCIII genes in transgenic mice. Biochemistry 43: 5084-5093.

41. van der Krieken SE, Popeijus HE, Mensink RP, Plat J (2015) CCAAT/enhancer binding protein beta in relation to ER-stress, inflammation, and metabolic disturbances. Biomed Res Int 2015: 324815.

42. Akira S, Isshiki H, Sugita T, Tanabe O, Kinoshita S, et al. (1990) A nuclear factor for IL-6 expression (NF-IL6) is a member of a C/EBP family. EMBO J 9: 1897-1906.

43. Matsumoto M, Sakao Y, Akira S (1998) Inducible expression of nuclear factor IL-6 increases endogenous gene expression of macrophage inflammatory protein-1 alpha, osteopontin and CD14 in a monocytic leukemia cell line. Int Immunol 10: 1825-1835.

44. Jahagirdar R, Zhang H, Azhar S, Tobin J, Attwell S, et al. (2014) A novel BET bromodomain inhibitor, RVX-208, shows reduction of atherosclerosis in hyperlipidemic ApoE deficient mice. Atherosclerosis 236: 91-100.

45. McLure KG, Gesner EM, Tsujikawa L, Kharenko OA, Attwell S, et al. (2013) RVX-208, an inducer of ApoA-I in humans, is a BET bromodomain antagonist. PLoS One 8: e83190.

46. Kempen HJ, Bellus D, Fedorov O, Nicklisch S, Filippakopoulos P, et al. (2013) Stimulation of Hepatic Apolipoprotein A-I Production by Novel

Thieno-Triazolodiazepines: Roles of the Classical Benzodiazepine

Receptor, PAF Receptor, and Bromodomain Binding. Lipid Insights 20136 47-54 doi:10.4137/LPI.S13258.

47. Hart LS, Cunningham JT, Datta T, Dey S, Tameire F, et al. (2012) ER stress-mediated autophagy promotes Myc-dependent transformation and tumor growth. J Clin Invest 122: 4621-4634.

48. Rong R, Ramachandran S, Penumetcha M, Khan N, Parthasarathy S (2002) Dietary oxidized fatty acids may enhance intestinal apolipoprotein A-I production. J Lipid Res 43: 557-564.

49. Evans-Molina C, Robbins RD, Kono T, Tersey SA, Vestermark GL, et al. (2009) Peroxisome proliferator-activated receptor gamma activation restores islet function in diabetic mice through reduction of endoplasmic reticulum stress and maintenance of euchromatin structure. Mol Cell Biol 29: 2053-2067.

50. Bragt MC, Popeijus HE (2008) Peroxisome proliferator-activated receptors and the metabolic syndrome. Physiol Behav 94: 187-197.

51. Arakawa R, Tamehiro N, Nishimaki-Mogami T, Ueda K, Yokoyama S (2005) Fenofibric acid, an active form of fenofibrate, increases apolipoprotein A-I-mediated high-density lipoprotein biogenesis by enhancing transcription of ATP-binding cassette transporter A1 gene in a liver $X$ receptor-dependent manner. Arterioscler Thromb Vasc Biol 25: 1193-1197.

52. Steiner G (1996) The Diabetes Atherosclerosis Intervention Study (DAIS): a study conducted in cooperation with the World Health Organization. The DAIS Project Group. Diabetologia 39: 1655-1661. 


\section{CHAPTER 3}

\section{Supplemental data}
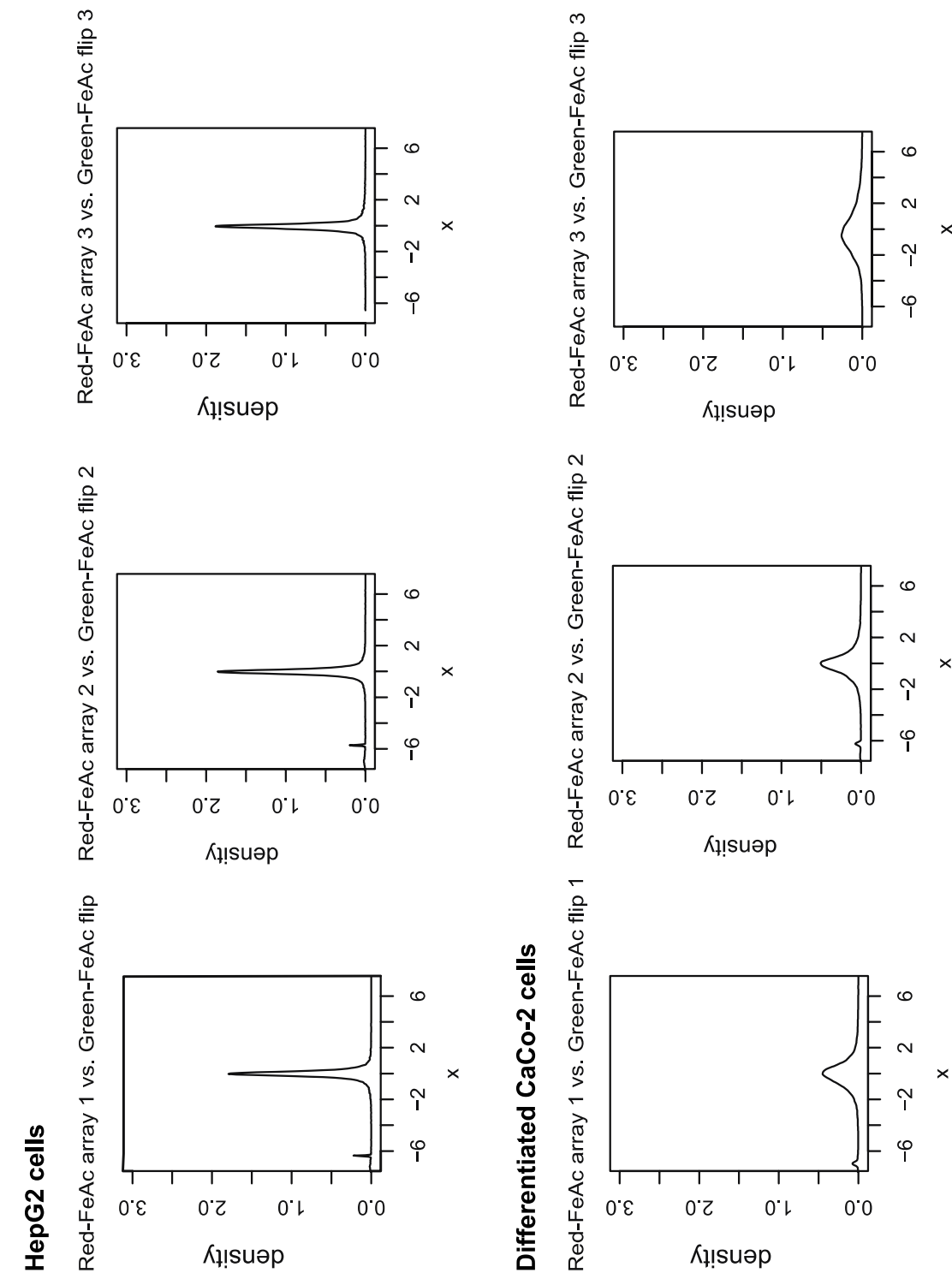

Supplemental figure S1: Micro-array quality check I

Quality check of the Agilent micro-arrays to verify the consistency of the signal intensity differences between the red and green dye of FeAc labelled samples in HepG2 and in differentiated CaCo-2 cells. 

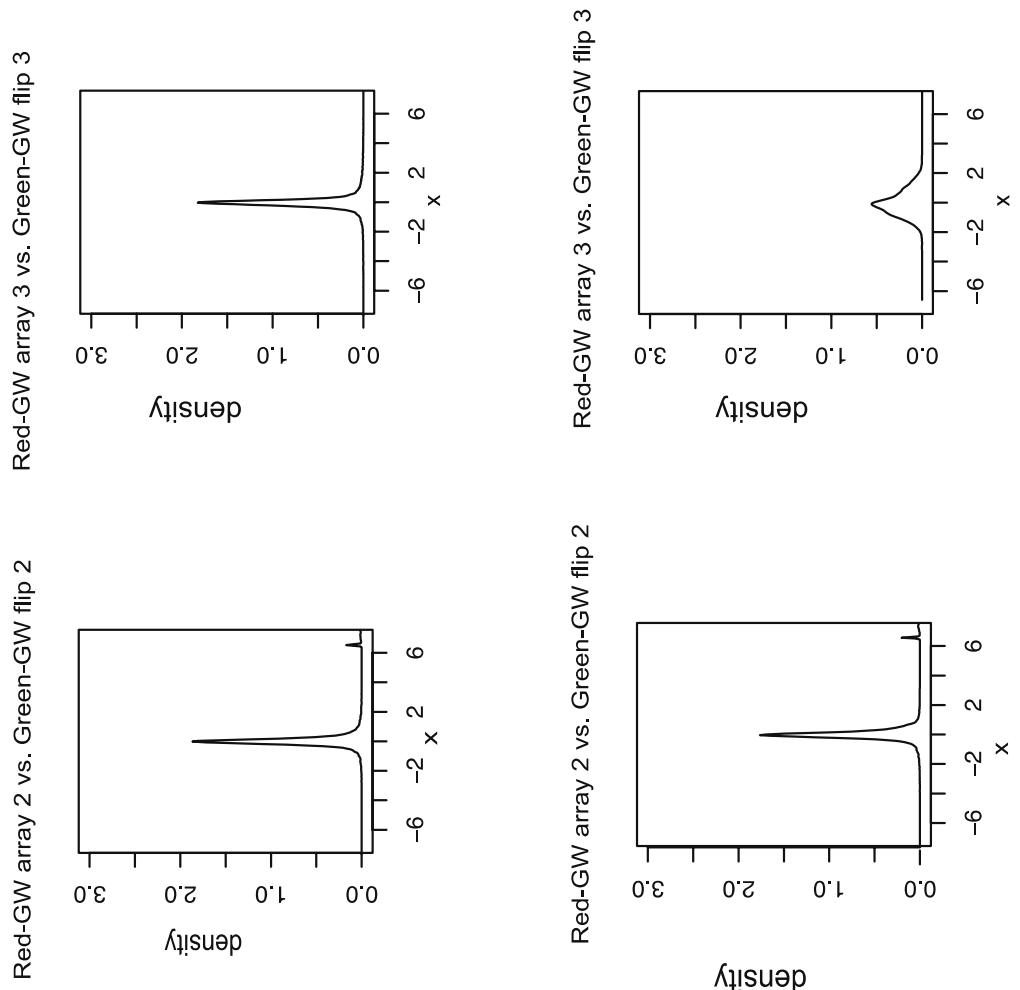

Kł!suəp
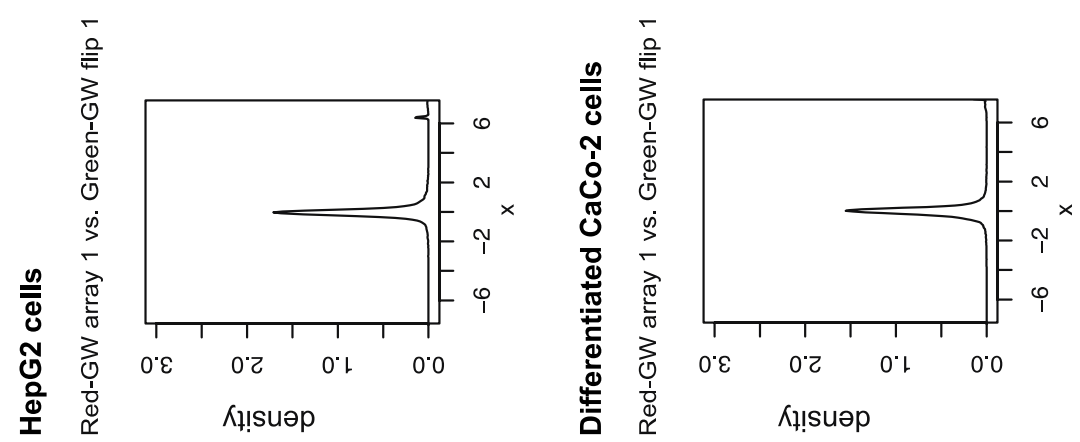

Supplemental figure S2: Micro-array quality check II

Quality check of the Agilent micro-arrays to verify the consistency of the signal intensity differences between the red and green dye of GW7647 labelled samples in HepG2 and in differentiated CaCo-2 cells. 


\section{CHAPTER 3}

A

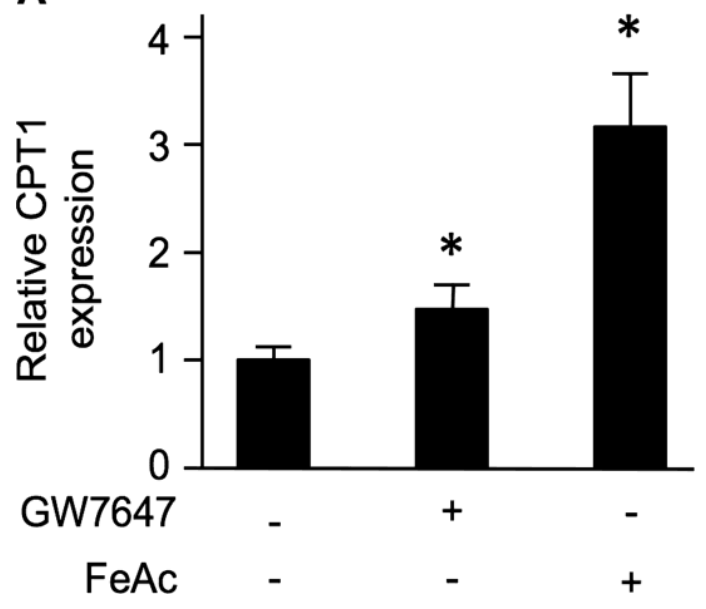

Supplemental figure S3A: CPT1 expression by GW7647 and FeAc.

Increased relative CPT1 expression in HepG2 cells following treatment with GW7647 or FeAc.

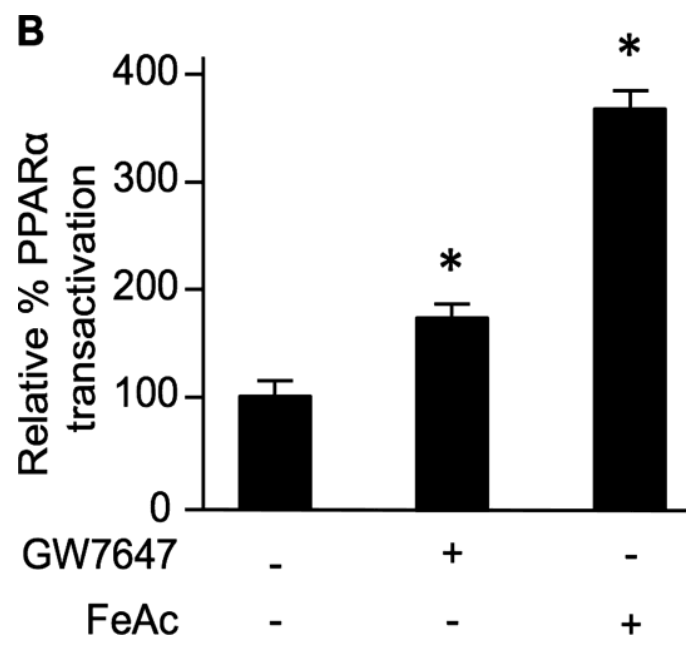

Supplemental figure S3B: PPAR $\alpha$ transactivation by GW7647 and FeAc.

Increased PPARa transactivation in HepG2 cells following treatment with 100nM GW7647 or $0.6 \mathrm{mM}$ FeAc. 


\section{NATURAL PPARa TRANSACTIVATING COMPOUNDS}

A

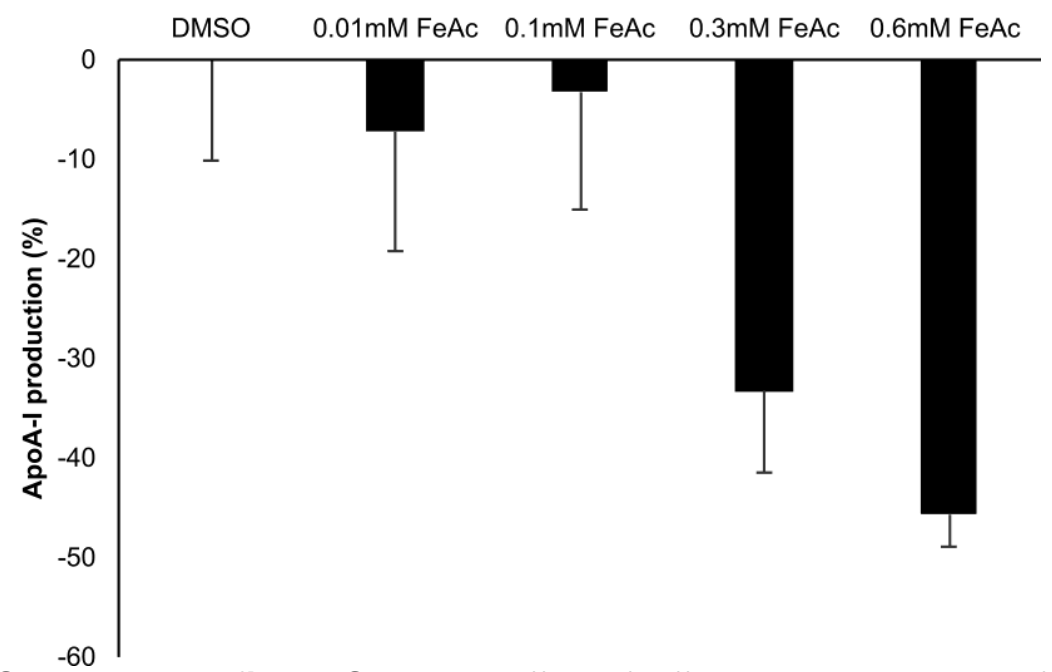

Supplemental figure S4A: The effect of different concentrations of fenofibric acid on percentual changes in apoA-I protein production in HepG2 cells after 48 hours of incubation. Values are expressed as percentual changes \pm percentual standard deviations compared to $0 \mathrm{mM}$ FeAc (DMSO only).

B

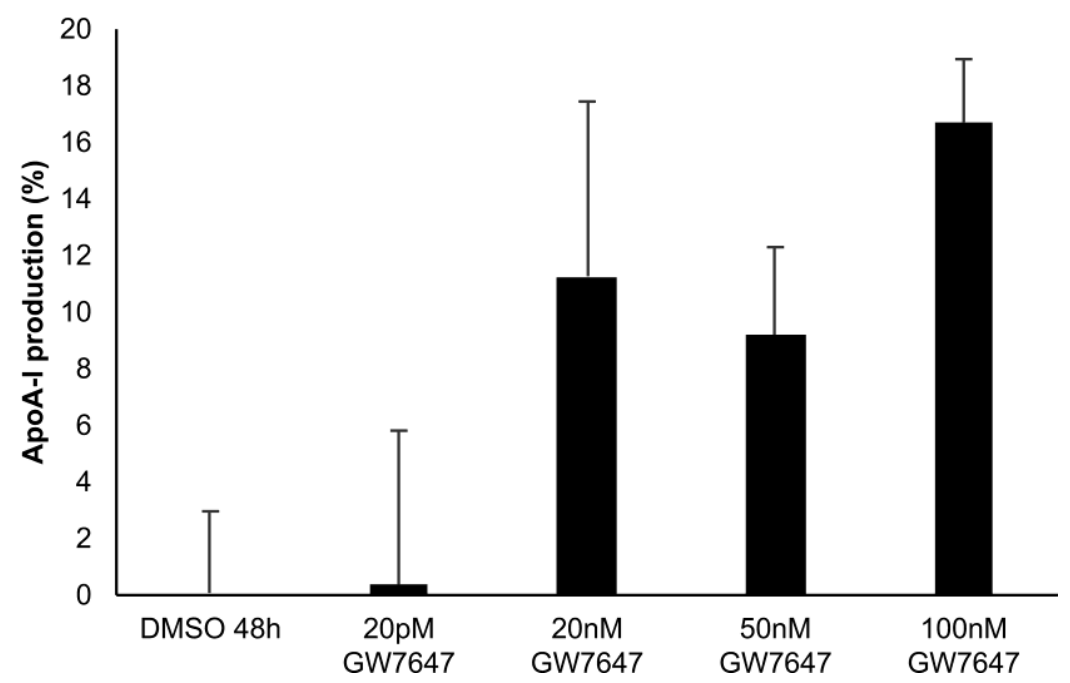

Supplemental figure S4B: The effect of different concentrations of GW7647 on percentual changes \pm standard deviation on apoA-I protein production in HepG2 cells after 48 hours of incubation. Values are expressed as percentual changes \pm percentual standard deviations compared to 0 mM GW7647 (DMSO only). 


\section{CHAPTER 3}

Supplemental table 1 (part 1). Differentially expressed genes by fenofibric acid versus GW7647 in HepG2 cells and in differentiated CaCo-2 cells.

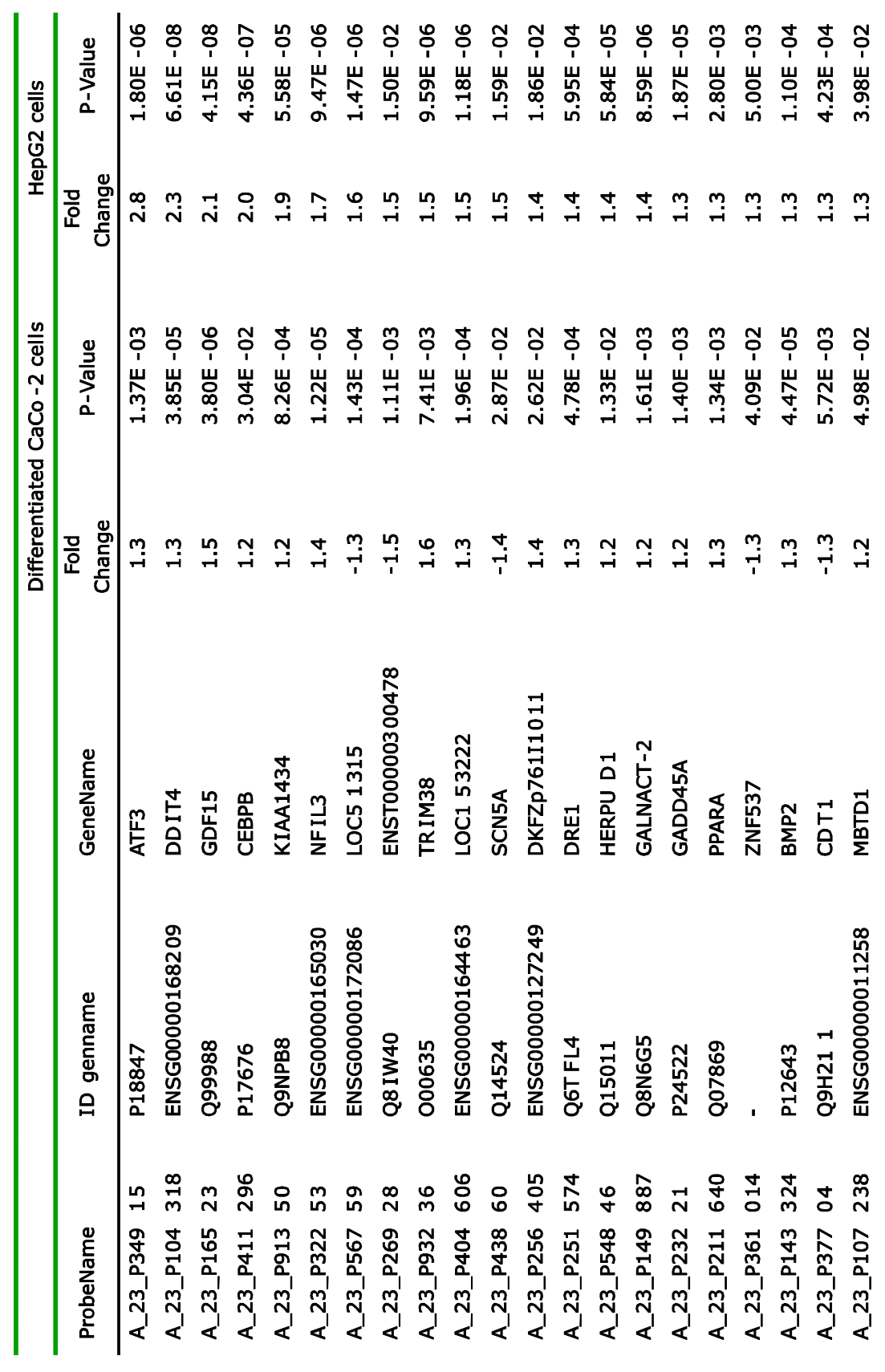




\section{NATURAL PPARa TRANSACTIVATING COMPOUNDS}

Supplemental table 1 (part 2). Differentially expressed genes by fenofibric acid versus GW7647 in HepG2 cells and in differentiated CaCo-2 cells.

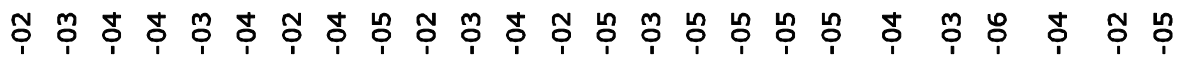

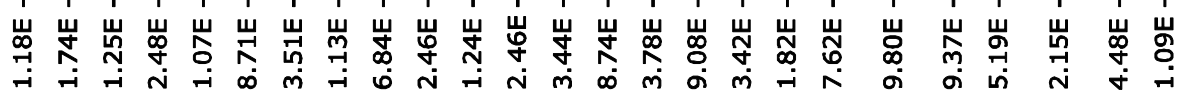

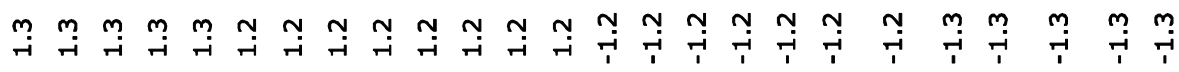

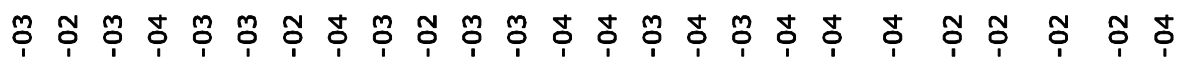

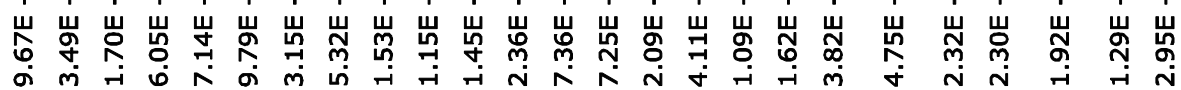

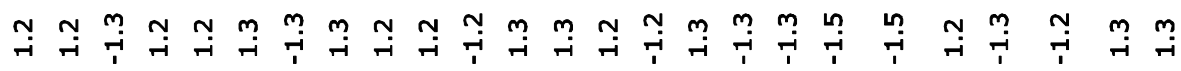

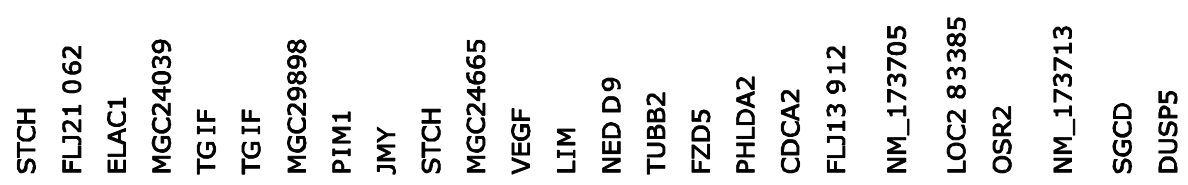

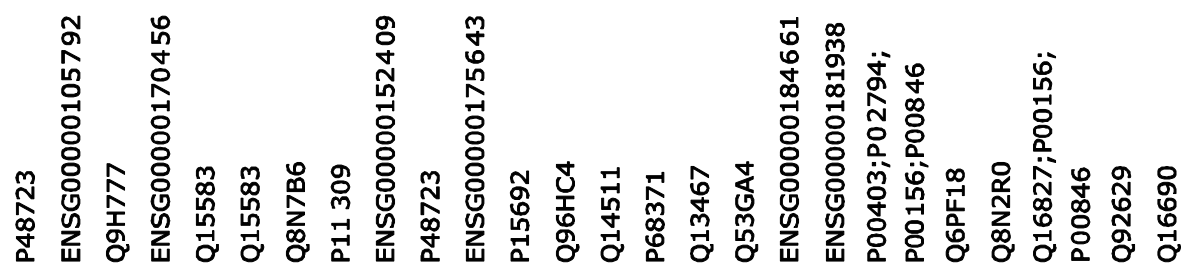

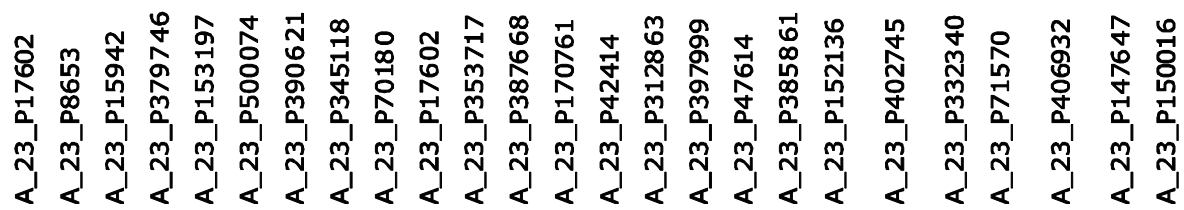




\section{CHAPTER 3}

Supplemental table 1 (part 3). Differentially expressed genes by fenofibric acid versus GW7647 in HepG2 cells and in differentiated CaCo-2 cells.

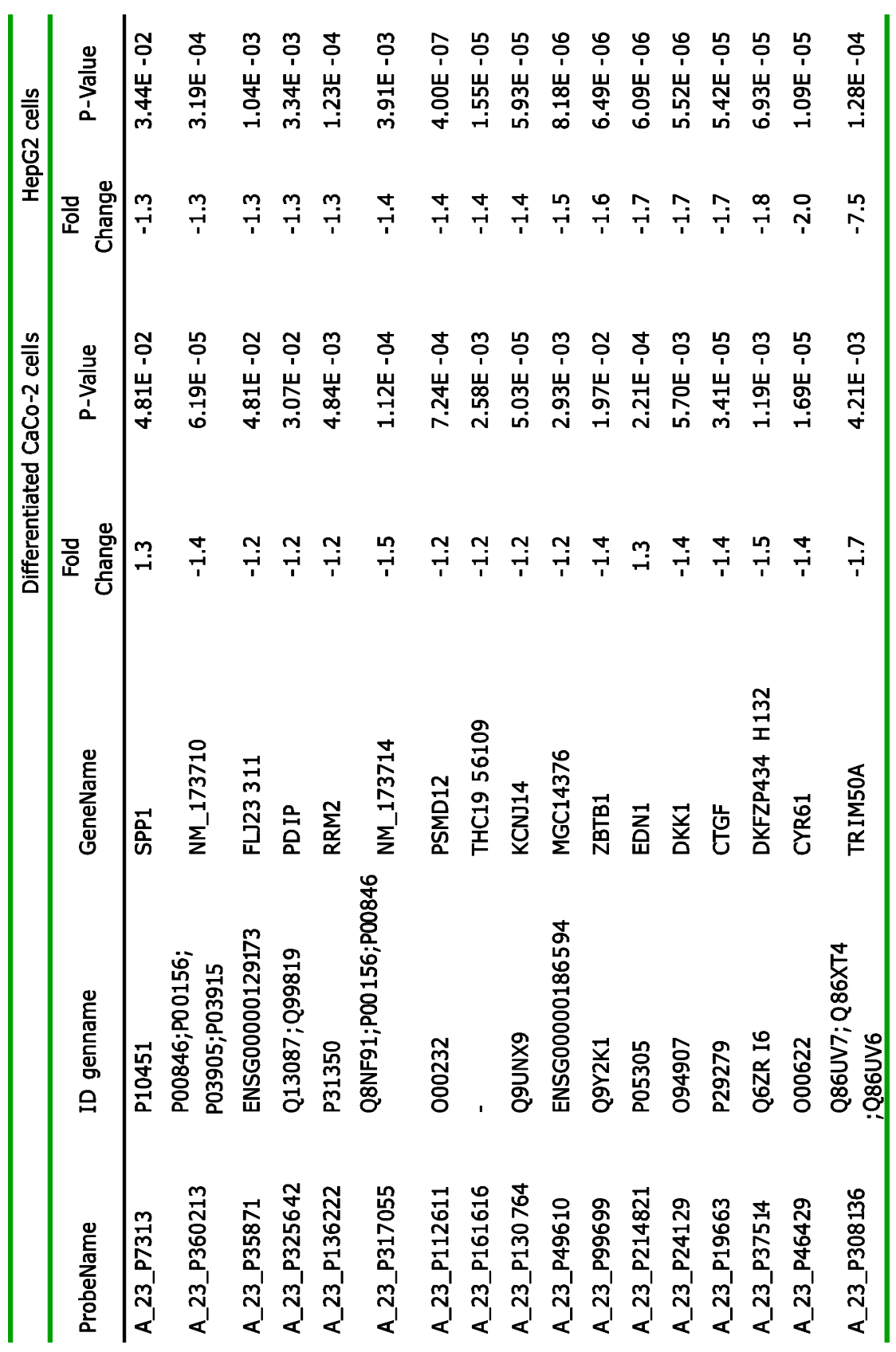


Supplemental table 2 (part 1). Differentially affected GenMAPP v2.1 pathways by fenofibric acid versus GW7647 in HepG2 cells and in differentiated CaCo-2 cells.

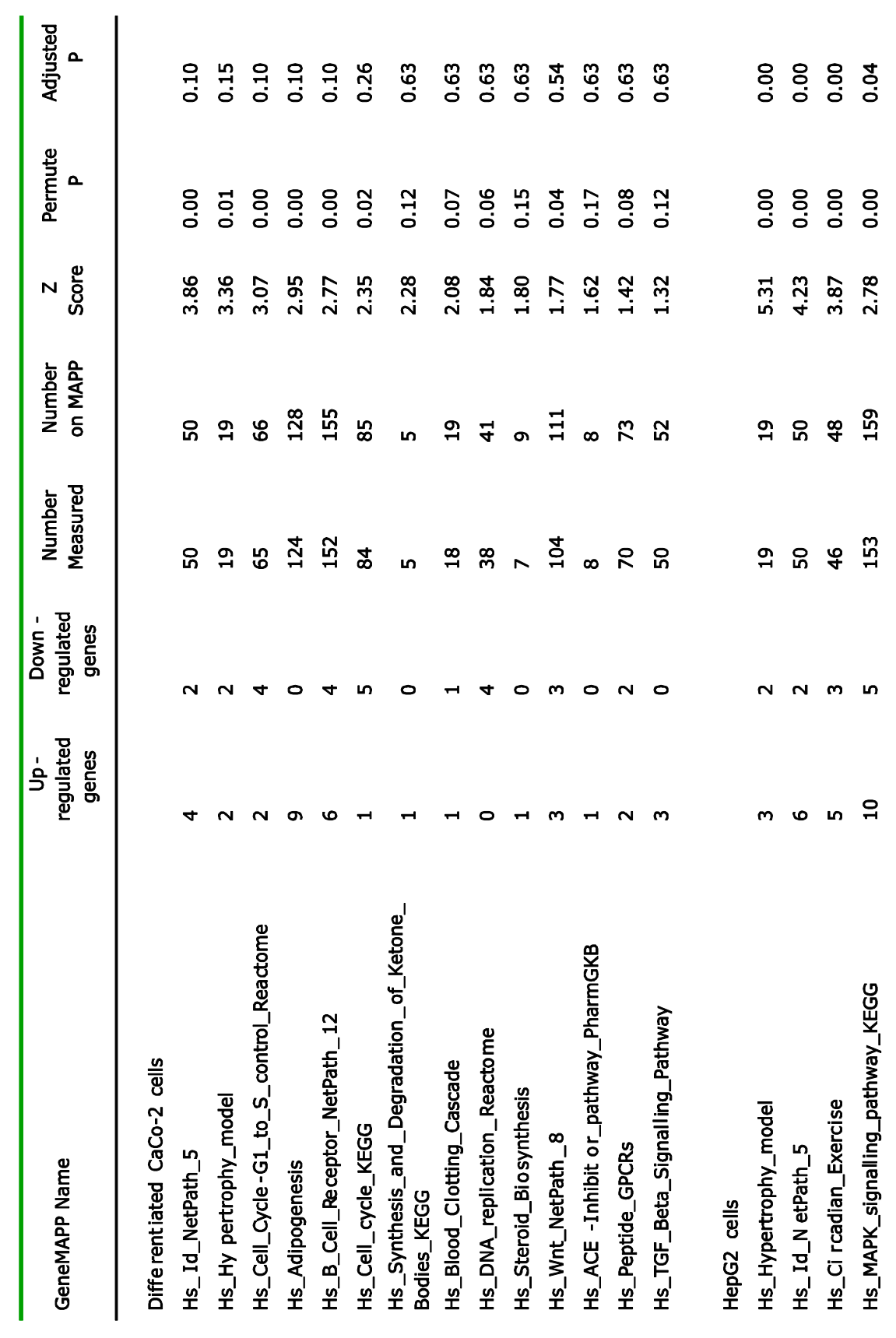




\section{CHAPTER 3}

Supplemental table 2 (part 1). Differentially affected GenMAPP v2.1 pathways by fenofibric acid versus GW7647 in HepG2 cells and in differentiated CaCo-2 cells.

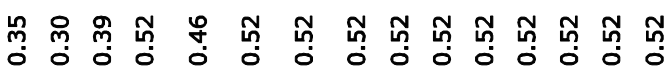

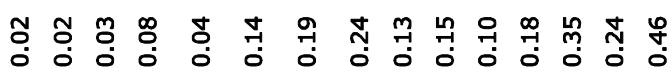

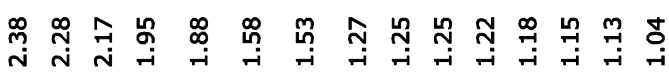

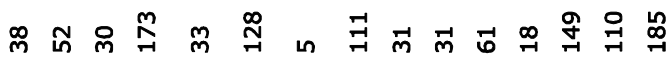

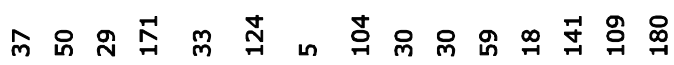

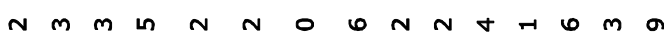

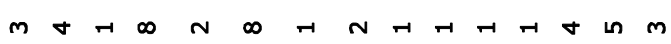

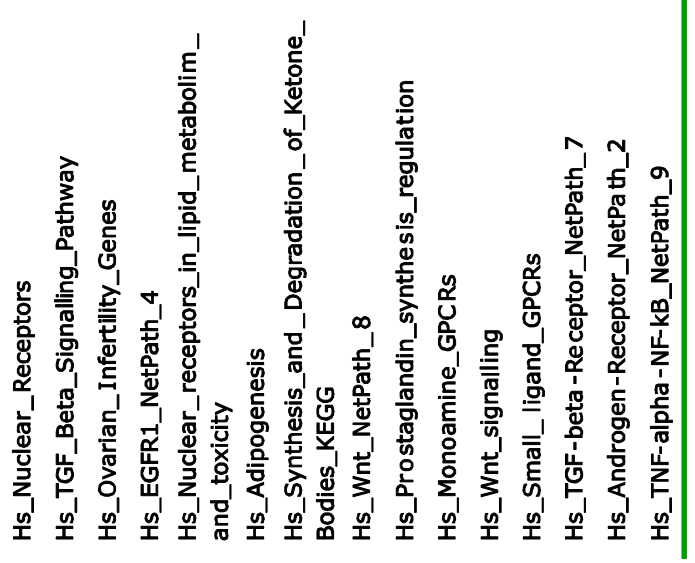




\section{NATURAL PPARa TRANSACTIVATING COMPOUNDS}

Supplemental table 3 (part 1). Differentially expressed genes by fenofibric acid versus GW7647 in HepG2 cells and/or in differentiated CaCo-2 cells present in affected human GenMAPP v2.1 pathways.

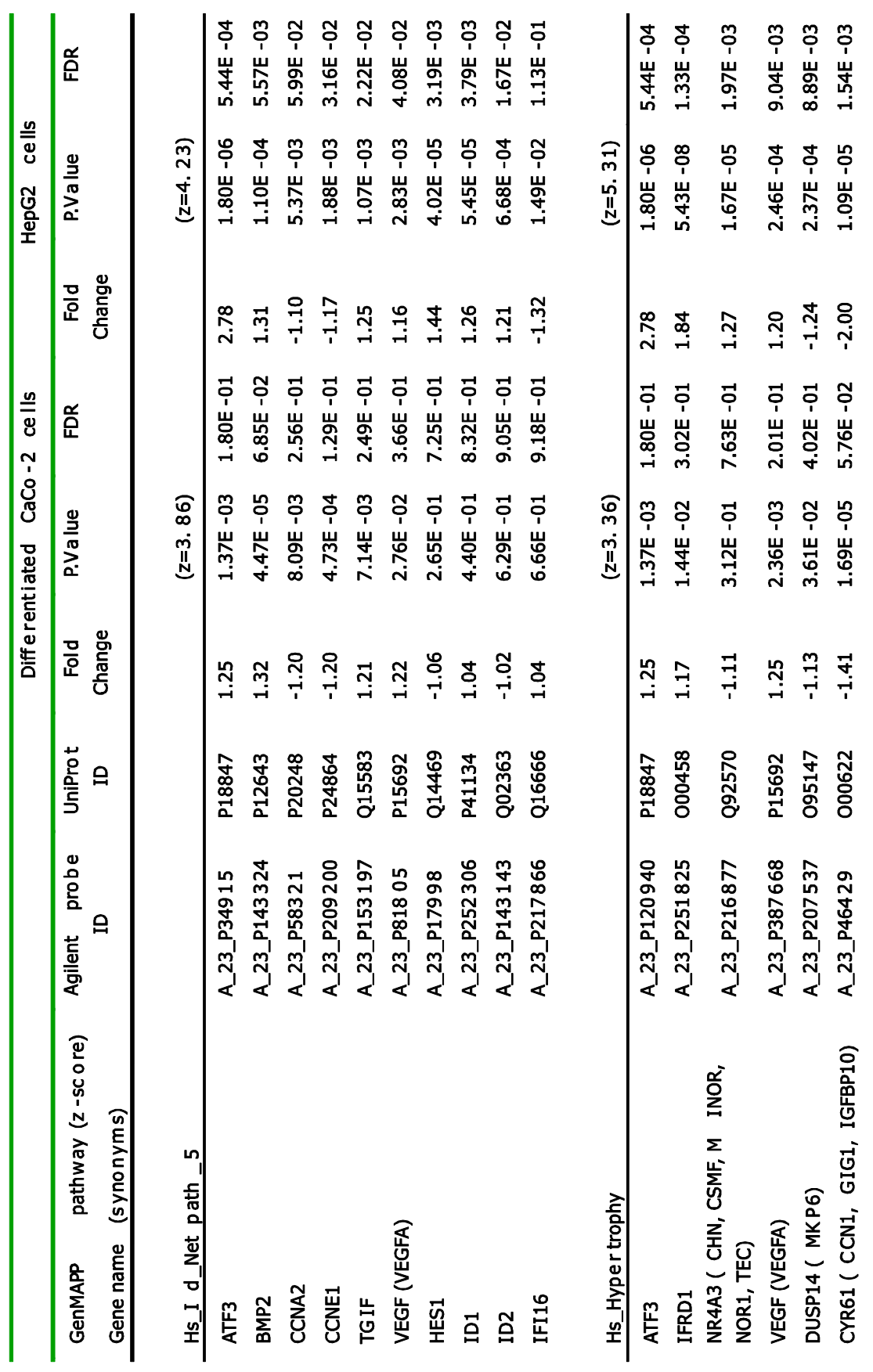




\section{CHAPTER 3}

Supplemental table 3 (part 2). Differentially expressed genes by fenofibric acid versus GW7647 in HepG2 cells and/or in differentiated CaCo-2 cells present in affected human GenMAPP v2.1 pathways.

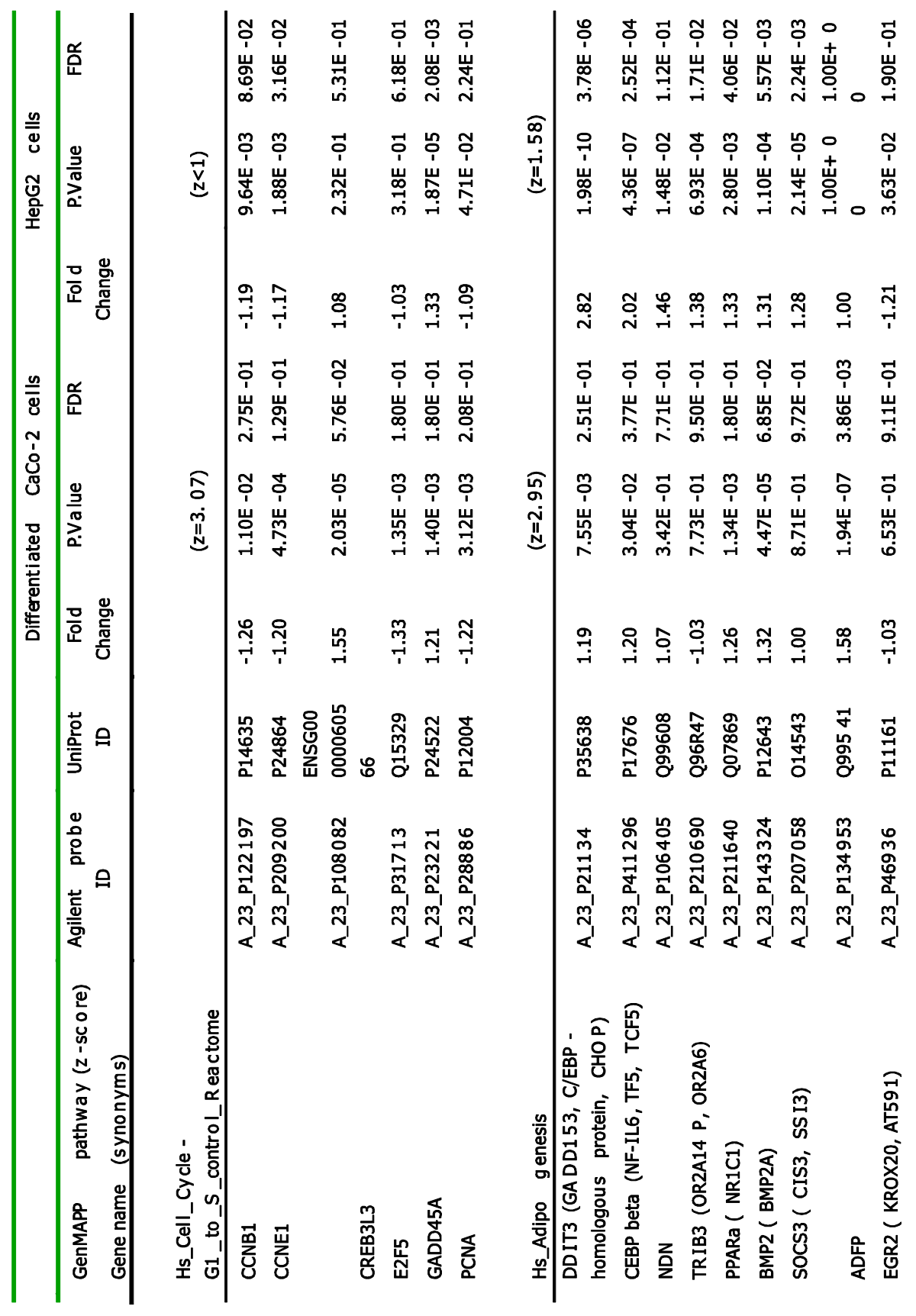




\section{NATURAL PPARa TRANSACTIVATING COMPOUNDS}

Supplemental table 3 (part 3). Differentially expressed genes by fenofibric acid versus GW7647 in HepG2 cells and/or in differentiated CaCo-2 cells present in affected human GenMAPP v2.1 pathways.

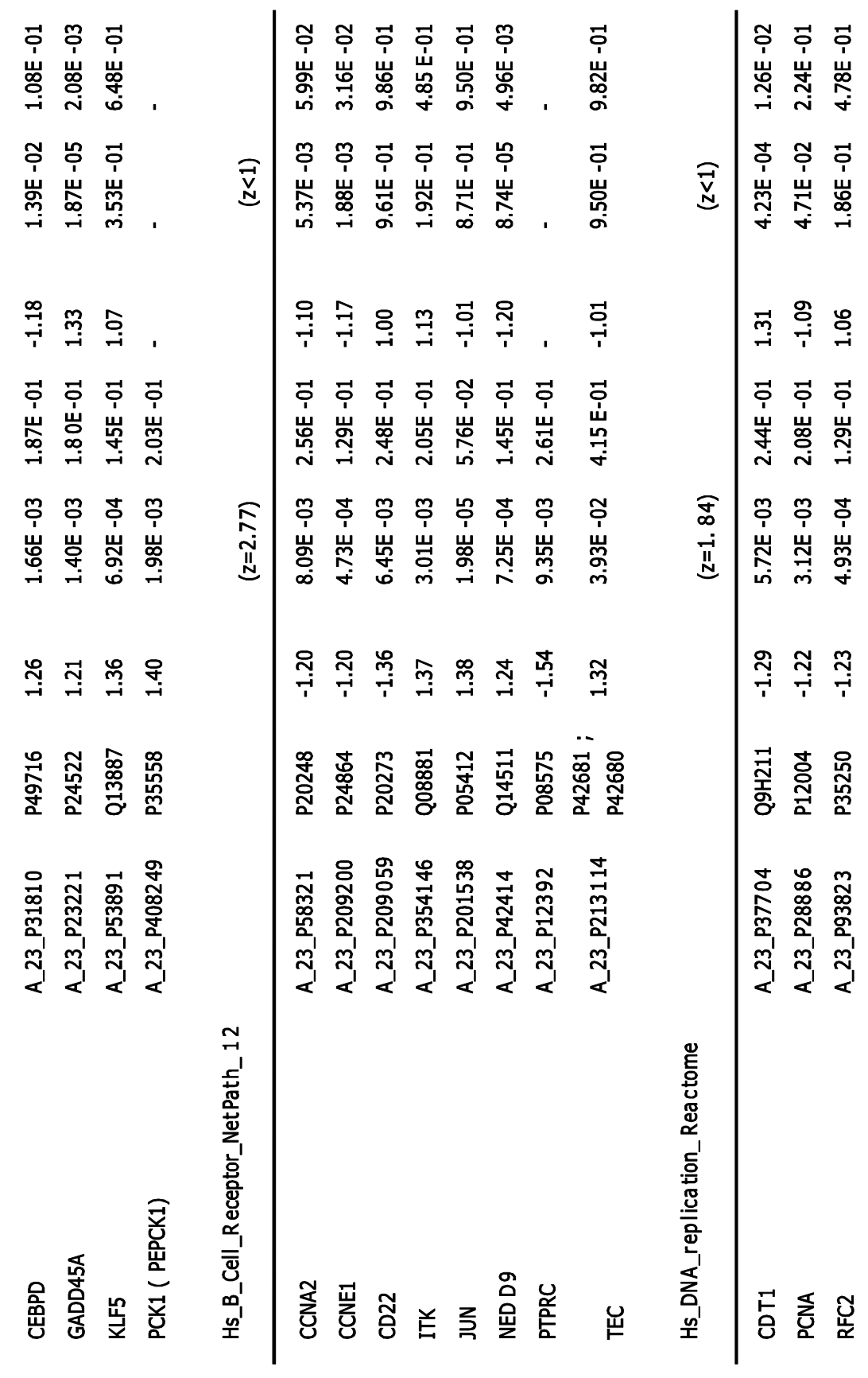




\section{CHAPTER 3}

Supplemental table 3 (part 4). Differentially expressed genes by fenofibric acid versus GW7647 in HepG2 cells and/or in differentiated CaCo-2 cells present in affected human GenMAPP v2.1 pathways.

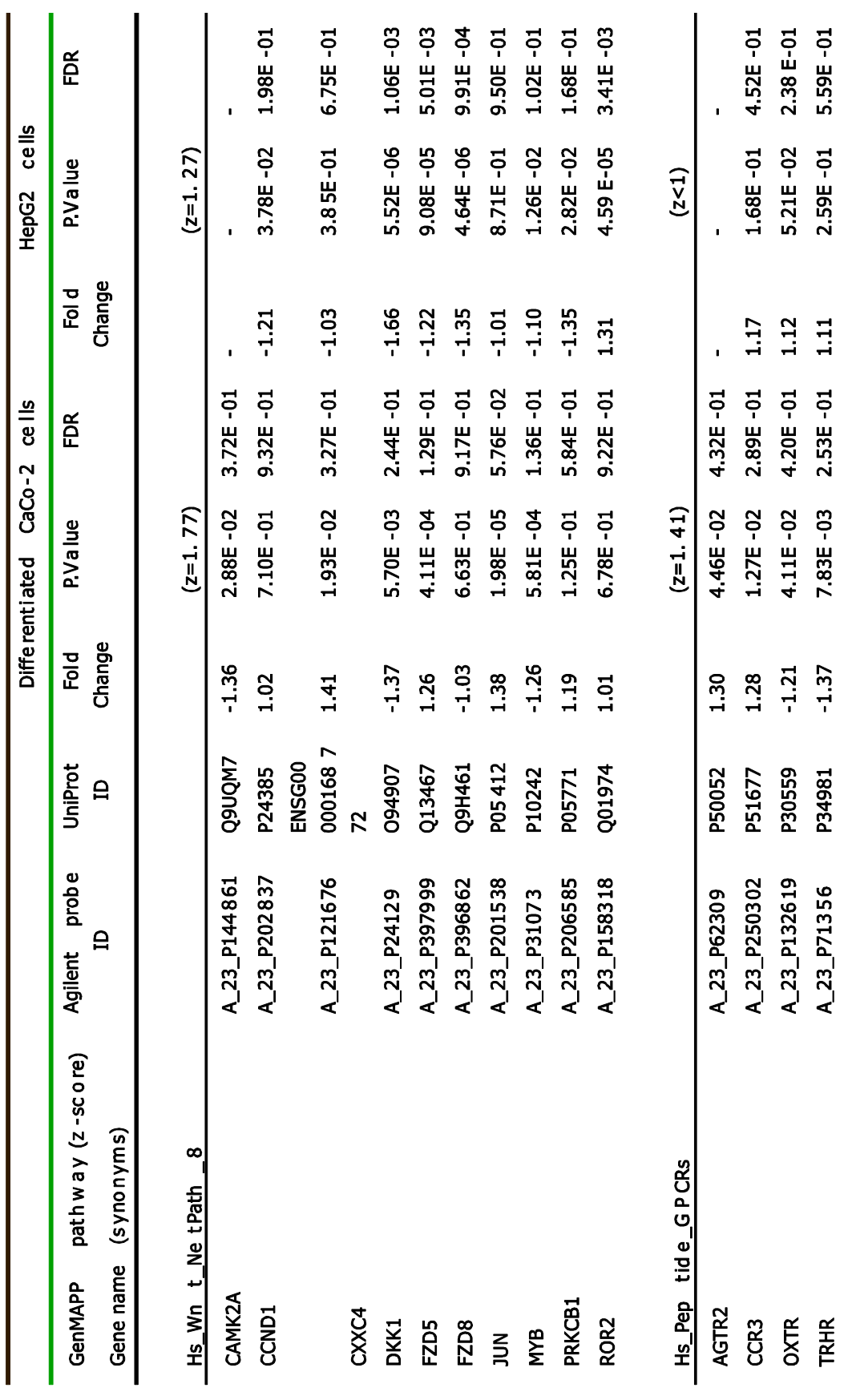




\section{NATURAL PPARa TRANSACTIVATING COMPOUNDS}

Supplemental table 3 (part 5). Differentially expressed genes by fenofibric acid versus GW7647 in HepG2 cells and/or in differentiated CaCo-2 cells present in affected human GenMAPP v2.1 pathways.

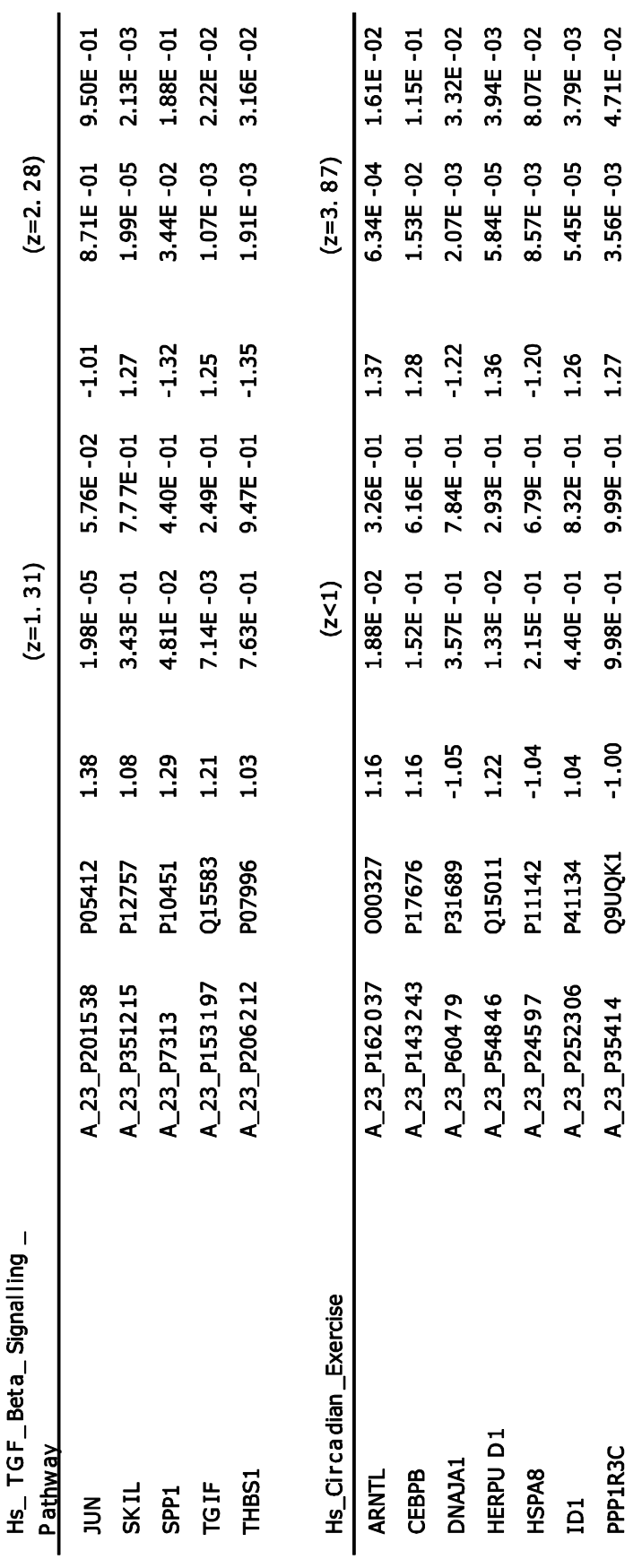




\section{CHAPTER 3}

Supplemental table 3 (part 6). Differentially expressed genes by fenofibric acid versus GW7647 in HepG2 cells and/or in differentiated CaCo-2 cells present in affected human GenMAPP v2.1 pathways.

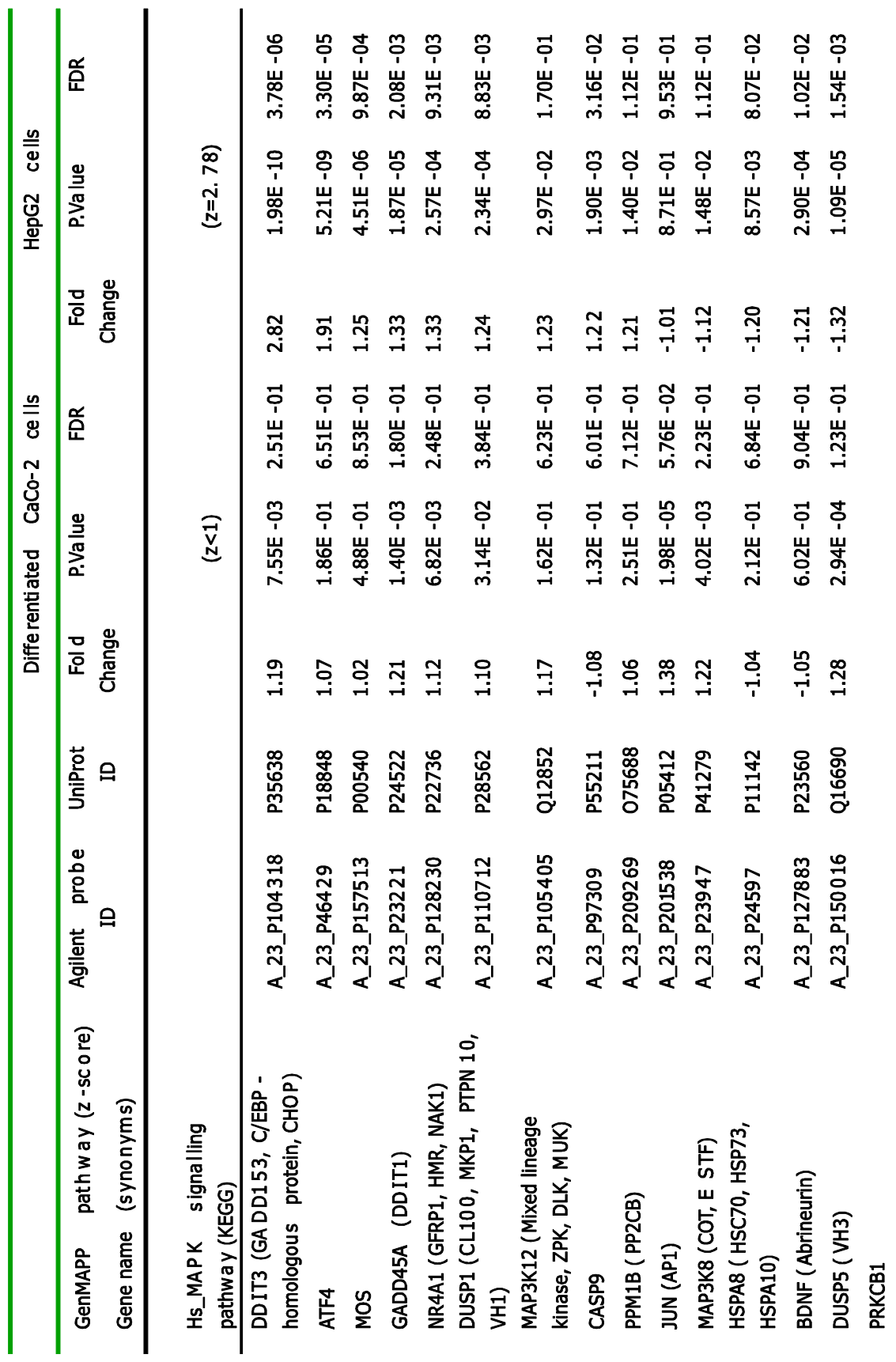




\section{NATURAL PPARa TRANSACTIVATING COMPOUNDS}

Supplemental table 3 (part 7). Differentially expressed genes by fenofibric acid versus GW7647 in HepG2 cells and/or in differentiated CaCo-2 cells present in affected human GenMAPP v2.1 pathways.

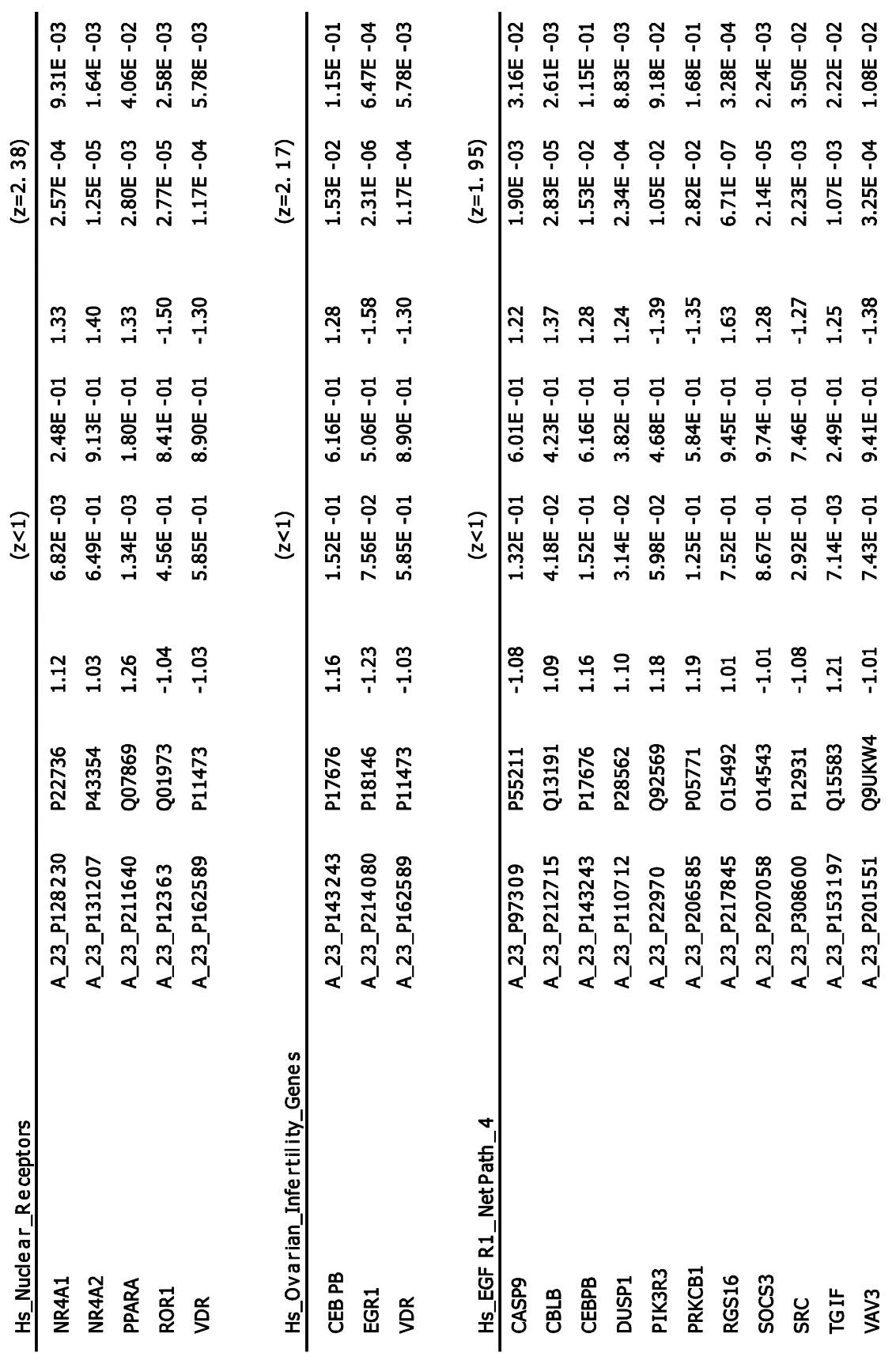




\section{CHAPTER 3}

Supplemental table 3 (part 8). Differentially expressed genes by fenofibric acid versus GW7647 in HepG2 cells and/or in differentiated CaCo-2 cells present in affected human GenMAPP v2.1 pathways.

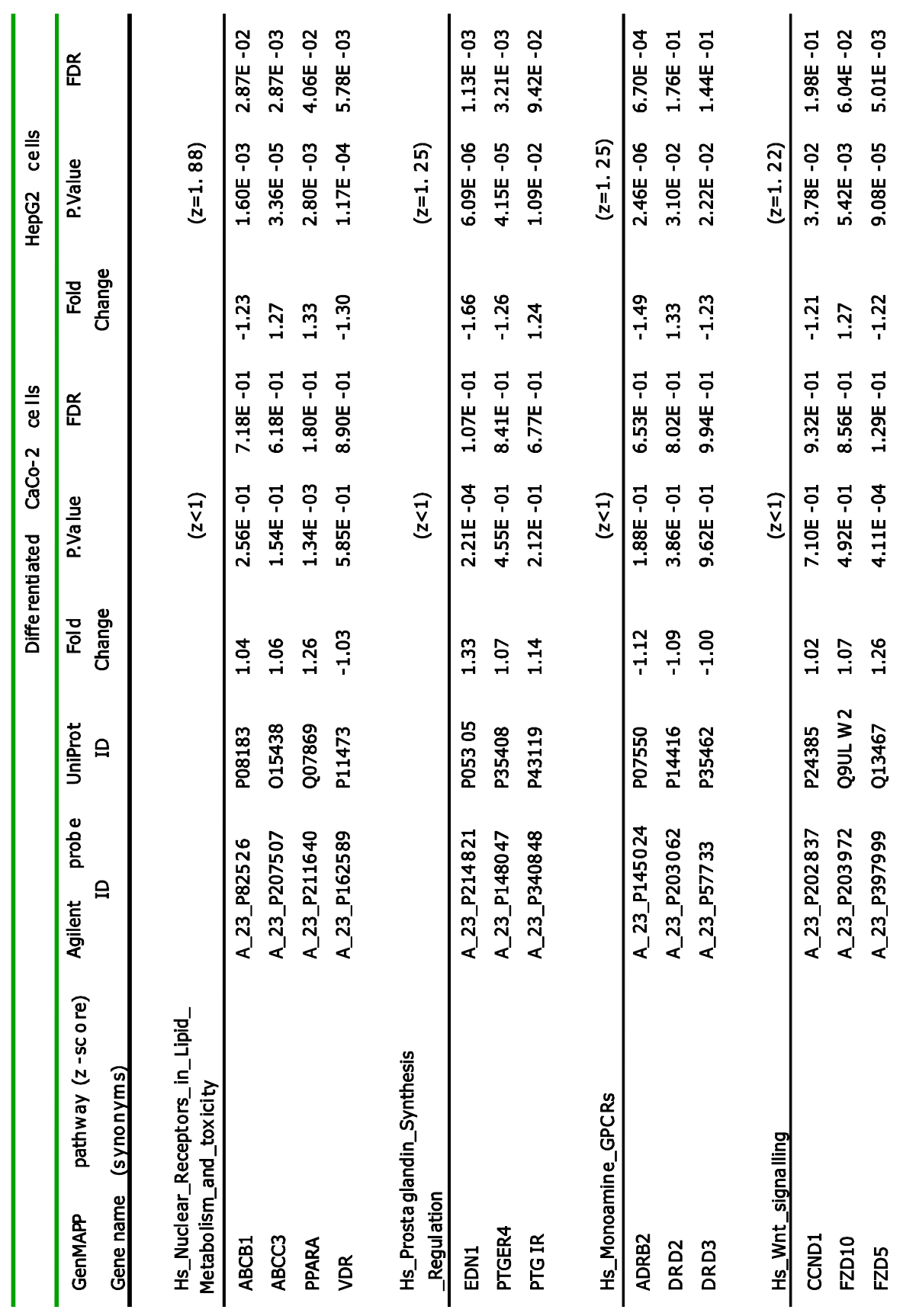




\section{NATURAL PPARa TRANSACTIVATING COMPOUNDS}

Supplemental table 3 (part 9). Differentially expressed genes by fenofibric acid versus GW7647 in HepG2 cells and/or in differentiated CaCo-2 cells present in affected human GenMAPP v2.1 pathways.

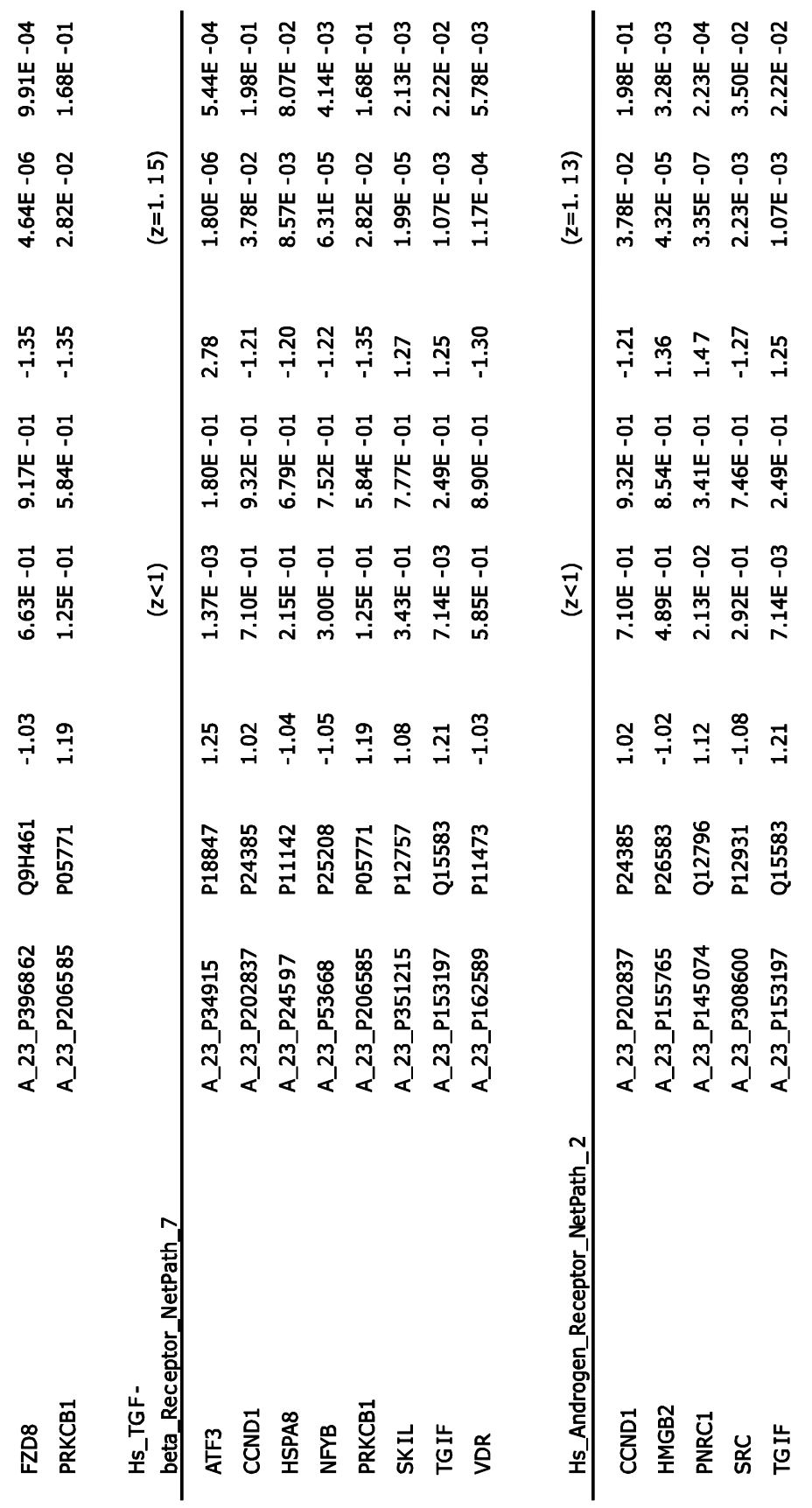




\section{CHAPTER 3}

Supplemental table 3 (part 10). Differentially expressed genes by fenofibric acid versus GW7647 in HepG2 cells and/or in differentiated CaCo-2 cells present in affected human GenMAPP v2.1 pathways.

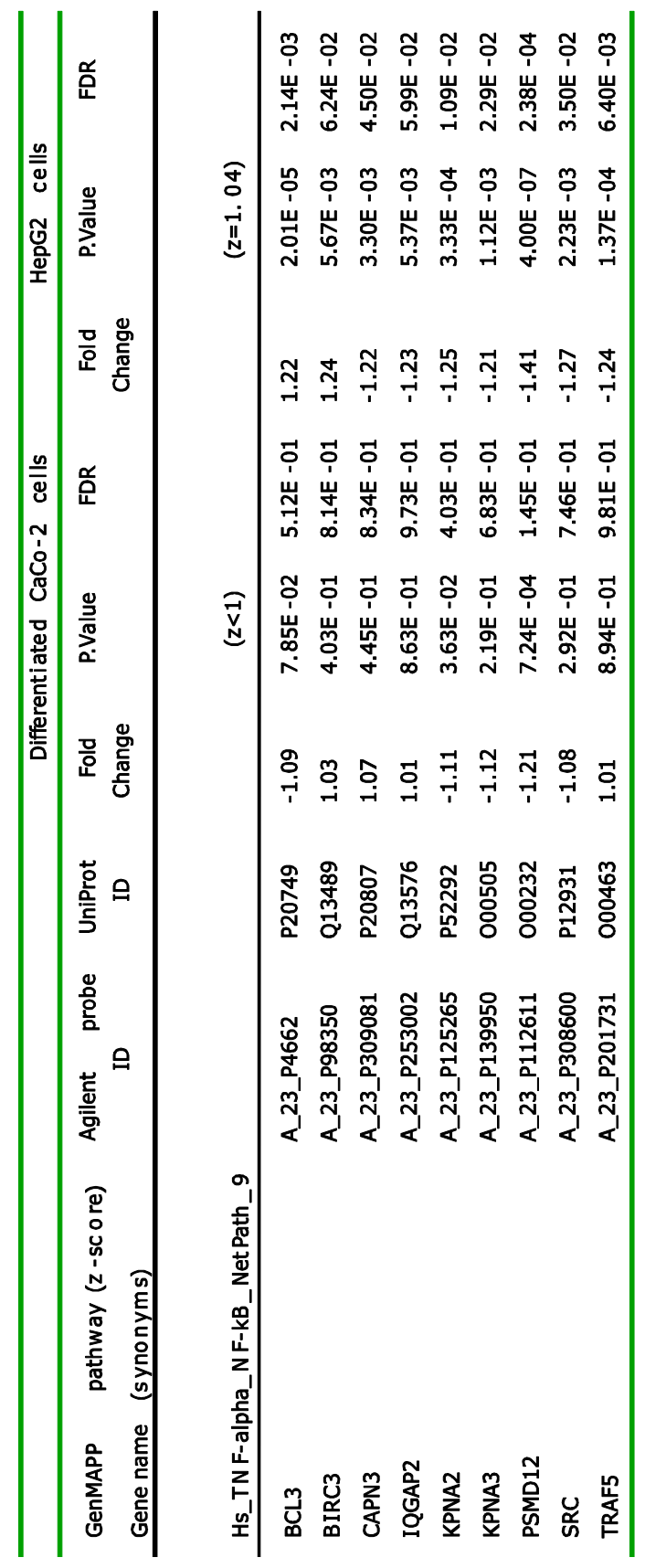




\section{NATURAL PPARa TRANSACTIVATING COMPOUNDS}

Supplemental table 4. Differentially expressed genes of selected transcription factors by fenofibric acid versus GW7647 in HepG2 cells and/or in differentiated CaCo-2 cells present in human GenMAPP v2.1 pathways.

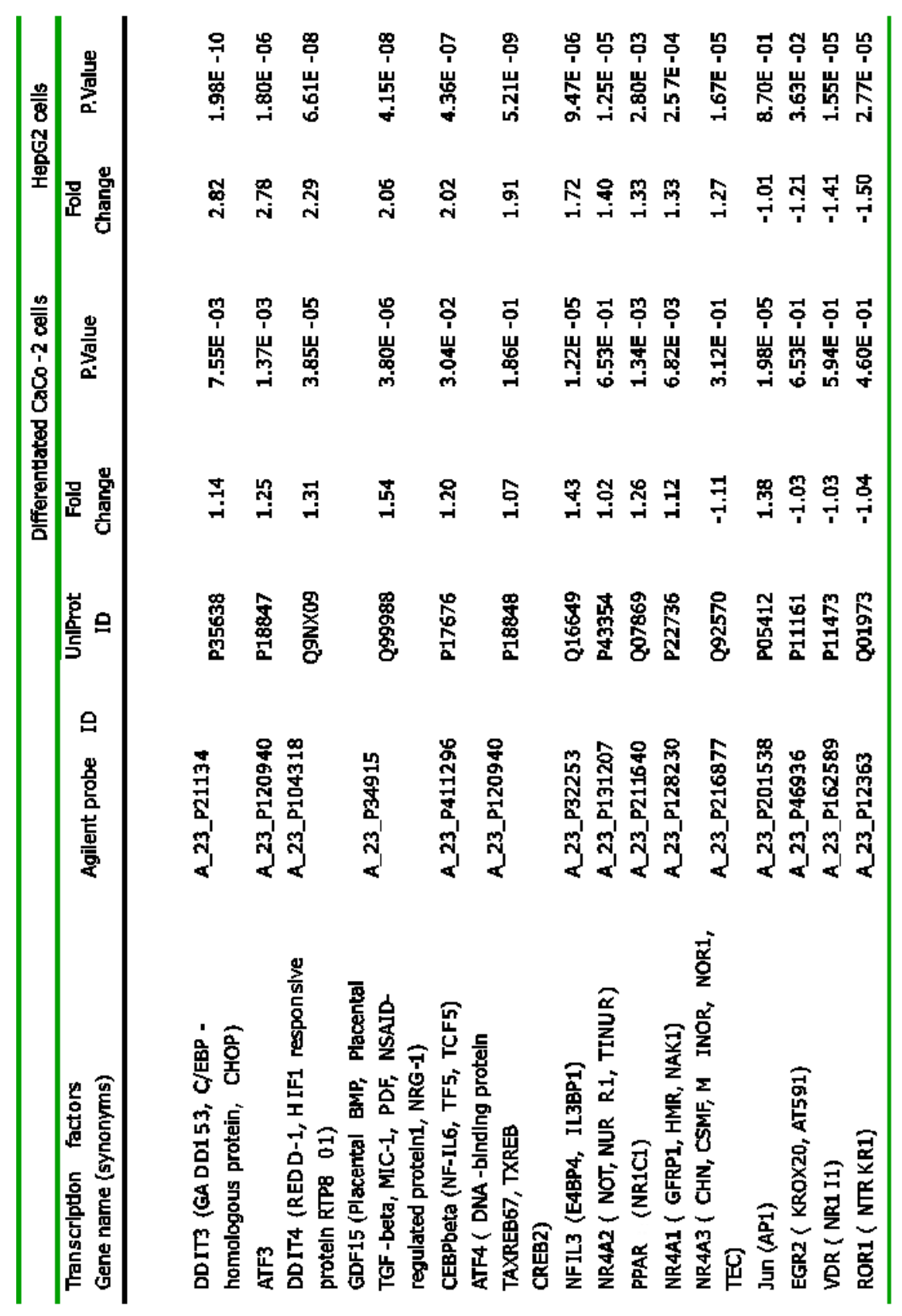




\section{CHAPTER 4}

Identification of natural PPARa transactivating compounds and their effects on apolipoprotein A-I transcription in HepG2 cells

Sophie E. van der Krieken, Herman E. Popeijus, Ronald P. Mensink and Jogchum Plat

Submitted 


\section{CHAPTER 4}

\section{Abstract}

Increasing apoA-I, the predominant protein of high-density lipoprotein (HDL) particles, has favorable effects on atherogenic risk factors. Although providing recombinant proteins and apoA-I mimetics is a promising method, this is not feasible at population level. In this study we aimed to I) discover novel natural compounds with the capacity to transactivate PPAR a and to II) determine the effects of the identified compounds on apoA-I transcription in HepG2 cells. By using transient PPARa agonist transactivation assays, 2500 compounds derived from two natural databases were tested for PPARa transactivation in HEK293 cells. To discover the effects of the selected natural compounds on apoA-I transcription, HepG2 cells were exposed to $0.1 ; 1$ and $10 \mu \mathrm{g} / \mathrm{ml}$ of each compound and apoA-I mRNA expression was determined using qPCR. Extensive doseresponse experiments were performed using compounds that increased apoA-I transcription minimally by $20 \%$. A decreased KEAP1 expression was used as a BRD4 inhibition marker and CPT1 $\alpha$ expression was measured to confirm PPARa activation. 28 out of 2500 natural compounds increased PPARa transactivation by 2 -fold. Despite the increased CPT1 $\alpha$ expression seen after addition of most PPAR $\alpha$ activating compounds, CPT1 $\alpha$ expression and PPAR $\alpha$ transactivation did not correlate. Addition of $0.05 \mu \mathrm{g} / \mathrm{ml}$ 9(S)-HOTrE increased apoA-I mRNA expression by $35 \%$, whereas 10 to $25 \mu \mathrm{g} / \mathrm{ml}$ cymarin increased apoA-I transcription by $37 \%$. Clearly, apoA-I transcription involves multiple regulatory players and PPARa transactivation alone is not sufficient. Since 9(S)-HOTrE and cymarin have clear limitations to be used for the general population, a search for natural compounds that resemble the molecular structure of 9(S)-HOTrE and cymarin could lead to additional components with comparable effects on apoA-I transcription. 


\section{NATURAL PPARa TRANSACTIVATING COMPOUNDS}

\section{Introduction}

A promising strategy to reduce the risk for cardiovascular diseases (CVDs) is raising intestinal or hepatic de novo production of apolipoprotein A-I (apoA-I) [1,2]. The relevance of increasing apoA-I, the predominant protein of high-density lipoprotein (HDL) particles, is related to its favorable effects on a variety of atherogenic risk factors. Amongst others, the apoA-I protein may dampen inflammation [3] and decrease the risk for type II diabetes in humans by increasing pancreatic $\beta$-cell function and improving glycemic control [4,5]. However, the major anti-atherogenic effect of apoA-I is enhancing reverse cholesterol transport (RCT). A key process of RCT, and an important biomarker for CVD development, is the efflux of cholesterol from macrophages from the arterial wall towards apoA-I particles in the circulation [6]. Indeed, intravenous infusion of recombinant apoA-I reduced atheroma volume in patients with acute coronary syndromes [7]. Moreover, infusion of CSL112, an HDL mimetic composed of purified, authentic human plasma apoA-I reconstituted with phospholipids [8], enhanced cholesterol efflux capacity thereby increasing functionality of the HDL lipoprotein fraction [9].

Obviously, providing recombinant proteins and mimetics is not feasible at a population level as part of prevention strategies. This emphasizes the need to discover novel strategies to increase endogenous apoA-I production. Current in vitro studies have mostly used pharmacological agents to increase apoA-I production, such as the synthetically derived PPARa activator GW7647, the Bromodomain and ExtraTerminal protein (BET) inhibitors RVX-208 [10] and JQ1(+) [11] or experimental members of the (thieno- or benzo-) triazolodiazepine family [12]. Although the effects of aforementioned strategies are certainly promising, detailed knowledge of natural compounds that have the capacity to increase apoAI transcription is lacking.

It is generally accepted that in human hepatocytes and intestinal cells, transcription of apoA-I is regulated by transcription factor Peroxisome Proliferator-Activated Receptor alpha (PPARa) [13]. This is underlined by the fact that the promoter of the apoA-I gene contains a PPAR response element (PPRE) [13,14], which functions as a binding place for the PPARa/RXR heterodimer following PPAR activation. Previous in vitro studies have indeed shown that PPAR agonists such as GW7647, WY14643 [15] and the fatty acid $\alpha$-linolenic acid [16] increased apoA-I production in HepG2 and CaCo-2 cells in a PPARa-dependent manner. In this study we aimed to I) discover novel natural compounds with the capacity to transactivate PPAR a and II) determine the effects of the identified compounds on apoA-I transcription in human hepatocellular carcinoma (HepG2) cells.

\section{Methods}

\section{Transient PPARa agonist transactivation assay}

Human embryonic kidney (HEK293) cells (ATCC, Molsheim, France) were cultured in Eagle minimum essential medium containing Earle's balanced salt solution without L-glutamine, supplemented with 10\% fetal bovine serum (Sigma-Aldrich Corp., St. Gallen, Switzerland), $1 \mathrm{mM}$ sodium pyruvate (Life Technologies), $2 \mathrm{mM}$ 


\section{CHAPTER 4}

glutamax (Life Technologies AG, Basel, Switzerland) and $0.1 \mathrm{mM}$ nonessential amino acids (Life Technologies) in an atmosphere of $37^{\circ} \mathrm{C}$ and $5 \% \mathrm{CO}_{2}$, as previously described [17]. For the transient transfections, HEK293 cells, were plated in white 96-well cell culture plates (Corning, Basel, Switzerland) at a density of $7.5 \times 10^{4}$ cells per well, in $80 \mu \mathrm{l}$ minimum essential medium (Eagle) containing Earle's balanced salt solution without L-glutamine and phenol red, supplemented with $10 \%$ charcoal-treated fetal bovine serum (HyClone Laboratories, Inc., Logan, UT, USA), $2 \mathrm{mM}$ glutamax, $0.1 \mathrm{mM}$ non-essential amino acids, and $1 \mathrm{mM}$ sodium pyruvate. When the cells reached $80 \%$ confluence the next day, they were transfected with the PPARa Ligand Binding Domain (LBD) and the 4xGAL4 binding sequence controlling the luciferase firefly reporter gene, using polyethylene-iminebased transfection (figure $\mathbf{1}$ ).

Stocks of the compounds of interest were dissolved in DMSO and pre-diluted in PBS, reaching a final DMSO concentration of $0.45 \%$. Five hours after the addition of the transfection mixture, the pre-diluted compounds were added in the respective dilution onto the cells. This was incubated for 16 hours, which was followed by firefly and renilla luciferases measurement according to the Promega protocol (Promega AG, Dübendorf, Switzerland). Transfection efficiency was checked by transfection of the pRL-TK renilla luciferase reporter. The ligandbinding domain of PPARa was expressed from a Gateway (Invitrogen, Zug, Switzerland)-compatible version of pCMVBD (Stratagene Corp., Santa Clara, CA, USA) as a fusion to the GAL4 DNA-binding domain (amino acids 1 to 147). pFRLuc (Stratagene Corp.) was used as a reporter plasmid.

A dose-response curve between GW7647 with PPARa normalized luciferase units is depicted in supplemental figure 1. Based on these results, a concentration of 1 $\mu \mathrm{M}$ GW7647 was used as positive control in the screening assays. By using the transactivation assay (figure 1), a total of 2500 compounds derived from an extensive natural compound database (established by DSM) was screened for their PPARa transactivation. A concentration of $9 \mu \mathrm{g} / \mathrm{ml}$ was used for each compound. Four biological replicate samples were analyzed, each in threefold. Compounds that consistently elevated PPARa transactivation for four consequent times by at least $200 \%$ compared to the DMSO carrier control were considered as candidates to examine apoA-I transcription in the subsequent HepG2 cell culture assay. Selection was also based on compound availability. 


\section{NATURAL PPARa TRANSACTIVATING COMPOUNDS}

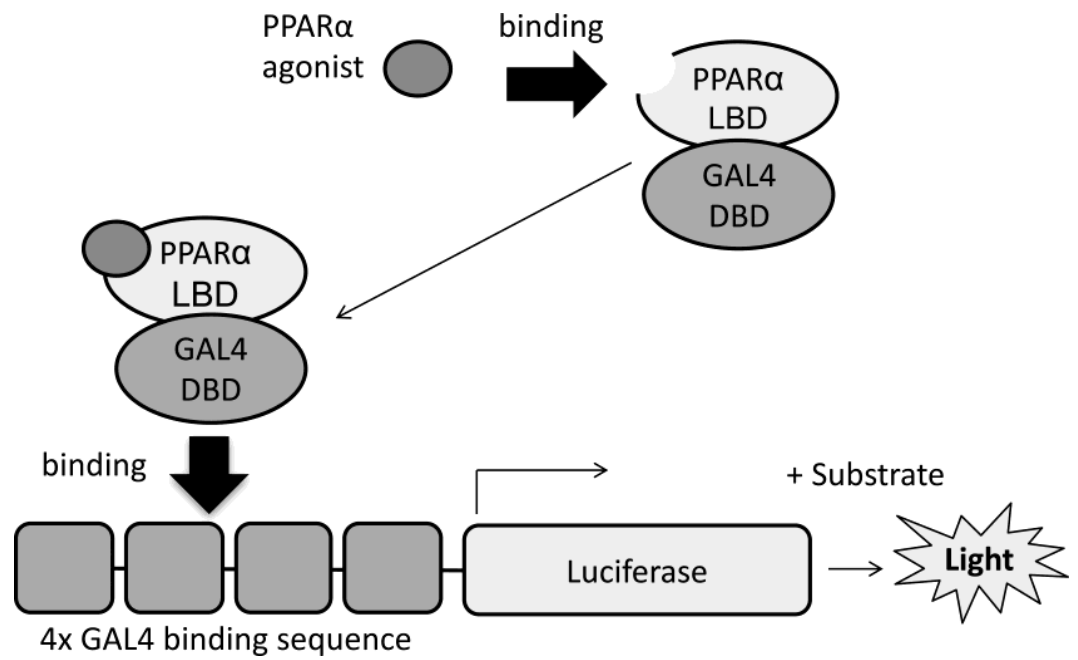

Figure 1. Schematic representation of the PPARa transactivation assay.

After addition, a PPARa agonist will bind to the PPARa Ligand Binding Domain (LBD). This LBD contains a GAL4 DNA Binding Domain (DBD) that will bind to the 4xGAL4 binding sequence inserted upstream of the thymidine kinase promoter, controlling the luciferase firefly reported gene. The transactivation of PPARa due to the PPARa agonist is monitored by measuring the expression of the luciferase reporter gene.

\section{Human liver cell culture and experiments}

Human hepatocellular liver carcinoma (HepG2) cells (kindly provided by Sten Braesch-Andersen, PhD, Mabtech, Nacka Strand, Sweden) were maintained at $37^{\circ} \mathrm{C}$ and $5 \% \mathrm{CO}_{2}$ in a humidified atmosphere. Cell culture medium was composed of Minimum Essential Medium (MEM) supplemented with L-glutamine (Invitrogen Life Technologies, Carlsbad, CA, USA), 10\% Fetal Calf Serum (v/v, SouthAmerican, Greiner Bio-one, Frickenhausen, Germany), 1\% NEAA (v/v), 1\% penicillin/streptomycin $(\mathrm{v} / \mathrm{v})$ and $1 \%$ sodium pyruvate $(\mathrm{v} / \mathrm{v}$, all from Invitrogen Life Technologies, Carlsbad, CA, USA).

To obtain insight into the effects of the selected natural compounds on in vitro apoA-I transcription, HepG2 cells were exposed to doses of $0.1,1$ and $10 \mu \mathrm{g} / \mathrm{ml}$ of each compound. Each dose was tested in fourfold and each sample was analyzed in duplo. JQ1(+) (3 $\mu \mathrm{M}$ final concentration, Tocris Bioscience, Abingdon, UK) was used as a positive control, whereas thapsigargin $(0.01 \mu \mathrm{M}$ final concentration, Sigma Aldrich, St. Louis, MO, USA), a commonly used ER-stress inducer known to decrease apoA-I transcription [18], was used as negative control. Compounds were diluted in DMSO with a DMSO concentration of $0.1 \%$ in medium. After incubation, cells were visually inspected for viability using a microscope (data not shown). For compounds that (i) transactivated PPAR $\alpha$ minimally by $200 \%$ and (ii) increased apoA-I mRNA expression by at least $20 \%$ compared to control in HepG2 cells after doses of $0.1,1$ or $10 \mu \mathrm{g} / \mathrm{ml}$, a more extensive dose-response curve was made. 
CPT1a, apoA-I and KEAP1 qPCR measurement

Total RNA was extracted from the HepG2 cells according the Trizol/Qiagen protocol, after which cDNA was synthesized using Taqman RT reagents (Applied Biosystems). mRNA expression of apoA-I (Hs00163641_m1) and CPT1a (Hs00912671_m1) were determined using the 7300 Real-Time PCR System. CPT1 $\alpha$ was determined as marker for PPARa activation. Further, to determine if the PPARa transactivating compounds possibly changed BET inhibitor function, KEAP1 (Hs00202227_m1) was measured. It is known that KEAP1 decreases upon BRD4 inhibition [19]. Cyclophilin A (Hs99999904_m1) was used as internal control. All TaqMan Gene Expression Assays were obtained from Applied Biosystems.

\section{Statistics}

The differences of the extensive dose-response curves for the compounds 9 (S)HOTrE and cymarin compared to control were tested statistically using a MannWhitney $U$ test. All data is shown as average \pm SD. Spearman correlation coefficients $\left(r_{s}\right)$ between PPARa transactivation and CPT1a mRNA expression were calculated using Graphpad Prism 7 (GraphPad Software, Inc., CA, USA).

\section{Results}

From the total list of 2500 natural compounds, $1.1 \%$ or 28 compounds increased PPARa transactivation minimally 2 -fold. Four of these compounds were excluded from further analysis, since they were not available for further testing. The transactivation of PPARa was highest for 9(S)-HOTrE, baicalein, 3,2'dihydroxyflavone, undecylenic acid and 5-deoxy-peonidin, and the lowest for undecanoic acid, gentisin, gamma-linolenic acid, 2'hydroxychalcone and cymarin (figure 2A). Following the PPARa transactivation assay in HEK293 cells, three different doses were tested for each of the 24 compounds in HepG2 cells: 0.1, 1.0, and $10 \mu \mathrm{g} / \mathrm{ml}$. To confirm PPAR $\alpha$ activation of these 24 compounds in HepG2 cells, mRNA expression of the PPAR $\alpha$ target CPT1 $\alpha$ was also analyzed (figure 2B). More results are presented in supplemental figures $\mathbf{S} 2$ panel A-D. 


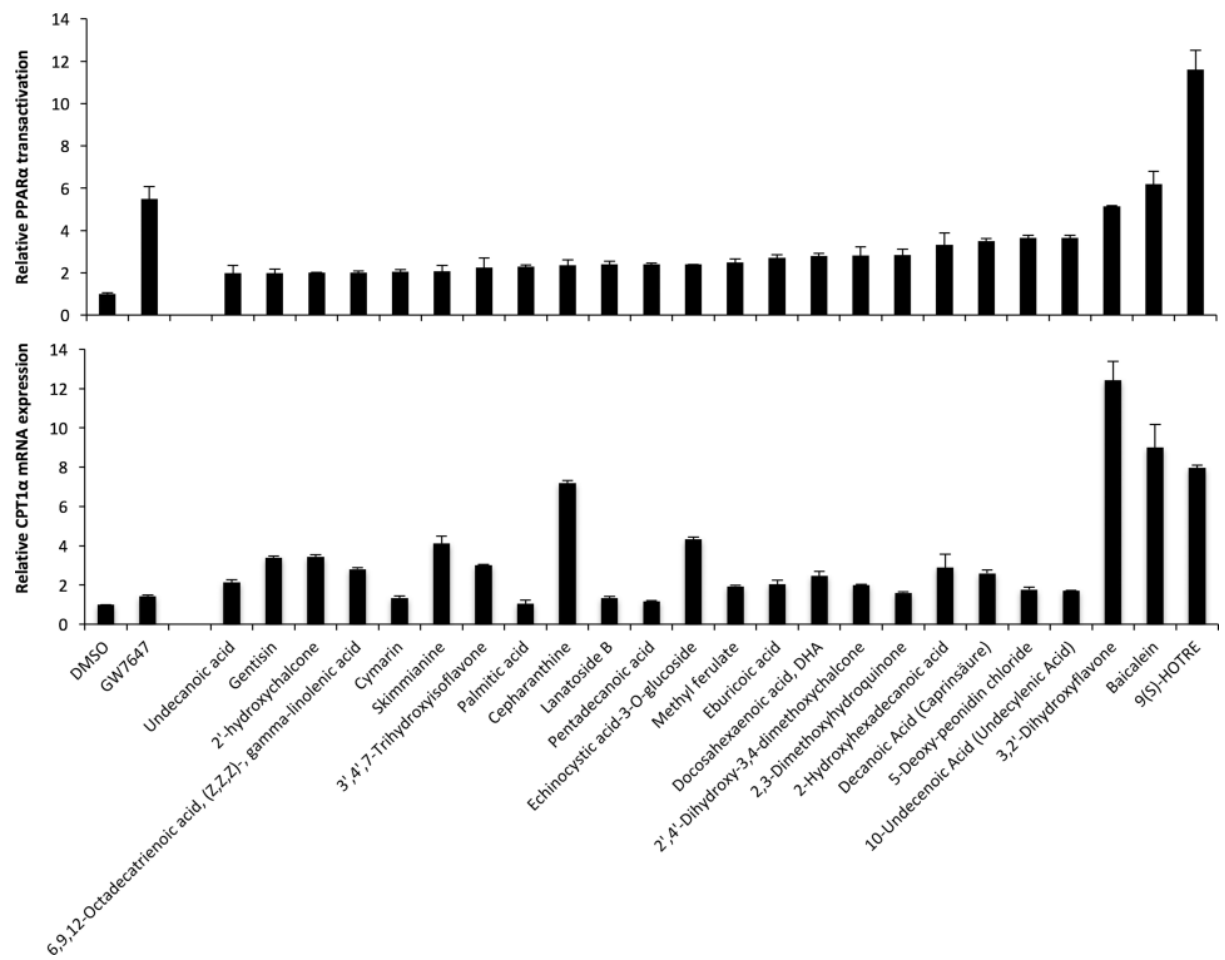

Figure 2. A) The effect of the 24 selected natural compounds on fold of PPARa transactivation (minimally 2-fold) in HEK293 cells. For each compound a dose of 9 $\mu \mathrm{g} / \mathrm{ml}$ was tested and the known PPARa agonist GW7647 was used as a positive control. Results are presented as average of four biological replicates samples and were all analyzed in triplicate. Values were compared to the control condition (DMSO carrier), which was arbitrarily set at 1. B) Relative CPT1a mRNA expression in HepG2 cells treated with $10 \mu \mathrm{g} / \mathrm{ml}$ of the 24 selected natural compounds. Results are presented as average of two biological samples measured in duplo, with standard deviation. Data are compared with the control condition (DMSO carrier), which was arbitrarily set at 1 .

The 24 identified compounds could be divided into five major categories: (I) fatty acids, (II) polyphenols or chalconoids, (III) triterpenoids, saponins or steroids, (IV) alkaloids or (V) quinones (table 1). The most potent PPARa activators were the fatty acids and the polyphenols or chalconoids. These findings were confirmed by the CPT1 $\alpha$ mRNA measurements, as changes in CPT1 $\alpha$ mRNA levels were most pronounced in these two categories (table 1). In general, except 2,3dimethoxyhydroquinone and eburicoic acid, all identified compounds with PPARa transactivating activity increased mRNA expression of the PPARa target gene CPT1 $\alpha$ by more than $20 \%$ (figure 2B and table 1). However, the expression of CPT1a mRNA fluctuated strongly between all compounds and did not correlate with the fold of PPARa transactivation (supplemental figure S3; $r_{s}=0.097$, $\mathrm{P}=0.645$ ). Also within subcategories, Spearman correlation coefficients did not reach statistical significance. 


\section{CHAPTER 4}

Table 1. The effect of the 24 selected natural compounds on fold of PPARa transactivation (minimally 2-fold) in HEK293 cells, and on CPT1a mRNA expression in HepG2 cells. For each compound a dose of $9 \mu \mathrm{g} / \mathrm{ml}$ was tested. The known PPARa agonist GW7647 was used as a positive control for PPAR transactivation. Results are presented as average of four biological replicates and were all analyzed in triplicate. Values were compared to the control condition (DMSO carrier), which was arbitrarily set at 1 . Compounds were categorized into different classes: I: $\mathrm{fa}=$ fatty acid; II: $\mathrm{pp} / \mathrm{ch}=$ polyphenols / chalconoids; III: $\mathrm{tt} / \mathrm{sp} / \mathrm{st}=$ triterpenoids / saponins / steroids; category IV: alk= alkaloids or category V: qu= quinone, from low to high fold PPARa transactivation.

\begin{tabular}{|c|c|c|c|c|}
\hline Category & Type & Name compound & $\begin{array}{c}\text { PPAR } \alpha \text { fold } \\
\text { transactivation }\end{array}$ & $\begin{array}{c}\text { CPT1 } \alpha \text { mRNA } \\
\text { production }\end{array}$ \\
\hline & Control & DMSO & 1.0 & 1.0 \\
\hline & Positive control & GW7647 & 5.5 & 1.4 \\
\hline \multirow{9}{*}{ I } & $\mathrm{fa}$ & 9(S)-HOTRE & 11.6 & 8.0 \\
\hline & $\mathrm{fa}$ & 10-Undecenoic Acid (Undecylenic Acid) & 3.7 & 1.7 \\
\hline & $\mathrm{fa}$ & Decanoic Acid (Caprinsäure) & 3.5 & 2.6 \\
\hline & $\mathrm{fa}$ & 2-Hydroxyhexadecanoic acid & 3.3 & 2.9 \\
\hline & fa & docosahexaenoic acid, DHA & 2.8 & 2.5 \\
\hline & $\mathrm{fa}$ & pentadecanoic acid & 2.4 & 1.2 \\
\hline & $\mathrm{fa}$ & palmitic acid & 2.3 & 1.0 \\
\hline & fa & $\begin{array}{l}\text { 6,9,12-Octadecatrienoic acid, (z,Z,Z)-, Gamma-linolenic } \\
\text { acid }\end{array}$ & 2.0 & 2.8 \\
\hline & $\mathrm{fa}$ & undecanoic acid & 2.0 & 2.1 \\
\hline \multirow{8}{*}{ II } & $\mathrm{pp} / \mathrm{ch}$ & baicalein & 6.2 & 9.0 \\
\hline & $\mathrm{pp} / \mathrm{ch}$ & 3,2'-Dihydroxyflavone & 5.1 & 12.4 \\
\hline & $\mathrm{pp} / \mathrm{ch}$ & 5-Deoxy-peonidin chloride & 3.7 & 1.8 \\
\hline & $\mathrm{pp} / \mathrm{ch}$ & 2',4'-Dihydroxy-3,4-dimethoxychalcone & 2.8 & 2.0 \\
\hline & $\mathrm{pp} / \mathrm{ch}$ & methyl ferulate & 2.5 & 1.9 \\
\hline & $\mathrm{pp} / \mathrm{ch}$ & 3',4',7-Trihydroxyisoflavone & 2.2 & 3.0 \\
\hline & $\mathrm{pp} / \mathrm{ch}$ & 2'-hydroxychalcone & 2.0 & 3.4 \\
\hline & $\mathrm{pp} / \mathrm{ch}$ & Gentisin & 2.0 & 3.4 \\
\hline \multirow{4}{*}{ III } & $\mathrm{tt} / \mathrm{sp} / \mathrm{st}$ & eburicoic acid & 2.7 & 2.0 \\
\hline & $\mathrm{tt} / \mathrm{sp} / \mathrm{st}$ & echinocystic acid-3-0-glucoside & 2.4 & 4.3 \\
\hline & $\mathrm{tt} / \mathrm{sp} / \mathrm{st}$ & Lanatoside B & 2.4 & 1.3 \\
\hline & $\mathrm{tt} / \mathrm{sp} / \mathrm{st}$ & cymarin & 2.0 & 1.3 \\
\hline \multirow{2}{*}{ IV } & alk & skimmianine & 2.1 & 4.1 \\
\hline & alk & cepharanthine & 2.4 & 7.2 \\
\hline v & qu & 2,3-Dimethoxyhydroquinone & 2.8 & 1.0 \\
\hline
\end{tabular}




\section{NATURAL PPARa TRANSACTIVATING COMPOUNDS}

Of the 22 compounds that elevated CPT1 $\alpha$ mRNA expression (figure 2B and table 1), only two compounds, i.e. 9(S)-HOTrE and cymarin, also increased apoA-I mRNA expression (figure 3 and 4). Changes in apoA-I transcription of all 24 compounds are presented in supplemental figures S4A-F. Next, dose-response curves ranging from 0.01 to $10 \mu \mathrm{g} / \mathrm{ml}$ were made for $9(\mathrm{~S})$-HOTrE (figure 3) and cymarin (figure 4). The addition of $9(\mathrm{~S})-\mathrm{HOTrE}$ at a concentration of $0.05 \mu \mathrm{g} / \mathrm{ml}$ increased apoA-I mRNA expression by 35\% (figure 3; $\mathrm{P}=0.0043$ ). At higher doses, starting at $3 \mu \mathrm{g} / \mathrm{ml}$, apoA-I mRNA expression gradually decreased. For cymarin, apoA-I expression seemed to decrease slightly in the range of 0.01 to $0.5 \mu \mathrm{g} / \mathrm{ml}$, after which apoA-I mRNA expression increased until 37\% at doses ranging from 15 to $25 \mu \mathrm{g} / \mathrm{ml}$ (figure 4; $\mathrm{P}=0,0186$ and $\mathrm{P}=0.003$ respectively). To put these changes into perspective, the positive control JQ1(+) increased apoA-I transcription by approximately $300 \%$, whereas the negative control thapsigargin reduced apoA-I transcription by $50 \%$ (figure 3 and 4 ).

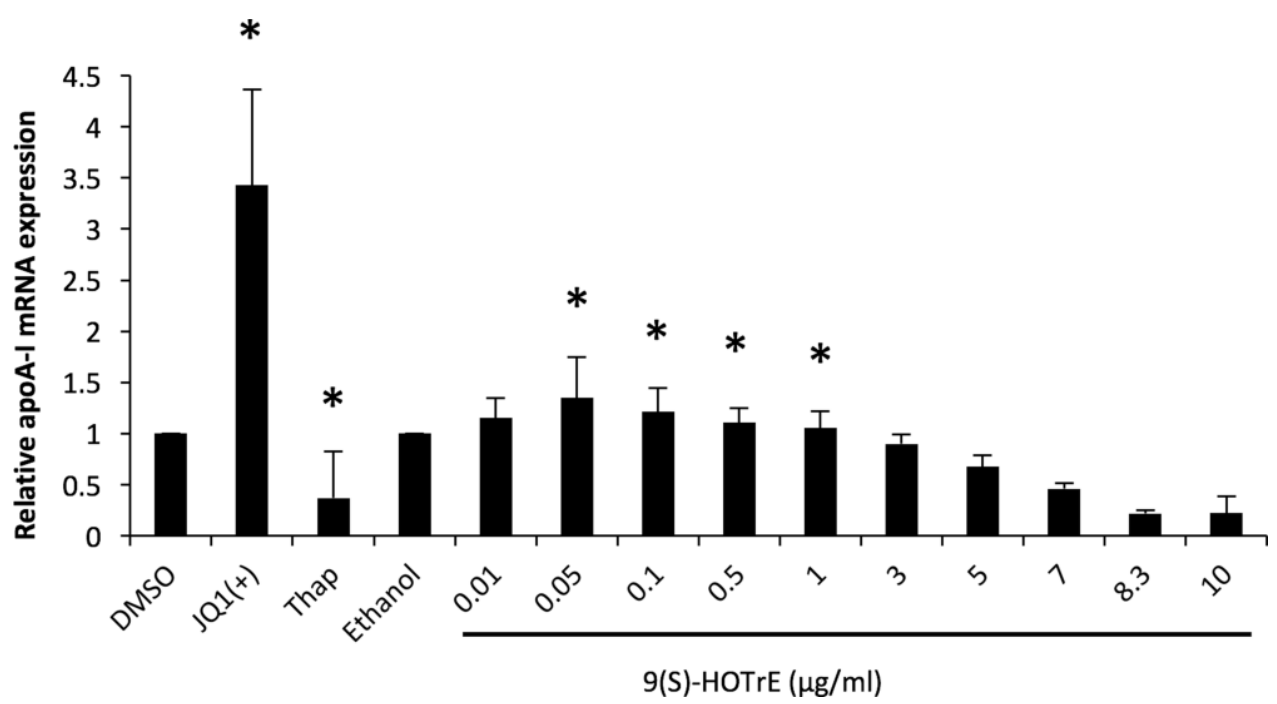

Figure 3. Relative apoA-I mRNA expression in HepG2 cells treated with different doses of the PPARa transactivating compound 9(S)-HOTrE. JQ1(+) $(3 \mu \mathrm{M})$ was used as a positive control for apoA-I transcription, whereas thapsigargin $(0.01 \mu \mathrm{M})$ was used as a control for reduced apoA-I transcription. Results are presented as average of 6 individual experiments, measured in duplo, with standard deviation. 


\section{CHAPTER 4}

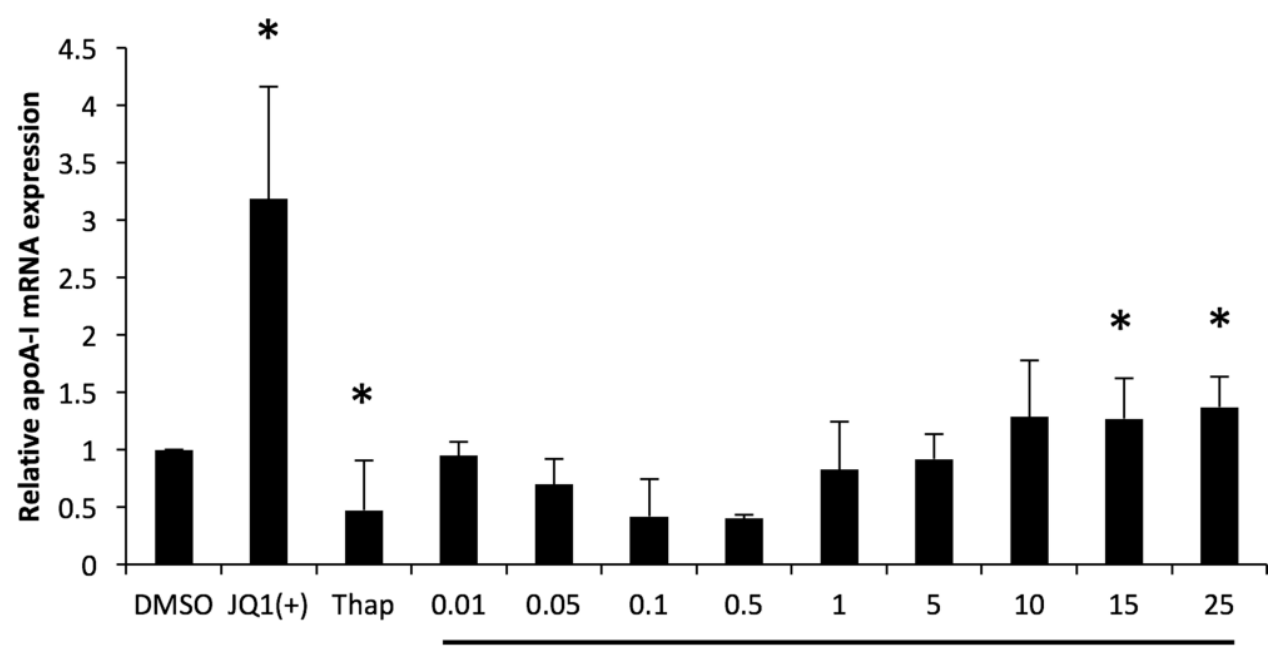

Cymarin $(\mu \mathrm{g} / \mathrm{ml})$

Figure 4. Relative ApoA-I mRNA transcription in HepG2 cells treated with different doses of PPARa transactivating compound Cymarin. JQ1(+) $(3 \mu \mathrm{M})$ was used as a positive control for apoA-I transcription, whereas thapsigargin $(0.01 \mu \mathrm{M})$ was used as a control for reduced apoA-I transcription. Results are presented as average of 6 individual experiments, measured in duplo, with standard deviation.

To examine if effects of $9(\mathrm{~S})$-HOTrE and cymarin on apoA-I transcription were related to BET inhibition next to PPARa activation, mRNA expression of the Bromodomain-containing protein 4 (BRD4) inhibitor target KEAP1 was measured in HepG2 cells. Compared to DMSO, the control for BET inhibition JQ1(+) clearly decreased KEAP1 mRNA expression (figure 5). At the optimal doses for apoA-I mRNA expression, 9(S)-HOTrE increased the expression of KEAP1 mRNA. Cymarin on the other hand clearly decreased KEAP1 and effects were in the same order $(-50 \%)$ as observed for JQ1(+). 


\section{NATURAL PPARa TRANSACTIVATING COMPOUNDS}

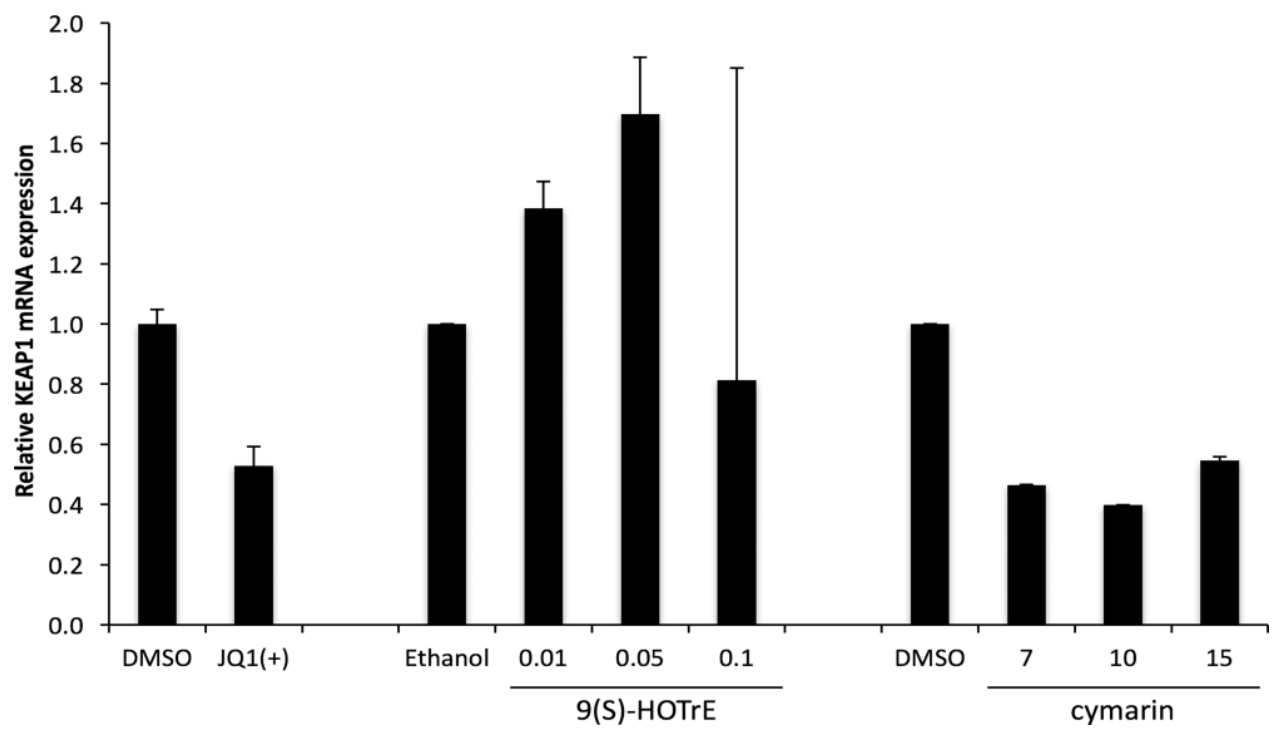

Figure 5. Relative KEAP1 mRNA expression after addition of 9(S)-HOTrE or Cymarin. Ethanol or DMSO was used as a control condition. JQ1(+) $(3 \mu \mathrm{M})$ was used as a control for BET inhibition. Results are presented as average of two wells measured in duplo, with standard deviation.

\section{Discussion}

In this study we aimed to identify natural compounds with the ability to transactivate PPARa, which may consequently result in increased apoA-I transcription. Our PPARa transactivating assay in HEK293 cells resulted in the identification of 24 natural PPARa transactivators. Obviously, all but two compounds also increased mRNA expression of the PPARa target gene CPT1 $\alpha$ in HepG2 cells. Surprisingly, out of the 24 identified PPARa transactivating compounds, only two compounds, 9(S)-HOTrE and cymarin clearly increased apoA-I transcription by $35 \%$ and $37 \%$ respectively. Interestingly, these two compounds were not the most potent in terms of elevating CPT1 $\alpha$ expression. Popeijus et al. [16] also suggested that individual fatty acids exerted different effects on PPAR $\alpha$ transactivation and on PPAR $\alpha$ target genes like apoA-I. This indicates that PPARa is not the only determinant for increased apoA-I transcription. Another explanation may be that besides the activation motif also the inhibitory motif of the PPARa protein becomes activated [20] by another (transcription)factor that is also produced upon adding the compound, which results in a lower apoA-I transcription.

Interestingly, recent studies have demonstrated that besides PPAR activation, also inhibition of bromodomain (BRD) 4 by Bromodomain and Extra-Terminal (BET) inhibitors increased the production of apoA-I [12,21]. Data of our group suggest that the effect of BET inhibitor JQ1(+) on apoA-I transcription is PPARa independent, since PPARa was decreased upon BET inhibition (Krieken et al. unpublished data). Next to beneficial effects on apoA-I production, BET inhibitor 


\section{CHAPTER 4}

JQ1(+) has been reported to reduce reactive oxygen species (ROS) formation and inflammation in mice [22]. Therefore, the discovery of natural BRD4 inhibitors may be a new strategy for the prevention of cardiovascular disease risk in general. To explore the possibility that our two candidate natural compounds $9(\mathrm{~S})-\mathrm{HOTrE}$ and cymarin increased apoA-I transcription via BRD4 inhibition, KEAP1 mRNA expression was measured. Interestingly, cymarin, which clearly increased apoA-I mRNA expression, also reduced KEAP1 mRNA expression, whereas 9(S)-HOTrE did not. One could now speculate that cymarin actually exerted its actions via BRD4 inhibition, whereas 9(S)-HOTrE increased apoA-I via PPARa activation.

The question is whether the two natural compounds that were identified can be applied in a human setting. 9(S)-HOTrE, a monohydroxy polyunsaturated fatty acid found in leaves of the Glechoma hederacea, is produced by the action of 5lipooxygenase on alpha-linolenic acid [23]. Interestingly, Popeijus et al. observed that alpha-linolenic acid increased apoA-I secretion in HepG2 cells [16]. This could provide a possible explanation for the fact that a metabolite of alpha-linolenic, namely 9(S)-HOTrE, induces apoA-I transcription. Although 9(S)-HOTrE was below detection limits in human plasma [24], it is likely that humans can produce this compound. In humans, 5-lipooxygenase, which is the enzyme needed to convert alpha-linolenic acid into 9(S)-HOTrE, is activated by 5-lipoxygenase activating protein (FLAP), a protein encoded by the ALOX5AP gene [25]. Although genetic variations in the ALOX5AP gene have never been related to 9(S)-HOTrE production in humans, genetic variation studies did not show a link between allelic variations in the 5-lipoxygenase gene and cardiovascular disease development risk [26,27].

Treatment of bone marrow-derived macrophages with 9(S)-HOTrE reduced inflammation-induced osteoclatogenesis, suggesting a potential role in the treatment of bone diseases such as rheumatoid and osteoporosis [28]. In that study, a dose of $25 \mu \mathrm{g} / \mathrm{ml}$ of $9(\mathrm{~S})-\mathrm{HOTrE}$ appeared to be non-cytotoxic [28]. We here show that for increasing apoA-I production in HepG2 cells, the optimal dose for $9(\mathrm{~S})$-HOTrE was much lower, i.e. $0.05 \mu \mathrm{g} / \mathrm{ml}$. Obviously, the fact that humans may be able to produce this compound does not necessarily mean that this compound is safe to use in vivo.

The second promising compound we discovered to enhance apoA-I transcription was cymarin. Cymarin, also referred to as Strophantisel, h-Strophanthin or Tsimarin, is a digoxine, of which the natural source is the digitalis plant. Although digoxin is already used in the clinic for the prevention of cardiac arrhythmias in doses ranging from 10 to $25 \mu \mathrm{g}$ per $\mathrm{kg}$ of bodyweight, there is discussion regarding its toxicity and long-term health effects. In the DIG study, the use of approximately $0.250 \mathrm{mg}$ digoxin a day $(0.8-2.5 \mathrm{ng} / \mathrm{ml}$ in serum) reduced hospitalization in diabetic patients with a decreased heart ejection fraction, without any signs of toxicity of digoxin $[29,30]$. Currently, guidelines prescribe that serum digoxin concentrations should be between 0.5 and $0.9 \mathrm{ng} / \mathrm{ml}$, which indicates that the optimal dose of cymarin that we used to increase apoA-I mRNA expression (between 10 and 25 $\mu \mathrm{g} / \mathrm{ml}$ ) was higher than the recommended serum concentration. However, in previous cell studies, even higher doses of $1 \mathrm{mg} / \mathrm{mL}$ appeared to be non-toxic in human lung carcinoma and murine leukemic cells [31,32]. This indicates that additional studies are needed to assess possible toxicity.

A limitation of our study relates to the dose of $9 \mu \mathrm{g} / \mathrm{ml}$ used in the screening to identify the PPARa transactivation potential of the natural compounds. Possibly, 


\section{NATURAL PPARa TRANSACTIVATING COMPOUNDS}

the selection of higher or lower doses would have revealed additional interesting compounds. However for the screening of 2500 compounds selection of more doses would have been too time consuming.

So far our results suggest that: (i) our screening system was functional, as the addition of most PPARa transactivating compounds also increased CPT1a in HepG2 cells. In other words, bioavailability of these compounds in HepG2 cells was not a limiting factor, but probably was different between compounds. This could explain the lack of a correlation between PPAR a transactivation and CPT1 $\alpha$ mRNA expression, and (ii) that activating PPARa only is not sufficient to elevate apoA-I transcription, clearly indicating that regulating apoA-I transcription involves multiple regulatory players.

Both apoA-I increasing compounds 9(S)-HOTrE and cymarin have clear limitations to be used for the general population. Therefore, an interesting step forward could be a search for natural compounds that resemble the molecular structure of 9(S)HOTrE and cymarin to find additional components with comparable effects on apoA-I transcription.

\section{Acknowledgements}

This research was supported by the Dutch Technology Foundation STW, which is part of the Netherlands Organization for Scientific Research (NWO), and which is partly funded by the Ministry of Economic Affairs 


\section{CHAPTER 4}

\section{References}

1. Dullens SP, Plat J, Mensink RP (2007) Increasing apoA-I production as a target for CHD risk reduction. Nutr Metab Cardiovasc Dis 17: 616-628.

2. Boekholdt SM, Arsenault BJ, Hovingh GK, Mora S, Pedersen TR, et al. (2013) Levels and changes of HDL cholesterol and apolipoprotein A-I in relation to risk of cardiovascular events among statin-treated patients: a meta-analysis. Circulation 128: 1504-1512.

3. Rye KA, Barter PJ (2008) Antiinflammatory actions of HDL: a new insight. Arterioscler Thromb Vasc Biol 28: 1890-1891.

4. Rye KA, Barter PJ, Cochran BJ (2016) Apolipoprotein A-I interactions with insulin secretion and production. Curr Opin Lipidol 27: 8-13.

5. Murphy AJ, Woollard KJ, Hoang A, Mukhamedova N, Stirzaker RA, et al. (2008) High-density lipoprotein reduces the human monocyte inflammatory response. Arterioscler Thromb Vasc Biol 28: 2071-2077.

6. Rohatgi A, Khera A, Berry JD, Givens EG, Ayers CR, et al. (2014) HDL cholesterol efflux capacity and incident cardiovascular events. N Engl J Med 371: 2383-2393.

7. Nissen SE, Tsunoda T, Tuzcu EM, Schoenhagen P, Cooper CJ, et al. (2003) Effect of recombinant ApoA-I Milano on coronary atherosclerosis in patients with acute coronary syndromes: a randomized controlled trial. JAMA 290: 2292-2300.

8. Kingwell BA, Chapman MJ, Kontush A, Miller NE (2014) HDL-targeted therapies: progress, failures and future. Nat Rev Drug Discov 13: 445-464.

9. Tricoci P, D'Andrea DM, Gurbel PA, Yao Z, Cuchel M, et al. (2015) Infusion of Reconstituted HighDensity Lipoprotein, CSL112, in Patients With Atherosclerosis: Safety and Pharmacokinetic Results From a Phase 2a Randomized Clinical Trial. J Am Heart Assoc 4: e002171.

10. Gilham D, Wasiak S, Tsujikawa LM, Halliday C, Norek K, et al. (2016) RVX-208, a BET-inhibitor for treating atherosclerotic cardiovascular disease, raises ApoA-l/HDL and represses pathways that contribute to cardiovascular disease. Atherosclerosis 247: 48-57.

11. Filippakopoulos P, Qi J, Picaud S, Shen Y, Smith WB, et al. (2010) Selective inhibition of BET bromodomains. Nature 468: 1067-1073.

12. Kempen HJ, Bellus D, Fedorov O, Nicklisch S, Filippakopoulos P, et al. (2013) Stimulation of Hepatic Apolipoprotein A-I Production by Novel Thieno-Triazolodiazepines: Roles of the Classical Benzodiazepine Receptor, PAF Receptor, and Bromodomain Binding. Lipid Insights 6: 47-54.

13. Duez H, Lefebvre B, Poulain P, Torra IP, Percevault F, et al. (2005) Regulation of human apoA-I by gemfibrozil and fenofibrate through selective peroxisome proliferator-activated receptor alpha modulation. Arterioscler Thromb Vasc Biol 25: 585-591.

14. Tzameli I, Zannis VI (1996) Binding specificity and modulation of the ApoA-I promoter activity by homo- and heterodimers of nuclear receptors. J Biol Chem 271: 8402-8415.

15. Dullens SP, Mensink RP, Mariman EC, Plat J (2009) Differentiated CaCo-2 cells as an in-vitro model to evaluate de-novo apolipoprotein A-I production in the small intestine. Eur $\mathrm{J}$ Gastroenterol Hepatol 21: 642-649.

16. Popeijus HE, van Otterdijk SD, van der Krieken SE, Konings M, Serbonij K, et al. (2014) Fatty acid chain length and saturation influences PPARalpha transcriptional activation and repression in HepG2 cells. Mol Nutr Food Res 58: 2342-2349.

17. Patel H, Lucas X, Bendik I, Gunther S, Merfort I (2015) Target Fishing by Cross-Docking to Explain Polypharmacological Effects. ChemMedChem 10: 1209-1217.

18. Rohrl C, Eigner K, Winter K, Korbelius M, Obrowsky S, et al. (2014) Endoplasmic reticulum stress impairs cholesterol efflux and synthesis in hepatic cells. J Lipid Res 55: 94-103.

19. Hussong M, Borno ST, Kerick M, Wunderlich A, Franz A, et al. (2014) The bromodomain protein BRD4 regulates the KEAP1/NRF2-dependent oxidative stress response. Cell Death Dis 5: e1195.

20. Bragt MC, Popeijus HE (2008) Peroxisome proliferator-activated receptors and the metabolic syndrome. Physiol Behav 94: 187-197.

21. McLure KG, Gesner EM, Tsujikawa L, Kharenko OA, Attwell S, et al. (2013) RVX-208, an inducer of ApoA-I in humans, is a BET bromodomain antagonist. PLoS One 8: e83190.

22. Belkina AC, Nikolajczyk BS, Denis GV (2013) BET protein function is required for inflammation: Brd2 genetic disruption and BET inhibitor JQ1 impair mouse macrophage inflammatory responses. J Immunol 190: 3670-3678.

23. Kim KR, An JU, Lee SH, Oh DK (2015) Selective Production of 9R-Hydroxy-10E,12Z,15ZOctadecatrienoic Acid from alpha-Linolenic Acid in Perilla Seed Oil Hydrolyzate by a Lipoxygenase from Nostoc Sp. SAG 25.82. PLoS One 10: e0137785. 


\section{NATURAL PPARa TRANSACTIVATING COMPOUNDS}

24. Browne RW, Armstrong D (2000) HPLC analysis of lipid-derived polyunsaturated fatty acid peroxidation products in oxidatively modified human plasma. Clin Chem 46: 829-836.

25. Yandava CN, Kennedy BP, Pillari A, Duncan AM, Drazen JM (1999) Cytogenetic and radiation hybrid mapping of human arachidonate 5-lipoxygenase-activating protein (ALOX5AP) to chromosome 13q12. Genomics 56: 131-133.

26. Assimes TL, Knowles JW, Priest JR, Basu A, Volcik KA, et al. (2008) Common polymorphisms of ALOX5 and ALOX5AP and risk of coronary artery disease. Hum Genet 123: 399-408.

27. Bisoendial RJ, Tanck MW, Golledge J, Broekhuizen LN, Legemate DA, et al. (2012) The association between the gene encoding 5-lipoxygenase activating protein and abdominal aortic aneurysms. Atherosclerosis 220: 425-428.

28. Hwang JK, Erkhembaatar M, Gu DR, Lee SH, Lee CH, et al. (2014) Glechoma hederacea Suppresses RANKL-mediated Osteoclastogenesis. J Dent Res 93: 685-690.

29. Digitalis Investigation G (1997) The effect of digoxin on mortality and morbidity in patients with heart failure. N Engl J Med 336: 525-533.

30. Abdul-Rahim AH, Maclsaac RL, Jhund PS, Petrie MC, Lees KR, et al. (2016) Efficacy and safety of digoxin in patients with heart failure and reduced ejection fraction according to diabetes status: An analysis of the Digitalis Investigation Group (DIG) trial. Int J Cardiol 209: 310-316.

31. Irie K, Sato T, Tanaka I, Nakajima J, Kawaguchi M, et al. (2009) Cardiotonic effect of Apocynum venetum L. extracts on isolated guinea pig atrium. J Nat Med 63: 111-116.

32. You YJ, Kim Y, Nam NH, Ahn BZ (2003) Inhibitory effect of Adonis amurensis components on tubelike formation of human umbilical venous cells. Phytother Res 17: 568-570. 
CHAPTER 4

Supplemental data

- Sigmoidal Model for $\mathrm{EC}_{50}$ calculation

- Fit $r^{2}=0.96$

- $\mathrm{EC}_{50}=7.1 \mathrm{nM}(\mathrm{GW} 7647)$

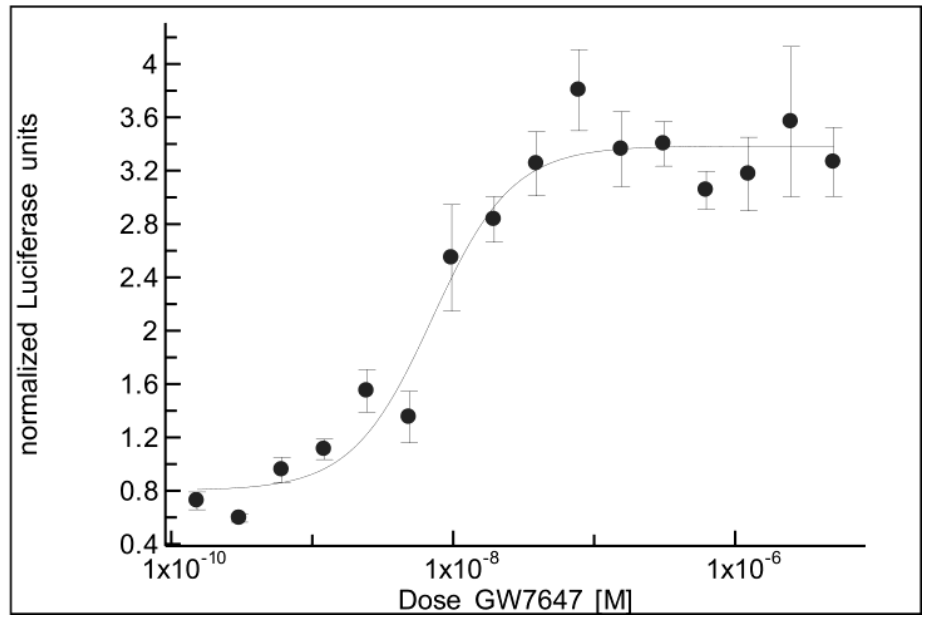

Supplemental figure S1. Dose-response curve between GW7647 with PPARa transactivation in HEK293 cells. 


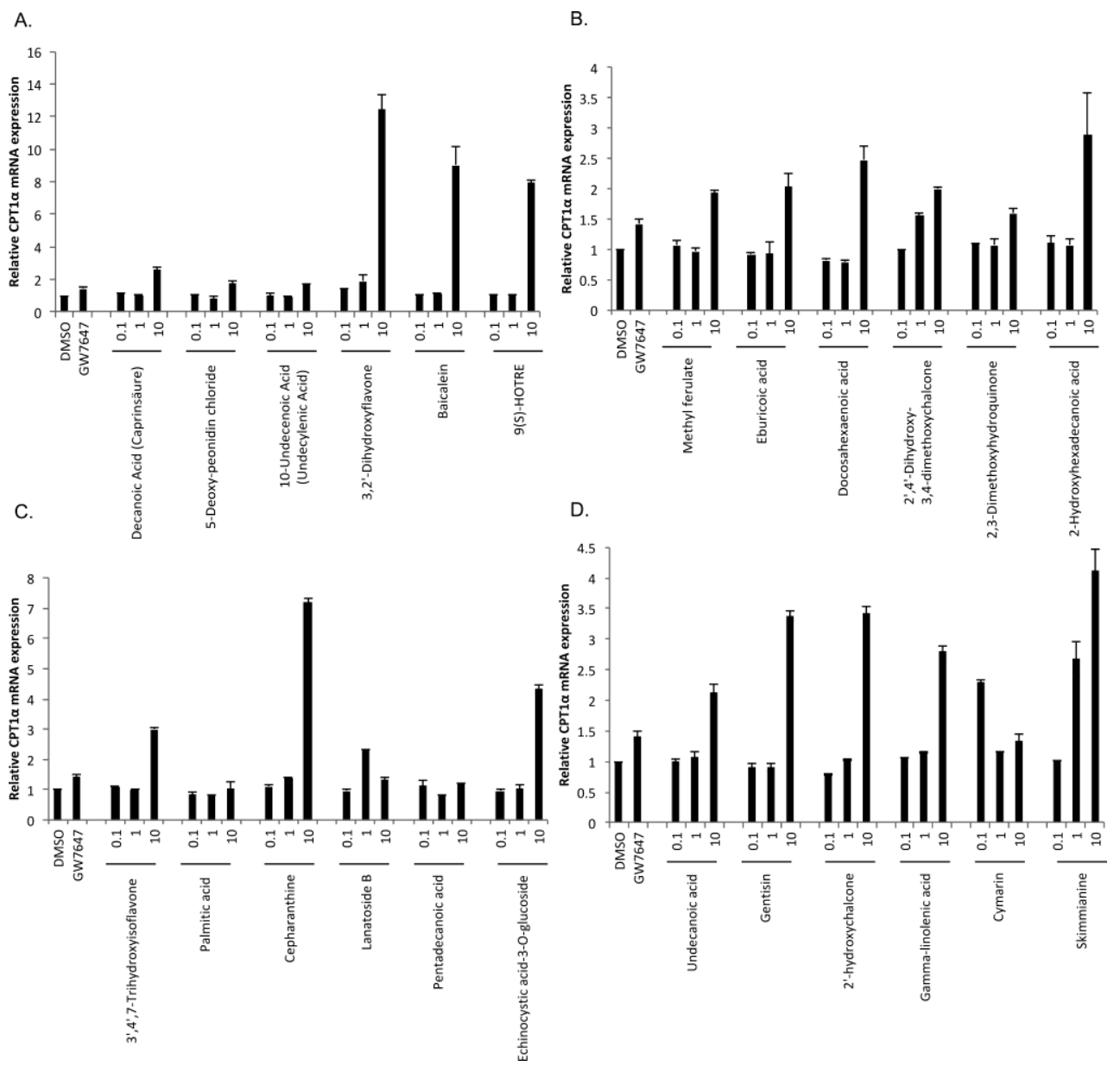

Supplemental figure S2. Relative CPT1a mRNA expression in HepG2 cells treated with three different doses $(0.1 ; 1 ; 10 \mu \mathrm{g} / \mathrm{ml})$ of PPAR $\alpha$ transactivating compounds. 


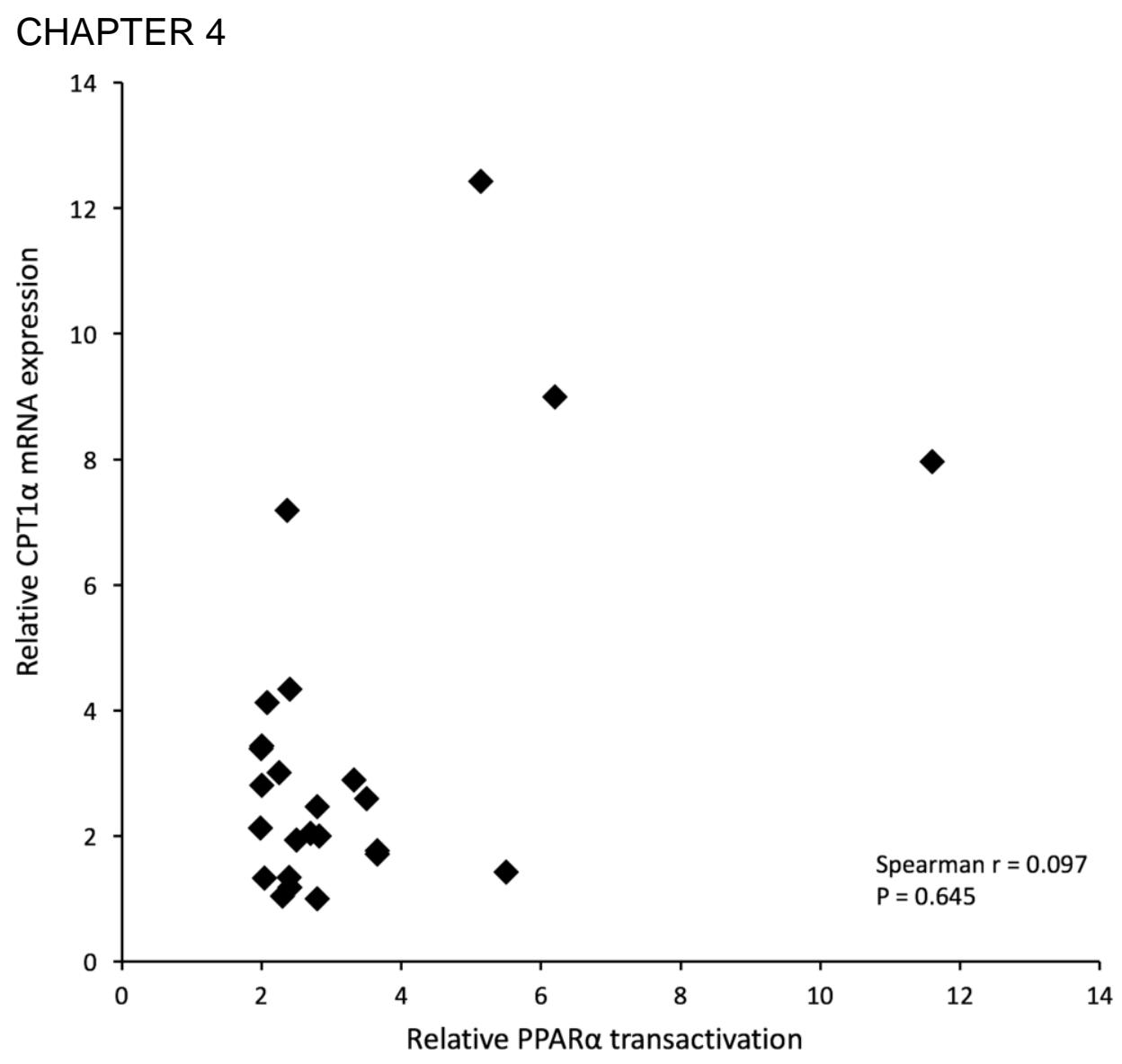

Supplemental figure S3. Spearman correlation of PPAR a transactivation related to CPT1 $a$ mRNA expression of all compounds tested. 


\section{NATURAL PPARa TRANSACTIVATING COMPOUNDS}
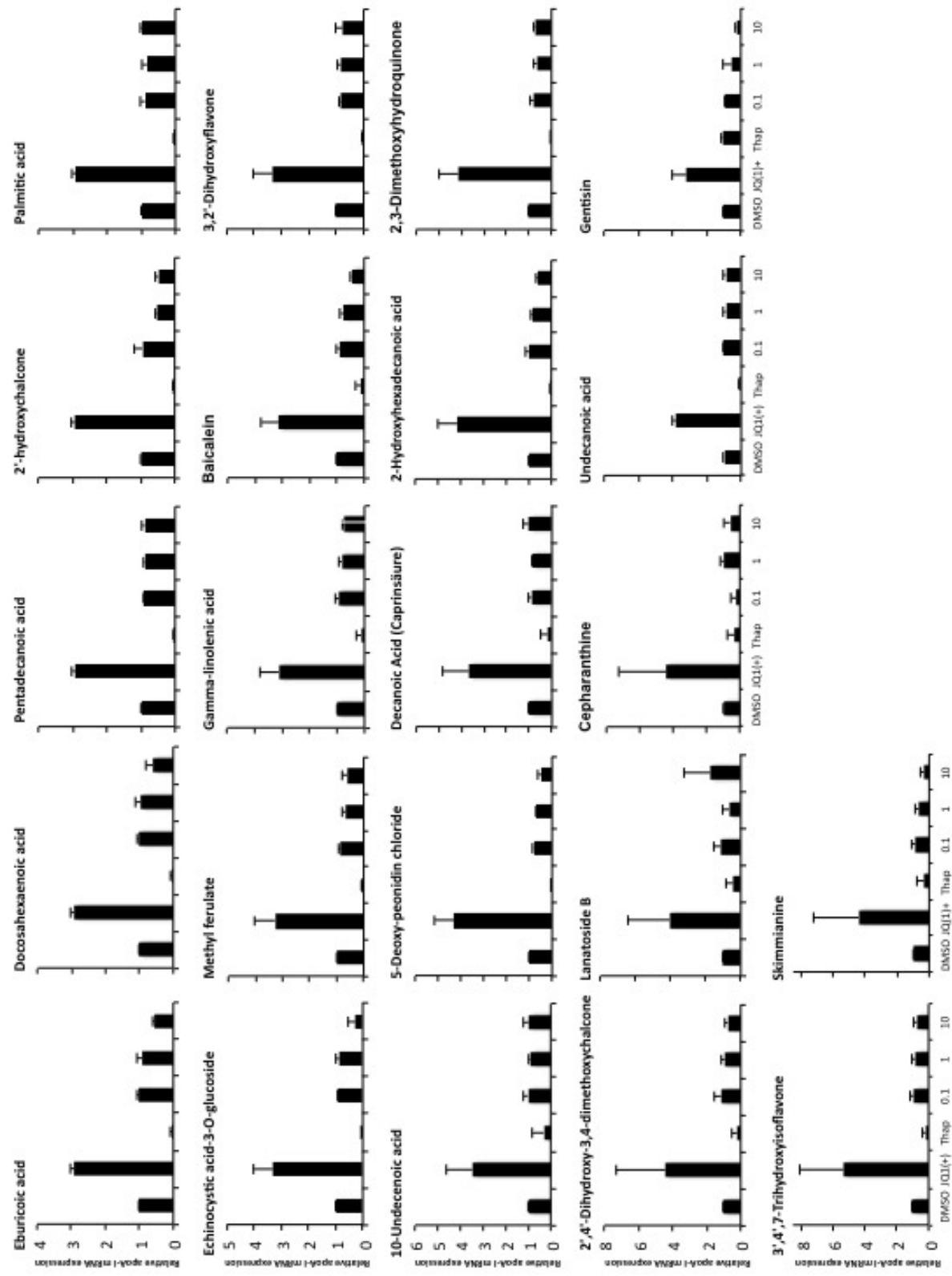

Supplemental figure S4. Relative apoA-I mRNA expression in HepG2 cells treated with three different doses $(0.1 ; 1 ; 10 \mu \mathrm{g} / \mathrm{ml})$ of each selected PPAR $\alpha$ transactivating compounds. 
CHAPTER 4 


\section{CHAPTER 5}

\section{Link between ER-stress, PPARa activation and BET inhibition in relation to apolipoprotein A-I transcription in HepG2 cells}

Sophie E. van der Krieken, Herman E. Popeijus, Ronald P. Mensink and Jogchum Plat

J. Cell. Biochem. 2016 dec 21. DOI:10.1002/jcb.25858 


\title{
CHAPTER 5
}

\begin{abstract}
Increasing apolipoprotein A-I (apoA-I) production is a promising strategy for enhancing reverse cholesterol transport. Activating transcription factor peroxisome proliferator-activated receptor alpha (PPARa) may increase apoA-I transcription. Furthermore, Bromodomain and Extra-Terminal domain (BET) protein inhibitors increase, whereas Endoplasmic Reticulum (ER) stress decreases apoA-I transcription. We examined possible interrelationships between these processes as related to apoA-I transcription in HepG2 cells. JQ1(+), thapsigargin and GW7647 were used to induce respectively BET inhibition, ER-stress and PPAR a activation. Expression of ER-stress markers (CHOP, XBP1s) was analyzed by western blotting. PPARa, KEAP1 (marker for BET inhibition) and apoA-I mRNAs were measured using qPCR. ER-stress and BET inhibition both decreased PPARa mRNA expression and activity, but did not interfere with each other, as ER-stress did not change KEAP1 and JQ1(+) did not influence ER-stress marker production. Interestingly, PPARa activation and BET-inhibition diminished ER-stress marker production and rescued apoA-I transcription during existing ER-stress. We conclude that ER-stress mediated reduction in apoA-I transcription could be partly mediated via the inhibition of PPAR $\alpha$ mRA expression and activity. In addition, BET inhibition increased apoA-I concentrations, even if PPARa production and activity were decreased. Finally, both BET inhibition and PPAR a activation ameliorate the apoA-I lowering effect of ER-stress and are therefore interesting targets to elevate apoA-I transcription.
\end{abstract}




\section{ER-STRESS, PPARa ACTIVATION AND BET INHIBITION}

\section{Introduction}

Despite the consistent finding that elevated plasma high-density lipoprotein cholesterol (HDL-c) concentrations are associated with a lower risk for atherosclerosis, recent intervention trials have questioned a causal relationship between HDL-c and cardiovascular diseases (CVDs) [1]. Therefore, not increasing HDL-C concentrations, but improving HDL functionality is the current target to reduce CVD risk [1]. A frequently used method to measure $H D L$ functionality is the capacity of HDL to accept cholesterol from cholesterol-loaded macrophages, i.e. cholesterol-efflux capacity [2]. Recent evidence has indeed suggested that an increased cholesterol-efflux capacity protects against CVD [3] and recurrent cardiovascular events [4].

Next to its anti-inflammatory, anti-oxidative, anti-coagulant and glucose-lowering properties [1], apolipoprotein A-I (apoA-I), the main protein in the HDL particle, is a key factor in the process of cholesterol efflux, since it is the ligand for human ATPbinding cassette $(A B C)$ transporter mediated efflux. Recently, Tricoci et al. have shown that infusion with the apoA-I mimetic CSL112 in subjects with stable atherosclerosis increased total cholesterol efflux capacity by 3-fold as compared to placebo [5]. This illustrates that increasing apoA-I synthesis is an interesting target for the prevention of CVD, and emphasizes the need to discover factors that influence apoA-I production.

It is generally accepted that activation of the transcription factor peroxisome proliferator-activated receptor alpha (PPARa) is involved in elevating apoA-I transcription [6]. On the other hand, several factors related to the metabolic syndrome, such as endoplasmic reticulum (ER) stress and inflammation, are known to lower apoA-I production and cholesterol efflux to apoA-I $[7,8]$. However, varying results are reported for apoA-I mRNA expression after the induction of ERstress, as in one study apoA-I mRNA expression decreased [8] whereas in the other study it increased [7]. In the in vivo situation an increased blood glucose level or increased inflammation are typical features of the metabolic syndrome, and have been shown to increase ER-stress. During ER-stress, proteins accumulate in the ER, thereby activating the Unfolded Protein Response UPR [9]. The UPR may either lead to cell rescue or to apoptosis. In humans, prolonged ER-stress was linked to the onset of diabetes due to damage of the pancreatic beta-cells [10]. Moreover, studies have demonstrated that Bromodomain and Extra-Terminal domain (BET) protein inhibitors such as RVX-208 and JQ1(+) increase the transcription and production of apoA-I $[11,12]$. In humans, the BET protein family consists of four members: BRD2, BRD3, BRD4 and the testes specific BRDT [13]. The relationship between BET proteins and apoA-I concentrations seems to be restricted to BRD4, since silencing of BRD4 increased apoA-I production, whereas BRD2 and BRD3 silencing did not[14]. Binding of RVX208 and JQ1(+) to BRD4 has been confirmed by the presence of crystal structures of these compounds bound to BRD4 [15-17]. Recently, it was also shown that knockdown of BRD4 resulted in decreased KEAP1 protein production, while KEAP1 mRNA expression was decreased upon treatment with the known BET inhibitor JQ1(+) [18]. This indicates that KEAP1 is a target for BRD4 inhibition.

It is not known whether these regulatory factors (PPAR a activation, ER-stress and BET inhibition) operate independently or interfere with each other. A possible link between ER-stress and BET inhibition might exist, as the expression of genes 


\section{CHAPTER 5}

involved in the ER-stress related unfolded protein response (UPR) response, such as $\mathrm{CHOP}, \mathrm{XBP} 1 \mathrm{~s}$ and ATF3 was reduced upon treatment with the bromodomain inhibitor JQ1 [19]. Interestingly, XBP1s, which is one of the main players of the ERstress response was linked to PPARa [20]. However, if ER-stress also affects BET inhibition and whether the regulatory factors between PPARa, ER-stress and BET inhibition overlap is unknown. Therefore, the main focus of the experiments described was to examine interrelationships between PPARa activation, ER-stress and BET inhibition, in relation to apoA-I transcription in HepG2 cells (figure 1).

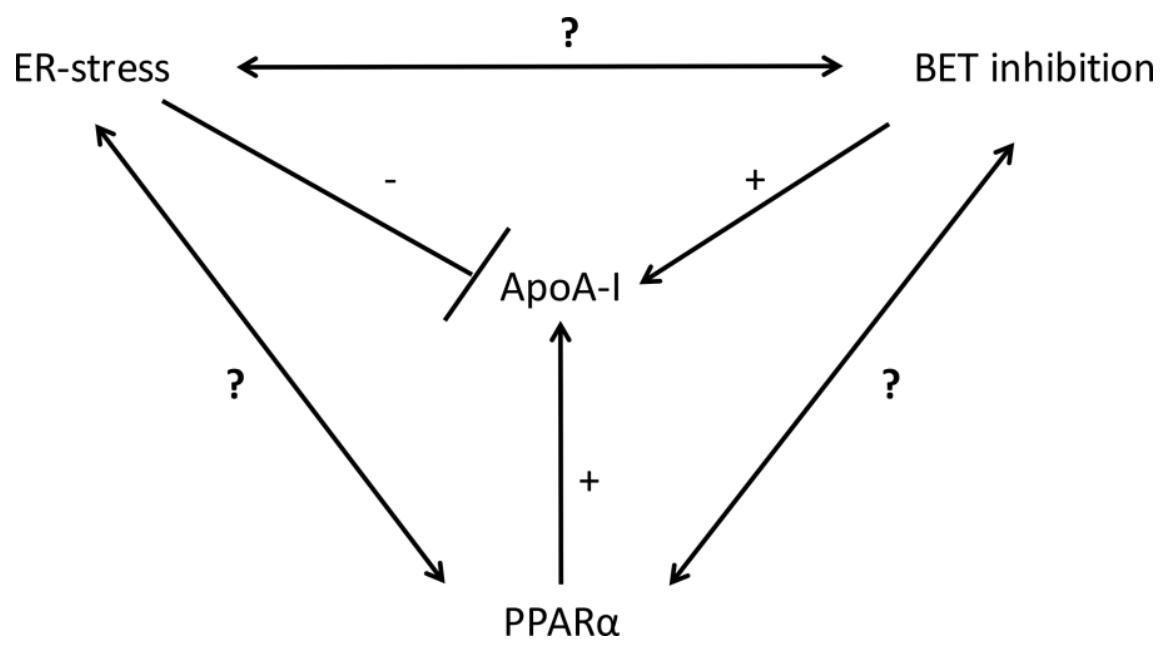

Figure 1. Schematic representation of the research questions. The lines in the middle represent apoA-I responses (+ positive or - negative) in HepG2 cells, which are already known from the literature. Activation of PPARa and inhibition of BET increase apoA-I production, whereas ER-stress decreases apoA-I production. The lines with the question marks are unknown relationships and relate to the research questions of our current experiments.

\section{Methods}

Reagents

To activate PPARa, GW7647 (100nM final concentration, Sigma Aldrich, St. Louis, $\mathrm{MO}$, USA) was used. ER-stress was induced by thapsigargin $(0.01 \mu \mathrm{M}$ final concentration, Sigma Aldrich, St. Louis, MO, USA) and BET was inhibited by JQ1(+) ( $3 \mu \mathrm{M}$ final concentration Tocris Bioscience, Abingdon, UK). All compounds were first dissolved in DMSO, before adding it to the medium. Medium supplemented with DMSO was used as negative control. 


\section{ER-STRESS, PPARa ACTIVATION AND BET INHIBITION}

Human hepatocellular liver carcinoma cell culture

Human hepatocellular liver carcinoma (HepG2) cells (kindly provided by Sten Braesch-Andersen, PhD, Mabtech, Nacka Strand, Sweden) were cultured in Minimum Essential Medium (MEM) containing L-glutamine (Invitrogen Life Technologies, Carlsbad, CA, USA), 10\% FCS (v/v, (FCS; South-American, Greiner Bio-one, Frickenhausen, Germany), 1\% NEAA (v/v), 1\% penicillin/streptomycin $(\mathrm{v} / \mathrm{v})$ and $1 \%$ sodium pyruvate ( $\mathrm{v} / \mathrm{v}$, all from Invitrogen Life Technologies, Carlsbad, CA, USA). Cells were maintained at $37^{\circ} \mathrm{C}$ in a humid atmosphere with $5 \% \mathrm{CO}_{2}$.

For each experiment, HepG2 cells were seeded in 24 well plates $\left(2 \times 10^{5}\right.$ cells per well) in MEM containing 10\% FBS, $1 \%$ NEAA and $1 \%$ penicillin/streptomycin. Two days after plating, the medium was replaced by MEM containing 1\% NEAA, $1 \%$ penicillin/streptomycin plus the compounds to be tested. After 48 hours of incubation, culture medium and cell lysate was collected.

Harvesting of HepG2 cells and bicinchoninic acid assay (BCA) protein quantification

Before harvesting, cells viability was ascertained by visual inspection using a microscope. Medium was collected and snap frozen for further analysis. HepG2 cells were washed twice with PBS and subsequently lysed using TRIzol $B$ (ThermoFisher, Bleiswijk, The Netherlands) for RNA isolation or for 20 minutes on

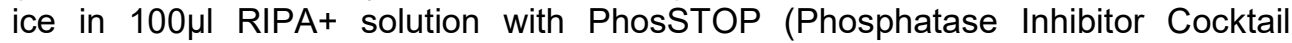
Tablets and Complete, Mini Protease inhibitor Cocktail Tablets, Roche). Total amount of protein was determined using the Pierce BCA assay kit according to the manufacturers' protocol (Pierce ${ }^{\circledR}$ BCA Protein Assay Kit).

\section{Western blotting}

To monitor changes in the synthesis of the markers for ER-stress, XBP1s and

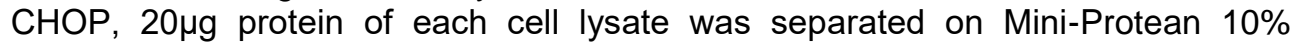
Precast gels and blotted on a nitrocellulose membrane using the Trans- Blot Turbo system (Biorad, Veenendaal, The Netherlands). Equal protein loading was checked using PonceauS staining after which the membranes were blocked with $5 \%$ non-fat dry milk solution in tris buffer saline containing $0.1 \%$ tween (TBS-T). Membranes were then probed with the primary antibody overnight at $4^{\circ} \mathrm{C}$. Blots were then washed with TBS-T and incubated for 4 hours at $4^{\circ} \mathrm{C}$ with the secondary antibody. After washing with TBS-T, proteins were visualized using the ChemiDocXRS imaging system (Biorad), with the SuperSignal West FEMTO kit from Pierce. The antibodies to XBP1s (\#647501, mouse) and CHOP (\#1649, mouse) were obtained from Biolegend and Cell Signaling respectively and the secondary antibody used was goat- anti-mouse from Pierce.

qPCR measurements

Following RNA extraction and CDNA production, the internal control Cyclophilin A (Hs99999904_m1), ApoA-I (Hs00163641_m1), KEAP1 (Hs00202227_m1) and PPARa (Hs00231882_m1) mRNA expression was determined using the 7300 Real-Time PCR System. All TaqMan Gene Expression Assays were purchased 


\section{CHAPTER 5}

from Aplied Biosystems. KEAP1 was measured as a marker for BET inhibition, since it is a transcriptional target of BET, and KEAP1 production is decreased after BET knockdown [18]. PPARa was measured as a marker for PPARa activation.

\section{PPAR transactivation}

Following the methods described by Popeijus et al. [21], PPARa transactivation was measured using a luciferase reporter PGL3 construct containing three PPRE elements [22]. The empty pGL3 luciferase reporter, which lacks the PPRE elements, was used as negative control. After treatment with luciferase lysis buffer (Promega Corporaton, Madison, Wisconsin, USA), PPARa transcriptional activity was measured using luciferase assay substrate (Promega Corporaton, Madison, Wisconsin, USA) using a luminometer (Gomex, 96 microplate luminometer, Promega Corporaton, Madison, Wisconsin, USA), according to the user manual.

\section{Results}

The effect of BET-inhibition, ER-stress and PPARa activation on apoA-I mRNA expression

48 hour treatment with $\mathrm{JQ1}(+)$ to induce BET inhibition doubled apoA-I mRNA expression compared to the control condition in HepG2 cells (figure 2). Likewise, activating PPARa via the addition of GW7647 increased apoA-I mRNA expression by $60 \%$. On the other hand, inducing ER-stress by using thapsigargin clearly lowered apoA-I mRNA expression (figure 2).
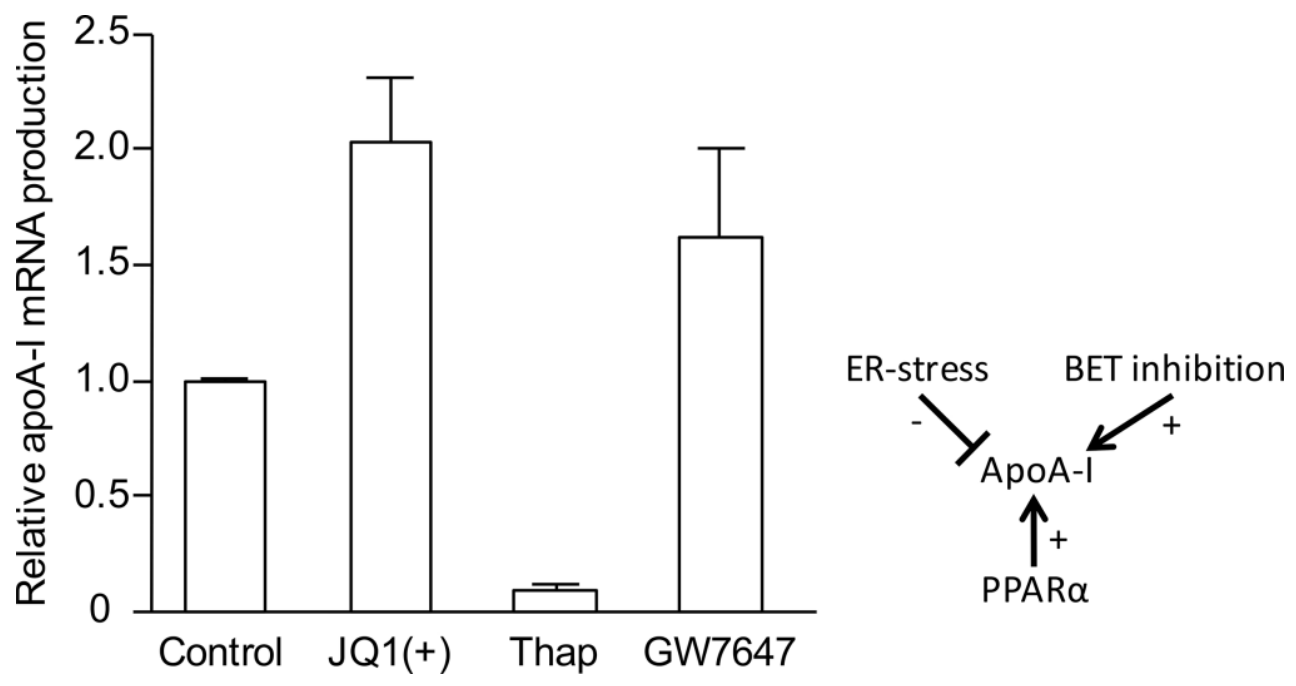

Figure 2. The effect of BET inhibition, ER-stress and PPARa activation on apoA-I mRNA expression in HepG2 cells. HepG2 cells were treated with $3 \mu \mathrm{M}$ JQ1(+) to induce BET inhibition, $0.01 \mu \mathrm{M}$ thapsigargin to induce ER-stress, or with $100 \mathrm{nM}$ 


\section{ER-STRESS, PPARa ACTIVATION AND BET INHIBITION}

GW7647 to activate PPARa, for 48 hours. ApoA-I mRNA expression was measured using qPCR. Each compound was tested in 3 -fold $(\mathrm{N}=3)$ and measurements were performed in duplicate. All results are presented as the mean, while error bars indicate the standard deviation. The arrows on the right indicate the effects as related to the research questions.

The effect of BET-inhibition and ER-stress on PPARa mRNA expression and PPARa transactivation

Addition of GW7647 resulted in a 20\% higher PPARa mRNA expression (figure 3A) and increased PPARa transactivation (figure 3B) compared to control. Interestingly, both the BET inhibitor JQ1(+) and the ER-stress inducer thapsigargin decreased PPARa mRNA expression by approximately 30\% compared to the control condition (figure 3A). Simultaneously, PPARa transactivation was decreased in both BET inhibition and ER-stress conditions (figure 3B).
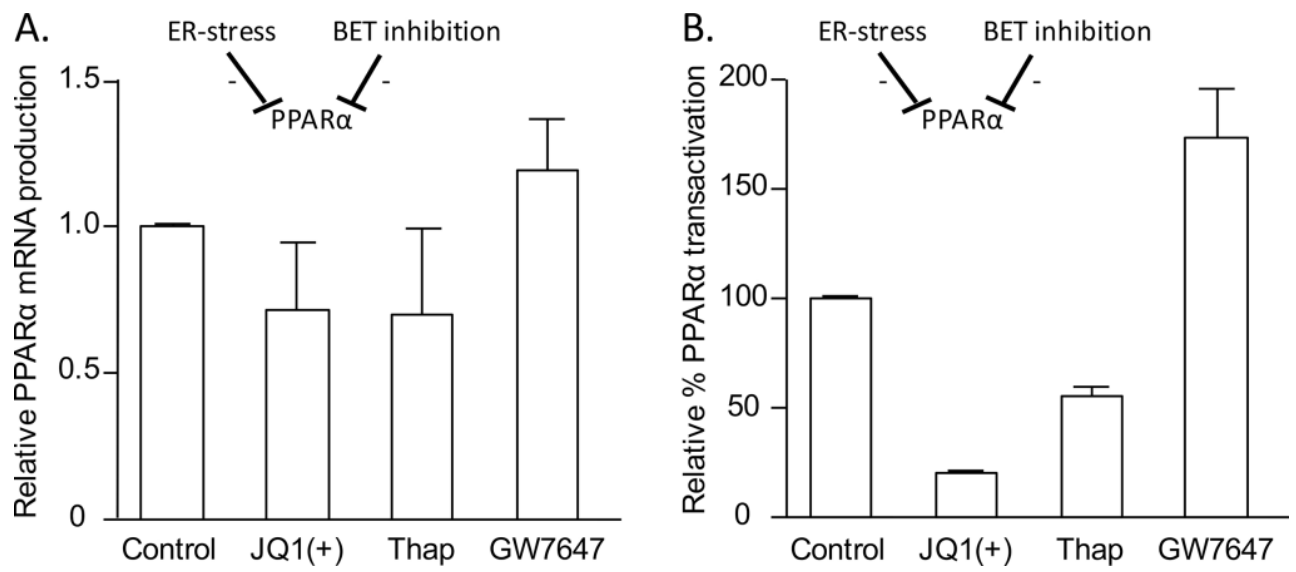

Figure 3. The effect of BET inhibition, ER-stress and PPARa activation on PPARa mRNA expression (A.) and PPARa transactivation (B.). A. Cells were incubated with $3 \mu \mathrm{M} J \mathrm{JQ}(+)$ to induce BET inhibition, or with $0.01 \mu \mathrm{M}$ thap to activate ERstress. 100nM GW7647 was used for PPARa activation. PPARa mRNA expression was measured after 48 hours of incubation. B. HepG2 cells were transfected with a luciferase reporter construct driven by three PPRE elements or with a construct without these PPRE elements. Then, $3 \mu \mathrm{M}$ JQ1(+), $0.01 \mu \mathrm{M}$ thapsigargin or $100 \mathrm{nM}$ GW7647 was added. PPAR $\alpha$ promoter transactivation was expressed in relative light units. Each compound was tested in 3-fold $(\mathrm{N}=3)$ and measurements were performed in duplicate. All results are presented as the mean, while error bars indicate the standard deviation. The arrows on the top of each graph indicate the effects as related to the research questions. 


\section{CHAPTER 5}

The effect of ER-stress and PPARa activation on BET inhibitor target KEAP1

Addition of the known BET inhibitor JQ1(+) lowered KEAP1 mRNA expression (figure 4). KEAP1 was used as a marker for BET inhibition, as KEAP1 was recently shown to decrease upon BET inhibition via JQ1(+) in Human Embryonic Kidney 293 cells [18]. Activation of ER-stress following addition of thapsigargin or activation of PPARa by GW7647 did not influence KEAP1 mRNA expression (figure 4).

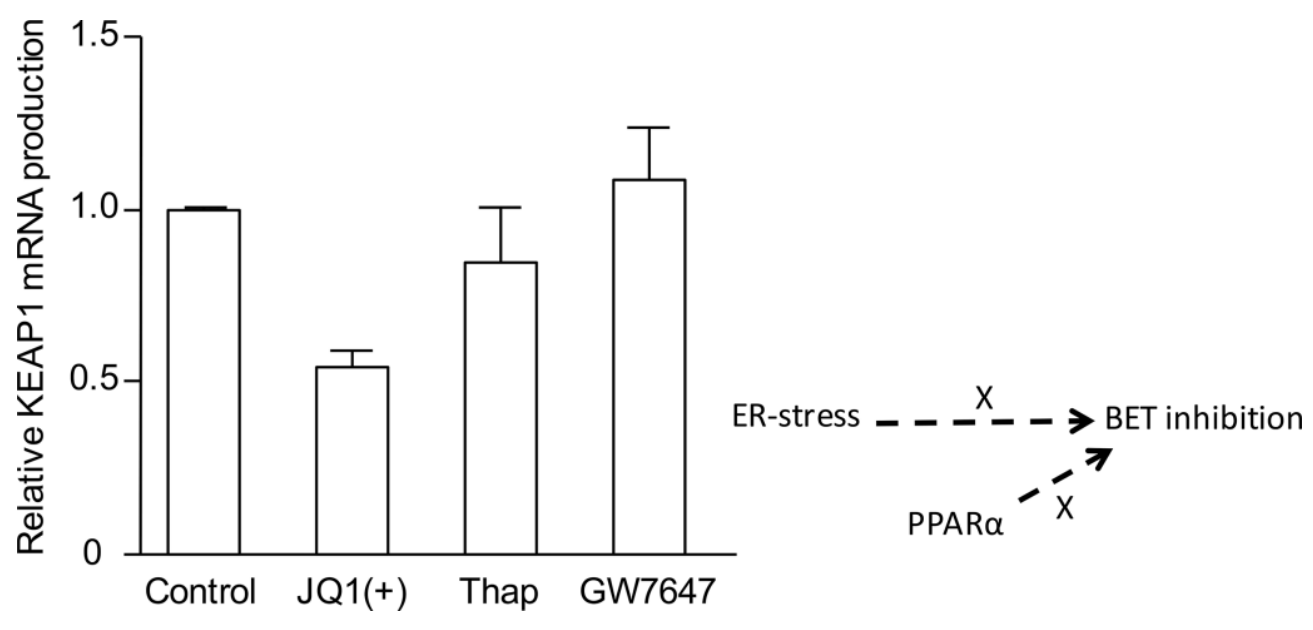

Figure 4. The effect of BET inhibition, ER-stress and PPARa activation on BET inhibition in HepG2 cells. HepG2 cells were incubated with $3 \mu \mathrm{M} J \mathrm{~J} 1\left(^{+}\right)$to induce BET inhibition, 100nM of GW7647 to activate PPARa, or with $0.01 \mu \mathrm{M}$ thapsigargin to activate ER-stress. KEAP1 mRNA expression, which is a marker for BET inhibition, was measured after 48 hours of incubation. Each compound was tested in 3 -fold $(\mathrm{N}=3)$ and measurements were performed in duplicate. All results are presented as the mean, while error bars indicate the standard deviation. The arrows on the right indicate the effects as related to the research questions.

The effect of BET-inhibition and PPARa activation on ER-stress markers CHOP and $X B P 1 s$

48-hour incubation with thapsigargin induced a pronounced ER-stress response in the HepG2 cells (figure 5). BET inhibition using JQ1(+) did not show an ER-stress response, since CHOP and XBP1s protein levels remained unchanged (figure 5). Likewise, PPAR $\alpha$ activation (GW7647) did not show any signs of ER-stress (figure 5). 


\section{ER-STRESS, PPARa ACTIVATION AND BET INHIBITION}
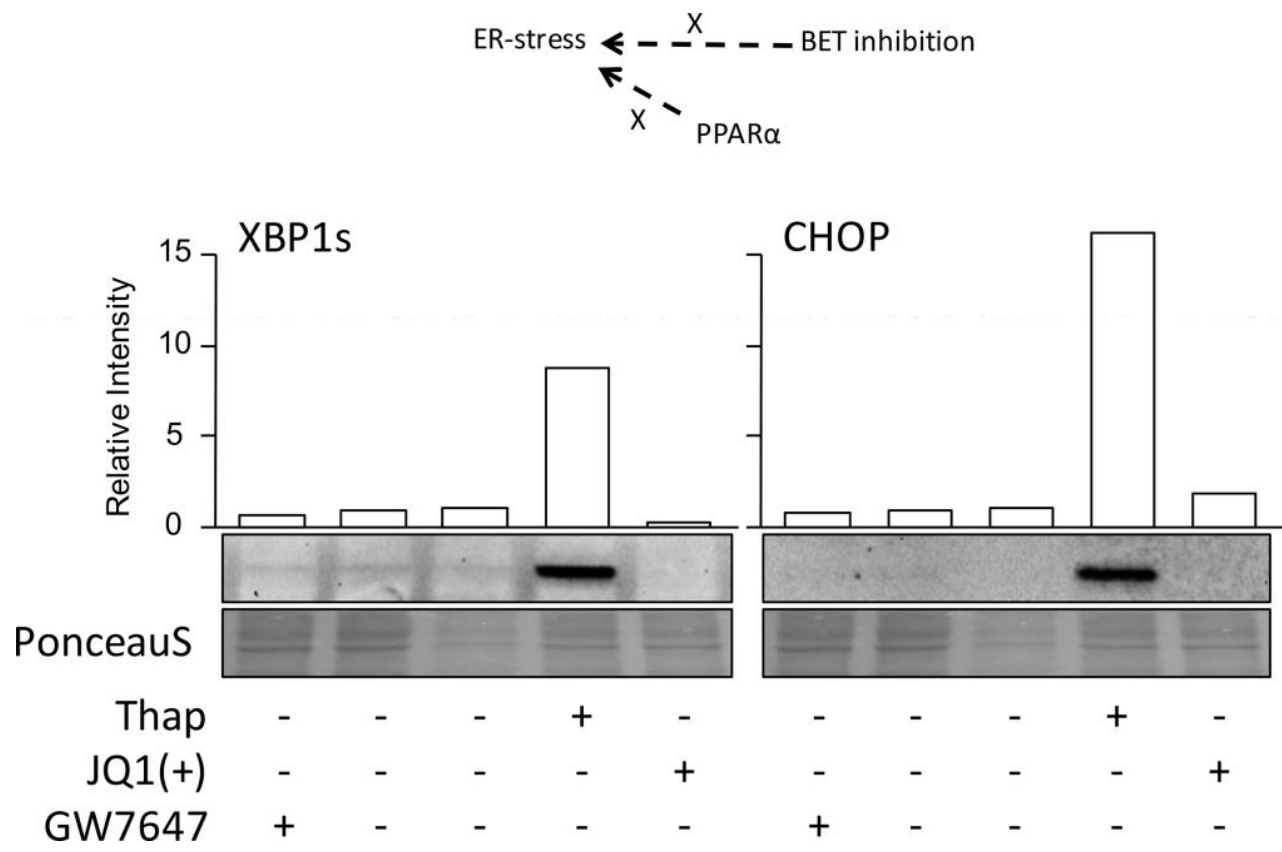

Figure 5. The effect of BET inhibition, ER-stress and PPARa activation on ERstress marker protein expression. HepG2 cells were incubated with $3 \mu \mathrm{M}$ JQ1(+) to induce BET inhibition, 100nM of GW7647 to activate PPARa, or with $0.01 \mu \mathrm{M}$ thapsigargin to activate ER-stress. Using western blotting ER-stress marker protein production of CHOP and XBP1s was assessed. The protein expression was quantified, and the control condition was set to 1. Each compounds was tested in 3 -fold $(\mathrm{N}=3)$ and western blots were performed in 3-fold. The arrows on the right indicate the effects as related to the research questions. 

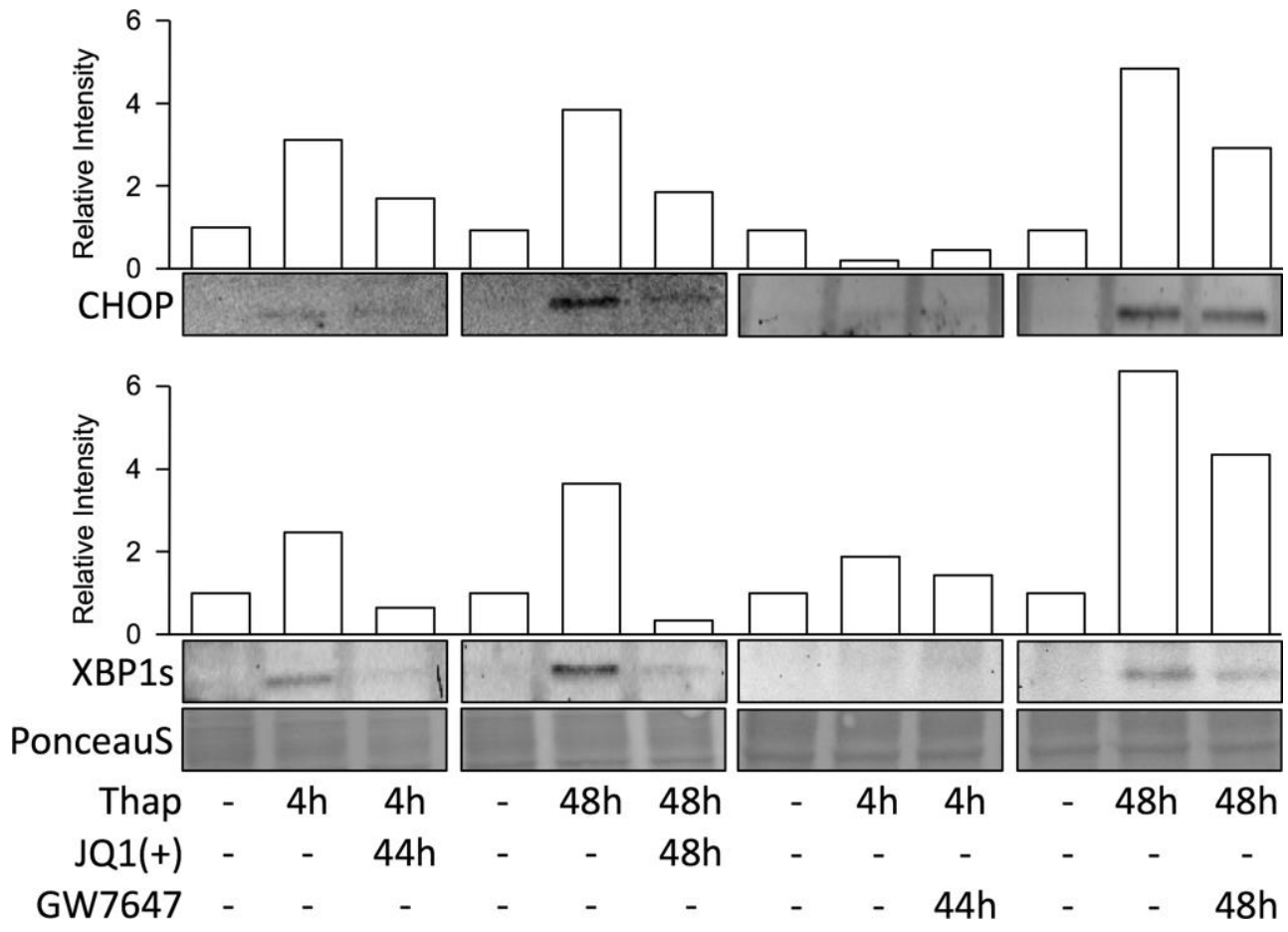

Figure 6. The effect of BET inhibition and PPARa activation on the presence, and the onset of ER-stress in HepG2 cells. Using western blotting ER-stress markers XBP1s and CHOP were detected. The protein expression was quantified, and the control condition was set to 1. ER-stress was induced using thapsigargin for 4 or 48 hours, after which BET inhibitor JQ1(+) or PPARa activator GW7647 were added. In the lower part of the figure the incubation duration of each compound is shown. For thapsigargin, GW7647 and JQ1(+) a suboptimal dosage was used, due to cell death with the combination of the optimal dosages. For thapsigargin a concentration of $0.005 \mu \mathrm{M}$ was used, for JQ1(+) a concentration of $1.5 \mu \mathrm{M}$ and for GW7647 50nM. Each compound was tested in 3-fold $(\mathrm{N}=3)$ and western blots were performed in 3-fold.

Although BET inhibition via JQ1(+) did not affect ER-stress directly (figure 5), JQ1(+) lowered CHOP and XBP1s expression after a four hour pre-incubation period of ER-stress induction (figure 6). Furthermore, when ER-stress and BET inhibition were induced simultaneously for 48 hours, this resulted in a lower ERstress marker protein expression compared to ER-stress alone (figure 6). Similar experiments were performed using GW7647. The effect of PPARa activation after a period of 4 hours of ER-stress and the effect of 48 hours of ER- stress plus BETinhibition were tested. In both situations, GW7647 addition slightly decreased ERstress marker protein production (figure 6). 


\section{ER-STRESS, PPARa ACTIVATION AND BET INHIBITION}

The effect of BET-inhibition and PPARa activation on PPAR $\alpha$ and apoA-I mRNA expression during ER-stress

After 4 hours of ER-stress, the addition of JQ1(+) further decreased the production of PPAR $\alpha$ mRNA (figure S1A), but apoA-I mRNA expression was rescued (figure S1B). To examine if BET inhibition could ameliorate the ER-stress induced decreased apoA-I and PPAR $\mathrm{mRNA}$ expression, HepG2 cells were treated with a combination of thapsigargin and JQ1(+) for 48 hours. Following this treatment, PPARa production increased slightly compared to the ER-stress condition alone. However, PPARa levels were still lower compared to the DMSO control condition (figure S1A). ApoA-I production clearly decreased following 48 hours of ER-stress, but slightly improved in the condition of combined ER-stress and BET-inhibition (figure S1B). Comparable experiments were performed using ER-stress and PPARa activation. After 4 hours of ER-stress, the activation of PPARa by GW7647 did not rescue PPARa mRNA expression (figure S1A). However, apoA-I mRNA expression was slightly increased (figure S1B). Likewise, 48-hour incubation of a combination of ER-stress and PPARa activation did not influence PPARa, but still increased apoA-I mRNA expression (figure $\mathbf{S} 1 \mathrm{~A}+\mathbf{B}$ ). A schematic summary of our findings is depicted in figure 7.

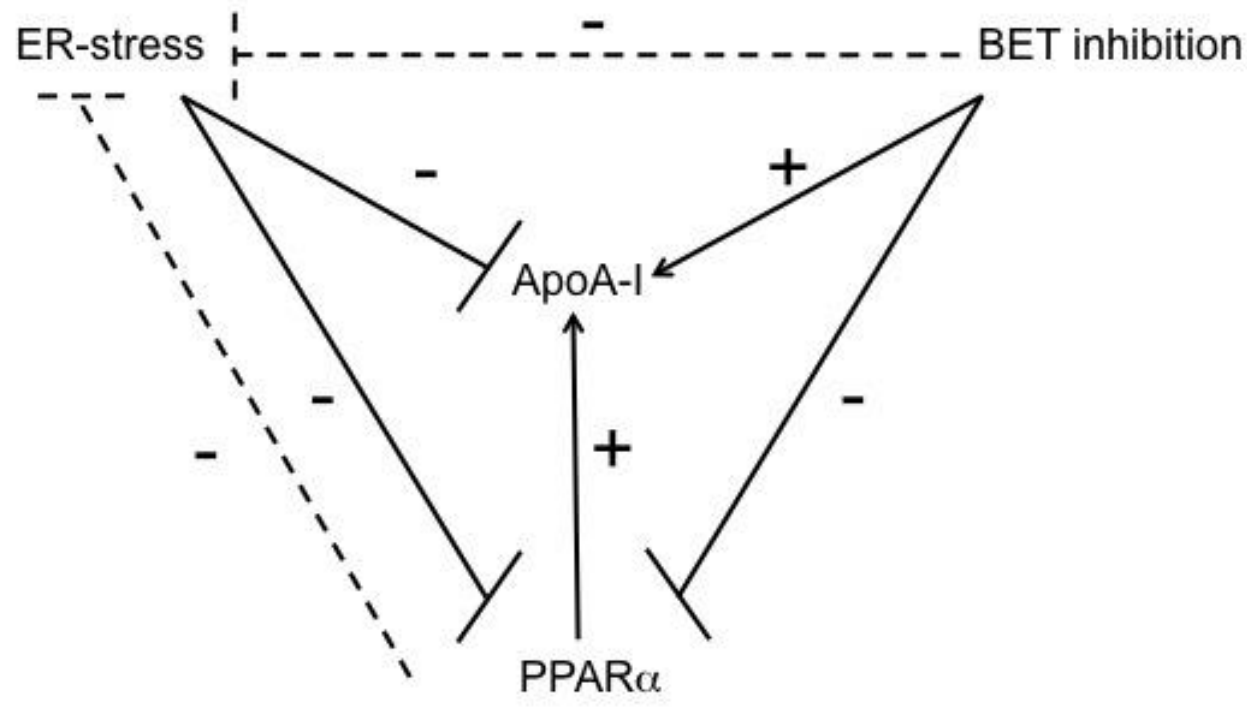

Figure 7. Schematic summary of our findings. In HepG2 cells, possibly the ERstress mediated reduction in apoA-I transcription is partly mediated via the inhibition of PPARa mRNA expression and activity. In addition, BET inhibition increased apoA-I concentrations, even if PPARa mRNA expression and activity were decreased. The dashed lines show the results of the experiments that were performed in a situation of ER-stress. Interestingly, BET inhibition and PPARa activation both decreased the production of ER-stress markers. 


\section{CHAPTER 5}

\section{Discussion}

Increasing endogenous apoA-I production is a promising target for enhancing reverse cholesterol transport and consequently the prevention of CVD [23]. Therefore, there is a clear need to discover pathways that influence apoA-I synthesis. The production of apoA-I is negatively associated with ER-stress [7], but both PPARa activation [6] and BET inhibition increase apoA-I production [12]. Here we have evaluated whether ER-stress, BET inhibition and PPAR $\alpha$ activation are independent processes affecting apoA-I transcription or if these three pathways share overlap. While BET inhibition and ER-stress both lowered PPARa transcription, BET inhibition increased, whereas ER-stress decreased apoA-I production. This suggests that at least a part of the ER-stress induced reduction in apoA-I production is related to a lower PPARa level. However, the finding that BET inhibition lowers PPAR $\alpha$ mRA expression and transactivation, suggests that the corresponding increase in apoA-I concentrations after BET inhibition is PPARa independent. Moreover, it shows that BET inhibition can even overcome the decrease in apoA-I production caused by reduced mRNA expression and transactivation of PPARa, suggesting that BET inhibition is a very potent mechanism.

Except for JQ1(+), also other BET inhibitors, such as the benzodiazepine GW841819X [14], RVX-208 [24] and I-BET726 (GSK1324726A) [25] were found to increase apoA-I promoter activity in HepG2 cells. Furthermore, the triazolodiazepine Ro 11-1464 and its derivatives MDCO-3770 and MDCO-3783, which were recently also identified as BET inhibitors, increased apoA-I protein production in human primary hepatocytes [12]. Benzodiazepine compounds are known modulators of the GABA ( $\gamma$-aminobutyric acid) receptor in the central nervous system and are used for treatment of sleeping disorder, muscle spasms and anxiety [26]. To prevent unfavorable side effects, when examining the use of BET inhibitors in the context of CVD prevention or treatment, the ability of binding to the GABA-receptor is an important feature that should be studied into detail.

BET inhibitors are already used in different conditions and diseases. Compound JQ1(+) for example is used in the field of cancer research, as it exhibits antiproliferative effects in several in vitro cancer malignancies models such as human lung adenocarcinoma cells, human leukaemia stem cells, human and murine mixed lineage leukaemic cell lines, and in vivo in an immunodeficient mice with neuroblastoma [27-30]. In addition, RVX-208 decreased the production of adhesion molecule and cytokine mRNA expression in hyperlipidemic apoE deficient mice [11], suggesting that BET inhibition could improve endothelial function by reducing inflammation. Interestingly, it is known that inflammation and apoA-I concentrations are inversely associated [31], which makes it tempting to suggest that BET inhibition could also increase apoA-I production via a decrease in inflammation.

The exact mechanism by which BET inhibitors increase endogenous apoA-I production is not known. Recently, Kokkola et al. have shown that SIRT1 is activated by BET inhibition via JQ1 [32]. This might point towards a role for SIRT1 in increased apoA-I production caused by BET inhibition. Although the direct involvement of SIRT-1 activation on apoA-I production needs to be determined, apoA-I-mediated cholesterol efflux was decreased in SIRT1 knockout mice [33]. Increased levels of SIRT-1 are also linked to attenuated ER-stress [34,35], as SIRT-1 overexpression in LDL knockout mice decreased UPR related protein 


\section{ER-STRESS, PPARa ACTIVATION AND BET INHIBITION}

production [36]. Furthermore, another BET inhibitor RVX-208, which is a derivative of the known SIRT-1 activator resveratrol (3,4',5-trihydroxy-transstilbene) [37,38], increased apoA-I production in vitro in primary human hepatocytes [12] and in HepG2 cells, and in vivo in cynomolgus monkeys and humans [24].

Our experiments demonstrated that BET inhibition did not induce ER-stress and ER-stress did not induce BET inhibition. However, an already existing ER-stress signature was clearly decreased by BET inhibition. These findings are in line with the results of Hart et al. [19], who also showed that expression of proteins from the ER-stress pathway including CHOP, XBP1s and ATF3, were reduced upon treatment with the bromodomain inhibitor JQ1. Several metabolic conditions, including hyperlipidemia, inflammation and hyperglycemia are known to disrupt normal protein folding in the ER, leading to ER-stress [39]. In HepG2 cells, thapsigargin induced ER-stress resulted in a decreased apoA-I production [7]. Therefore, our finding that BET inhibition lowers the existing ER-stress response makes BET inhibitors even more interesting in the context of apoA-I production [7]. Next to the effect of BET inhibition in a situation of ER-stress, we also determined if PPAR $\alpha$ activation via GW7647 addition could rescue HepG2 cells from ER-stress. According to Su et al. [40], PPARa knockout mice express higher CHOP mRNA levels compared to wild type mice, and restoration of PPARa activity could relieve ER-stress by decreasing CHOP. In support, our results showed that GW7647 slightly reduced ER-stress marker protein production in a situation where ER-stress was induced beforehand. This suggests that PPARa activation can attenuate an existing ER-stress phenotype and thereby could rescue the ER-stress related decreased production of apoA-I in HepG2 cells. Although GW7647 is a very potent PPARa inducer [41], the effect of GW7647 in the luciferase assay was less pronounced. These findings are in line with earlier observations of Popeijus et al. [21], who showed that compounds like $C 20: 5(n-3)$ or $C 22: 6(n-3))$ which are known PPARa binders, did not necessarily increase, but could even repress PPARa transactivation.

To conclude, we here show that the ER-stress mediated reduction on apoA-I transcription is mediated via the inhibition of PPARa production and transactivation. In addition, BET inhibition increased apoA-I transcription, even if PPARa production and activity were decreased. Finally, BET inhibition as well as PPARa activation ameliorate the apoA-I lowering effects of ER-stress. This underscores the importance of BET inhibition and PPARa activation as targets to elevate apoA-I transcription.

\section{Acknowledgements}

This research was supported by the Dutch Technology Foundation STW, which is part of the Netherlands Organization for Scientific Research (NWO), and which is partly funded by the Ministry of Economic Affairs. 


\section{CHAPTER 5}

\section{References}

1. Kingwell BA, Chapman MJ, Kontush A, Miller NE (2014) HDL-targeted therapies: progress, failures and future. Nat Rev Drug Discov 13: 445-464.

2. Borja MS, Ng KF, Irwin A, Hong J, Wu X, et al. (2015) HDL-apolipoprotein A-I exchange is independently associated with cholesterol efflux capacity. J Lipid Res 56: 2002-2009.

3. Rohatgi A, Khera A, Berry JD, Givens EG, Ayers CR, et al. (2014) HDL cholesterol efflux capacity and incident cardiovascular events. N Engl J Med 371: 2383-2393.

4. Ishikawa T, Ayaori M, Uto-Kondo H, Nakajima T, Mutoh M, et al. (2015) High-density lipoprotein cholesterol efflux capacity as a relevant predictor of atherosclerotic coronary disease. Atherosclerosis 242: 318-322.

5. Tricoci P, D'Andrea DM, Gurbel PA, Yao Z, Cuchel M, et al. (2015) Infusion of Reconstituted HighDensity Lipoprotein, CSL112, in Patients With Atherosclerosis: Safety and Pharmacokinetic Results From a Phase 2a Randomized Clinical Trial. J Am Heart Assoc 4: e002171.

6. Duez H, Lefebvre B, Poulain P, Torra IP, Percevault F, et al. (2005) Regulation of human apoA-I by gemfibrozil and fenofibrate through selective peroxisome proliferator-activated receptor alpha modulation. Arterioscler Thromb Vasc Biol 25: 585-591.

7. Naem E, Haas MJ, Wong NC, Mooradian AD (2013) Endoplasmic reticulum stress in HepG2 cells inhibits apolipoprotein A-I secretion. Life Sci 92: 72-80.

8. Rohrl C, Eigner K, Winter K, Korbelius M, Obrowsky S, et al. (2014) Endoplasmic reticulum stress impairs cholesterol efflux and synthesis in hepatic cells. J Lipid Res 55: 94-103.

9. Kim I, Xu W, Reed JC (2008) Cell death and endoplasmic reticulum stress: disease relevance and therapeutic opportunities. Nat Rev Drug Discov 7: 1013-1030.

10. Fonseca SG, Gromada J, Urano F (2011) Endoplasmic reticulum stress and pancreatic beta-cell death. Trends Endocrinol Metab 22: 266-274.

11. Jahagirdar R, Zhang H, Azhar S, Tobin J, Attwell S, et al. (2014) A novel BET bromodomain inhibitor, RVX-208, shows reduction of atherosclerosis in hyperlipidemic ApoE deficient mice. Atherosclerosis 236: 91-100.

12. Kempen HJ, Bellus D, Fedorov O, Nicklisch S, Filippakopoulos P, et al. (2013) Stimulation of Hepatic Apolipoprotein A-I Production by Novel Thieno-Triazolodiazepines: Roles of the Classical Benzodiazepine Receptor, PAF Receptor, and Bromodomain Binding. Lipid Insights 6: 47-54.

13. Gallenkamp D, Gelato KA, Haendler B, Weinmann H (2014) Bromodomains and their pharmacological inhibitors. ChemMedChem 9: 438-464.

14. Chung CW, Coste H, White JH, Mirguet O, Wilde J, et al. (2011) Discovery and characterization of small molecule inhibitors of the BET family bromodomains. J Med Chem 54: 3827-3838.

15. McLure KG, Gesner EM, Tsujikawa L, Kharenko OA, Attwell S, et al. (2013) RVX-208, an inducer of ApoA-I in humans, is a BET bromodomain antagonist. PLoS One 8: e83190.

16. Filippakopoulos P, Qi J, Picaud S, Shen Y, Smith WB, et al. (2010) Selective inhibition of BET bromodomains. Nature 468: 1067-1073.

17. Jung M, Philpott M, Muller S, Schulze J, Badock V, et al. (2014) Affinity map of bromodomain protein 4 (BRD4) interactions with the histone $\mathrm{H} 4$ tail and the small molecule inhibitor JQ1. J Biol Chem 289: 9304-9319.

18. Hussong M, Borno ST, Kerick M, Wunderlich A, Franz A, et al. (2014) The bromodomain protein BRD4 regulates the KEAP1/NRF2-dependent oxidative stress response. Cell Death Dis 5: e1195. 


\section{ER-STRESS, PPARa ACTIVATION AND BET INHIBITION}

19. Hart LS, Cunningham JT, Datta T, Dey S, Tameire F, et al. (2012) ER stress-mediated autophagy promotes Myc-dependent transformation and tumor growth. J Clin Invest 122: 4621-4634.

20. Shao M, Shan B, Liu Y, Deng Y, Yan C, et al. (2014) Hepatic IRE1alpha regulates fasting-induced metabolic adaptive programs through the XBP1s-PPARalpha axis signalling. Nat Commun 5: 3528.

21. Popeijus HE, van Otterdijk SD, van der Krieken SE, Konings M, Serbonij K, et al. (2014) Fatty acid chain length and saturation influences PPARalpha transcriptional activation and repression in HepG2 cells. Mol Nutr Food Res 58: 2342-2349.

22. Gilde AJ, van der Lee KA, Willemsen PH, Chinetti G, van der Leij FR, et al. (2003) Peroxisome proliferator-activated receptor (PPAR) alpha and PPARbeta/delta, but not PPARgamma, modulate the expression of genes involved in cardiac lipid metabolism. Circ Res 92: 518-524.

23. Gadkar K, Lu J, Sahasranaman S, Davis J, Mazer N, et al. (2015) Evaluation of HDL modulating interventions for cardiovascular risk reduction using a systems pharmacology approach. $\mathrm{J}$ Lipid Res.

24. Bailey D, Jahagirdar R, Gordon A, Hafiane A, Campbell S, et al. (2010) RVX-208: a small molecule that increases apolipoprotein A-I and high-density lipoprotein cholesterol in vitro and in vivo. J Am Coll Cardiol 55: 2580-2589.

25. Gosmini R, Nguyen VL, Toum J, Simon C, Brusq JM, et al. (2014) The discovery of I-BET726 (GSK1324726A), a potent tetrahydroquinoline ApoA1 up-regulator and selective BET bromodomain inhibitor. J Med Chem 57: 8111-8131.

26. Olkkola KT, Ahonen J (2008) Midazolam and other benzodiazepines. Handb Exp Pharmacol: 335360.

27. Lockwood WW, Zejnullahu K, Bradner JE, Varmus H (2012) Sensitivity of human lung adenocarcinoma cell lines to targeted inhibition of BET epigenetic signaling proteins. Proc Natl Acad Sci U S A 109: 19408-19413.

28. Dawson MA, Prinjha RK, Dittmann A, Giotopoulos G, Bantscheff M, et al. (2011) Inhibition of BET recruitment to chromatin as an effective treatment for MLL-fusion leukaemia. Nature 478: 529-533.

29. Delmore JE, Issa GC, Lemieux ME, Rahl PB, Shi J, et al. (2011) BET bromodomain inhibition as a therapeutic strategy to target c-Myc. Cell 146: 904-917.

30. Puissant A, Frumm SM, Alexe G, Bassil CF, Qi J, et al. (2013) Targeting MYCN in neuroblastoma by BET bromodomain inhibition. Cancer Discov 3: 308-323.

31. Ettinger WH, Varma VK, Sorci-Thomas M, Parks JS, Sigmon RC, et al. (1994) Cytokines decrease apolipoprotein accumulation in medium from Hep G2 cells. Arterioscler Thromb 14: 8-13.

32. Kokkola T, Suuronen T, Pesonen M, Filippakopoulos P, Salminen A, et al. (2015) BET Inhibition Upregulates SIRT1 and Alleviates Inflammatory Responses. Chembiochem 16: 1997-2001.

33. Li X, Zhang S, Blander G, Tse JG, Krieger M, et al. (2007) SIRT1 deacetylates and positively regulates the nuclear receptor LXR. Mol Cell 28: 91-106.

34. Jung TW, Lee KT, Lee MW, Ka KH (2012) SIRT1 attenuates palmitate-induced endoplasmic reticulum stress and insulin resistance in HepG2 cells via induction of oxygen-regulated protein 150. Biochem Biophys Res Commun 422: 229-232.

35. Ghosh HS, Reizis B, Robbins PD (2011) SIRT1 associates with elF2-alpha and regulates the cellular stress response. Sci Rep 1: 150.

36. Li Y, Wong K, Giles A, Jiang J, Lee JW, et al. (2014) Hepatic SIRT1 attenuates hepatic steatosis and controls energy balance in mice by inducing fibroblast growth factor 21. Gastroenterology 146: 539-549 e537. 


\section{CHAPTER 5}

37. Picaud S, Wells C, Felletar I, Brotherton D, Martin S, et al. (2013) RVX-208, an inhibitor of BET transcriptional regulators with selectivity for the second bromodomain. Proc Natl Acad Sci U S A 110: 19754-19759.

38. Cote CD, Rasmussen BA, Duca FA, Zadeh-Tahmasebi M, Baur JA, et al. (2015) Resveratrol activates duodenal Sirt1 to reverse insulin resistance in rats through a neuronal network. Nat Med 21: 498-505.

39. Kaufman RJ (2002) Orchestrating the unfolded protein response in health and disease. J Clin Invest 110: 1389-1398.

40. Su Q, Baker C, Christian P, Naples M, Tong X, et al. (2014) Hepatic mitochondrial and ER stress induced by defective PPARalpha signaling in the pathogenesis of hepatic steatosis. Am J Physiol Endocrinol Metab 306: E1264-1273.

41. Brown PJ, Stuart LW, Hurley KP, Lewis MC, Winegar DA, et al. (2001) Identification of a subtype selective human PPARalpha agonist through parallel-array synthesis. Bioorg Med Chem Lett 11: 1225-1227. 


\section{ER-STRESS, PPARa ACTIVATION AND BET INHIBITION}

\section{Supplemental data}

A

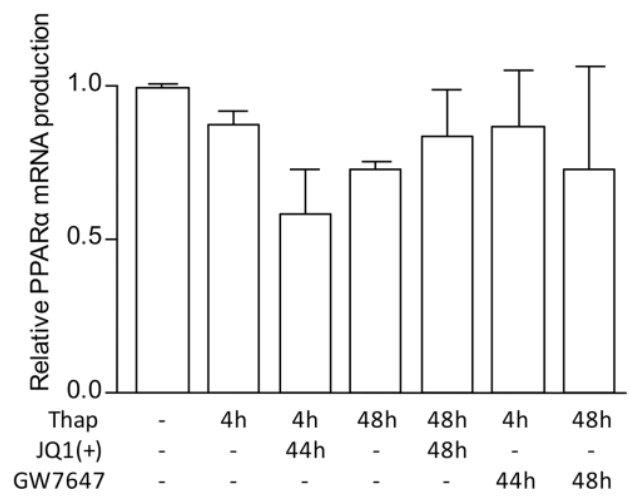

B

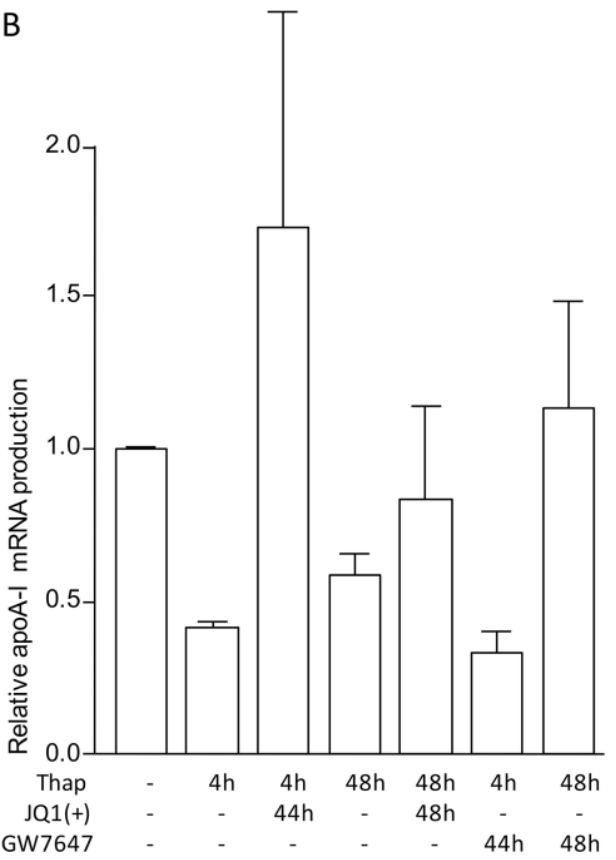

Supplemental figure 1. The effect of BET-inhibition and PPARa activation on PPARa and apoA-I mRNA expression during ER-stress. 
CHAPTER 5 


\section{CHAPTER 6}

Fatty acid chain length and saturation influences PPARa transcriptional activation and repression in HepG2 cells

Herman E. Popeijus, Sanne D. van Otterdijk, Sophie E. van der Krieken, Maurice Konings, Kenrick Serbonij, Jogchum Plat and Ronald P. Mensink

Mol Nutr Food Res. 2014 Dec;58(12):2342-9 


\section{CHAPTER 6}

\section{Abstract}

Fatty acids regulate PPAR a activity, however, most studies evaluated the binding ability of fatty acids to PPAR $\alpha$, which does not necessarily results in PPAR transactivation. We therefore examined dose-response relationships between fatty acids and PPARa transactivation in HepG2 cells. Secretion of apoA-I protein aswell-as CPT1, ACO, and PPARa mRNA expression, all accepted PPARa targets, were determined as read-outs. HepG2 cells transfected with full-length human PPARa and a PPRE luciferase reporter were exposed to different fatty acid concentrations. Lauric and lower doses of myristic acid increased PPAR $\alpha$ transactivation. Palmitic and stearic acid inhibited and their monounsaturated counterparts palmitoleic and oleic acid increased PPARa transactivation. Linoleic and $y$-linolenic acid did not influence PPARa transactivation, while $\alpha$-linolenic acid strongly increased transactivation. Arachidonic, eicosapentaenoic (EPA), and docosahexaenoic (DHA) acid all activated PPARa transactivation at lower doses, but acted at higher concentrations as PPARa repressors. In line with these results, a-linolenic acid increased and DHA decreased apoA-I protein secretion and PPARa mRNA expression. Interestingly, ACO mRNA expression did not change while CPT1 mRNA expression showed the opposite pattern. We conclude that fatty acids, reported to bind to PPARa, could even repress PPARa transactivation though results may vary gene dependently illustrating involvement of multiple regulatory factors. 


\section{FATTY ACIDS AND PPARa ACTIVITY}

\section{Introduction}

Peroxisome proliferator activated receptors (PPARs) are members of the nuclear receptor super family of ligand-activated receptors. Within this super family, they form a group of transcription factors that consist of three isoforms, PPARa, PPAR $\delta$ and PPAR $\gamma$, which are encoded by separate genes and are differentially expressed [1]. All PPAR genes contain six exons that encode for several functional domains. These domains include the $\mathrm{N}$-terminal $\mathrm{A} / \mathrm{B}$ domain, a ligand binding domain (LBD), and a DNA binding domain (DBD) [2]. Upon ligand binding to the LBD, the consequent conformational change in the PPAR modulates its transactivation ability $[3,4]$. The two zinc fingers present in the DBD enable binding of the PPARs to the consensus DNA sequence $(A / G) G G T(C / G / A) A A A G G T C A$, which is called the PPAR response element (PPRE), present in the regulatory domains of PPAR responsive genes [3,4].

PPARa plays an important role in maintaining lipid homeostasis. Therefore, PPARa agonists have received and still receive a lot of attention [5]. PPARa agonists include synthetic compounds like fibrates, but also natural ligands like dietary fatty acids. The effects of fatty acids on PPARa have almost exclusively been studied by using ligand-binding assays [6,7]. From these studies, it can be concluded that polyunsaturated fatty acids (PUFAs) and monounsaturated fatty acids (MUFAs) have a higher binding affinity for PPARs than saturated fatty acids (SAFAs) have $[3,6]$. However, only limited information is available concerning the effects of dietary fatty acids on PPAR-mediated transcriptional activity. Using a luciferase system with GAL4 fused to the LBD of either ratPPARa or ratPPAR $\gamma$, Mochizuki et al. have shown that especially linoleic acid, $\alpha$-linolenic acid, $y$-linolenic acid, arachidonic acid, and eicosapentaenoic acid stimulated ratPPAR-induced transactivation [8]. Less induction was seen for palmitic acid, while oleic acid and docosahexaenoic acid hardly induced any transactivation of the LBD-GAL4 fused construct [9]. However, a Gal4 fusion system is not suitable to investigate the effects of PPAR transactivation on PPREs. In addition, they used only the LBD of ratPPAR fused to the DNA-binding domain of Gal4, which means the PPAR protein lacked a major part of the full length PPAR that might contain other important regulatory parts. Therefore, we investigated the ability of different fatty acids to transactivate human PPARa (hPPARa) by overexpression of the full-length hPPARa. Its transcriptional activity following fatty-acid stimulation was monitored using a luciferase reporter construct driven by three PPRE elements in HepG2 cells, a liver cell-line model. We hypothesized that the effects of fatty acids on PPARa transactivation or repression (a) depend on fatty-acid chain length and saturation; (b) is dose-dependent. In addition, it was hypothesized that binding of a fatty acid to PPARa does not necessarily result in transactivation. To investigate whether the observed PPARa transactivation or repression was functional, we also measured apoA-I protein secretion by HepG2 cells, since apoA-I is a well-known PPARa-regulated protein [10]. Moreover, mRNA expression of three additional PPARa target genes, CPT1, ACO and PPARa itself, were determined as additional read-out. We conclude that fatty acids, reported to bind to PPARa, could even repress PPARa transactivation though results may vary gene dependently illustrating involvement of multiple regulatory factors. 


\section{Methods}

\section{Reagents}

Caprilic acid (C8:0), lauric acid (C12:0), myristic acid (C14:0), palmitic acid (C16:0), palmitoleic acid (C16:1(n-7)), stearic acid (C18:0), oleic acid (C18:1(n-9)), linoleic acid (C18:2(n-6)), arachidonic acid (C20:4(n-6)), eicosapentaenoic acid (EPA, C20:5(n-3)), docosahexaenoic acid (DHA, C22:6(n-3)), a-linolenic acid (C18:3(n3)), $y$-linolenic acid $(C 18: 3(n-6))$ and fenofibric acid (FeAc) and fatty acid free Bovine Serum Albumin (BSA) were purchased from Sigma-Aldrich.

\section{Expression plasmids}

Full length PPARa was PCR amplified from CDNA derived from human embryonal kidney cells (HEK cells) and cloned via topo-TA cloning (Invitrogen Corporation, Paisley, UK) into the Notl/Xbal restriction sides of the pcDNA3.1 vector (Invitrogen Corporation, Paisley, UK) using the forward primer 5'ATGGTGGACACGGAAAGCC-3' and the reverse primer 5'TCAGTACATGTCCCTGTAGATCTCC-3'. The pCDNA3.1(+)-PPARa construct was checked for the proper orientation and sequence verified. PPAR transactivation was determined using a luciferase reporter pGL3 vector containing three PPRE as previously described [11]. The pcDNA3.1 (empty vector) and the empty pGL3 luciferase reporter (without PPRE elements) were used as negative control.

Cell culture, transfections, fatty acid treatment and luciferase assays

Human hepatocellular liver carcinoma cells (HepG2 cells, kindly provided by Sten Braesch-Andersen, PhD, Mabtech, Nacka Strand, Sweden) and human embryonal kidney cells (293T HEK, Invitrogen) were cultured at $37^{\circ} \mathrm{C}$ in a humidified atmosphere of $5 \% \mathrm{CO}_{2}$ in minimal essential medium (MEM) containing $10 \%$ head inactivated Fetal Calf Serum (FCS; South-American, Greiner Bio-one, Frickenhausen, Germany), L-Glutamine, sodium pyruvate, non essential amino acids (NEAA) and penicillin \& streptomycin (Pen/Strep). Minimal Essential Medium (MEM), trypsin, penicillin streptomycin (PS), sodium pyruvate (SP) and nonessential amino acids (NEAA) were obtained from Invitrogen Corporation (Paisley, UK). Three days prior to seeding the cells, the growing medium was replaced by MEM containing 10\% FBS, L-Glutamine, NEAA and Pen/Strep. Cells were allowed to grow to $80 \%$ confluence.

For each experiment, HepG2 cells were seeded in 24 well plates at a density of $2 \times 10^{5}$ cells per well. When the cells reached a density of $40 \%$ ( 24 hours after seeding), they were transfected with the appropriate plasmids using Fugene 6 Transfection Reagent according to the user manual (Roche Diagnostics, Basel, Switzerland). All transfections were performed with an equal amount of $0.2 \mu \mathrm{g}$ DNA by adding the pCDNA3.1 empty vector when necessary. 


\section{FATTY ACIDS AND PPARa ACTIVITY}

Various fatty acids, dissolved in DMSO, were added 6 hours after transfection, in testing medium (Gibco, MEM, Invitrogen) containing NEAA, L-Glutamine and Pen/Strep and BSA $(0.1 \%)$. The cells were incubated for 24 hours. Prior to harvesting, cells were visually inspected using a microscope to ensure cells were viable. No differences were seen in cells treated with fatty acid concentrations up to $175 \mu \mathrm{M}$ when compared to the negative control. Cells treated with fatty acids at a concentration of $200 \mu \mathrm{M}$ started to grow slower and in some cases became apoptotic. To ensure the cells were in proper condition, the highest dose used was restricted to $125 \mu \mathrm{M}$. After 24 hours, cells were lysed in lysis buffer (Promega Corporaton, Madison, Wisconsin, USA) and the medium was directly snap-frozen and stored at $-80{ }^{\circ} \mathrm{C}$ for further analysis. The transcriptional activity was measured using a luminometer (Gomex, 96 microplate luminometer, Promega Corporaton, Madison, Wisconsin, USA) and luciferase assay substrate (Promega Corporaton, Madison, Wisconsin, USA) according to the user manual.

\section{Detection of apoA-I}

ApoA-I concentrations in culture medium were determined using an EnzymeLinked Immuno Sorbent Assay (ELISA) (Mabtech, Nacka Strand, Sweden) according manufacturers instructions. The apoA-I calibration curve was obtained with purified human apoA-I from Sigma (St. Louis, MO, USA). The detection limit of this ELISA was $1.3 \mathrm{ng} / \mathrm{mL}$ and the variation coefficient was less than $5 \%$.

\section{Detection of PPARa overexpression}

Prior lyses on ice in lysis buffer $(10 \mathrm{mM}$ Tris pH7.5, $150 \mathrm{mM} \mathrm{NaCl}, 1 \% \mathrm{NP} 40,1 \%$ sodium deoxycholate, and $0.1 \%$ sodium dodecylsulfate (SDS) containing protease and phosphatase inhibitors) cells were washed twice with ice-cold PBS. Lysates were cleared by centrifugation and $30 \mu \mathrm{g}$ of protein was loaded and run on $10 \%$ acrylamide gels and transferred onto nitrocellulose membranes (immun-blotTM PVDF membrane; Bio-rad laboratories). The PPARa antibody used was rabbit antihuman PPARa (Santa Cruz, CA, USA).

\section{Detection of CPT1a, ACO, and PPAR $\alpha$ mRA}

Total RNA was isolated from cells using TRI Reagent (Sigma Aldrich). 350ng RNA was used to produce cDNA. TaqMan Gene Expression Assays were used to quantify carnitine palmitoyltransferase 1a (CPT1a; Hs00912671_m1), acyl coA oxidase 1 (ACO; Hs01074241_m1), PPARa (Hs00231882_m1), and the internal control cyclophilin A (Hs99999904_m1) by the Aplied Biosystems 7300 Real-Time PCR System according to the manufacturers manual (Life Technologies). The thermocycling conditions were: $50^{\circ} \mathrm{C}$ for $2 \mathrm{~min}, 95^{\circ} \mathrm{C}$ for $10 \mathrm{~min}$, and then 40 cycles of $95^{\circ} \mathrm{C}$ for 15 seconds and $60^{\circ} \mathrm{C}$ for $1 \mathrm{~min}$. Values are presented as relative gene expression normalized for the internal control cyclophilin A and compared to the DMSO. 


\section{CHAPTER 6}

Experimental design and statistical data analysis

Luciferase experiments were performed in 24 well-plates. In all the experiments, the compounds were added at the same time points before cell lyses. To account for biological variation between samples, all the experimental conditions were tested in quadruplicate. All the experiments were performed at least three times, with the exception of the detection of CPT1a, ACO, and PPARa mRNA levels, for which one experiment was preformed in four fold. Effects of PPARa activation/inhibition on the PPRE and apoA-I production were statistically tested with the non-parametric Wilcoxon signed rank test. Statistical analysis was performed using SPSS 17.0 for Macintosh (SPSS, Chicago, IL, USA). Results are presented as means \pm standard error of mean. Unless stated otherwise, the luciferase values were normalized to the activity of the reporter gene combined with PPARa, which was set to zero.

\section{Results}

Functional hPPARa transactivation via the PPRE

First, the hPPARa was PCR amplified from human embryonal kidney cells (HEK cells), cloned into the pcDNA3.1 expression construct, sequence verified, and transfected into HEK cells for protein analysis. hPPARa was expressed at the expected size of 53kDa (Fig. 1a).

To demonstrate that hPPARa transactivation was mediated through the PPRE and did not influence the reporter construct without the PPRE elements, we performed a double transfection with hPPARa $(0.02 \mu \mathrm{g}$ to $0.10 \mu \mathrm{g})$ and the reporter construct $(0.10 \mu \mathrm{g})$ with and without the PPRE. No transactivation was observed without the PPRE elements (Fig. 1b). Increasing the amount of the hPPARa expression construct dose-dependently increased transactivation (Fig. 1b). Based on these results, $0.06 \mu \mathrm{g}$ hPPARa expression construct was used in all further experiments to be able to detect an increase as well as a decrease of PPRE-mediated transactivation. FeAc, a well-known PPARa ligand [10], clearly enhanced PPAR transactivation by approximately $90 \%$, showing the functionality of the LBD of hPPARa (Fig. 1c). 


\section{FATTY ACIDS AND PPARa ACTIVITY}

A

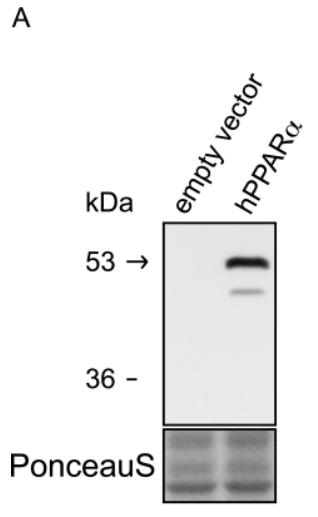

B

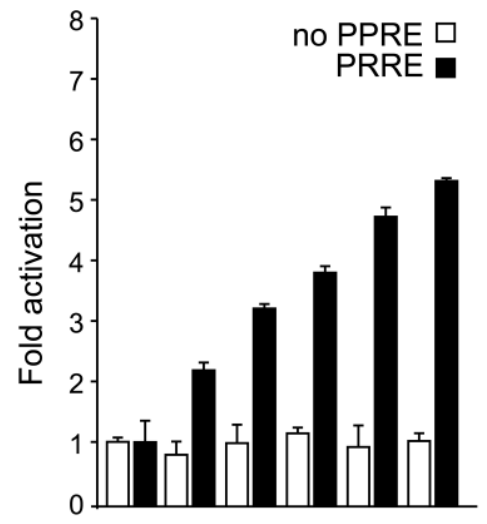

hPPAR $\alpha \quad 0.000 .020 .040 .060 .080 .10$
C

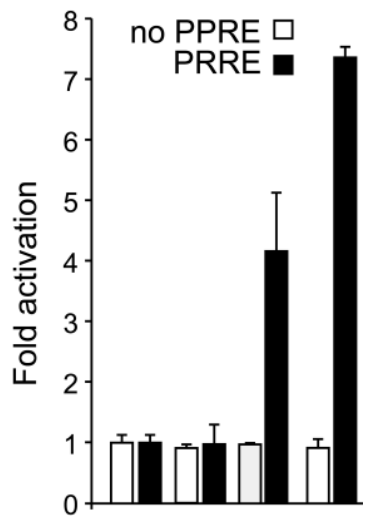

hPPAR $\alpha---++++$

FeAc --++--++

Figure 1. A: Western blot detection of hPPARa after transient transfection of the hPPAR $\alpha$ and the empty vector (pcDNA3.1) in HEK cells using an hPPAR $\alpha$ specific antibody. The arrow indicates hPPARa at $53 \mathrm{kDa}$. Equal protein loading was shown by using PonceauS. B: Dose-response curve of hPPARa $(0.02,0.04,0.06$, 0.08 and $0.10 \mu \mathrm{g}$ ) using the PPRE luciferase reporter construct. Co-transfection of this construct with the empty vector pCDNA3.1 allowed determination of the basal level of expression $(0.00 \mu \mathrm{g}$ hPPARa) which was set at 1 . The correlation coefficient between the amount of hPPARa and fold activation was 0.99. C: Effect of $10 \mathrm{mM}$ fenofibric acid (FeAc) on hPPARa transactivation in HepG2 cells transfected with hPPARa $(0.06 \mu \mathrm{g})$, using a luciferase reporter construct driven by three PPRE elements or without these PPRE elements.

\section{Fatty acid specific hPPARa regulation}

We first tested the ability of SAFA and MUFA to regulate PPAR transcriptional activity. Caprilic acid (C8:0) increased PPARa transactivation, although effects did not reach statistical significance (Fig. 2). Lauric acid (C12:0), on the other hand, increased PPARa transactivation dose-dependently $(\mathrm{P}<0.05$ for 50 and $125 \mu \mathrm{M})$. At the lower dose, myristic acid (C14:0) slightly activated whereas at the higher dose it inhibited transactivation (Fig. 2). Palmitic acid (C16:0) and stearic acid (C18:0) dose-dependently inhibited PPARa transactivation (Fig. 2). This clearly illustrated that effects of individual SAFAs on PPARa transactivation are not uniform and can even be the opposite. The monounsaturated counterparts of C16:0 and C18:0, i.e. palmitoleic acid $(C 16: 1(n-7))$ and oleic acid (C18:1(n-9)) significantly $(p<0.05)$ increased PPARa transactivation at lower concentrations (50 and $75 \mu \mathrm{M}$ ), but this effect was lost at higher concentrations (Fig. 2). 


\section{CHAPTER 6}

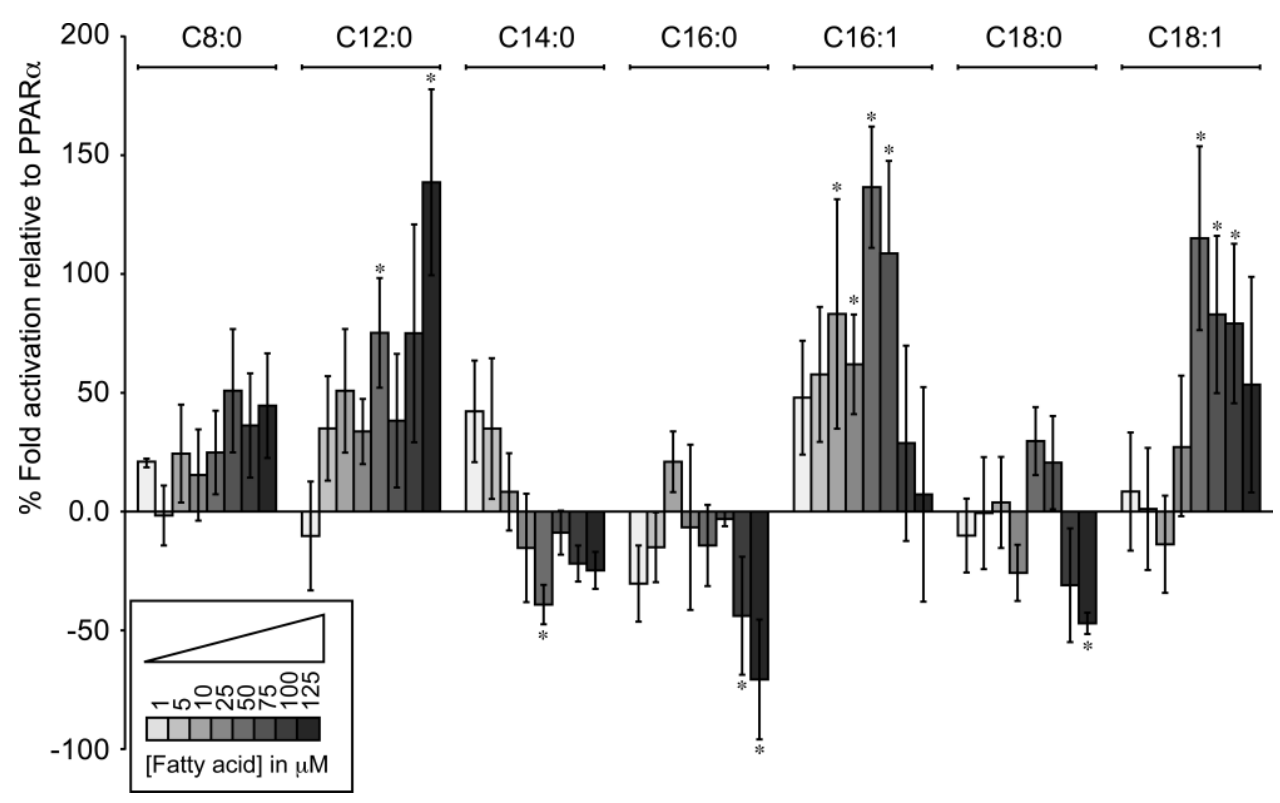

Figure 2. Effects of the fatty acids C8:0, C12:0, C14:0, C16:0, C16:1(n-7), C18:0 and $\mathrm{C} 18: 1(\mathrm{n}-9)$ at concentrations ranging from $1-125 \mu \mathrm{M}$ on PPARa transactivation. The transactivation properties of fatty acids are shown relative to the transactivation of PPARa alone. Basal PPARa transactivation without fatty acids was set at zero \% activation. The maximum reduction is $-100 \%$ (no transactivation). Statistically significant changes $(p<0.05)$ are indicated with an asterisk $\left({ }^{*}\right)$.

We also evaluated the effects of different PUFAs. Linoleic acid (C18:2(n-6)) and $\mathrm{y}^{-}$ linolenic acid (C18:3(n-6)) did not significantly influence PPARa transactivation (Fig. 3). Interestingly, a-linolenic acid (C18:3(n-3)) increased PPARa transactivation. In fact, this effect was the strongest of all fatty acids tested, especially at doses between 50 to $125 \mu \mathrm{M}(\mathrm{p}<0.05)$ (Fig. 3). Arachidonic acid (C20:4(n-6)), eicosapentaenoic acid (EPA; 20:5(n-3)), and docosahexaenoic acid $(\mathrm{DHA} ; \mathrm{C} 22: 6(\mathrm{n}-3))$ all significantly $(\mathrm{p}<0.05)$ activated PPARa transactivation at lower doses. However, transactivation decreased dose-dependently and at higher concentrations these fatty acids even significantly inhibited PPARa transactivation $(\mathrm{p}<0.05)$ (Fig. 3). Especially DHA (C22:6(n-3)) inhibited PPARa transactivation at concentrations of $50 \mu \mathrm{M}$ and higher (Fig. 3). 


\section{FATTY ACIDS AND PPARa ACTIVITY}

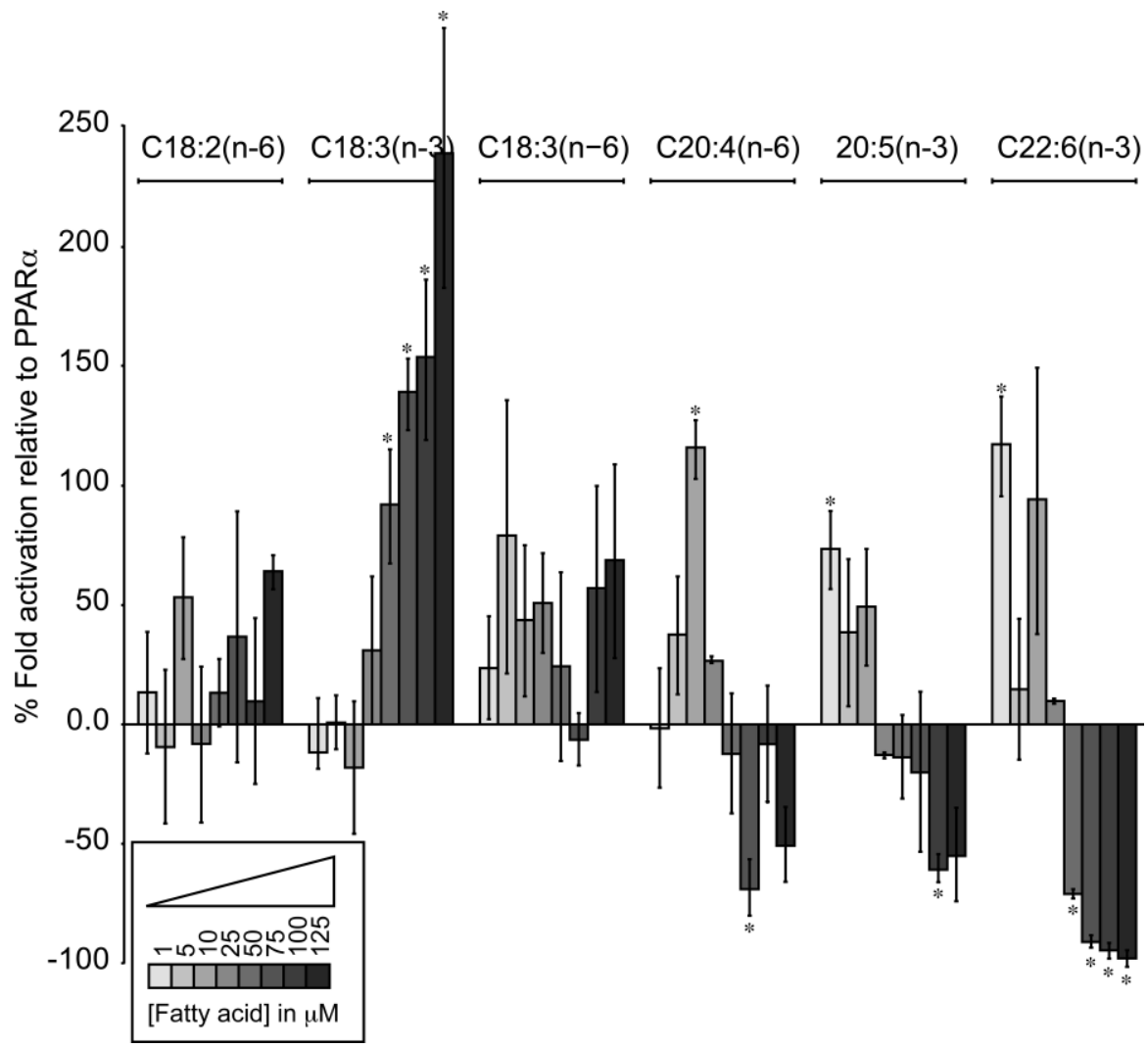

Figure 3. Effects of C18:2(n-6), C18:3(n-3), C18:3(n-6), C20:4(n-6), C20:5(n-3) and $\mathrm{C} 22: 6(\mathrm{n}-3)$ at concentrations ranging between $1-125 \mu \mathrm{M}$ on PPARa transactivation. Effects are shown relative to transactivation of PPARa alone. PPARa activation without fatty acids was set zero \%. Significant changes relative to the control condition $(p<0.05)$ are indicated with an asterisk $\left(^{*}\right)$.

Fatty acid induced changes in of CPT1a, ACO, and PPARa mRNA expression

To examine whether the fatty acid induced transactivation of the luciferase assay is also reflected in changes in mRNA expression of a panel of other known PPAR $\alpha$ target genes we evaluated mRNA expression of CPT1a, ACO, and PPARa. CPT1a was dose-dependently increased after treatment with a-linolenic acid (C18:3(n-3)) up to 1.8 fold and DHA (C22:6(n-3)) up to 6 fold (Fig. 4). No changes were observed for ACO mRNA expression (Fig. 4). Finally, $\alpha$-linolenic acid (C18:3(n-3)) increased PPARa mRNA expression dose dependently up to 1.9 fold whereas DHA (C22:6(n-3)) initially increased PPARa expression up to 1.7 fold from 1 to 10 $\mu \mathrm{M}$, following a decrease in expression to basal level (Fig. 4), which is in line with the PPAR luciferase data (Fig. 3). 


\section{CHAPTER 6}
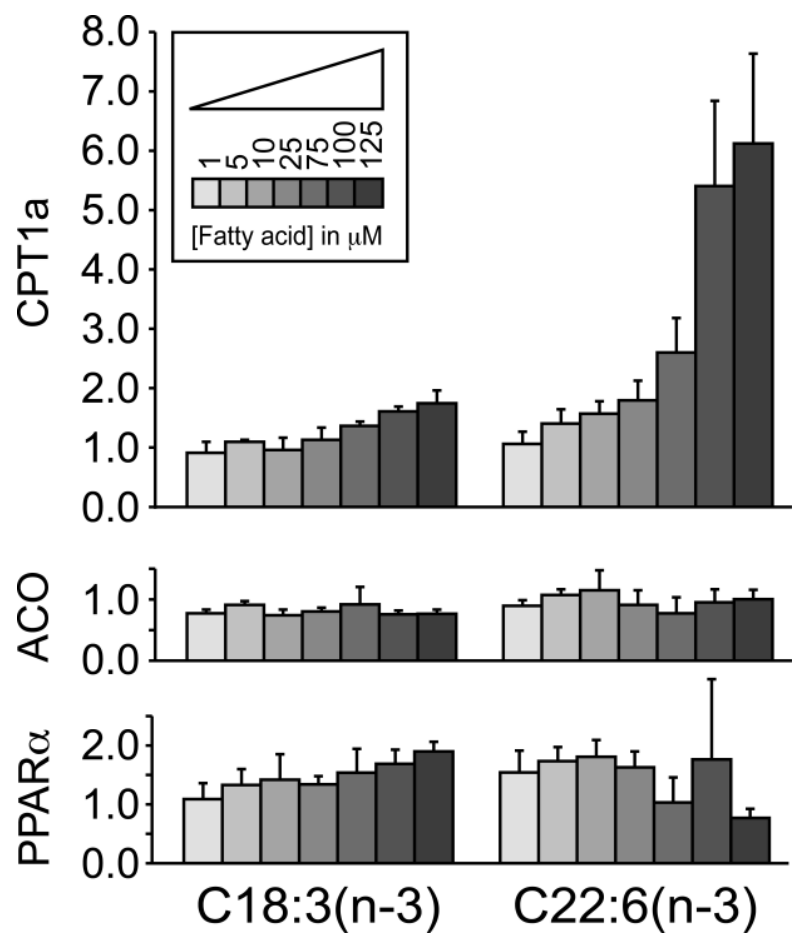

Figure 4. The effect of $C 18: 0, C 18: 1, C 18: 3(n-3)$ and $C 22: 6(n-3)$ in a concentration ranging from $1-125 \mu \mathrm{M}$, on CPT1, ACO, and PPAR $\alpha$ mRNA expression. The mRNA expression is shown relative to the condition without fatty acids set at 1 normalized for the internal control cyclophilin $A$.

\section{Fatty acid induced changes in apoA-I production}

To determine whether PPARa transactivation / repression was translated into regulation of a PPARa target gene, we determined the production of apoA-I protein in the medium of HepG2 liver cells following incubation with the different fatty acids. As typical examples, data for a-linolenic acid which showed the strongest PPARa transactivation and DHA which had the strongest inhibitory effect on PPAR $\alpha$ transactivation, are shown. Incubation with $\alpha$-linolenic acid (50 to $125 \mu \mathrm{M})$ indeed resulted in a dose-dependent and significant $(p<0.05) 50 \%$ increased apoAI protein concentration in the HepG2 culture medium (Fig. 5). On the other hand, incubation with DHA (50 to $125 \mu \mathrm{M})$ significantly reduced the apoA-I protein concentration by $50 \%$ (Fig. 5). Interestingly, changes in apoA-I concentrations paralleled the pattern of PPARa transactivation, suggesting a functional relationship between these two parameters. 


\section{FATTY ACIDS AND PPARa ACTIVITY}

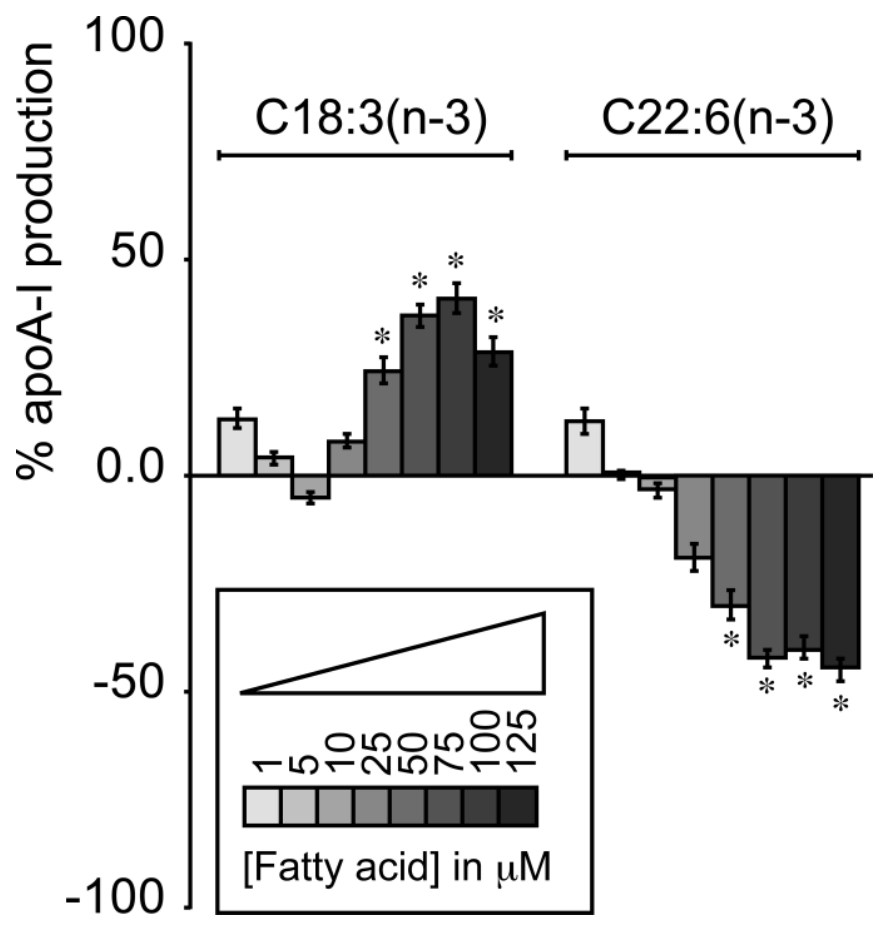

Figure 5. The effect of $C 18: 3(n-3)$ and $C 22: 6(n-3)$ in a concentration ranging from $1-125 \mu \mathrm{M}$, on apoA-I production. The percentage apoA-I production is relative to the condition without fatty acids set at zero \% apoA-I production. Significant changes $(p<0.05)$ is indicated with an asterisk $\left({ }^{*}\right)$.

\section{Discussion}

It has been shown that fatty acids are able to bind to the LBD of PPARs, including the LBD of PPARa $[12,13]$. However, since binding does not necessarily result in transactivation, we investigated systematically the effects of various fatty acids on PPARa transactivation on its natural DNA binding elements (PPRE's), using a luciferase reporter system. Based on data from ligand-binding assays [12,13], we expected that all fatty acids could lead to PPARa transactivation, although to various degrees due to the reported differences in binding strength of the fatty acids to hPPARa. Several fatty acids (caprilic acid (C8:0), lauric acid (C12:0), palmitoleic acid (C16:1(n-7)), oleic acid (C18:1(n-9)), linoleic acid (C18:2(n-6)), Ylinolenic acid $(C 18: 3(n-6))$, and $\alpha$-linolenic acid $(C 18: 3(n-3))$ indeed showed variation in transactivation. Interestingly, Forman et al., have reported earlier that C8:0 and C12:0 poorly bind to the LBD [13]. However, in our hands - despite this potentially poor binding capacity - these two fatty acids clearly and dosedependently increased PPARa transactivation. Furthermore, we observed for myristic acid (C14:0), palmitic acid (C16:0), stearic acid (C18:0), arachidonic acid $(C 20: 4(n-6))$, EPA $(C 20: 5(n-3))$ and DHA $(C 22: 6(n-3))$, after an initial increased transactivation of hPPAR a at lower concentrations, a decrease at higher 


\section{CHAPTER 6}

concentrations even followed by repression. At $75 \mu \mathrm{M}$, DHA repressed PPARa transactivation almost completely. These observations are comparable to results of Mochizuki et al., who reported in a Gal4 fusion experiment that DHA strongly binds to hPPARa, but does not increase transactivation [9]. Repression, however, cannot be determined with this Gal4 fusion system.

We here show that mRNA expression of the known PPARa target gene CTP1a dose dependently increased up to 1.6 fold by a-linolenic acid $(C 18: 3(n-3))$ and up to 6 fold by DHA (C22:6(n-3)). The relatively high increase in CPT1a mRNA expression by DHA (C22:6(n-3)) seems to contradict with our transactivation assay data (Fig. 3). However, we observed that $\alpha$-linolenic acid $(C 18: 3(n-3))$ and DHA (C22:6(n-3)) also modulated PPARa in line with transactivation assay. This means that the transactivation assay has predictive value though not for all fatty acids investigated. Interestingly, mRNA expression of a third PPARa target gene, ACO, did not change at all after fatty acid exposure. Combining the results of Mochizuki et al. and our study suggests that for fatty acids binding does not necessarily mean activation of hPPAR $\alpha$ and in addition seems specific for the gene of interest. This illustrates that besides fatty acid induced PPAR a activation to explain changes in gene expression other regulatory factors play a role, which are probably genespecific. Moreover, our results point to different optimal concentrations for maximal transactivation for the various fatty acids, which could be rather low for some fatty acids. The inhibitory effect of certain fatty acids on PPARa transactivation might be explained by small changes in PPAR conformation. Instead of activating the coactivator domain, these fatty acids may activate the co-repressor domain [14]. The PPRE elements in the luciferase transactivation system that are derived from the CPT1a promotor [11] show a reduction in transactivation at higher doses of DHA while it is exactly the opposite in the native situation based on CPT1a mRNA expression. Therefore, the constitution of the promotor of the gene of interest probably plays an important role as well.

$\alpha$-Linolenic acid, the strongest PPAR $\alpha$ transactivator and DHA, the strongest inhibitor of PPARa transactivation, were also tested for their effects on apoA-I production. In line with the transactivation experiments, $\alpha$-linolenic acid significantly increased apoA-I and DHA significantly decreased apoA-I production in a dosedependent manner. This apoA-I lowering effect of DHA is in line with a previous study using human HepG2 in which a mixture of EPA and DHA at a 5-20 $\mu \mathrm{M}$ range tended to lower apoA-I production [15]. Comparable effects for DHA were recently also described by Kuang et al [16], who showed that both fatty acids lowered apoA-I mRNA and protein expression in HepG2 cells. Moreover, for DHA it was also shown that the apoA-I promotor activity was lowered. In addition, effects of DHA on apoA-I gene expression in HepG2 cells were mediated via hepatocyte nuclear factor-3b (HNF3b) [16]. This suggests that both PPARa and HNF3b are involved in DHA-induced reduction of apoA-I production in HepG2 cells. In conclusion, PPARa plays a prominent role in apoA-I production pathways, but increasing PPARa activation alone may not be sufficient to induce apoA-I increases in vivo.

Another interesting observation is that in contrast to the SAFAs palmitic acid (C16:0) and stearic acid (C18:0) that both repress PPARa activation, their unsaturated metabolites palmitoleic acid (C16:1(n-7)) and oleic acid (C18:1(n-9)) 


\section{FATTY ACIDS AND PPARa ACTIVITY}

do activate PPAR transcription. It is generally assumed that in vitro palmitoleic acid $(\mathrm{C} 16: 1(\mathrm{n}-7))$ and oleic acid $(\mathrm{C} 18: 1(\mathrm{n}-9))$ have different effects than palmitic acid (C16:0) and stearic acid (C18:0). For example, Hommelberg et al., described that incubation with palmitic acid (C16:0) and stearic acid (C18:0) induced both $N F-\kappa B$ transactivation and insulin resistance in skeletal $\mathrm{C} 2 \mathrm{C} 12$ cells, whereas palmitoleic acid (C16:1(n-7)) and oleic acid (C18:1(n-9)) did not [17]. This suggests that efficient conversion of palmitic acid $(\mathrm{C} 16: 0)$ and stearic acid (C18:0) into respectively palmitoleic acid $(C 16: 1(n-7))$ and oleic acid $(C 18: 1(n-9))$ via stearoylCoenzymeA desaturase 1 (SCD1) ultimately affects regulation of PPAR activation or repression. As far as we know, this concept to influence apoA-I production through fatty acid desaturation has not been discussed before. This may open new venues to consider SCD1 as a desirable target for interventions to change PPAR activation / repression, when our body is in a situation of palmitic acid (C16:0) and stearic acid (C18:0) surplus.

It is well known that PPAR activation inhibits NF- $\kappa B$ activation [18]. The finding that palmitic acid (C16:0) activated NF- $\mathrm{NB}$ very strongly in the $\mathrm{C} 2 \mathrm{C} 12$ skeletal muscle cells [17] might also imply that the repression of PPAR activation by palmitic acid (C16:0) is responsible for a lack of PPARa induced blocking of NF- $\mathrm{NB}$ activation. If $\mathrm{NF}-\kappa \mathrm{B}$ activation results in a more pronounced low-grade pro-inflammatory status, this might in turn also have a lowering effect on apoA-I production.

An intriguing question is whether a pattern could be detected in the effects of (clusters of) certain fatty acids on PPARa binding and transactivation potential. It has been demonstrated that PUFAs and MUFAs have a higher binding affinity for PPARs than SAFAs [3,6]. In line with this, medium chain SAFAs (C10:0-C16:0) apparently were poor PPARa transactivators [13]. Furthermore, it has been postulated that optimal PPARa binding is achieved by fatty acids containing 16-20 carbons with several double bonds in their chain $[13,19]$. This was confirmed by Mochizuki et al. [9], who further found that fatty acids with 22 carbon atoms did not result in transactivation of PPARa. Which of these findings do also apply to our experiments when considering PPARa transactivation instead of binding? In contrast to the binding studies, the medium chain SAFAs C8:0 and C12:0 dosedependently increased PPARa transactivation in our study. In agreement with the results from Mochizuki et al. [9] our results showed that a high dose of the 22 carbon DHA (C22:6(n-3)) results in strong inhibition of PPAR $\alpha$ transactivation. On the other hand, we did not find that all unsaturated fatty acids with 16-20 carbon atoms increased transactivation, e.g. linoleic acid $(C 18: 2(n-6))$ and $y$-linolenic acid $(\mathrm{C} 18: 3(n-6))$. Besides structure, also the dose of a particular fatty acid was a critical factor in our experiments. Like Mochizuki et al. [9], we found that arachidonic acid (C20:4(n-6)), EPA (20:5(n-3)), and DHA (C22:6(n-3)) increased PPAR a transactivation at low doses, but decreased transactivation at high doses. Our data confirm the observation that, next to PPARa binding, low doses of PUFA increases PPARa transactivation. Interestingly, it should be noted that this is probably also dependent of the target gene that is researched as CPT1 is strongly induced at high doses DHA (C22:6(n-3)), while ACO does not alter and PPARa follows the expected pattern. This is also in line with data of Pawar, et al. who tested high doses of PUFA $(250 \mu \mathrm{M}$ and higher) and found no induction of PPARa activity [20]. Thus, it seems that transactivation is not only depending on PPARa 


\section{CHAPTER 6}

binding affinity, the number of carbon atoms and of double bonds, but also on the concentration of fatty acids that is used. A clear structure-function relationship is therefore difficult to deduce.

In conclusion, except for linoleic and $\mathrm{y}$-linolenic acid, all fatty acids studied dosedependently changed PPARa transactivation. We even found that fatty acids, reported to bind strongly to PPARa, could repress PPAR a activation illustrating that these binding assays should be interpreted with caution. Functionality of our fatty acid induced transactivation / repression findings was suggested by the association between PPAR $\alpha$ transactivation and secretion of apoA-I, a well-known PPAR $\alpha$ target gene. Most important to realize, though the data from transactivation assays do provide an indication for changes in target gene expression but at the same time it should be noted that individual PPARa target genes might react in a different way than expected and should therefore be tested individually.

\section{Acknowledgements}

This research was supported by the Dutch Technology Foundation STW, which is part of the Netherlands Organization for Scientific Research (NWO), and which is partly funded by the Ministry of Economic Affairs 


\section{FATTY ACIDS AND PPARa ACTIVITY}

\section{References}

1. Escher P, Wahli W (2000) Peroxisome proliferator-activated receptors: insight into multiple cellular functions. Mutat Res 448: 121-138.

2. Bragt MC, Popeijus HE (2008) Peroxisome proliferator-activated receptors and the metabolic syndrome. Physiol Behav 94: 187-197.

3. Desvergne B, Wahli W (1999) Peroxisome proliferator-activated receptors: nuclear control of metabolism. Endocr Rev 20: 649-688.

4. Feige JN, Gelman L, Michalik L, Desvergne B, Wahli W (2006) From molecular action to physiological outputs: peroxisome proliferator-activated receptors are nuclear receptors at the crossroads of key cellular functions. Prog Lipid Res 45: 120-159.

5. Balder JW, Staels B, Kuivenhoven JA (2013) Pharmacological interventions in human HDL metabolism. Curr Opin Lipidol 24: 500-509.

6. Krey G, Braissant O, L'Horset F, Kalkhoven E, Perroud M, et al. (1997) Fatty acids, eicosanoids, and hypolipidemic agents identified as ligands of peroxisome proliferator-activated receptors by coactivator-dependent receptor ligand assay. Mol Endocrinol 11: 779-791.

7. Kliewer SA, Sundseth SS, Jones SA, Brown PJ, Wisely GB, et al. (1997) Fatty acids and eicosanoids regulate gene expression through direct interactions with peroxisome proliferatoractivated receptors alpha and gamma. Proc Natl Acad Sci U S A 94: 4318-4323.

8. Mochizuki K, Suzuki T, Goda T (2008) PPAR alpha and PPAR delta transactivity and p300 binding activity induced by arachidonic acid in colorectal cancer cell line Caco-2. J Nutr Sci Vitaminol (Tokyo) 54: 298-302.

9. Mochizuki K, Suruga K, Fukami H, Kiso Y, Takase S, et al. (2006) Selectivity of fatty acid ligands for PPARalpha which correlates both with binding to cis-element and DNA bindingindependent transactivity in Caco-2 cells. Life Sci 80: 140-145.

10. Vu-Dac N, Chopin-Delannoy S, Gervois P, Bonnelye E, Martin G, et al. (1998) The nuclear receptors peroxisome proliferator-activated receptor alpha and Rev-erbalpha mediate the species-specific regulation of apolipoprotein A-I expression by fibrates. J Biol Chem 273: 25713-25720.

11. Gilde AJ, van der Lee KA, Willemsen PH, Chinetti G, van der Leij FR, et al. (2003) Peroxisome proliferator-activated receptor (PPAR) alpha and PPARbeta/delta, but not PPARgamma, modulate the expression of genes involved in cardiac lipid metabolism. Circ Res 92: 518-524.

12. Forman BM, Chen J, Evans RM (1996) The peroxisome proliferator-activated receptors: ligands and activators. Ann N Y Acad Sci 804: 266-275.

13. Forman BM, Chen J, Evans RM (1997) Hypolipidemic drugs, polyunsaturated fatty acids, and eicosanoids are ligands for peroxisome proliferator-activated receptors alpha and delta. Proc Natl Acad Sci U S A 94: 4312-4317.

14. Cronet P, Petersen JF, Folmer R, Blomberg N, Sjoblom K, et al. (2001) Structure of the PPARalpha and -gamma ligand binding domain in complex with $A Z$ 242; ligand selectivity and agonist activation in the PPAR family. Structure 9: 699-706.

15. Rudkowska I, Verreault M, Barbier O, Vohl MC (2009) Differences in transcriptional activation by the two allelic (L162V Polymorphic) variants of PPARalpha after Omega-3 fatty acids treatment. PPAR Res 2009: 369602.

16. Kuang YL, Paulson KE, Lichtenstein AH, Lamon-Fava S (2012) Regulation of the expression of key genes involved in HDL metabolism by unsaturated fatty acids. Br J Nutr 108: 1351-1359.

17. Hommelberg PP, Plat J, Langen RC, Schols AM, Mensink RP (2009) Fatty acid-induced NFkappaB activation and insulin resistance in skeletal muscle are chain length dependent. Am J Physiol Endocrinol Metab 296: E114-120.

18. Mishra A, Chaudhary A, Sethi S (2004) Oxidized omega-3 fatty acids inhibit NF-kappaB activation via a PPARalpha-dependent pathway. Arterioscler Thromb Vasc Biol 24: 1621-1627.

19. Xu HE, Lambert MH, Montana VG, Parks DJ, Blanchard SG, et al. (1999) Molecular recognition of fatty acids by peroxisome proliferator-activated receptors. Mol Cell 3: 397-403.

20. Pawar A, Jump DB (2003) Unsaturated fatty acid regulation of peroxisome proliferator-activated receptor alpha activity in rat primary hepatocytes. J Biol Chem 278: 35931-35939. 
CHAPTER 6 


\section{CHAPTER 7}

Search strategy for natural compounds that increase apolipoprotein A-I transcription in HepG2 cells; a focus on BRD4 inhibition

Sophie E. van der Krieken, Pieter van-der Pijl, Yuguang Lin, Herman E. Popeijus, Ronald P. Mensink and Jogchum Plat

In preparation 


\section{CHAPTER 7}

\section{Abstract}

Although increasing apoA-I production is a promising strategy to reduce the risk for cardiovascular diseases (CVDs), our knowledge on natural compounds with the capacity to elevate hepatic apolipoprotein A-I (apoA-I) transcription is limited. Therefore, we aimed to discover natural compounds that elevate apoA-I transcription in HepG2 cells. Since evidence points towards a role for BRD4 inhibitors in increasing apoA-I transcription, we also focused on natural compounds with the ability to bind to BRD4. Literature was screened for compounds that might increase apoA-I and/or were BRD inhibitor. This resulted in the compilation of list $A$, containing apoA-I increasing compounds with unknown BRD4 protein-binding capacity; list $B$ with known BRD4 inhibitors that increased apoA-I production; and list $C$ with reported BRD4 binding function, but with unknown effects on apoA-I production. Using virtual fingerprint analyses, the structures of the compounds on each list were compared to each other and to two natural compound databases. Comparing list $A$ and $B$ to the natural databases resulted in the recognition of four compounds: hesperetin, equilenin, 9(S)-HOTrE and cymarin. In list C, a common substructure was discovered in $60 \%$ of all BRD4-inhibitor compounds. This substructure was found in 179 compounds from one of the two natural databases we used, i.e. the Dictionary of Natural Products (DNP). Experiments in HepG2 cells revealed that equilenin, 9(S)-HOTrE and cymarin increased apoA-I transcription respectively by $27 \%, 35 \%$ and $37 \%$ whereas hesperetin did not. For each of these compounds also a structural look a like compound was selected. For hesperetin this look a like was eriodictyol, for equilenin we chose hordenine, for 9(S)-HOTrE this was $5(\mathrm{~S}), 15(\mathrm{~S})$-DiHETE and for cymarin we chose emicymarin. Of the structural look a likes, eriodictyol and emicymarin increased apoA-I transcription by $35 \%$ and $77 \%$. Based on these findings, we conclude that next to equilenin, $9(\mathrm{~S})$ HOTrE and cymarin, which were found in literature, the two natural compounds eriodictyol and emicymarin may be interesting targets for further studies to increase apoA-I production. 


\section{SEARCH FOR NATURAL COMPOUNDS TO INCREASE APOA-I}

\section{Introduction}

Cholesterol efflux capacity, which is defined by the amount of cholesterol taken up from cholesterol-loaded macrophages by high-density lipoprotein (HDL) particles, is inversely associated with the incidence of cardiovascular events [1]. As an elevated in vitro cholesterol efflux capacity may reflect increased reverse cholesterol transport in vivo, the efflux capacity may be a useful biomarker for the development of cardiovascular disease (CVD) lowering strategies [1]. Apolipoprotein A-I (apoA-I) is the principal component of HDL, which can acquire cholesterol by binding to the ATP-binding cassette A1 (ABCA1), the trans membrane cholesterol transporter on macrophages [2]. As the plasma concentration of apoA-I is associated with increased cholesterol efflux capacity [3], a promising strategy to increase cholesterol efflux capacity is to increase the amount of nascent HDL particles by increasing de novo apoA-I production $[4,5]$. The effectiveness of increasing apoA-I concentrations in the combat against CVD is supported by several in vivo animal $[6,7]$ and human studies [8,9]. For example, intravenous infusion of recombinant apoA-I particles decreased atherosclerosis progression, as it reduced atheroma volume in patients with acute coronary syndromes [8]. Moreover the use of apoA-I mimetics like CSL112 [9] clearly enhanced cholesterol efflux capacity. Besides the involvement of apoA-I in enhancing cholesterol efflux capacity, apoA-I may also provide other cardioprotective effects. ApoA-I is anti-inflammatory [10], anti-thrombotic [11] and has glucose lowering properties [12,13]. Altogether, this illustrates the crucial role for elevating apoA-I production in CVD risk management.

Several studies have indicated a role for the family of bromodomain and extraterminal (BET) protein inhibitors in apoA-I production. For example, in in vitro as well as in vivo studies the BET inhibitor RVX-208 (or apabetalone) increased apoAI transcription and protein production [14]. Additionally, there are many other compounds with BET inhibiting function and the capacity to increase apoA-I synthesis, at least in vitro, such as JQ1(+) [15], Ro11-1464 [16], GW841819X [17], GSK1210151A or I-BET151 [18], alaprazolam [19], GSK1324762A or I-BET762 [20], and thieno- or benzo-triazolodiazepines [15] such as U-34599 and U-51477 $[15,21]$. In humans, four types of BET proteins have been identified namely, bromodomain-containing protein (BRD) 2, BRD3, BRD4 and testes-specific BRDT. Although many BET inhibitors are multi-BET active, experiments have shown that specifically the silencing of BRD4 is involved in increasing apoA-I production [17]. Also JQ1(+) and RVX208 inhibit BRD4, which may explain their effects on increasing apoA-I production. Currently, BET-inhibition is considered a promising therapy to increase apoA-I transcription and most BET inhibitors that are development are of synthetic origin. Possibly, natural compounds can, when safe, be used as a functional food ingredient. Therefore, the aim of this research was to identify by an in silico and in vitro approach natural compounds that increase apoAI transcription, thereby also focusing on BRD4 binding capacity. 


\section{CHAPTER 7}

\section{Methods}

To generate leads of compounds or structures with the potency to increase apoA-I transcription, three different lists (Lists $A, B$ and $C$ ) were compiled based on results of a systematic literature search. Using in silico screening the structures of the compounds in these lists were compared to each other and to natural compounds from two databases. Compounds of interest were tested in vitro for their ability to increase apoA-I transcription (for a schematic representation of the study design see figure 1).

\begin{tabular}{|c|c|c|c|}
\hline Literature compound search $\rightarrow$ & $\begin{array}{l}\text { List A } \\
\text { ApoA-I } \\
\text { increasing } \\
\text { - } \text { BET inhibitor } \\
\text { capacity } \\
\text { unknown }\end{array}$ & \begin{tabular}{ll}
\multicolumn{2}{l}{ List B } \\
- & ApoA-I \\
& increasing \\
- & BET \\
& inhibiting
\end{tabular} & $\begin{array}{l}\text { List C } \\
\text { - ApoA-I } \\
\text { increasing } \\
\text { capacity } \\
\text { unknown } \\
\text { - BET inhibiting }\end{array}$ \\
\hline \multirow[t]{2}{*}{ Virtual screening $\rightarrow$} & \multicolumn{3}{|c|}{$\begin{array}{l}\text { 1) In silico 2D-fingerprint comparison of list A and B. To } \\
\text { find common features that are possibly responsible for } \\
\text { the effect on apoA-I } \\
\text { 2) In silico 2D-fingerprint comparison of compounds in list } \\
\text { C, to discover if there is a common substructure present } \\
\text { in BRD4 binding compounds. } \\
\text { 3) In silico 2D-fingerprint comparison of the structures of } \\
\text { list A, B and C to two natural compound databases, to } \\
\text { find natural structural look a likes }\end{array}$} \\
\hline & In vit & est for apoA-I t & ription \\
\hline
\end{tabular}

Figure 1. Schematic representation of the study design. In order to find natural compounds with the ability to increase apoA-I transcription in HepG2 cells, a literature compound search was performed, which resulted in three lists (Lists $A, B$ and $\mathrm{C}$ ). In the virtual screening process these lists were compared to two natural compound databases. Additionally, a search for a common substructure was performed in all three lists. Subsequently, 4 hits from the screening, and for each compound a structural look a like, were tested for their effect on apoA-I transcription in HepG2 cells.

\section{Literature review}

To search for compounds that increase apoA-I production, inhibit BET proteins especially BRD4 - or both, a computer-assisted literature search was performed in the PubMed database for articles published until August 2015. The following 
search terms were used: (((BRD*) OR bromodomain)) AND (((apo*) OR HighDensity Lipoproteins, Pre-beta) OR apolipoprotein A-I). In addition, a well-curated database of bioactivities named CHEMBL [22] was used to search for compounds with binding ability to BRD4. Additionally, we have found earlier that cymarin and 9(S)-HOTrE have apoA-I transcriptional elevating effects (data unpublished). Therefore, these two compounds were included in our search results as well.

When their simplified molecular-input line-entry system (SMILES) was available, identified compounds were used for further analysis, which resulted in the formation of three lists (figure 1): List $A$ contained compounds that increased apoA-I production with unknown BRD4 protein-binding capacity. List $B$ contained compounds that were BRD4 inhibitors and increased apoA-I production. List $C$ was composed of compounds with reported BRD4 inhibitor function, but with unknown effects on apoA-I production. For classification as a BRD4 inhibitor, a cut off IC50 of lower than $500 \mathrm{nM}$ was used.

\section{Virtual screening}

Two databases were searched for natural compounds that may inhibit BRD4 and/or increase apoA-I transcription: a database provided by DSM ( $N=2.000$; available upon request) and a commercially available one, the Dictionary of Natural Products database (version 18.1; $\mathrm{N} \approx 260.000$, Francis \& Taylor).

The method used to screen for molecules depended on the list of molecules: since lists $A$ and $B$ contained relatively few compounds, a structural similarity search was performed for each compound from these lists in both databases (Tanimoto-based, using Functional Class Fingerprints of maximum diameter 4 (FCFP_4)). In addition, the structural similarity of compounds from lists $A$ and $B$ was calculated based on a structural similarity matrix search. By performing a substructure search in list $C$, we determined if the BRD4 inhibitors in this list contained a common substructure. All compounds retrieved were filtered on a) having a structural similarity of at least 0.5 , and b) being commercially available. In the results section the top 10 of compounds with the highest similarity will be presented. BioVIA's PipelinePilot version 9.2 was used for all cheminfo-related calculations (similarity calculations, substructure searches) and virtual screening tasks.

\section{Human liver cell culture}

Human hepatocellular liver carcinoma (HepG2) cells (kindly provided by $\mathrm{S}$. Braesch-Andersen, Mabtech, Nacka Strand, Sweden) were cultured at $37^{\circ} \mathrm{C}$ in a humidified atmosphere and $5 \% \mathrm{CO}_{2}$. For cell culturing, Minimum Essential Medium (MEM) was used supplemented with $10 \%$ Fetal Calf Serum (v/v, South-American, Greiner Bio-one, Frickenhausen, Germany), L-glutamine (Invitrogen Life Technologies, Carlsbad, CA, USA), 1\% penicillin/streptomycin ( $\mathrm{v} / \mathrm{v}), 1 \%$ nonessential amino acids (NEAA, $\mathrm{v} / \mathrm{v})$, and $1 \%$ sodium pyruvate $(\mathrm{v} / \mathrm{v}$, all from Invitrogen Life Technologies, Carlsbad, CA, USA). To gain insight into the effect of the selected natural compounds on apoA-I transcription, HepG2 cells were exposed for 48 hours to different doses of each compound. Stocks were prepared in recommended carrier solutions and were diluted in culture medium. For carrier controls, maximally $0.5 \%$ DMSO or ethanol was used. After incubation, cells were 


\section{CHAPTER 7}

microscopically inspected and pictures of each condition were made to confirm cell vitality (data not shown). Different doses of the BRD4 inhibitor RVX208 were used as positive controls for their ability to increase apoA-I transcription. Furthermore, in each experiment $3 \mu \mathrm{M}$ JQ1(+), another known BRD4 inhibitor was used as a control for increased apoA-I transcription in HepG2 cells.

qPCR measurements

Total RNA was isolated according to the Qiagen Trizol protocol. Next, cDNA was produced using Taqman reagents. ApoA-I (Hs00163641_m1) and internal control cyclophilin A (Hs99999904_m1) mRNA expression was determined using the 7300 Real-Time PCR System. Both TaqMan Gene Expression Assays and reagents were obtained from Applied Biosystems.

\section{Results}

\section{Literature review and virtual screening}

The literature review resulted in the identification of 8 compounds that increased HDL-C or apoA-I protein and/or mRNA expression, but with unknown BRD4 binding capacity (table 1; list A), and 6 compounds that increased apoA-I production (either measured as transcription, protein secretion or luciferase reporter activity) with known BRD4 inhibitor activity (table 1; list B). Two of the compounds from list $A$ and three of the compounds of list $B$ also increased in vitro apoA-I protein secretion. By virtual comparison of the molecular structures within list $A$ and $B$, a structural overlap of 0.7 was found between $U-51477$ and alprazolam (supplemental table 1). Data derived from the searches for structural similarity of the compounds found in literature (list $A$ and $B$ ) to the natural databases of DNP and DSM are presented in table 1. Four literature hits were confirmed to be of natural origin: hesperetin, equilenin, 9(S)-HOTrE and cymarin (figure 2, upper panel). For each of these four hits, a "look a like" compound was selected based on commercial availability (figure 2, lower panel) and the highest structural similarity (supplemental tables 2, 3, 4 and 5). For compound hesperetin, eriodictyol was selected (0.79 similarity); for compound equilenin we selected hordenine (0.53 similarity); for compound 9(S)-HOTrE we selected $5(\mathrm{~S}), 15(\mathrm{~S})$-DiHETE (0.91 similarity), and for the compound cymarin we selected the structural look a like emicymarin ( 0.81 similarity). These eight compounds were tested for effects on apoA-I transcription in HepG2 cells. 


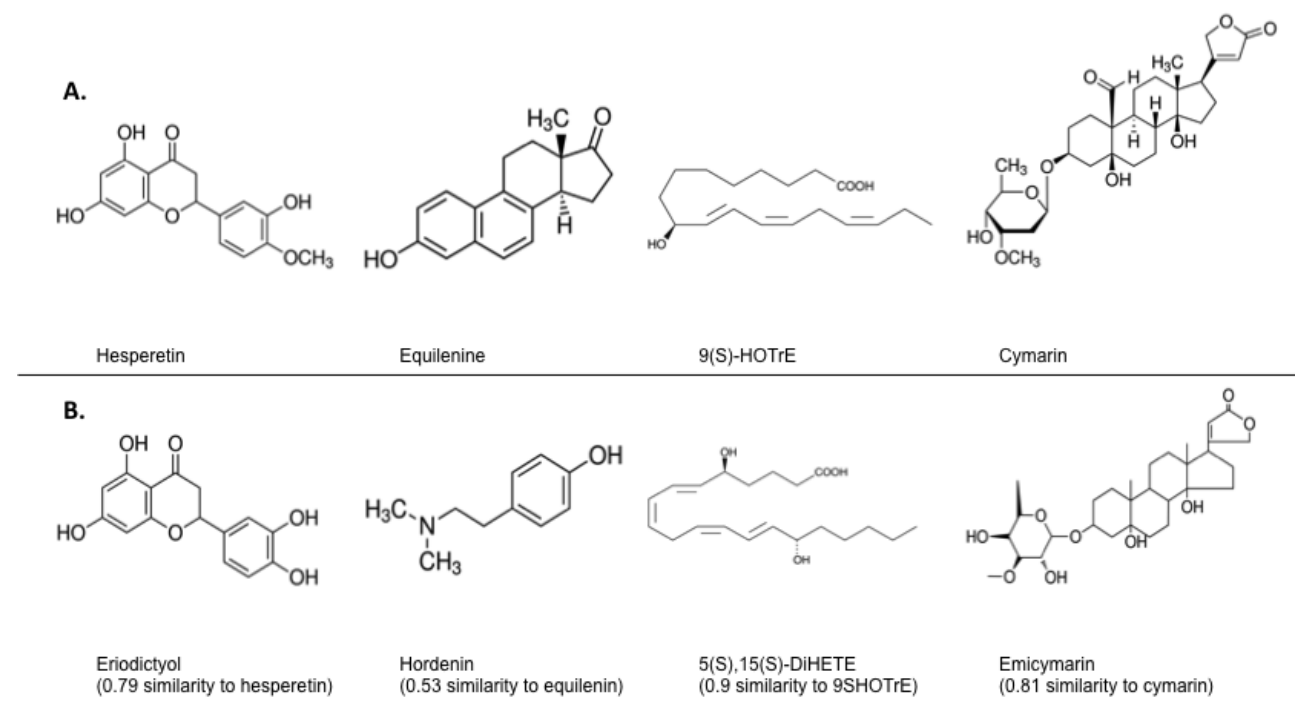

Figure 2. Comparison of list $A$ and $B$ to the DNP and DSM natural database resulted in the confirmation of 4 structures: hesperetin, equilenin, (9)S-HOTrE and cymarin (panel A). In panel B the structural look a likes are presented: eriodictyol, hordenine, 5(S),15(S)-DiHETE and emicymarin.

The literature review also resulted in the identification of 48 compounds that were described to bind to BRD4 $($ IC50 $<500 \mathrm{nM})$ but without known effects on apoA-I transcription (table 2; list C). After comparing the structures of these BRD4 inhibitors within list $C$ to each other, a common substructure was discovered in $60 \%$ of all compounds (figure 3). Again, the DNP and DSM databases were searched for natural compounds that contained this common structure. This search resulted in the identification of approximately 100 compounds with a similarity of $>0.5$ (supplemental table 6).

Figure 3. The common ethylbenzene substructure found in $60 \%$ of all BRD4 inhibitor compounds with unknown effects on apoA-I.

Effects of the selected compounds on apoA-I mRNA expression in HepG2 cells

Addition of different doses of the known BET inhibitor RVX208 (supplemental figure 1) clearly increased dose-dependently the production of apoA-I mRNA. Likewise, the positive control JQ1(+) increased apoA-I transcription in all experiments (figure 4). One of the hits resulting from the fingerprint analyses, hesperetin, did not increase apoA-I transcription. If anything, apoA-I transcription 


\section{CHAPTER 7}

was reduced (figure 4a). However, eriodictyol, the selected compound with a high similarity to hesperetin, did induce apoA-I transcription by $35 \%$ at a dose of $50 \mu \mathrm{M}$ (figure 4b). Eriodictyol in doses ranging from 100 to $250 \mu \mathrm{M}$ decreased apoA-I and had no effect at lower doses. Equilenin raised apoA-I transcription in HepG2 cells, although no clear dose-response pattern was evident (figure 4c). Hordenine, the compound with a look a like structure of equilenin, did not affect apoA-I transcription (figure 4d). 9(S)-HOTrE increased apoA-I transcription by $35 \%$ at a dose of $170 \mathrm{nM}$ (figure 4e), while the structural variant of this compound 5(S),15(S)-DiHETE, reduced apoA-I transcription (figure 4f). Cymarin slightly decreased apoA-I mRNA expression at low concentrations, but increased its expression by $37 \%$ at doses ranging from 18 to $45 \mu \mathrm{M}$ (figure $4 \mathrm{ff}$ ). The structural look a like emicymarin increased apoA-I up to $77 \%$ (figure $4 \mathrm{~h}$ ). All compound doses were tested in duplo in HepG2 cells, and measurements were performed in duplo. 

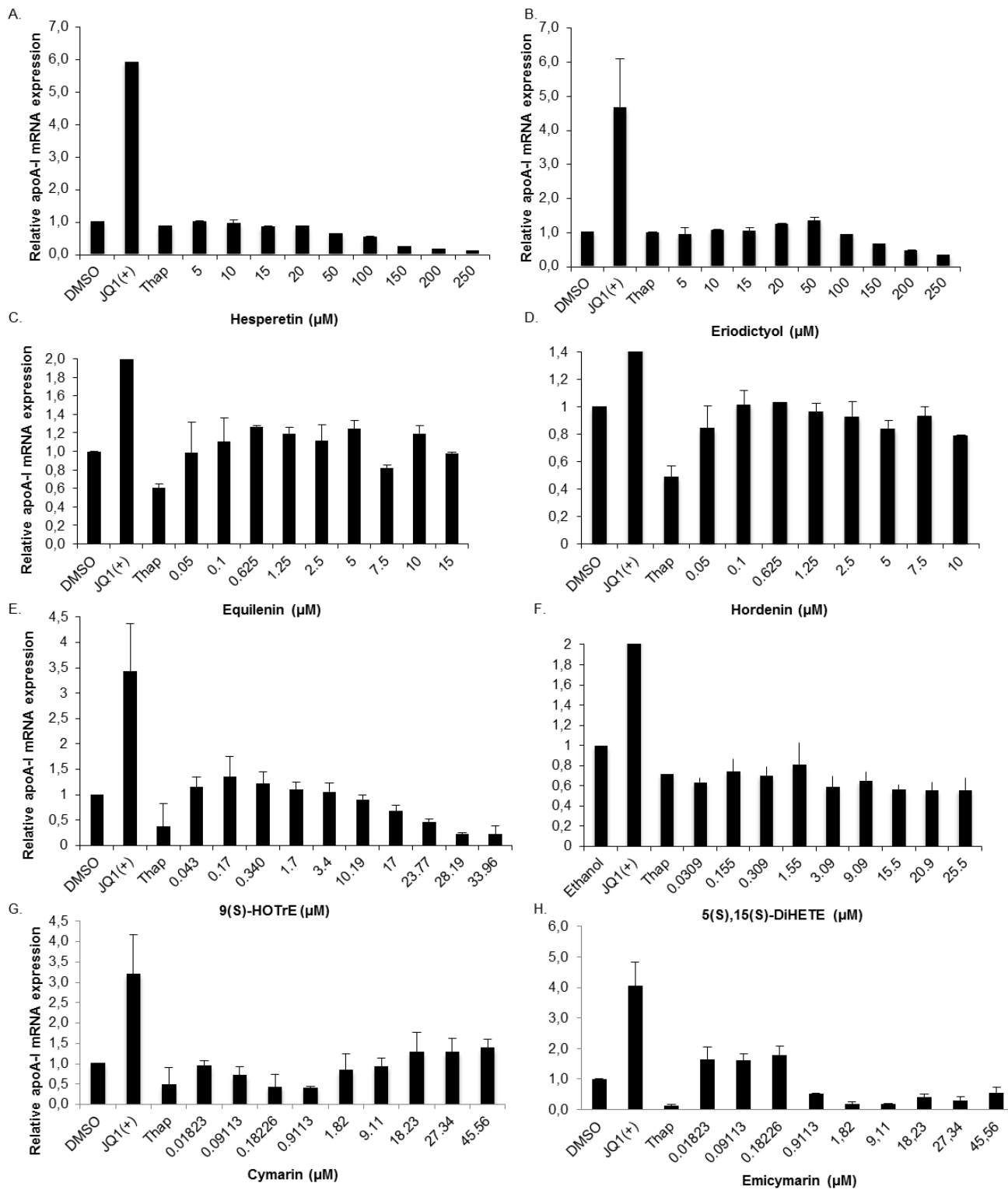

Figure 4. Relative apoA-I mRNA expression in HepG2 cells treated with different doses of a) hesperetin, b) eriodictyol, c) equilenin, d) hordenine, e) 9(S)-HOTrE, f) 5(S),15(S)-DiHETE, g) cymarin and h) emicymarin. Known BET inhibitor and apoAI increaser JQ1(+) $(3 \mu \mathrm{M})$ was used as a positive control, whereas thapsigargin $(0.01 \mu \mathrm{M})$ was used as a control to confirm decreased apoA-I expression. Compounds were tested in duplo. 


\section{CHAPTER 7}

Table 1. Results of the literature review and virtual screening in the Dictionary of Natural Products (DNP) and DSM databases.

\begin{tabular}{|c|c|c|c|c|c|c|}
\hline \multicolumn{5}{|c|}{ Compounds from literature } & \multicolumn{2}{|c|}{$\begin{array}{l}\text { Compounds from the virtual } \\
\text { screen }\end{array}$} \\
\hline List & $\begin{array}{l}\text { Relation to } \\
\text { apoA-I }\end{array}$ & BET & Molecule & Reference & DNP & DSM \\
\hline A & $\begin{array}{l}\uparrow \\
\text { transcription }\end{array}$ & $?$ & 9(S)-HOTrE & * & $\begin{array}{l}\text { Supplemental } \\
\text { table } 4\end{array}$ & $\begin{array}{l}\text { Supplemental } \\
\text { table } 4\end{array}$ \\
\hline A & $\uparrow_{\text {transcription }}$ & $?$ & Cymarin & * & $\begin{array}{l}\text { Supplemental } \\
\text { table } 5\end{array}$ & $\begin{array}{l}\text { Supplemental } \\
\text { table } 5\end{array}$ \\
\hline A & $\begin{array}{l}\uparrow \text { cholesterol } \\
\text { efflux } \\
\text { apoA-I }\end{array}$ & $?$ & $\begin{array}{l}\text { BMS- } \\
309403\end{array}$ & Furuhashi, 2007 & 0 & 0 \\
\hline A & $\begin{array}{l}\uparrow \text { cholesterol } \\
\text { efflux to to } \\
\text { apoA-I }\end{array}$ & $?$ & Equilenin & Zhang, 2001 & $\begin{array}{l}\text { Supplemental } \\
\text { table } 3\end{array}$ & $\begin{array}{l}\text { Supplemental } \\
\text { table } 3\end{array}$ \\
\hline A & $\begin{array}{l}\uparrow \quad \text { luciferase } \\
\text { reporter } \\
\text { activity }\end{array}$ & $?$ & GW694481 & Mirguet, 2012 & 0 & 0 \\
\hline$A$ & $\begin{array}{l}\uparrow \text { cholesterol } \\
\text { efflux to } \\
\text { apoA-I }\end{array}$ & $?$ & Hesperetin & Lio, 2012 & $\begin{array}{l}\text { Supplemental } \\
\text { table } 2\end{array}$ & $\begin{array}{l}\text { Supplemental } \\
\text { table } 2\end{array}$ \\
\hline A & $\begin{array}{l}\uparrow \\
\text { transcription } \\
\text { and protein } \\
\text { secretion }\end{array}$ & $?$ & U-34599 & $\begin{array}{l}\text { Kempen, 2013; } \\
\text { Princen, } 2003\end{array}$ & 0 & 0 \\
\hline$A$ & $\begin{array}{l}\uparrow \\
\text { transcription } \\
\text { and secretion }\end{array}$ & $?$ & U-51477 & $\begin{array}{l}\text { Kempen, 2013; } \\
\text { Princen, } 2003\end{array}$ & 0 & 0 \\
\hline$B$ & $\begin{array}{l}\uparrow \quad \text { luciferase } \\
\text { reporter } \\
\text { activity }\end{array}$ & $\downarrow$ & GW841819X & Chung, 2011 & 0 & 0 \\
\hline
\end{tabular}




\section{SEARCH FOR NATURAL COMPOUNDS TO INCREASE APOA-I}

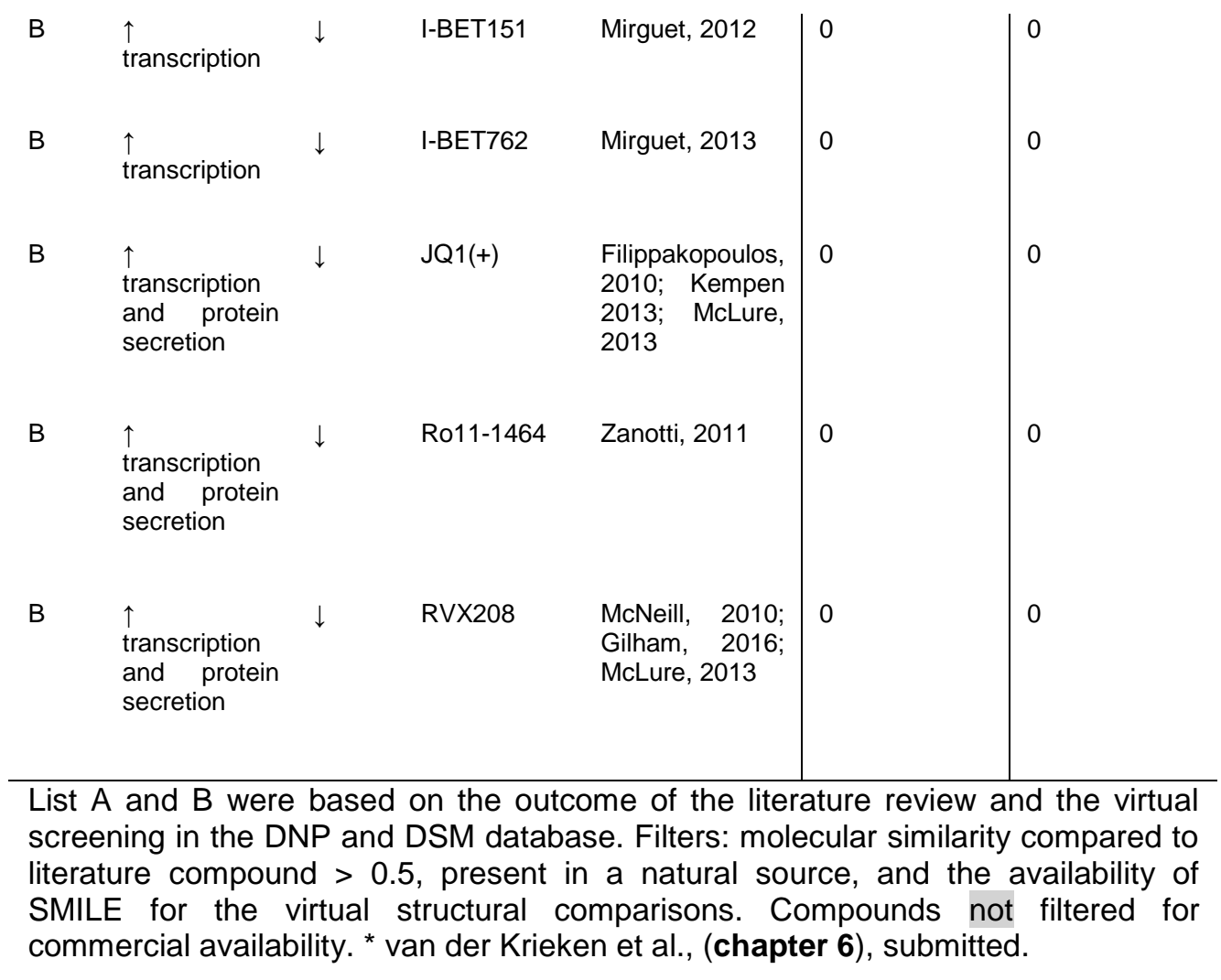




\section{CHAPTER 7}

Table 2. Results of the literature review and virtual screening in the Dictionary of Natural Products (DNP) and DSM databases of list C. Molecular structures, CHEMBL ID and IC50 of BRD4 binding compounds are presented.

\begin{tabular}{|l|l|l|}
\hline CHEMBL ID & IC50 (nM) \\
\hline & CHEMBL1828979 & 1 \\
\hline & CHEMBL1738926 & \\
\hline
\end{tabular}


SEARCH FOR NATURAL COMPOUNDS TO INCREASE APOA-I

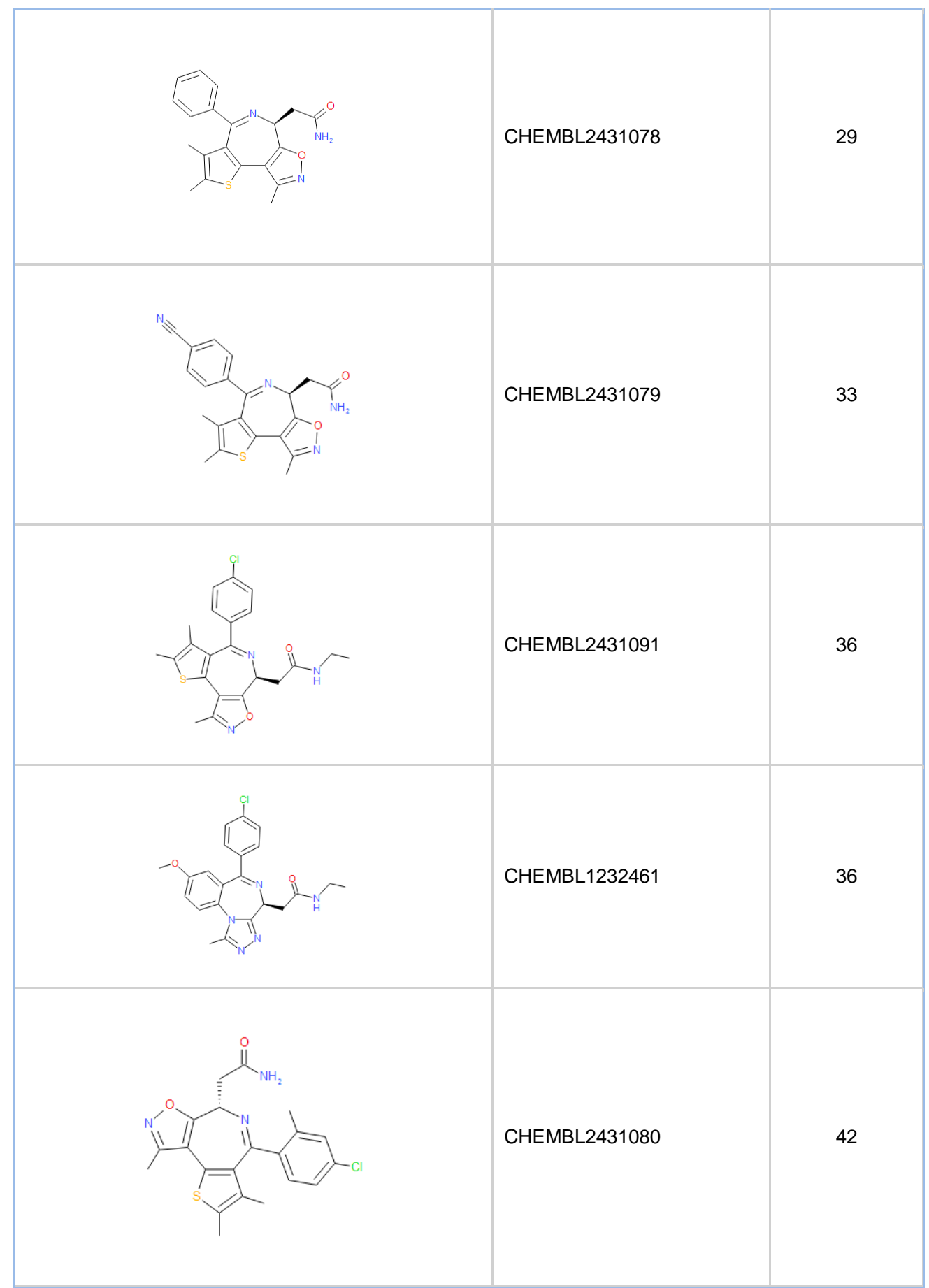




\section{CHAPTER 7}

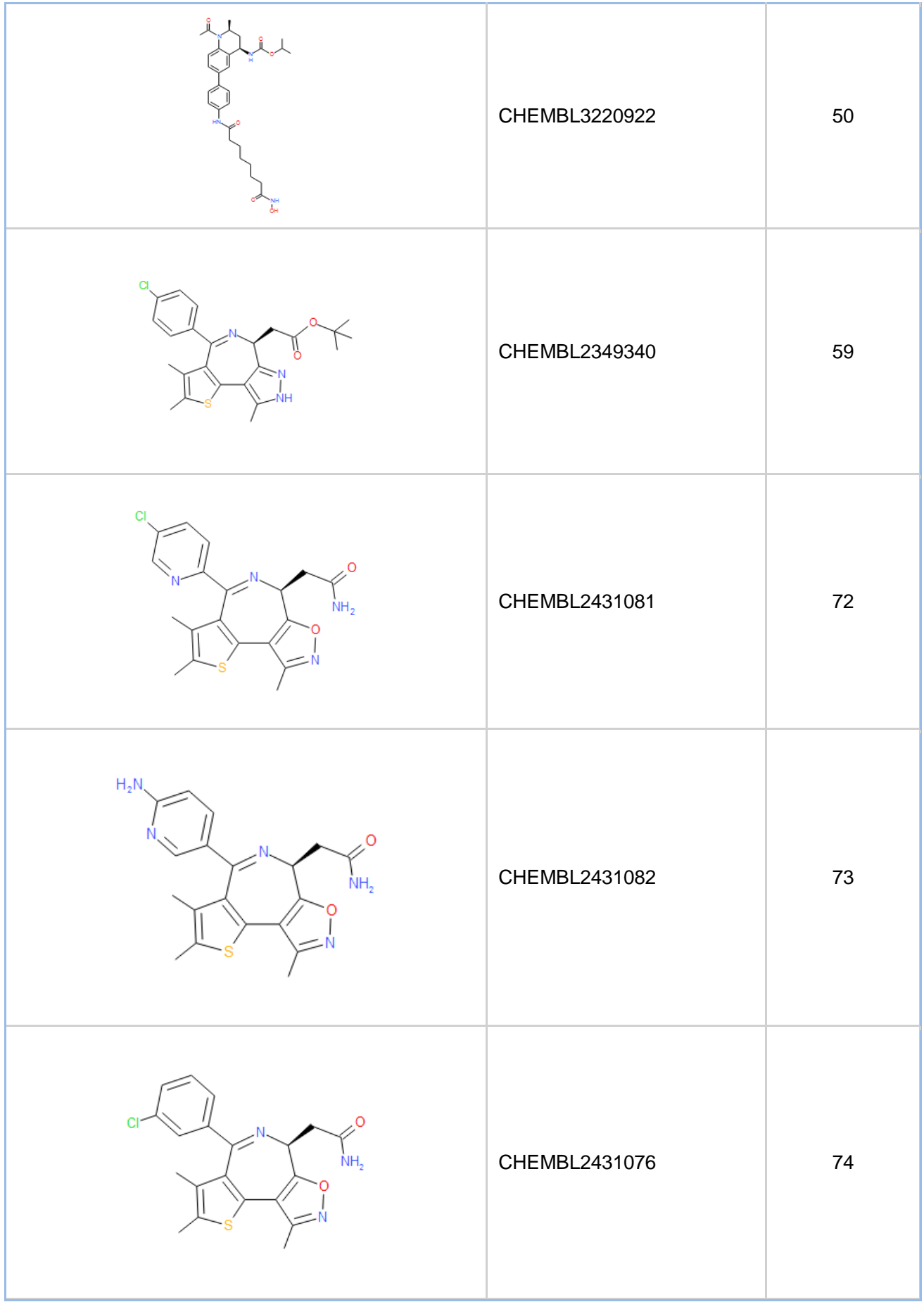


SEARCH FOR NATURAL COMPOUNDS TO INCREASE APOA-I

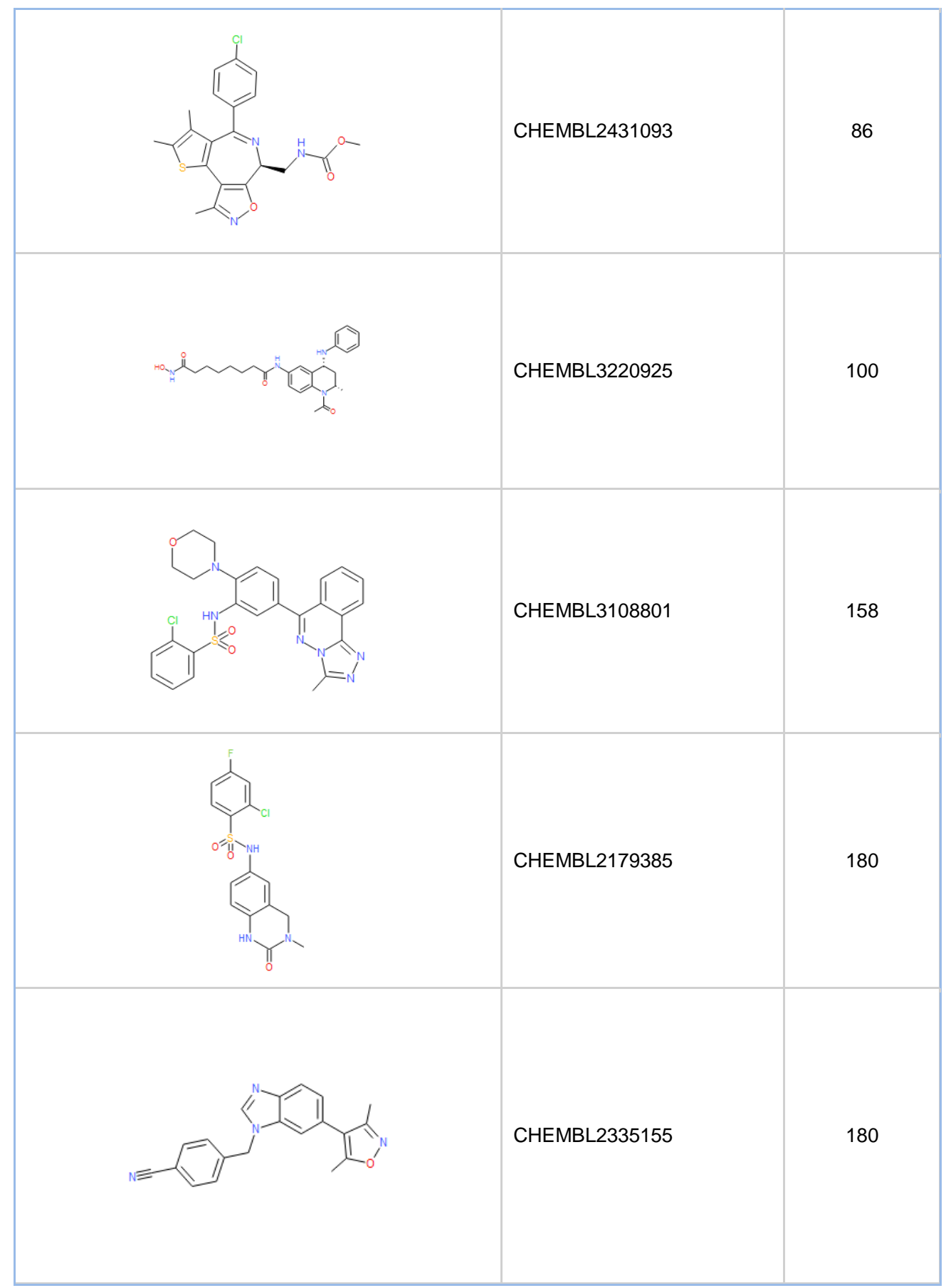




\section{CHAPTER 7}

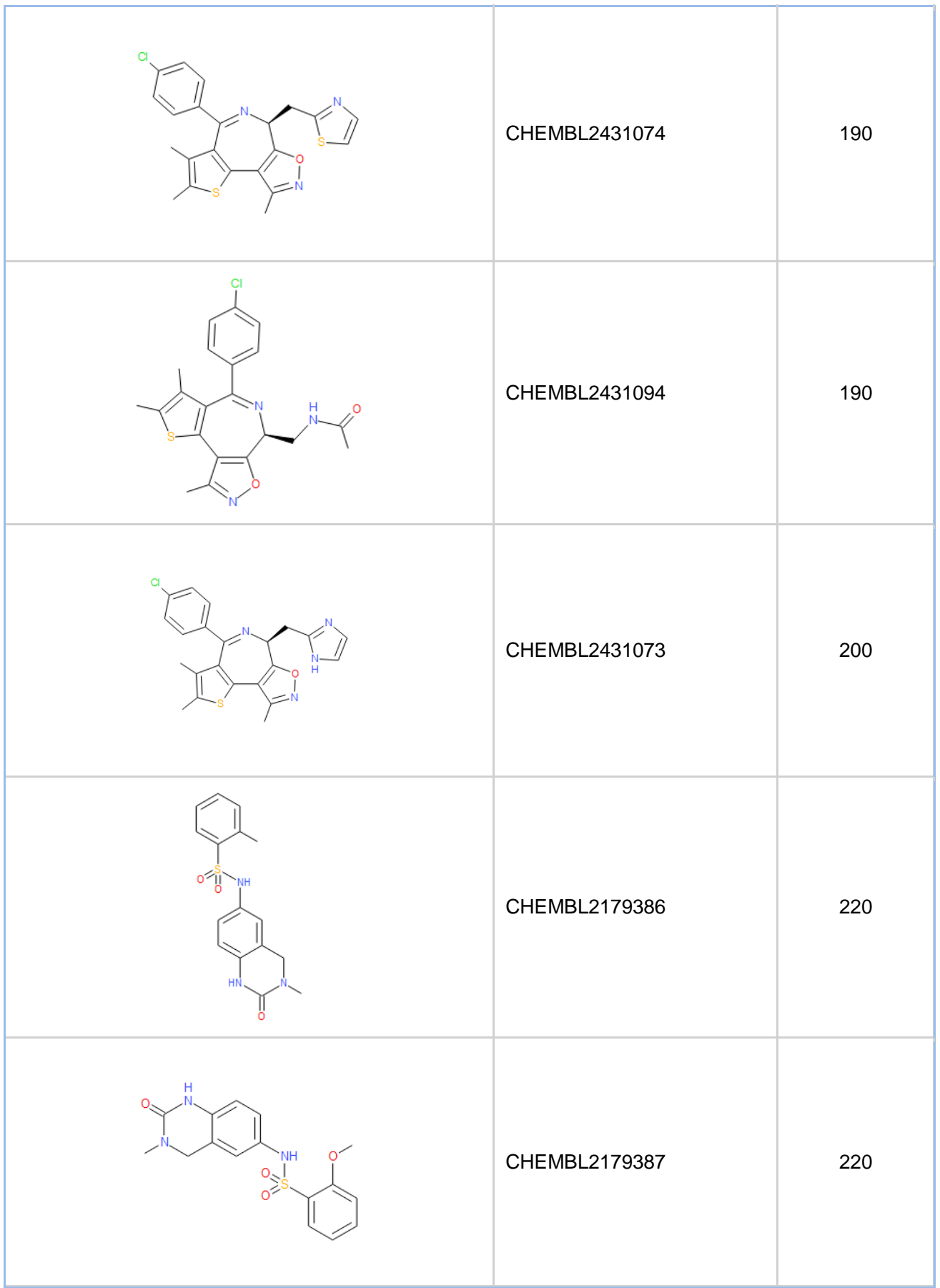


SEARCH FOR NATURAL COMPOUNDS TO INCREASE APOA-I

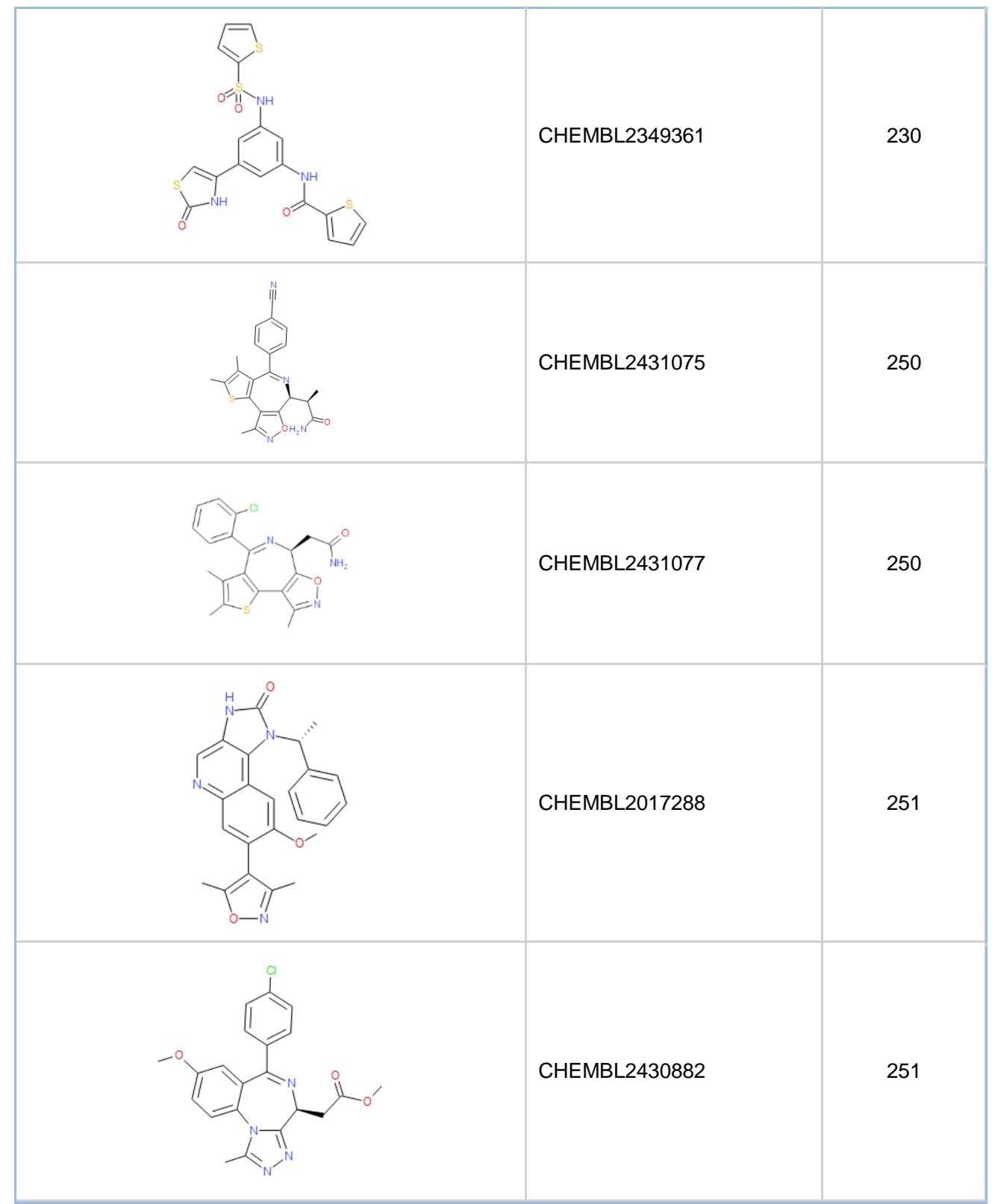




\section{CHAPTER 7}

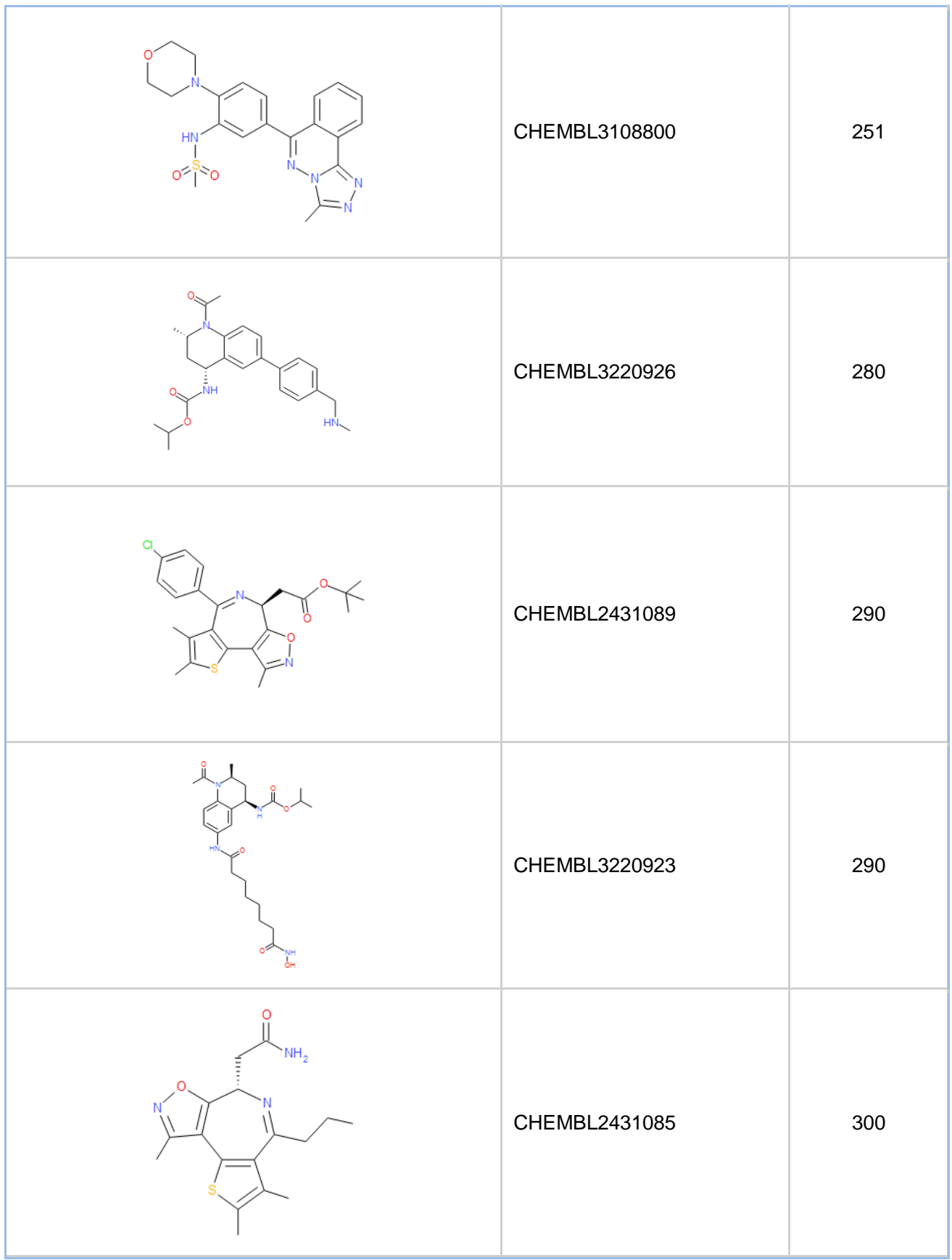


SEARCH FOR NATURAL COMPOUNDS TO INCREASE APOA-I

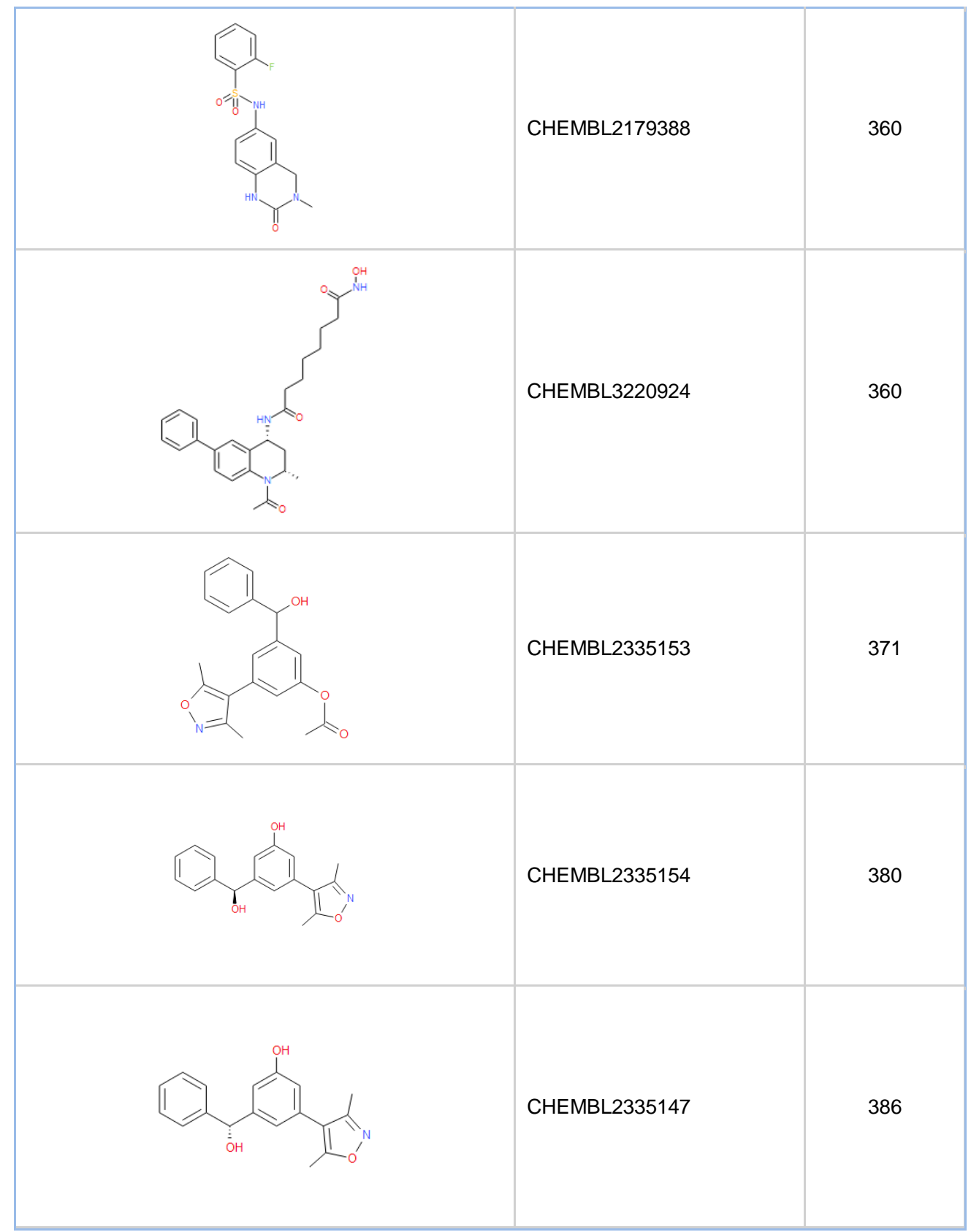




\section{CHAPTER 7}

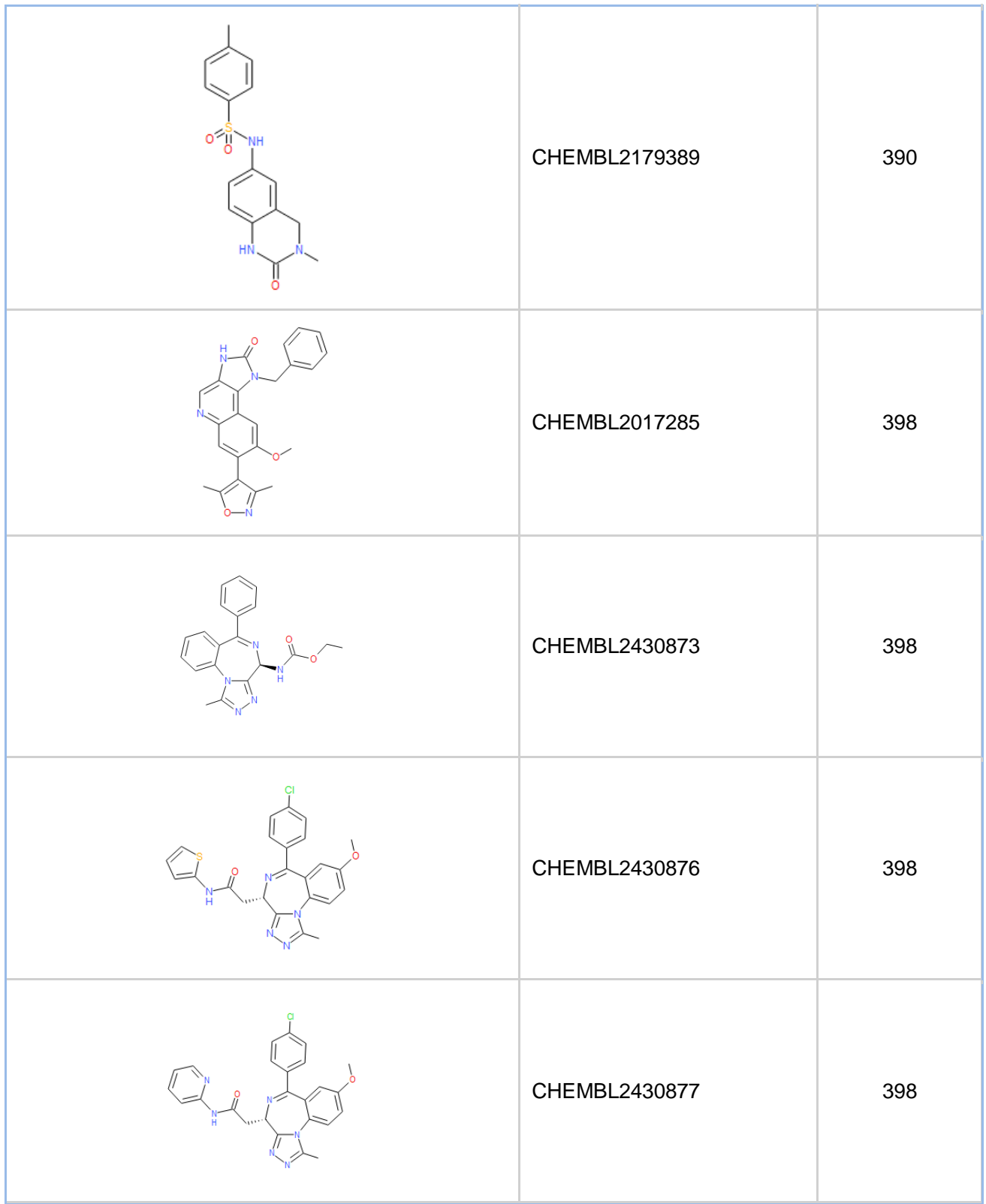


SEARCH FOR NATURAL COMPOUNDS TO INCREASE APOA-I

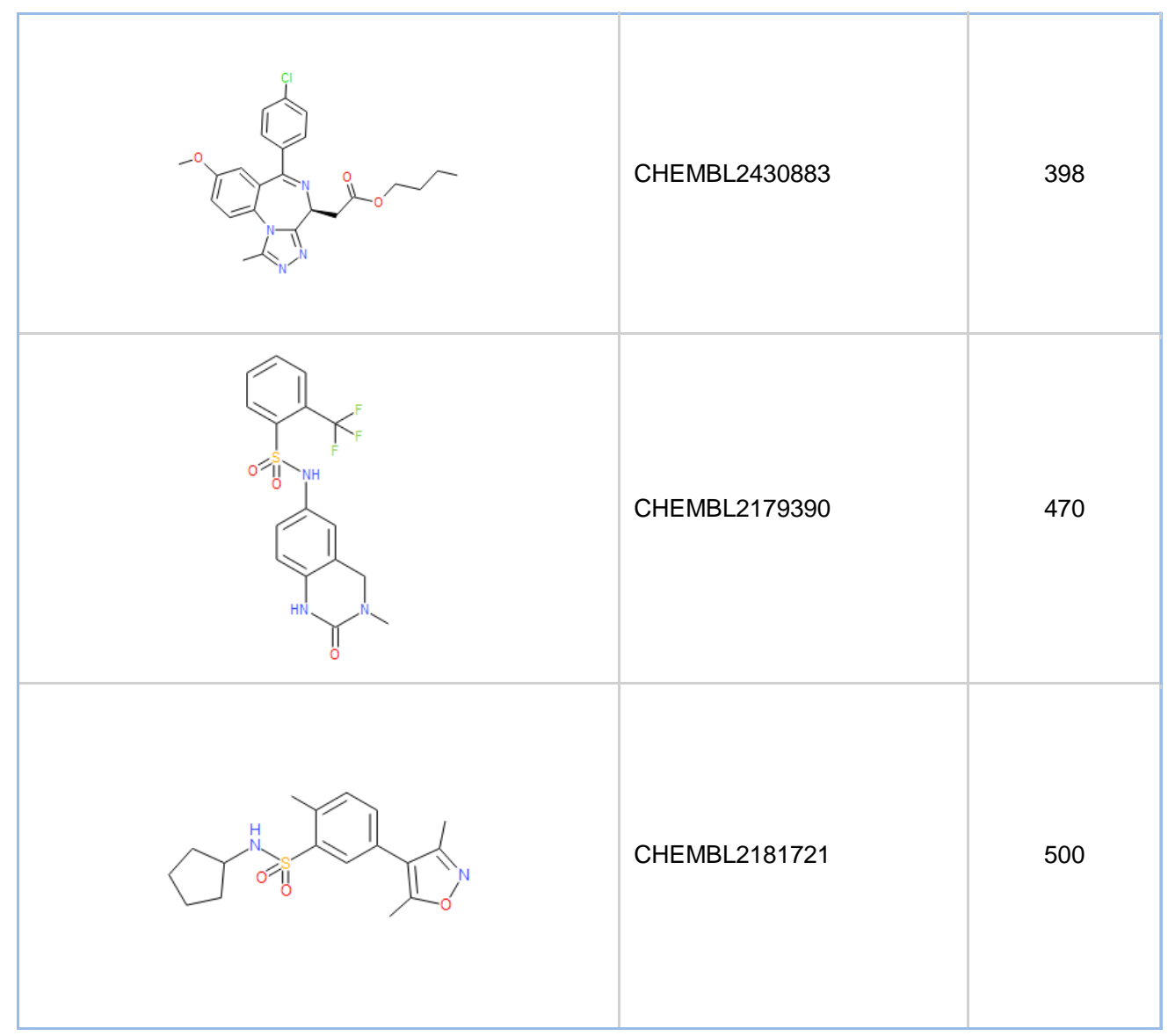




\section{Discussion}

In this study we aimed to identify natural compounds that increased apoA-I transcription via a systematic literature search and virtual screening. In addition, we focused on natural compounds with the ability to bind to BRD4, since a growing number of studies points towards a role for BRD4 inhibitors for increasing apoA-I transcription [17].

All compounds that were found in literature to increase apoA-I or HDL-C (table 1) were compared to the natural databases. The compounds that were selected because they are of natural origin were: hesperetin, equilenin, 9(S)-HOTrE and cymarin. Based on the assumption that molecules with comparable structures interact similarly with their molecular targets [23], we examined the effects of a look a like compound for each of the four identified compounds on apoA-I transcription in HepG2 cells. These look a like compounds were respectively eriodictyol, hordenine, 5(S),15(S)-DiHETE and emicymarin. Surprisingly, of the three main structures that increased apoA-I transcription (equilenin, 9(S)-HOTrE, cymarin), only the look a likes eriodictyol and emicymarin increased apoA-I transcription.

Hesperetin is the aglycone of hesperidin and both are present in oranges. Although hesperetin was reported to increase HDL-C in rats [24], it did not increase apoA-I transcription in our HepG2 cells. The hesperetin look a like compound eriodictyol, which is a metabolite of hesperitin, induced apoA-I transcription by $35 \%$ at a dose of $50 \mu \mathrm{M}$. It is known that hesperidin can be metabolized into hesperetin in the intestine [25] before entering the circulation. Possibly, hesperetin needs to be converted into eriodictyol to exert its effects on apoA-I transcription. If so, it would be of interest to study also other metabolites of hesperetin on apoA-I transcription. The dose of eriodictyol of $50 \mu \mathrm{M}$ which was the optimal dose used in our study has been reported earlier as being non-toxic in various cell lines, such as macrophage mouse cells, NIH3T3 (fibroblast) cells and HaCaT (human skin) cells [26]. In vivo studies in mice suggested that eriodictyol is anti-inflammatory [27], while in vitro studies in mouse spleen cells showed that this compound has anti-oxidant properties [28]. In HepG2 cells, eriodictyol increased insulin-stimulated glucose uptake [29] and inhibited of c-Jun N-terminal kinase (JNK) in macrophages [26]. Since JNK is also activated during ER-stress [30], it is of interest to examine if eriodictyol is also able to prevent ER-stress induced decreases in apoA-I transcription.

The second compound from the in silico screening, equilenin is a natural occurring estrogenic steroid that can be extracted from the urine of pregnant mares [31]. It has been shown, that equilenin $(10 \mu \mathrm{M})$ is a potent activator of the apoA-I promoter (3-fold increase), and increased apoA-I transcription with 140\% in HepG2 cells [32]. At a dose of $10 \mu \mathrm{M}$, we observed that equilenin increased apoA-I transcription by $19 \%$. However, in our experiments the optimal dose of equilenin was $0.6 \mu \mathrm{M}$, which increased apoA-I transcription by $27 \%$. In women, estrogen replacement therapy in postmenopausal women is associated with increased plasma HDL-C, and apoA-I concentrations [33]. Long-term estrogen treatment reduced the risk of mortality, myocardial infarction or heart failure in early post menopausal women, but not in women who start hormone therapy many years (5 to 20) after menopause. Moreover, unwanted effects such as thromboembolic disease or breast cancer have been observed [34]. Hordenine, the structural look a like of 


\section{SEARCH FOR NATURAL COMPOUNDS TO INCREASE APOA-I}

equilenin (0.53 similarity) did not influence apoA-I transcription. Hordenine is an alkaloid found in the roots of the germinating barley plant or the Stapelia hirsute [35], and may possess antibacterial and antibiotic properties [36]. However, no studies so far have investigated the effect of hordenine on apoA-I. Unfortunately, no other compounds with a resemblance to equilenin above 0.53 were commercially available.

An earlier study of our group has shown that 9(S)-HOTrE increased apoA-I transcription in HepG2 cells by $35 \%$ at a dose of $170 \mathrm{nM}$. 9(S)-HOTrE is a monohydroxy polyunsaturated fatty acid, found in the leaves of a plant called glechoma hederacea [37]. The leaves of the glechoma hederacea are used in a traditional folk tea in Japan [38], whereas another plant that contains 9(S)-HOTrE, the Planchonia careya, is already used for many years by indigenous people of northern Australia in the treatment of wounds [39]. A previous study in primary macrophages suggested a protective role for glechoma hederacea extract on rheumatoid arthritis and osteoporosis, due to anti-inflammatory actions [40]. In humans, 9(S)-HOTrE can be produced from the essential fatty acid alpha-linolenic acid by the action of 5-lipoxygenase [41]. To investigate the effect of a compound with a comparable structure to $9(\mathrm{~S})$-HOTrE, we tested the effect of $5(\mathrm{~S}), 15(\mathrm{~S})$ DiHETE on apoA-I transcription. Only few studies have focused on this compound, which seems to be involved in attracting white blood cells (eosinophils) via inducing chemotaxis. 5(S),15(S)-DiHETE is synthesized by arachidonate 15-lipoxygenase (ALOX-15) from 5(S)-HETE, which on its turn originates from the polyunsaturated omega-6 fatty acid arachidonic acid [42]. Unfortunately, 5(S),15(S)-DiHETE did not increase apoA-I transcription.

A previous study of our group also found that the cardiac glycoside cymarin increased apoA-I transcription in HepG2 cells. Cymarin is produced by the digitalis plant as a protective mechanism against herbivores or predators [43]. We found that this compound increased transcription of apoA-I by $37 \%$ at doses ranging from 18 to $45 \mu \mathrm{M}$. Currently, some digitalis like digoxins are used in the treatment of certain cardiac arrhythmia and effective when plasma concentrations are around $0.8-2 \mu \mathrm{g} / \mathrm{l}$. Although digoxins are used in the clinic, there is concern about its toxicity, as an in vivo plasma concentration above $3 \mu \mathrm{g} / \mathrm{l}$ could give rise to symptoms of toxicity, accompanied by nausea, fatigue, vomiting or problems with vision [44]. Current guidelines for serum digoxin concentrations range from 0.5 to $0.9 \mathrm{ng} / \mathrm{ml}$, which suggests that the optimal dose for increasing apoA-I mRNA expression that was used in our study (estimated between 10 and $25 \mu \mathrm{g} / \mathrm{ml}$ ) was higher than these concentrations. The structural look a like of this compound, emicymarin increased apoA-I transcription up to $77 \%$. Emicymarin is like cymarin a cardenolide and cardiac glycoside.

Obviously, the bioavailability of any compound that was used in our studies is of importance for its possible in vivo effects on apoA-I transcription. In future experiments, bioavailability can be addressed by using a transwell system that combines intestinal and hepatic cells. Using the metabolites of a compound of interest after it was in contact with the enzymatic content of the stomach and the microbioal ecosystem, for example by using the Simulator of the Human Intestinal Microbial Ecosystem (SHIME), a more in vivo situation could be mimicked. Also, more structural derivatives of the main structures that were presented could be tested for effects on apoA-I transcription. In fact, it would be interesting to test all 


\section{CHAPTER 7}

natural compounds that have a minimum similarity above 0.5 for their effect on apoA-I transcription. To be sure that natural compounds with a high similarity to compounds that were investigated are not toxic, structural look a likes should be tested for both their effect on apoA-I transcription as well as toxicity. Our findings suggest that the lack of effect could be caused by the removal of a specific structural element that is essential for increasing apoA-I transcription. It would be interesting for further research to discover which part of a molecular structure is responsible for the increased apoA-I transcription. In respect to this, a common substructure was found for BRD4 binding compounds of list $\mathrm{C}$. Therefore future studies could test natural compounds that contain this substructure.

In summary, using on literature review based in silico predictions, the effect of equilenin, cymarin and $9(\mathrm{~S})$-HOTrE on apoA-I transcription was confirmed in HepG2 cells. In addition, two new structural look a like compounds eriodictyol and emicymarin were identified that increased apoA-I. Additional experiments are needed to confirm whether these compounds increase apoA-I transcription by inhibiting BRD4.

\section{Acknowledgments}

We would like to thank M. Konings, M. Beckers and J. Tayyeb for their contribution to cell culture experiments.

This research was supported by the Dutch Technology Foundation STW, which is part of the Netherlands Organization for Scientific Research (NWO), and which is partly funded by the Ministry of Economic Affairs. 


\section{SEARCH FOR NATURAL COMPOUNDS TO INCREASE APOA-I}

\section{References}

1. Rohatgi A, Khera A, Berry JD, Givens EG, Ayers CR, et al. (2014) HDL cholesterol efflux capacity and incident cardiovascular events. N Engl J Med 371: 2383-2393.

2. Phillips MC (2014) Molecular mechanisms of cellular cholesterol efflux. J Biol Chem 289: 2402024029.

3. Saleheen D, Scott R, Javad S, Zhao W, Rodrigues A, et al. (2015) Association of HDL cholesterol efflux capacity with incident coronary heart disease events: a prospective case-control study. Lancet Diabetes Endocrinol 3: 507-513.

4. Dullens SP, Plat J, Mensink RP (2007) Increasing apoA-I production as a target for CHD risk reduction. Nutr Metab Cardiovasc Dis 17: 616-628.

5. Smits LP, Kootte RS, Stroes ES (2014) Reversal of atherosclerosis with apolipoprotein A1: back to basics. Atherosclerosis 232: 217-219.

6. Schultz JR, Verstuyft JG, Gong EL, Nichols AV, Rubin EM (1993) Protein composition determines the anti-atherogenic properties of HDL in transgenic mice. Nature 365: 762-764.

7. Rubin EM, Krauss RM, Spangler EA, Verstuyft JG, Clift SM (1991) Inhibition of early atherogenesis in transgenic mice by human apolipoprotein Al. Nature 353: 265-267.

8. Nissen SE, Tsunoda T, Tuzcu EM, Schoenhagen P, Cooper CJ, et al. (2003) Effect of recombinant ApoA-I Milano on coronary atherosclerosis in patients with acute coronary syndromes: a randomized controlled trial. JAMA 290: 2292-2300.

9. Tricoci P, D'Andrea DM, Gurbel PA, Yao Z, Cuchel M, et al. (2015) Infusion of Reconstituted HighDensity Lipoprotein, CSL112, in Patients With Atherosclerosis: Safety and Pharmacokinetic Results From a Phase 2a Randomized Clinical Trial. J Am Heart Assoc 4: e002171.

10. Umemoto T, Han CY, Mitra P, Averill MM, Tang C, et al. (2013) Apolipoprotein Al and high-density lipoprotein have anti-inflammatory effects on adipocytes via cholesterol transporters: ATPbinding cassette A-1, ATP-binding cassette G-1, and scavenger receptor B-1. Circ Res 112: 1345-1354.

11. Epand RM, Stafford A, Leon B, Lock PE, Tytler EM, et al. (1994) HDL and apolipoprotein A-I protect erythrocytes against the generation of procoagulant activity. Arterioscler Thromb 14: 17751783.

12. Drew BG, Duffy SJ, Formosa MF, Natoli AK, Henstridge DC, et al. (2009) High-density lipoprotein modulates glucose metabolism in patients with type 2 diabetes mellitus. Circulation 119: 2103-2111.

13. Dalla-Riva J, Stenkula KG, Petrlova J, Lagerstedt JO (2013) Discoidal HDL and apoA-I-derived peptides improve glucose uptake in skeletal muscle. J Lipid Res 54: 1275-1282.

14. Gilham D, Wasiak S, Tsujikawa LM, Halliday C, Norek K, et al. (2016) RVX-208, a BET-inhibitor for treating atherosclerotic cardiovascular disease, raises $A p O A-1 / H D L$ and represses pathways that contribute to cardiovascular disease. Atherosclerosis 247: 48-57.

15. Kempen HJ, Bellus D, Fedorov O, Nicklisch S, Filippakopoulos P, et al. (2013) Stimulation of Hepatic Apolipoprotein A-I Production by Novel Thieno-Triazolodiazepines: Roles of the Classical Benzodiazepine Receptor, PAF Receptor, and Bromodomain Binding. Lipid Insights 6: 47-54.

16. Zanotti I, Maugeais C, Pedrelli M, Gomaraschi M, Salgam P, et al. (2011) The thienotriazolodiazepine Ro 11-1464 increases plasma apoA-I and promotes reverse cholesterol transport in human apoA-I transgenic mice. Br J Pharmacol 164: 1642-1651.

17. Chung CW, Coste H, White JH, Mirguet O, Wilde J, et al. (2011) Discovery and characterization of small molecule inhibitors of the BET family bromodomains. J Med Chem 54: 3827-3838.

18. Seal J, Lamotte Y, Donche F, Bouillot A, Mirguet O, et al. (2012) Identification of a novel series of BET family bromodomain inhibitors: binding mode and profile of I-BET151 (GSK1210151A). Bioorg Med Chem Lett 22: 2968-2972.

19. Filippakopoulos P, Picaud S, Fedorov O, Keller M, Wrobel M, et al. (2012) Benzodiazepines and benzotriazepines as protein interaction inhibitors targeting bromodomains of the BET family. Bioorg Med Chem 20: 1878-1886.

20. Mirguet O, Lamotte Y, Donche F, Toum J, Gellibert F, et al. (2012) From ApoA1 upregulation to BET family bromodomain inhibition: discovery of I-BET151. Bioorg Med Chem Lett 22: 2963-2967.

21. Princen JMG KT (May 28, 2003) Method for controlling the level of plasma lipoproteins. US patent $6,444,664$ European Patent Specification EP0875247.

22. ChEMBL v https://wwwebiacuk/chembl.

23. Martin YC, Kofron JL, Traphagen LM (2002) Do structurally similar molecules have similar biological activity? J Med Chem 45: 4350-4358. 


\section{CHAPTER 7}

24. Haidari F, Rashidi MR, Mohammad-Shahi M (2012) Effects of orange juice and hesperetin on serum paraoxonase activity and lipid profile in hyperuricemic rats. Bioimpacts 2: 39-45.

25. Brand W, van der Wel PA, Rein MJ, Barron D, Williamson G, et al. (2008) Metabolism and transport of the citrus flavonoid hesperetin in Caco-2 cell monolayers. Drug Metab Dispos 36: 17941802.

26. Lee E, Jeong KW, Shin A, Jin B, Jnawali HN, et al. (2013) Binding model for eriodictyol to Jun-N terminal kinase and its anti-inflammatory signaling pathway. BMB Rep 46: 594-599.

27. Zhu GF, Guo HJ, Huang Y, Wu CT, Zhang XF (2015) Eriodictyol, a plant flavonoid, attenuates LPSinduced acute lung injury through its antioxidative and anti-inflammatory activity. Exp Ther Med 10: 2259-2266.

28. Mokdad-Bzeouich I, Mustapha N, Sassi A, Bedoui A, Ghoul M, et al. (2016) Investigation of immunomodulatory and anti-inflammatory effects of eriodictyol through its cellular anti-oxidant activity. Cell Stress Chaperones 21: 773-781.

29. Zhang WY, Lee JJ, Kim Y, Kim IS, Han JH, et al. (2012) Effect of eriodictyol on glucose uptake and insulin resistance in vitro. J Agric Food Chem 60: 7652-7658.

30. Lee H, Park MT, Choi BH, Oh ET, Song MJ, et al. (2011) Endoplasmic reticulum stress-induced JNK activation is a critical event leading to mitochondria-mediated cell death caused by betalapachone treatment. PLoS One 6: e21533.

31. Bhavnani BR, Stanczyk FZ (2014) Pharmacology of conjugated equine estrogens: efficacy, safety and mechanism of action. J Steroid Biochem Mol Biol 142: 16-29.

32. Zhang X, Jiao JJ, Bhavnani BR, Tam SP (2001) Regulation of human apolipoprotein A-I gene expression by equine estrogens. J Lipid Res 42: 1789-1800.

33. Lamon-Fava S, Posfai B, Asztalos BF, Horvath KV, Dallal GE, et al. (2003) Effects of estrogen and medroxyprogesterone acetate on subpopulations of triglyceride-rich lipoproteins and highdensity lipoproteins. Metabolism 52: 1330-1336.

34. Mosca L, Collins P, Herrington DM, Mendelsohn ME, Pasternak RC, et al. (2001) Hormone replacement therapy and cardiovascular disease: a statement for healthcare professionals from the American Heart Association. Circulation 104: 499-503.

35. Shabana M, Gonaid M, Salama MM, Abdel-Sattar E (2006) Phenylalkylamine alkaloids from Stapelia hirsuta L. Nat Prod Res 20: 710-714.

36. Rao GS (1970) Identity of peyocactin, an antibiotic from peyote (Lophophora williamsii), and hordenine. J Pharm Pharmacol 22: 544-545.

37. Kim KR, An JU, Lee SH, Oh DK (2015) Selective Production of 9R-Hydroxy-10E,12Z,15ZOctadecatrienoic Acid from alpha-Linolenic Acid in Perilla Seed Oil Hydrolyzate by a Lipoxygenase from Nostoc Sp. SAG 25.82. PLoS One 10: e0137785.

38. Masuda A, Takahashi C, Inai M, Miura Y, Masuda T (2013) Chemical evidence for potent xanthine oxidase inhibitory activity of Glechoma hederacea var. grandis leaves (kakidoushi-cha). J Nutr Sci Vitaminol (Tokyo) 59: 570-575.

39. McRae JM, Yang Q, Crawford RJ, Palombo EA (2008) Antibacterial compounds from Planchonia careya leaf extracts. J Ethnopharmacol 116: 554-560.

40. Hwang JK, Erkhembaatar M, Gu DR, Lee SH, Lee CH, et al. (2014) Glechoma hederacea Suppresses RANKL-mediated Osteoclastogenesis. J Dent Res 93: 685-690.

41. Yandava CN, Kennedy BP, Pillari A, Duncan AM, Drazen JM (1999) Cytogenetic and radiation hybrid mapping of human arachidonate 5-lipoxygenase-activating protein (ALOX5AP) to chromosome 13q12. Genomics 56: 131-133.

42. Green FA (1990) Transformations of 5-HETE by activated keratinocyte 15-lipoxygenase and the activation mechanism. Lipids 25: 618-623.

43. Gozalpour E, Wittgen HG, van den Heuvel JJ, Greupink R, Russel FG, et al. (2013) Interaction of digitalis-like compounds with p-glycoprotein. Toxicol Sci 131: 502-511.

44. Vivo RP, Krim SR, Perez J, Inklab M, Tenner T, Jr., et al. (2008) Digoxin: current use and approach to toxicity. Am J Med Sci 336: 423-428. 


\section{SEARCH FOR NATURAL COMPOUNDS TO INCREASE APOA-I}

\section{Supplemental data}

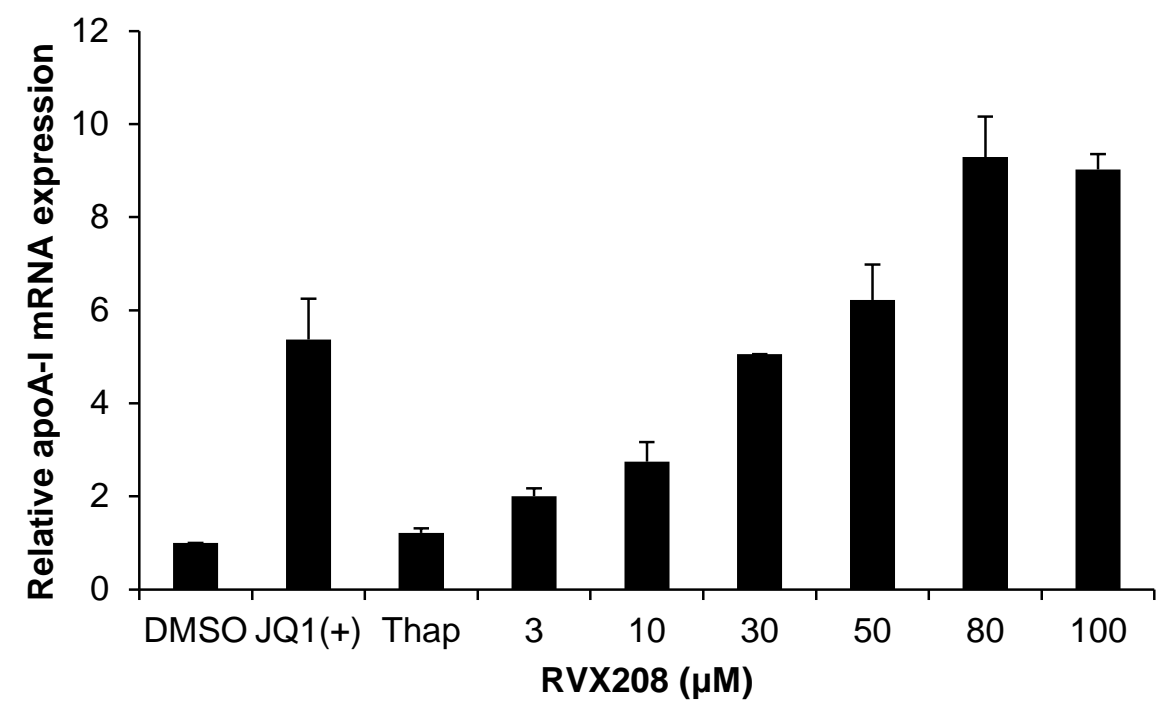

Supplemental figure 1. Relative apoA-I mRNA expression in HepG2 cells treated

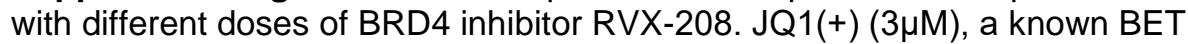
inhibitor and apoA-I increaser, was used as positive control for apoA-I expression. 


\section{CHAPTER 7}

Supplemental table 1. Similarity of compounds from List A and C.

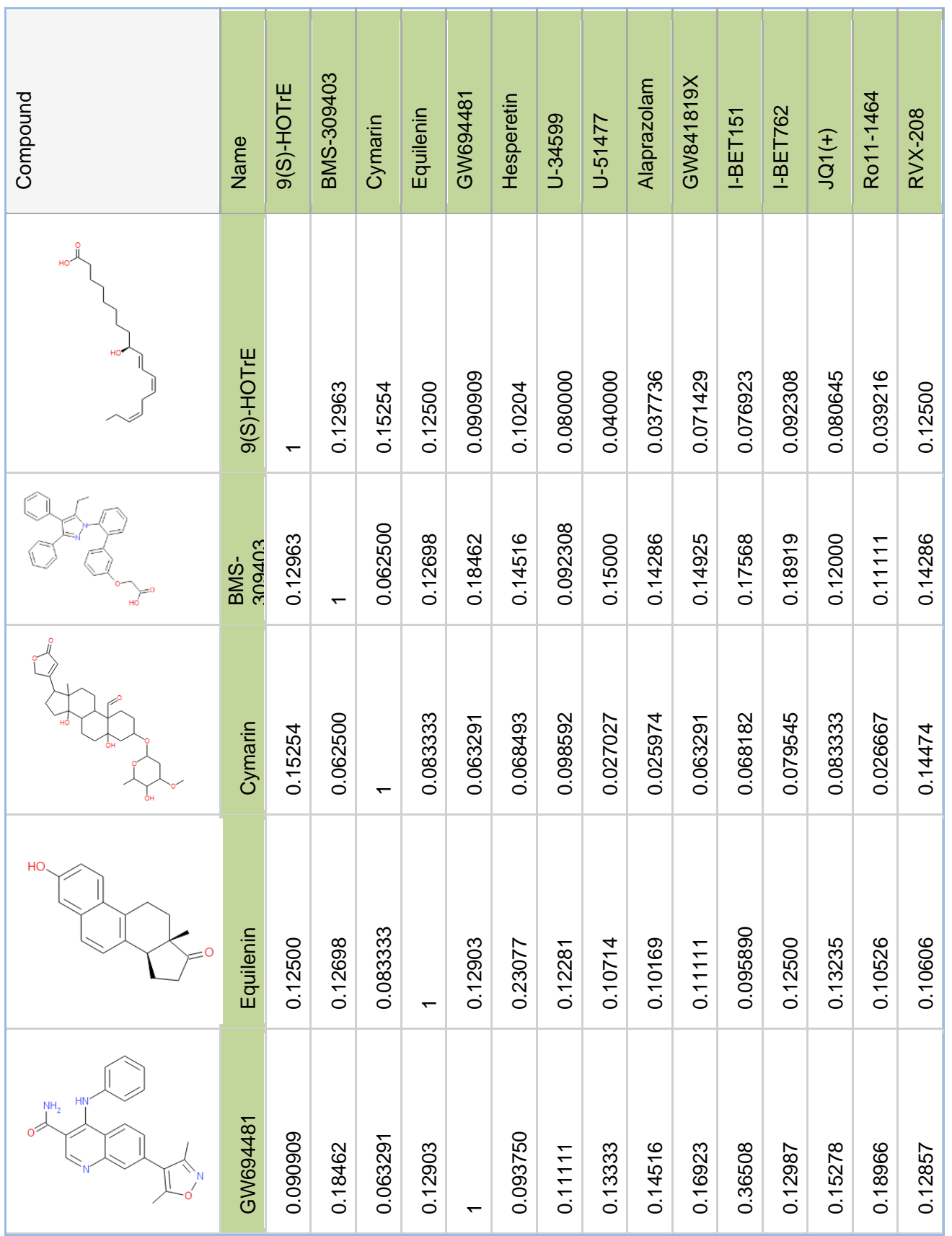




\section{SEARCH FOR NATURAL COMPOUNDS TO INCREASE APOA-I}

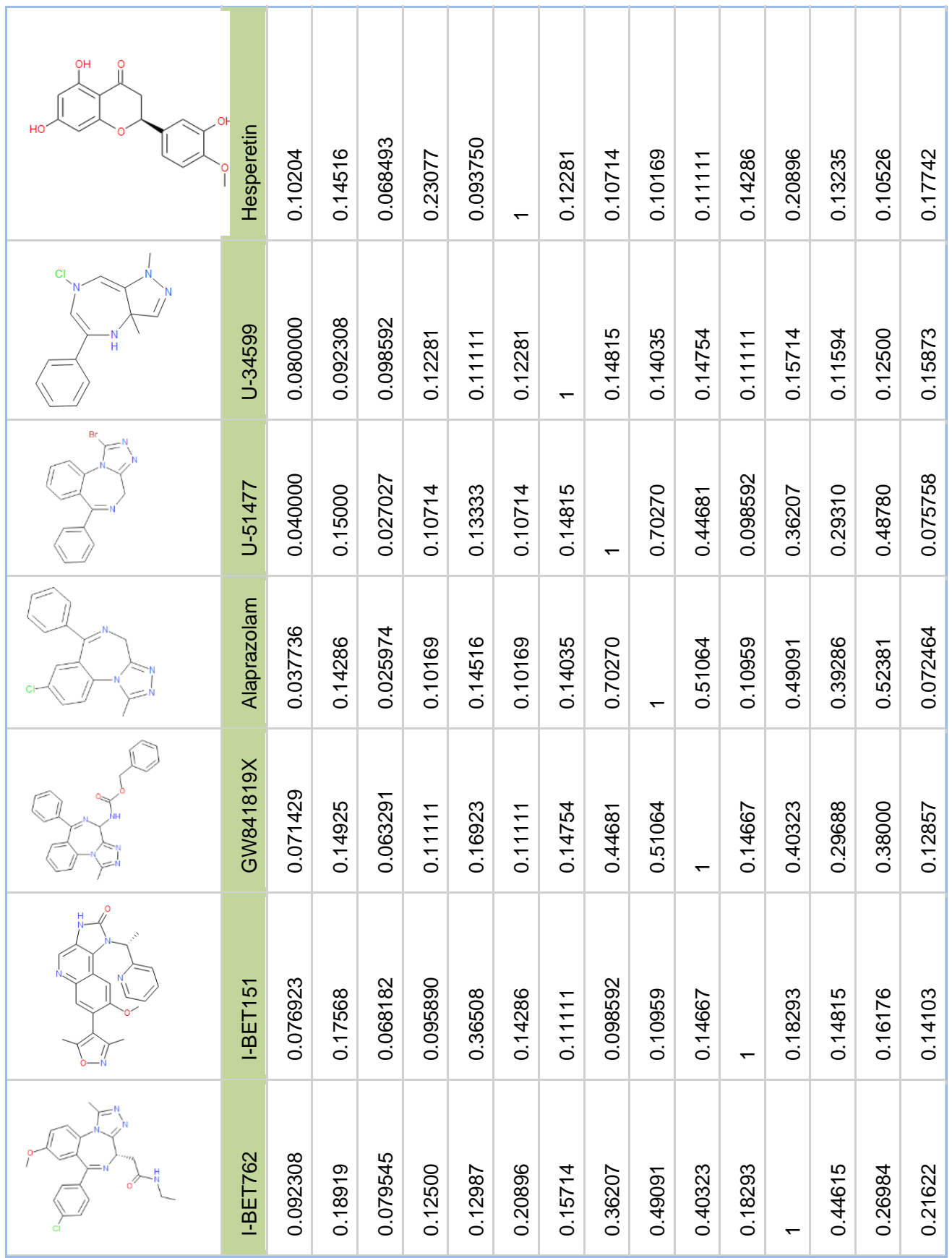




\section{CHAPTER 7}

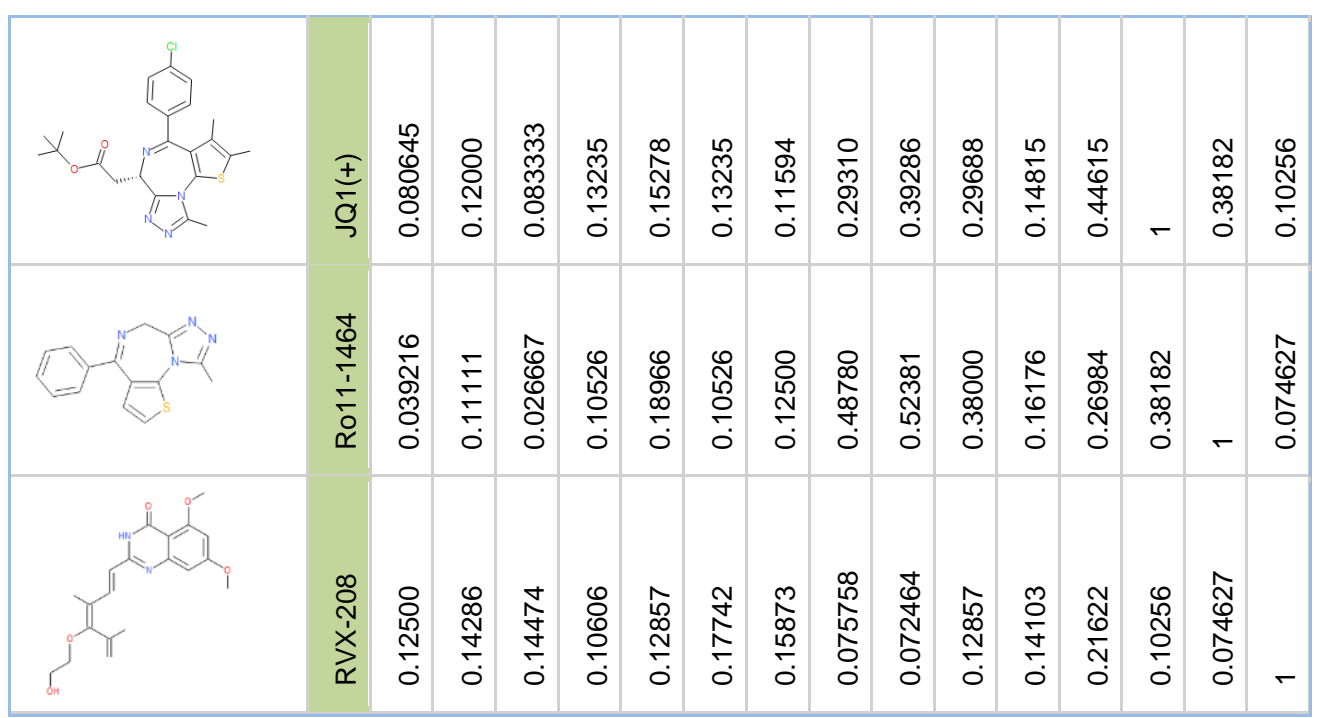




\section{SEARCH FOR NATURAL COMPOUNDS TO INCREASE APOA-I}

Supplemental table $\mathbf{2 a}$. Output of the virtual screening for natural compounds that have a structural similarity to hesperetin in the DSM database. The top 10 of compounds with the highest similarity is shown in this table. For each compound, the name, Chemical Abstracts Service (CAS) number and the similarity to hesperetin is presented. The compound that was selected for additional experiments on apoA-I transcription in HepG2 cells is presented in bold.

\begin{tabular}{lcc}
\hline Name & CAS number & Closest Similarities \\
\hline Homoeriodictyol & $446-71-9$ & 0.88 \\
\hline Isosakuranetin & $480-43-3$ & 0.88 \\
\hline Eriodictyol & $\mathbf{5 5 2 - 5 8 - 9}$ & $\mathbf{0 . 7 9}$ \\
\hline (+/-)-Naringenin & $93602-28-9$ & 0.79 \\
\hline Naringenin & & 0.79 \\
\hline Pinocembrin & $51876-18-7$ & 0.79 \\
\hline 5,7-Dihydroxyflavanone & $51876-18-7$ & 0.79 \\
\hline Sakuranetin & $2957-21-3$ & 0.77 \\
\hline Pinostrobin & $480-37-5$ & 0.74 \\
\hline Alpinetin & $36052-37-6$ & 0.74 \\
\hline
\end{tabular}

Supplemental table $\mathbf{2 b}$. Output of the virtual screening for natural compounds that have a structural similarity to hesperetin in the DNP database. The top 10 of compounds with the highest similarity is shown in this table. For each compound, the name, CAS number and the similarity to compound hesperetin is presented.

\begin{tabular}{|c|c|c|c|}
\hline Name & Derivative & CAS number & $\begin{array}{c}\text { Closest } \\
\text { Similarities }\end{array}$ \\
\hline $\begin{array}{l}\text { 3_p,5,7-Trihydroxy-4_p- } \\
\text { methoxyflavanone }\end{array}$ & & $520-33-2$ & 1.00 \\
\hline $\begin{array}{l}\text { 3_p,4_p,5,7- } \\
\text { Tetrahydroxyflavanone }\end{array}$ & 4_p,7-Di-Me ether & $28590-40-1$ & 0.88 \\
\hline $\begin{array}{l}\text { 3_p,4_p,5,7- } \\
\text { Tetrahydroxyflavanone }\end{array}$ & 3_p-Me ether & $446-71-9$ & 0.88 \\
\hline $\begin{array}{l}\text { 3_p,4_p,5,7- } \\
\text { Tetrahydroxyflavanone }\end{array}$ & 3_p-Me ether & $107657-60-3$ & 0.88 \\
\hline $\begin{array}{l}\text { 5,7-Dihydroxy-4_p- } \\
\text { methoxyflavanone }\end{array}$ & & $480-43-3$ & 0.88 \\
\hline $\begin{array}{l}\text { 3_p,4_p,5,7- } \\
\text { Tetrahydroxyflavanone }\end{array}$ & 3_p,4_p-Di-Me ether & $89294-54-2$ & 0.85 \\
\hline $\begin{array}{l}\text { 3_p,4_p,5,7,8- } \\
\text { Pentahydroxyflavanone }\end{array}$ & 4_p,7,8-Tri-Me ether & $90850-98-9$ & 0.83 \\
\hline 3_p,5,7-Trihydroxyflavanone & 3_p-Me ether & $80368-65-6$ & 0.83 \\
\hline $\begin{array}{l}\text { 3_p,4_p,6- } \\
\text { Trihydroxyflavanone }\end{array}$ & 4_p-Me ether & $124547-60-0$ & 0.82 \\
\hline $\begin{array}{l}\text { 3_p,5,5_p,7- } \\
\text { Tetrahydroxyflavanone }\end{array}$ & 3_p-Me ether & $183857-79-6$ & 0.82 \\
\hline
\end{tabular}




\section{CHAPTER 7}

Supplemental table 3a. Output of the virtual screening for natural compounds that have a structural similarity to equilenin in the DSM database. For each compound, the name, CAS number and the similarity to compound equilenin is presented.

\begin{tabular}{llc}
\hline Name & CAS number & Closest Similarities \\
\hline D-Equilenin & $517-09-9$ & 1.00 \\
\hline
\end{tabular}

Supplemental table $\mathbf{3 b}$. Output of the virtual screening for natural compounds that have a structural similarity to equilenin in the DNP database. The top 10 of compounds with the highest similarity is shown in this table. For each compound, the name, CAS number and the similarity to compound equilenin is presented. The compound that was selected for additional experiments on apoA-I transcription in HepG2 cells is presented in bold.

\begin{tabular}{llc}
\hline Name & CAS number & Closest Similarities \\
\hline Estra-1,3,5,7,9-pentaen-17-one & 0.78 \\
\hline Estra-1,3,5,7,9-pentaene-3,17-diol & 0.68 \\
\hline Estrone & $53-16-7$ & 0.54 \\
\hline Hordenine & 0.53 \\
\hline $\begin{array}{l}\text { 20(10 r5)-Abeo-12-hydroxy-4,5-seco-5,7,9,11,13- } \\
\text { abietapentaen-3-one }\end{array}$ & 0.53 \\
\hline $\begin{array}{l}\text { 20(10 r5)-Abeo-12-hydroxy-13-methyl-4,5-seco- } \\
\text { 5(10),6,8,11,13-podocarpapentaen-3-one }\end{array}$ & 0.51 \\
\hline 3-Hydroxyestra-1,3,5(10),7-tetraen-17-one & $877248-37-8$ & 0.5 \\
\hline 3,8-Dihydroxyestra-1,3,5(10)-trien-17-one & $474-86-2$ & 0.5 \\
\hline 3,14-Dihydroxyestra-1,3,5(10)-trien-17-one & & 0.5 \\
\hline Salvinone & $5949-46-2$ & 0.5 \\
\hline
\end{tabular}




\section{SEARCH FOR NATURAL COMPOUNDS TO INCREASE APOA-I}

Supplemental table $\mathbf{4 a}$. Output of the virtual screening for natural compounds that have a structural similarity to 9(S)-HOTRE in the DSM database. The top 10 of compounds with the highest similarity is shown in this table. For each compound, the name, CAS number and the similarity to compound 9(S)-HOTRE is presented.

\begin{tabular}{llc}
\hline Name & CAS number & ClosestSimilarities \\
\hline cis-5,8,11,14,17-Eicosapentaenoic acid & $10417-94-4$ & 0.65 \\
\hline Aminopimelic acid, DL-a- & $627-76-9$ & 0.65 \\
\hline Linolenic acid & $463-40-1$ & 0.65 \\
\hline Prostaglandin J2 & $60203-57-8$ & 0.61 \\
\hline Prostaglandin A1 & $14152-28-4$ & 0.60 \\
\hline cis-7,10,13,16-Docosatetraenoic acid & $2091-25-0 ; 28874-58-0$ & 0.58 \\
\hline Linoleic acid & $60-33-3$ & 0.58 \\
\hline Hydroxymyristic acid, 3- & $1961-72-4$ & 0.58 \\
\hline Linoleic acid Free Acid & $60-33-3$ & 0.58 \\
\hline Arachidonic acid & $506-32-1$ & 0.58
\end{tabular}

Supplemental table $\mathbf{4 b}$. Output of the virtual screening for natural compounds that have a structural similarity to 9(S)-HOTRE in the DNP database. The top 10 of compounds with the highest similarity is shown in this table. For each compound, the name, CAS number and the similarity to compound 9(S)-HOTRE is presented. The compound that was selected for additional experiments on apoA-I transcription in HepG2 cells is presented in bold.

\begin{tabular}{|c|c|c|c|}
\hline Name & $\begin{array}{l}\text { Derivativ } \\
\text { e }\end{array}$ & $\begin{array}{l}\text { CAS } \\
\text { number }\end{array}$ & $\begin{array}{l}\text { Closest } \\
\text { Similarities }\end{array}$ \\
\hline 5,12-Dihydroxy-6,8,10,14,17-eicosapentaenoic acid & & $80445-66-5$ & 0.96 \\
\hline 4-Hydroxy-5,7,10,13-hexadecatetraenoic acid & & $\begin{array}{l}1607814-44- \\
7\end{array}$ & 0.95 \\
\hline 9-Hydroxy-10,12-pentadecadienoic acid & & $105798-57-0$ & 0.95 \\
\hline $\begin{array}{l}\text { 4,14-Dihydroxy-5,7,10,12,16,19-docosahexaenoic } \\
\text { acid }\end{array}$ & & $1141795-3-0$ & 0.91 \\
\hline 5,18-Dihydroxy-6,8,11,14,16-eicosapentaenoic acid & & $\begin{array}{l}1338215-76- \\
1\end{array}$ & 0.91 \\
\hline 5,15-Dihydroxy-6,8,11,13-eicosatetraenoic acid & & $82200-87-1$ & 0.91 \\
\hline 5,18-Dihydroxy-6,8,11,14,16-eicosapentaenoic acid & & $865532-70-3$ & 0.91 \\
\hline $\begin{array}{l}\text { 4,17-Dihydroxy-5,7,10,13,15,19-docosahexaenoic } \\
\text { acid }\end{array}$ & & $528583-87-1$ & 0.91 \\
\hline $\begin{array}{l}\text { 4,17-Dihydroxy-5,7,10,13,15,19-docosahexaenoic } \\
\text { acid }\end{array}$ & & $578008-42-1$ & 0.91 \\
\hline 15-Hydroxy-5,8,11,13,17-eicosapentaenoic acid & & $86282-92-0$ & 0.88 \\
\hline
\end{tabular}




\section{CHAPTER 7}

Supplemental table 5a. Output of the virtual screening for natural compounds that have a structural similarity to cymarin in the DSM database. The top 10 of compounds with the highest similarity is shown in this table. For each compound, the name, CAS number and the similarity to compound cymarin is presented. The compound that was selected for additional experiments on apoA-I transcription in HepG2 cells is presented in bold.

\begin{tabular}{lcc}
\hline Name & CAS number & Closest Similarities \\
\hline Periplocymarin & & 0.93 \\
\hline Emicymarin & $508-75-8$ & 0.81 \\
\hline Convallatoxin & & 0.80 \\
\hline k-strophanthin beta & 0.78 \\
\hline Folinerin & $465-16-7$ & 0.76 \\
\hline Neriifolin & $466-07-9$ & 0.76 \\
\hline Strophanthidin acetate & & 0.74 \\
\hline Sarmentoside B & & 0.74 \\
\hline Periplocin & $13137-64-9$ & 0.72 \\
\hline Convallatoxin & & 0.71 \\
\hline
\end{tabular}

Supplemental table $5 \mathbf{b}$. Output of the virtual screening for natural compounds that have a structural similarity to cymarin in the DNP database. The top 10 of compounds with the highest similarity is shown in this table. For each compound, the name, CAS number and the similarity to compound cymarin is presented.

\begin{tabular}{lllc}
\hline Name & Derivative & $\begin{array}{l}\text { CAS } \\
\text { number }\end{array}$ & $\begin{array}{l}\text { Closest } \\
\text { Similarities }\end{array}$ \\
\hline 3,5,14-Trihydroxycard-20(22)-enolide & $3-<i>0</ i>-(2,6-$ Dideoxy- & $221380-$ & 0.93 \\
& $3-<i>0</ i>-$ methyl- $\beta-$ & $14-9$ & \\
& $<$ small $>$ D $</$ small $>-$ & \\
& $<i>$ lyxo</i $>-$ & \\
& hexopyranoside $)$
\end{tabular}

\begin{tabular}{llll}
\hline 3,5,14-Trihydroxycard-20(22)-enolide & $3-<\mathrm{i}>\mathrm{O}</ \mathrm{i}>-(2,6-\mathrm{Dideoxy}-$ & $32476-67-$ & 0.93 \\
& $3-<\mathrm{i}>\mathrm{O}<\mathrm{i}>-$ methyl-B- & 8 \\
& $<$ small>D $<$ small $>-$ & \\
& $<\mathrm{i}>\mathrm{r}<\mathrm{i}><\mathrm{i}>\mathrm{i}</ \mathrm{i}><\mathrm{i}>\mathrm{b}</ \mathrm{i}><\mathrm{i}$ \\
& $>0</ \mathrm{i}>-$ hexopyranoside $)$
\end{tabular}




\section{SEARCH FOR NATURAL COMPOUNDS TO INCREASE APOA-I}

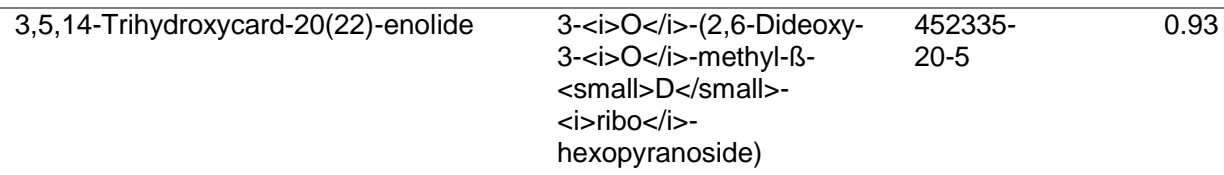

\begin{tabular}{llll}
\hline $3,5,14,16-$ Tetrahydroxy-19-oxocard- & $3-<\mathrm{i}>\mathrm{O}</ \mathrm{i}>-\beta-$ & $905289-$ & 0.92 \\
$20(22)$-enolide & $<$ small>D</small>- & $94-3$ & \\
& Cymaropyranoside & &
\end{tabular}

\begin{tabular}{|c|c|c|}
\hline $\begin{array}{l}\text { 3,5,14,16-Tetrahydroxy-19-oxocard- } \\
20(22) \text {-enolide }\end{array}$ & 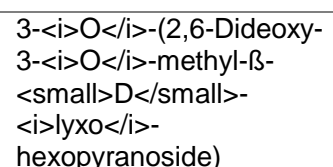 & 0.92 \\
\hline
\end{tabular}

\begin{tabular}{ll}
\hline 3,14-Dihydroxy-19-oxocard-20(22)- & $3-<\mathrm{i}>\mathrm{O}<<$ i $>-(2,6-$ Dideoxy- \\
enolide & $3-<\mathrm{i}>\mathrm{O}<<\mathrm{i}>-$ methyl- \\
& $<$ small $>\mathrm{D}</$ small>- \\
& $<\mathrm{i}>$ ribo $<$ i $>-$ \\
& hexopyranoside $)$
\end{tabular}

\begin{tabular}{|c|c|c|c|}
\hline $\begin{array}{l}\text { 3,14-Dihydroxy-19-oxocard-20(22)- } \\
\text { enolide }\end{array}$ & $\begin{array}{l}3-<\mathrm{i}>\mathrm{O}<\text { <i>-(2,6-Dideoxy- } \\
3-<\mathrm{i}>\mathrm{O}</ \mathrm{i}>- \text {-methyl- } \\
<\text { small }>\mathrm{D}<\text { small }>- \\
<\mathrm{i}>\text { xylo }<\text { i }>- \\
\text { hexopyronoside) }\end{array}$ & $59331-9-8$ & 0.89 \\
\hline
\end{tabular}

\begin{tabular}{lll}
\hline 3,14-Dihydroxy-19-oxocard-20(22)- & $3-<\mathrm{i}>\mathrm{O}</ \mathrm{i}>-(2,6-$ Dideoxy- & 0.89 \\
enolide & $3-<\mathrm{i}>\mathrm{O}</ \mathrm{i}>-$ methyl- \\
& $<$ small $>\mathrm{D}</$ small $>-$ \\
& $<\mathrm{i}>$ xylo $<$ i $>-$ \\
& hexopyranoside $)$
\end{tabular}

\begin{tabular}{|c|c|c|c|}
\hline $\begin{array}{l}\text { 3,14-Dihydroxy-19-oxocard-20(22)- } \\
\text { enolide }\end{array}$ & $\begin{array}{l}3-<\mathrm{i}>\mathrm{O}</ \mathrm{i}>-(2,6-\text {-Dideoxy- } \\
3-<\mathrm{i}>\mathrm{O}</ \mathrm{i}>- \text { methyl- } \\
<\text { small }>\mathrm{D}</ \text { small }>- \\
<\mathrm{i}>\text { ribo }</ \mathrm{i}>- \\
\text { hexopyranoside) }\end{array}$ & $3751-87-9$ & 0.89 \\
\hline
\end{tabular}




\section{CHAPTER 7}

\begin{tabular}{|c|c|c|}
\hline $\begin{array}{l}\text { 3,5,14-Trihydroxy-19-oxocarda-6,20(22)- } \\
\text { dienolide }\end{array}$ & $\begin{array}{l}3-<\mathrm{i}>\mathrm{O}</ \mathrm{i}>-(2,6-\text {-Dideoxy- } \\
3-<\mathrm{i}>\mathrm{O}</ \mathrm{i}>- \text { methyl-B- } \\
<\text { small }>\mathrm{D}</ \text { small }>- \\
<\mathrm{i}>\text { arabino }</ \mathrm{i}>- \\
\text { hexopyranoside) }\end{array}$ & $\begin{array}{l}166900- \\
32-9\end{array}$ \\
\hline
\end{tabular}




\section{SEARCH FOR NATURAL COMPOUNDS TO INCREASE APOA-I}

Supplemental table 6: Top 10 selection of all compounds from the DNP database that contain the common structure $(\mathrm{N}=179)$.

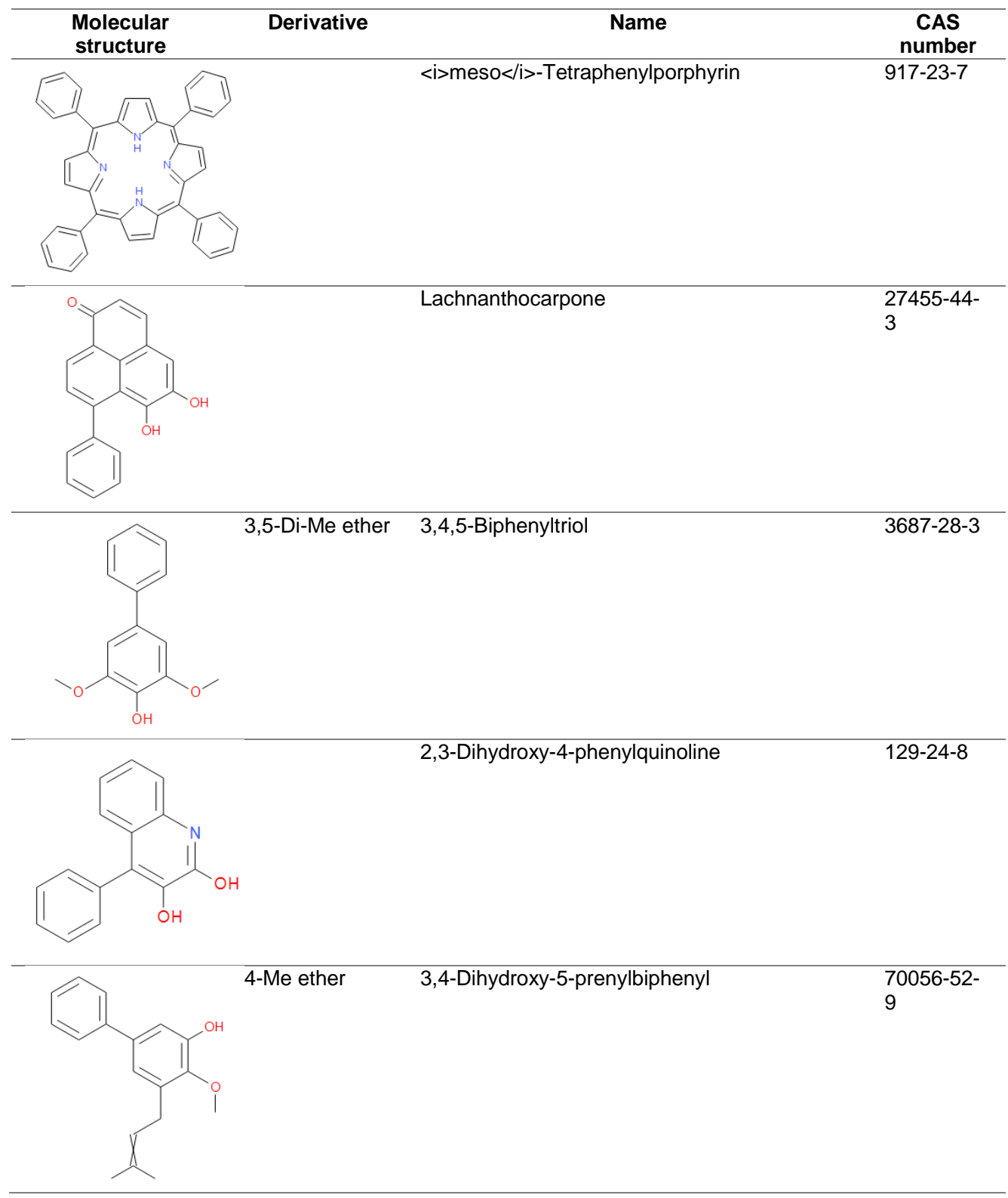




\section{CHAPTER 7}

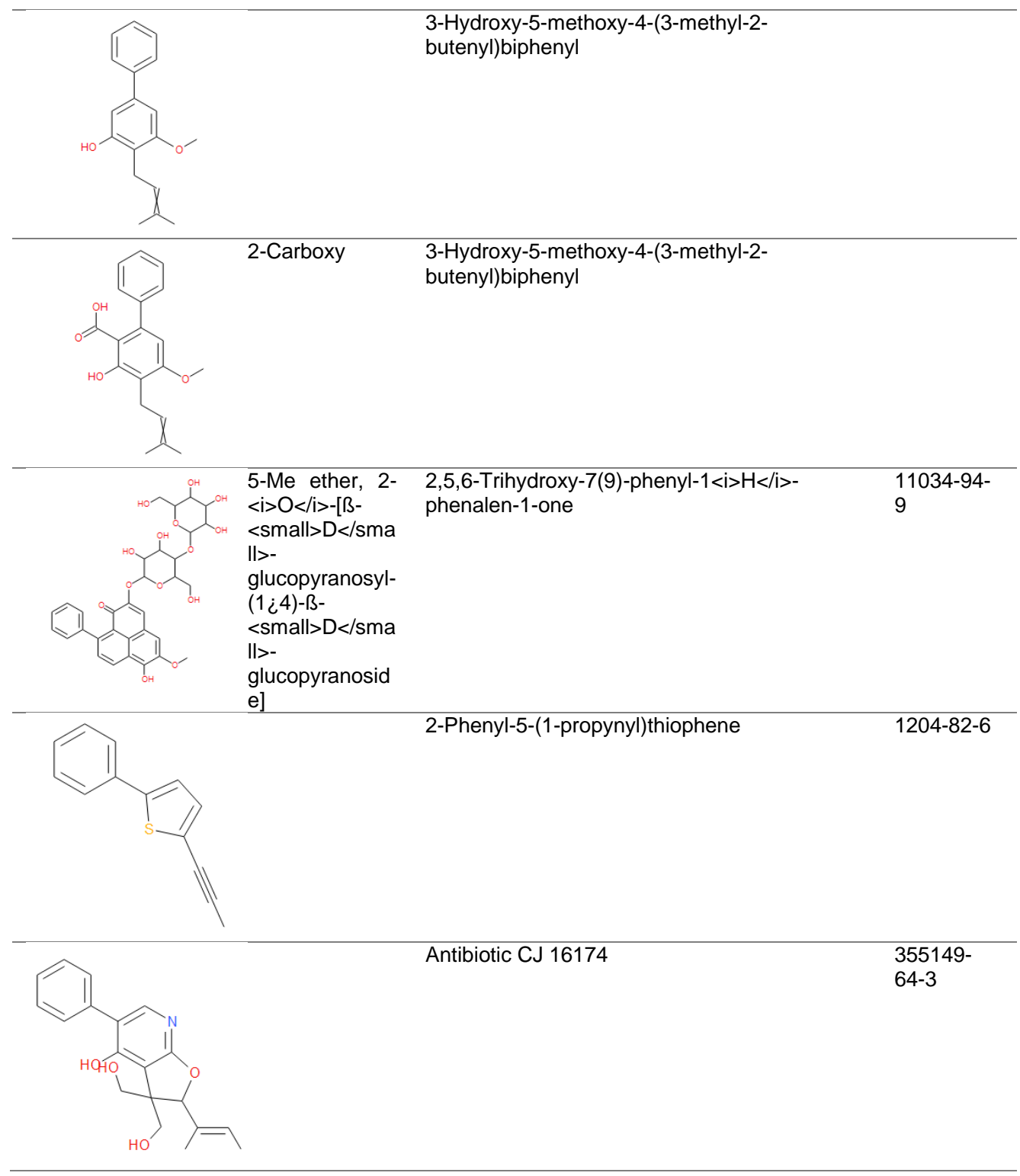




\section{CHAPTER 8}

General discussion 


\section{CHAPTER 8}

\section{General discussion}

\section{Introduction}

Cardiovascular diseases (CVDs) are the leading cause of morbidity and mortality worldwide [1]. In Europe, the CVD related costs add up to 196 billion euros annually and globally the number of CVD related deaths is estimated to grow to 23 million in the year 2030 [2]. Therefore, there is an urgent need to combat the development of this detrimental group of diseases, which is highly associated with the metabolic syndrome. Although several definitions exist, the International Diabetes Federation has defined the metabolic syndrome as the presence of central obesity and minimally two related abnormalities such as an elevated level of triglycerides, reduced HDL cholesterol, raised blood pressure or increased fasting plasma glucose levels [3]. When aiming for prevention or treatment of metabolic disease related disturbances, it is important to realize that the reason behind the current obesity epidemic is multi-factorial. Next to genetic susceptibility, lifestyle is an important contributor to the development of the metabolic syndrome and thus CVD development. Although increased physical activity, weight reduction [4] and cessation of smoking [5] have been shown to decrease CVD risk, these lifestyle changes are often found difficult to maintain. Another important determinant of the metabolic syndrome is the surrounding environment. Our environment drives people towards sedentary behavior, as changes in communication, workplace and technology have reduced the demand for physical activity [6]. Often this is combined with eating high-dense energy and easy-to-obtain foods, in which sugar, fat and salt are added to increase food palatability, without increasing the satiating power [7]. This could contribute to a positive energy balance and subsequently to obesity-induced metabolic disturbances. For example, studies have shown a link between obesity-induced hyperglycemia and the development of cellular ERstress, a pathology in which hepatic apoA-I transcription and production is reduced $[8,9]$. However, ER-stress also damages the pancreatic cells leading to type II diabetes mellitus development [10]. Interestingly, a decrease in sedentary time and increased moderate physical activity on a daily basis is associated with a more favorable plasma lipid profile [11], as HDL and apoA-I levels increase [12]. Increasing apoA-I production may lower the risk for CHD [13,14].

The research presented in this thesis focused on discovering regulatory factors involved in apoA-I transcription (figure 1). Since metabolic disturbances such as ER-stress and inflammation are often present in subjects that suffer from the metabolic syndrome, the effects of these disturbances on apoA-I transcription were evaluated. Additionally, this thesis provided insight into new possibilities to increase apoA-I transcription using natural compounds. 
Metabolic syndrome

related processes

Compounds

(e.g ER-stress, inflammation) (natural, synthetic)

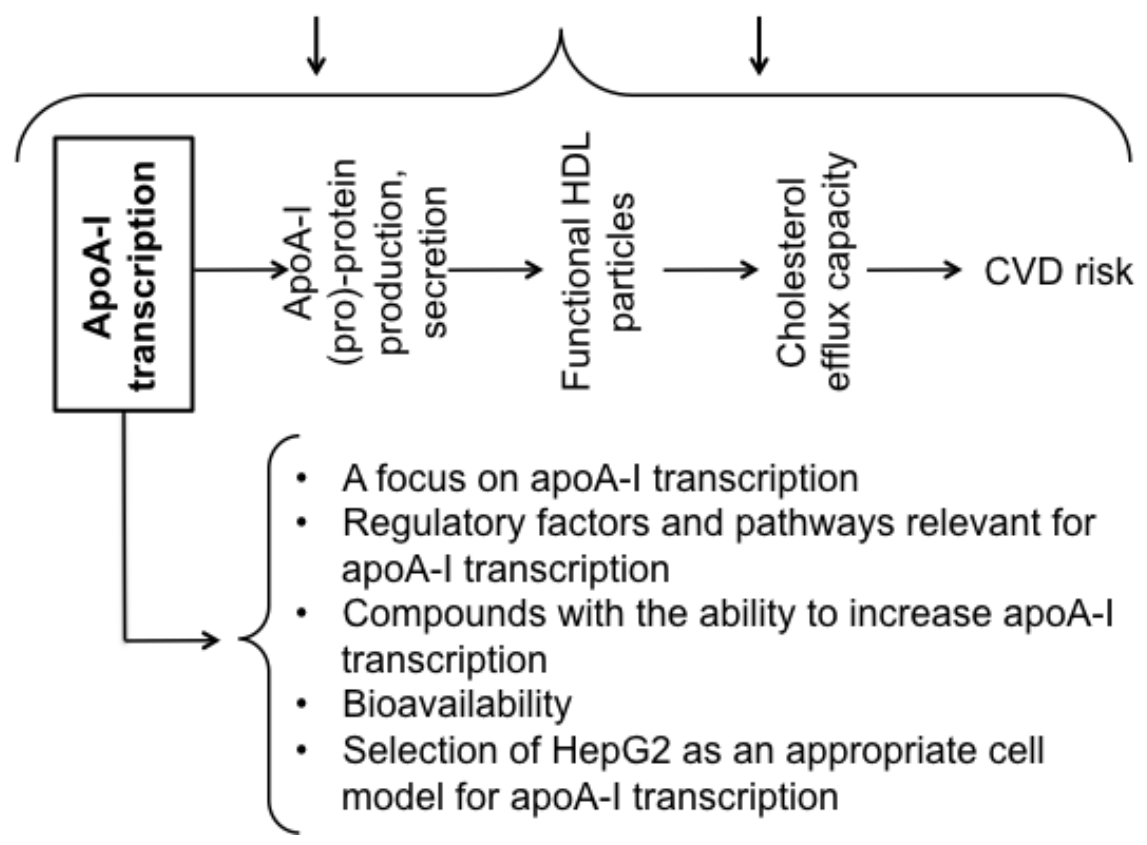

Figure 1. Schematic representation of the main focus of this thesis. Metabolic syndrome related processes or certain (natural or synthetic) compounds can influence CVD risk factors. They could exert their action on different pathways that may eventually affect CVD risk. First of all, natural or synthetic compounds and metabolic syndrome related processes could interfere with the process of apoA-I transcription. Secondly, they could influence apoA-I (pro-) protein production and subsequent (pro-) apoA-I secretion. Thirdly, the formation of functional HDL particles or finally, their cholesterol efflux capacity could be targeted. De novo apoA-I production can lead to the production of more functional HDL particles, thereby contributing to increased cholesterol efflux and related CVD risk reduction. Theoretically, an apoA-I increasing compound will increase apoA-I transcription, which may result in increased production and secretion of the apoA-I protein. Formation of functional HDL via increased apoA-I in the bloodstream enhances cholesterol efflux capacity, which has been related to a reduced risk for atherosclerosis development. CVD related research can be performed at different stages in the apoA-I production cycle. The focus of this thesis is on understanding and manipulating the first step in this process: apoA-I transcription, as is indicated in the figure rectangle in bold. The bullet points in the bottom part of the figure represent the topics that will be discussed in this chapter. 


\section{CHAPTER 8}

\section{A focus on apoA-I transcription}

First of all, this thesis has contributed to the understanding of apoA-I transcription and the discovery of compounds with apoA-I transcriptional regulatory activity in human liver cells. This research provides a basis for future (human) studies on CVD prevention. Accumulating evidence from cholesterol efflux studies points out that increasing apoA-I is a promising strategy for CVD prevention [14]. Although very promising, the use of apoA-I mimetics is a strategy that is focused on curing a patient. To be effective on the long run, any apoA-I mimetic therapy should be applied at a regular basis. Especially, since there is such a large population that needs to be treated, more benefit could be obtained from a preventive strategy to increase apoA-I production levels. Thus, there is an urgent need to increase our understanding on how apoA-I is produced. Therefore, the research described in this dissertation focused on understanding de novo apoA-I transcription. Although there are already some pharmaceutical options to increase apoA-I production (fibrates, BET inhibitors, or synthetic PPARa activators), we searched for compounds of natural or nutritional origin (chapter 4 and chapter 7 ) that have the capacity to increase apoA-I transcription. To lower the financial costs of current CVD treatment and to treat a large population safely, it would be interesting to focus on the ability for natural substances to prevent the onset of CVD. By using natural instead of synthetic compounds, probably smaller effects will be reached compared to using synthetically derived therapies. Like synthetic compounds, natural compounds can also be toxic, as plants often produce toxic products to defend themselves against microbes and herbivores [15]. Studies are therefore needed to assess not only in vivo efficacy, but also the possible toxic effects of these compounds. Eventually, the discovered compounds can be used as a functional food ingredient in the prevention of CVDs. Additionally, it would be interesting to test these compounds also on their effects on lipid profiles of subjects with a higher risk for CVD development, who are for example using statins. Possibly, the discovered agents could be combined with currently available drug therapies.

Besides our aim to identify compounds with regulatory activity on apoA-I transcription, another focus of this thesis was to increase the understanding of the effects of metabolic syndrome related processes (chapter 5), such as endoplasmic reticulum (ER) stress and inflammation, but also the effect of the C/EBP- $\beta$ gene (chapter 3), on apoA-I transcription.

The effect of a certain compound or process on apoA-I induced cholesterol efflux capacity strongly depends on processes that occur from mRNA transcription to the formation of functional HDL particles. All these processes start by the transcription of the apoA-I gene. Theoretically, the transcription of the apoA-I gene leads to the production of apoA-I mRNA. The amount of apoA-I mRNA that will be translated into protein is strongly influenced by post-transcriptional modifications. The next step is the transportation of the pre-pro-apoA-I protein through the ER, where the pre-segment is cleaved off. The remaining pro-apoA-I is then excreted from the cell into the lymph or the circulation $[16,17]$, where the pro-segment is removed by Bone Morphogenetic Protein-1 (BMP-1) and Pro-collagen-C proteinase Enhancer-2 Protein (PCPE2) $[18,19]$. Thus the cleavage of the pro-segment is essential for the 
secretion of apoA-I protein from the cell into the bloodstream. Next, the secreted apoA-I particle binds to the ABCA1 transporter to collect cholesterol and phospholipids. From this point on, the apoA-I particle enables reverse cholesterol transport, thereby reducing cholesterol accumulation in the artery wall, and the risk for atherosclerosis development and related CVD. Obviously, each stage of this pathway is complex and detailed studies are needed to examine the effects of interesting compounds on each step separately, but especially on the effect on HDL functionality in vivo. Looking at our studies, a next step could be to measure apoA-I protein production and release into the circulation.

\section{Regulatory factors and pathways relevant for apoA-I transcription}

\section{PPARa in relation to apoA-I transcription}

Although PPARa is an important player in apoA-I transcription [20,21], mainly due to the presence of a binding place for PPAR in the promoter of apoA-I, not all PPARa agonists increase apoA-I transcription. In chapter 3 we showed that two PPARa activators influenced apoA-I production differently, as fenofibric acid clearly decreased apoA-I protein secretion compared to GW7647. This finding indicates that it is important to gain insight into regulatory transcription factors next to PPARa, which are related to apoA-I secretion. Therefore, we compared genetic expression profiles of fenofibric acid or GW7647 treated CaCo-2 and HepG2 cells using microarrays. We discovered that in the fenofibric acid condition, where apoAI was decreased, expression of genes related to the ER-stress pathway was increased. One of the genes we focused on was the C/EBP- $\beta$ gene, which was differentially expressed between the two treatments and has a binding place in the promoter of apoA-I (chapter 3). Since processes such as ER-stress and inflammation are known to decrease apoA-I transcription and production and are often present during the metabolic syndrome $[8,9,22,23]$, we also tested the effects of the C/EBP- $\beta$ gene under these conditions. Interestingly C/EBP- $\beta$ overexpression or silencing during inflammation, ER-stress or in the untreated situation did not induce changes in apoA-I production. While we have clearly shown successful overexpression of C/EBP- $\beta$ in our HepG2 cell line using western blotting, it would also have been informative to develop a luciferase reporter gene containing the apoA-I promoter and the binding place for C/EBP to ascertain if in our experiments the $\mathrm{C} / \mathrm{EBP}-\beta$ protein that was produced after successful overexpression, indeed bound to the apoA-I promoter. Furthermore, when measuring protein secretion using ELISA, it is unknown if post-transcriptional processes may have interfered with the mRNA translation into protein. This is a main reason why in the remaining chapters in this thesis the focus was on apoA-I transcription.

We showed that the binding of different types of fatty acids to PPARa, including polyunsaturated fatty acids (PUFAs), monounsaturated fatty acids (MUFAs) and saturated fatty acids (SAFAs), did not necessarily result in PPAR $\alpha$ transactivation. Interestingly, some fatty acids (e.g. eicosapentaenoic acid (EPA)) transactivated PPARa at a low dose, but dose-dependently inhibited PPARa transactivation at 


\section{CHAPTER 8}

higher doses (chapter 6). By using a luciferase transactivation study, we discovered that out of 24 PPARa transactivating compounds almost all clearly induced CPT1a mRNA expression (chapter 4). However, apoA-I transcription was only increased by two PPAR $\alpha$ transactivating compounds. Since CPT1 $\alpha$ is a wellaccepted target of PPARa we concluded that the compounds that transactivated PPARa also induced PPARa transcriptional activity. However, the fact that this increased PPAR activity did not translate into increased apoA-I transcription, suggests that additional factors are involved in apoA-I transcription.

\section{ER-stress in relation to apoA-I transcription}

In chapter 5 we investigated the effect of ER-stress on PPARa transcription and activation, and the effect of PPARa activation during ER-stress on apoA-I transcription. We found that ER-stress decreased PPARa mRNA expression and that the activation of PPAR $\alpha$ by GW7647 addition could rescue cells from existing ER-stress. In addition, increasing PPARa activity by GW7647 ameliorated the apoA-I lowering effects of ER-stress.

The outcome of our experiments raises the question if decreasing ER-stress is always beneficial, as the ER-stress pathway can either save a cell in a response to short-term fluctuations in unfolded protein load, but when the ER-stress is prolonged, it may lead to apoptosis. However, earlier studies have suggested that prolonged ER-stress is implicated in the development and progression of many diseases, such as neurodegeneration, type 2 diabetes, liver disease and cancer [24]. Therefore, it would be of interest to focus in future studies on interventions that target to decrease long term (e.g. 24 hour) ER-stress. Moreover, the role of ER-stress in HDL metabolism [24,25] and atherosclerosis development is becoming more evident [26-28]. Apoptosis of the intima of the artery may lead to rupture of arteriosclerotic plaques and consequently to clinical implications caused by thrombus formation [27]. Studies have shown that especially in the unstable atherosclerotic plaque, there are clear signs of ER-stress [29,30]. ER-stress is also known to induce apoptosis in the beta cells of the pancreas, which could induce type II diabetes development [31]. Therefore, it would also be of interest to find ways to prevent or decrease the presence of ER-stress in other cell lines such as pancreatic cells.

\section{BRD4 inhibition in relation to apoA-I transcription}

The family of the Bromodomain and Extra-Terminal domain (BET) protein inhibitors are more and more related to apoA-I transcription [32-35]. Especially, the inhibition of bromodomain-containing protein 4 (BRD4) seems to be involved in the transcription of apoA-I [36]. Our studies have indicated that BET inhibitor JQ1(+) increased apoA-I mRNA production despite the fact that PPARa mRNA and activity was decreased. In other words, the increased apoA-I transcription that results from BRD4 inhibition seems to occur independent of PPARa. Moreover, we showed that BET inhibition by JQ1 (+) clearly rescued cells from present ER-stress (chapter 5), which seemed to attenuate the decreased production of apoA-I. 
BET family members are not only involved in apoA-I transcription, but also in other fundamental biological processes such as BRD4 in transcription machinery recruitment [37], adipogenesis [38] and the related development of obesity [39], whereas BRDT is involved in spermatogenesis [40]. ApoA-I increaser JQ1(+), for example, is also used as a male anti-fertility in mice [41], because it inhibits testes specific BRDT. Next to the involvement of BRD4 inhibition in apoA-I transcription, BET inhibitors possess anti-inflammatory effects $[42,43]$ and are involved in the suppression of proto-oncogenes such as MYC and BCL2 [44,45]. Based on promising effects of pre-clinical studies, in 2013 several phase I clinical safety and efficacy trials were started in human cancer patients [46]. The finding that BET inhibition is applicable and beneficial for treatment of many types of disease highlights the importance of research on the exact mechanism.

\section{Mechanism behind BET inhibition}

Although BRD4 inhibition is a promising strategy to increase apoA-I, the way BET inhibitors exert their effects is not well understood. What is known, is that BET proteins contain two conserved $\mathrm{N}$-terminal bromodomains (BD1 and BD2), which can recognize acetylated lysine residues, an extra terminal domain and a Cterminal recruitment domain (CT motif) [47]. Normally, the BET proteins are mediators of transcription, as they bind P-TEFb via their CT motif, leading to recruitment of the transcription machinery and RNA polymerase II activation [48]. Recruitment of part of the transcription machinery is inhibited by the addition of a BET inhibitor, because the binding of the BET protein to the acetylated lysine residues is prevented, which leads to less accessible DNA [47]. It is interesting, that despite inhibition of the transcription machinery, apoA-I transcription is still increased following BET inhibition. This suggests a possible mechanism, where the inhibition of BRD4 prevents the transcription of another factor that normally suppresses apoA-I gene expression. In addition, it is also possible that BRD4 inhibition diminishes the negative effects of ER-stress (chapter 5) or inflammation. Interestingly, Kokkola et al. [42] have shown that BRD4 inhibition via JQ1(+) decreased the secretion of the inflammatory mediator IL-8 in A549 epithelial cells. They also showed that this was probably explained by the activation of antiinflammatory SIRT1 $[42,49,50]$. Since inflammation, which is often present in the metabolic syndrome, lowers apoA-I production, a reduced inflammation may be beneficial and may be another way how BET inhibition lowers CVD risk.

Several BRD4 inhibitors increase apoA-I transcription, amongst others RVX-208 and JQ1(+). Based on our recent findings (chapter 7, supplemental figure 1) it is evident that for apoA-I transcription in HepG2 cells, RVX-208 is more potent than JQ1(+). In another study, after treatment of HepG2 cells with $0.5 \mu \mathrm{M}$ JQ1(+) or 5 $\mu M$ RVX-208, the transcriptional effect of JQ1(+) was 10 times higher than that of RVX-208 [51]. Thus, even though the dose of JQ1(+) was 10 times lower compared to the dose of RVX-208, JQ1(+) was much more potent in changing general gene expression. A possible explanation is that RVX-208 has only a high affinity for the second binding domains of the BET proteins, while JQ1(+) binds to both binding domains. In general, it would be of great importance for future studies 


\section{CHAPTER 8}

that focus on increasing apoA-I transcription via a BET inhibitor approach, to monitor possible adverse effects of BET-inhibition.

\section{Compounds with the ability to increase apoA-I transcription}

In order to discover natural compounds with the ability to increase apoA-I transcription, we performed two different searches. In the first search, we aimed to find PPARa transactivating compounds via a transactivation assay approach. This search led to the identification of only two compounds (9(S)-HOTrE and cymarin), which clearly increased apoA-I transcription in HepG2 cells (chapter 4). In the second search, we compared the molecular structures of compounds known to increase HDL or apoA-I according to the literature to two natural compound databases. This comparison led to the identification of hesperetin, equilenin, 9(S)HOTrE, and cymarin. Our studies in HepG2 cells revealed that equilenin, 9(S)HOTrE and cymarin indeed increased apoA-I transcription in HepG2 cells, whereas hesperetin did not (table 1). Interestingly, a metabolite of hesperetin, eriodictyol did induce apoA-I transcription. Possibly, hesperetin needs to be converted into eriodictyol to exert its actions on apoA-I transcription (see paragraph Bioavailability).

As substances with a molecular similarity to aforementioned compounds might also be able to increase apoA-I, the structural look a likes eriodictyol, hordenine, 5(S),15(S)-DiHETE and emicymarin were tested for their ability to increase apoA-I. Only eriodictyol, the selected compound with a high similarity to hesperetin, induced apoA-I transcription by 35\% (table 1). Although equilenin, 9(S)-HOTrE, cymarin, eriodictyol and emicymarin clearly increased apoA-I transcription (table 1), the question may arise if their effects on apoA-I transcription is clinically relevant. The answer to this question is not straightforward, since this depends on several issues like the translation of the mRNA into protein, the secretion of the apoA-I protein into the circulation and the capacity of the newly formed apoA-I particles to induce cholesterol efflux from the macrophages or tissues.

Table 1. The effect of the main compounds and their look a like derivatives on apoA-I transcription in HepG2 cells. For each compound the effect on apoA-I transcription is described, where (+) means increased; (-) decreased; and (=) no effect. In case of an increase, the percentage compared to the control condition is reported.

\begin{tabular}{|c|c|c|c|}
\hline Main compound & ApoA-I (+/-/=) & Look a like structure & ApoA-I (+/-) \\
\hline hesperetin & $=/-$ & eriodictyol & $+35 \%$ \\
\hline equilenin & $+27 \%$ & hordenine & $=$ \\
\hline $9(\mathrm{~S})-\mathrm{HOTrE}$ & $+35 \%$ & $5(\mathrm{~S}), 15(\mathrm{~S})$-DiHETE & - \\
\hline cymarin & $+37 \%$ & emicymarin & $+77 \%$ \\
\hline
\end{tabular}




\section{GENERAL DISCUSSION}

The structural comparison of the four main structures hesperetin equilenin, 9(S)HOTrE and cymarin with the natural compound databases, resulted in a long list containing also other compounds with a resemblance of at least 0.5 to each main structure (see supplemental data chapter 7). Obviously, all compounds on this list are interesting in relation to apoA-I transcription and clearly, in future research multiple compounds from this list could be tested for their effect on apoA-I transcription.

\section{Bioavailability}

For all compounds that were (or will be) tested in vitro, bioavailability will influence the effect on apoA-I transcription. The in vivo bioavailability of a compound strongly depends on the digestion and solubility in the gastrointestinal tract, the absorption of the compound by the intestinal cells, transport into the circulation and incorporation from the circulation into the target tissue [52,53]. When performing a study on the effects of one of our main structures hesperetin, equilenin, 9(S)HOTrE and cymarin or their look a like compounds, one should keep in mind that an in vitro cell set up does not take into account the effects of in vivo digestion and bioavailability. There is always a chance that the compound of interest has a different in vivo effect on apoA-I transcription due to the conversion into metabolites or the uptake in the intestine. When a compound does not reach the blood, due to lack of intestinal uptake, it will never reach the liver cells and can not influence hepatic apoA-I production. Moreover, it is very well possible that after the compound is metabolized it reaches the hepatocytes in a different form. To study the effect of a certain compound on apoA-I transcription, the cross talk between the intestine and the liver could be evaluated by using a trans-well system (figure 2). In a trans-well system, intestinal $\mathrm{CaCo}-2$ cells can be cultured on the apical side of the transwell until confluency $(A)$ and the hepatocytes could be plated on the basolateral side in the lower compartment (B). In this way the effect of the compound/ metabolites on the production of both cell lines can be studied. Ideally this experiment would be performed using the (metabolites of a) compound of interest after it has been in contact with the enzymatic content of the stomach and the microbiota in the intestine, for example by using the Simulator of the Human Intestinal Microbial Ecosystem (SHIME) [54]. 


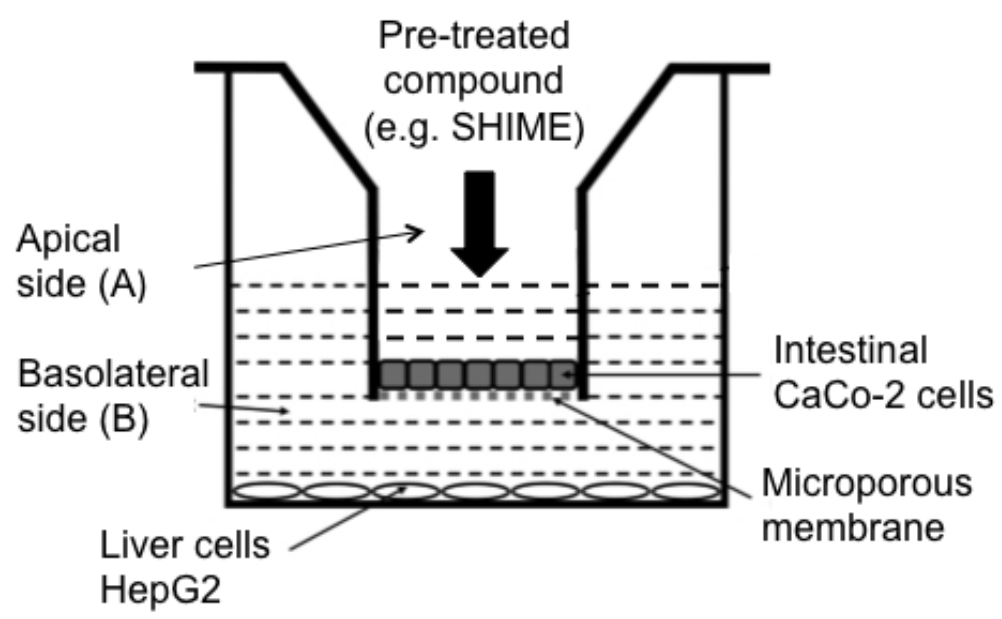

Figure 2. Schematic example of a transwell system. This picture was modified from Fang et al. [55]. The Simulator of the Human Intestinal Microbial Ecosystem (SHIME) pre-treated compound will be added to the apical side of the transwell system, and will have an effect on the CaCo-2 cells that are seeded on the transwell microporous membrane. Using this approach the effect of a compound on both intestinal and hepatic cells can be investigated in a more in vivo reflecting setup.

\section{Selection of HepG2 as an appropriate cell model for apoA-I transcription}

Although the combination of the transwell and SHIME system may be used to address the issue of metabolite formation and bioavailability when performing cell culture studies, it is often questioned how valid the HepG2 cell line is for the human condition. Clearly, to discover compounds that increase apoA-I production there is a need for a human-relevant hepatic cellular model. Currently, human primary hepatocytes are considered the gold standard, whereas human hepatocellular carcinoma (HepG2) cells are most frequently used. The use of each model has its own advantages and disadvantages; therefore there is often discussion on the most appropriate in vitro cell model. Although primary hepatocytes are probably reflecting the in vivo situation better than HepG2 cells, there are individual differences between primary cells of subjects. Possibly these differences are caused by variation in mRNA levels of certain liver cytochrome P450 (CYP) enzymes [56], which are involved in drug metabolism [57]. In relation to this, subjects from which the primary cells are derived often suffer from a severe disease and are treated with medication. Factors like medication, inflammation or ER-stress may thus influence the experimental outcome. HepG2 cells, on the other hand, may have low CYP and phase II enzymes, which suggests they are less suitable for toxicity studies [58-61], as these enzymes are involved in the elimination of toxic compounds from the circulation. However, in another study using HepG2 cells, 243 different drugs with known varying toxicity were validated accordingly [62]. This suggests that HepG2 are in fact a good model for toxicity 
studies.

We performed a side-by-side comparison of the apoA-I producing capacity of two different donors of primary human hepatocytes versus HepG2. In response to $\mathrm{JQ1}(+)$, inflammatory cytokines and ER-stress inducer thapsigargin in general, HepG2 cells seem slightly more responsive as compared to primary cells (figure 3). The positive control for apoA-I transcription JQ1(+) increased apoA-I mRNA production in both cell types. However, in HepG2 cells this response was more pronounced as compared to the response in primary hepatocytes (figure 3 ). Thapsigargin and a mix of cytokines decreased apoA-I mRNA expression in HepG2, but in primary hepatocytes thapsigargin even increased apoA-I mRNA expression. The question now is how to interpret these findings. In comparison to the in vivo situation, metabolic syndrome related processes such as ER-stress and inflammation reduce apoA-I transcription $[8,9,22,23]$. Based on this knowledge and the finding that thapsigargin only decreased apoA-I in the HepG2 cells, it could be suggested the HepG2 cells more closely reflect the in vivo situation. BET inhibitor JQ1(+) has not been used in human studies yet. Therefore, we do not know the normal human in vivo response of this compound. However, since another BET inhibitor RVX-208, which has already been tested in humans, did increase apoA-I transcription, it is likely that the apoA-I increase in HepG2 cells and primary hepatocytes after JQ1(+) addition represents a normal in vivo response. Furthermore, we also tested the effect of RVX-208 in our HepG2 cell model, which clearly resulted in increased apoA-I transcription (chapter 7). Also, the addition of increasing doses of gemfibrozil, a fibrate, is known to increase apoA-I in both human as monkey primary hepatocytes [63]. Based on these findings, it could be suggested that in vitro HepG2 cells responded according to expectations (figure 4). However, in hyperlipidemic patients, gemfibrozil only increased plasma HDL-C, not the plasma apoA-I level, which suggests that an unknown mechanism is responsible for the increase in $\mathrm{HDL}-\mathrm{C}$ that is induced in vivo.

Previously, it was reported that the carcinoma cell line HepG2 has relatively low levels of PPARa compared to normal hepatocyte cells [64]. We have taken this into account by transfecting our HepG2 cells also with PPAR $\alpha$ before treatment with the compounds that were tested for their ability to increase apoA-I transcription. However, we did not find different results, and therefore we decided not to transfect our HepG2 cells before use (data not shown).

Another question relates to the use of freshly plated cells versus cryopreserved cells. In our experiments using the primary cells (figure 3 ), the cells from one donor were plated freshly after surgery, while the cells of a second donor were frozen and thawed before use. Interestingly, similar results were found for apoA-I transcription when using primary hepatocytes of a donor, which were transported frozen (data not shown). This suggests that freezing and thawing of the primary cells did not influence their capacity to transcribe apoA-I.

Based on the discussed findings and results, HepG2 cells seem a suitable model to evaluate compounds that increase apoA-I transcription in vitro. Possibly, in future research for apoA-I elevating compounds, the use of Human Precision Cut Liver Slices (HPCLS) could be implemented. HPCLS are a mini-model in which many features of the natural environment of the liver, such as the different types of 


\section{CHAPTER 8}

cells, tissues, cell matrices remain intact. This may reflect more the in vivo situation, suggesting that it is an appropriate cell model to study apoA-I production. At this moment, it is unknown if liver slices will respond to treatment with compounds that affect apoA-I transcription and if their apoA-I response is similar to the response seen the in vivo situation. Therefore the use of liver slices in order to study apoA-I production should be determined.

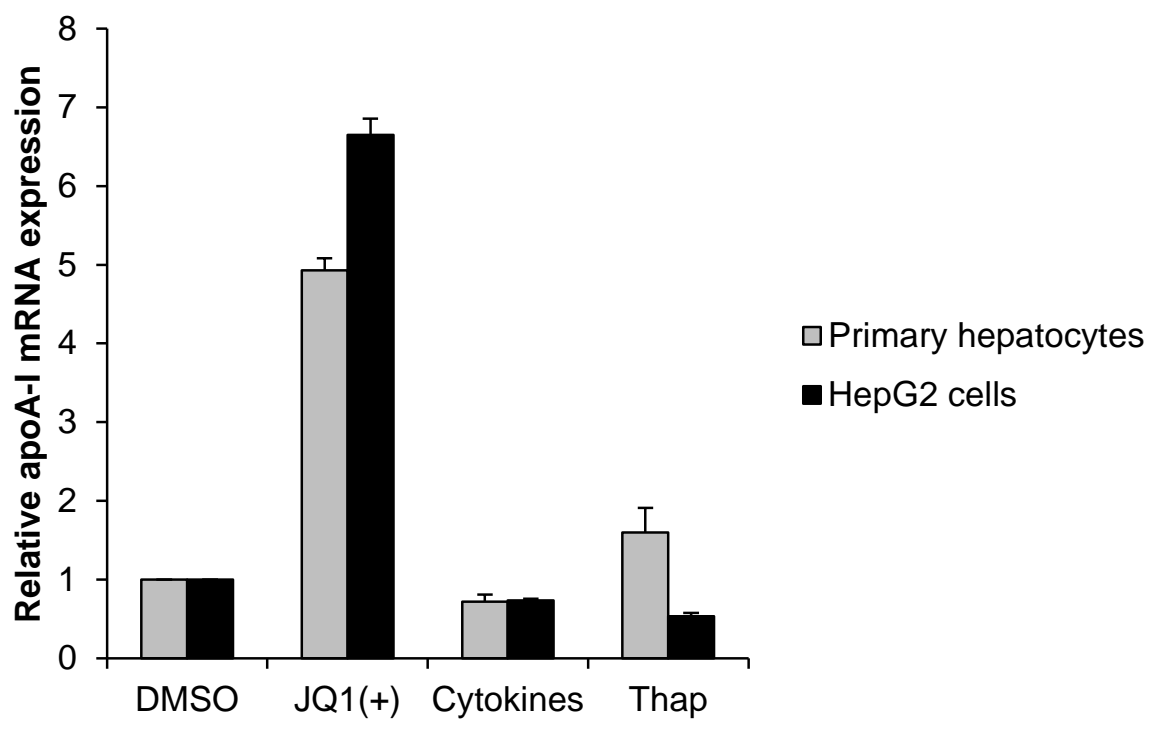

Figure 3. The effect of positive control JQ1(+) $(3 \mu \mathrm{M})$ and negative controls cytokines and thapsigargin $(0.01 \mu \mathrm{M})$ on apoA-I mRNA production in HepG2 cells and in freshly plated primary hepatocytes. 


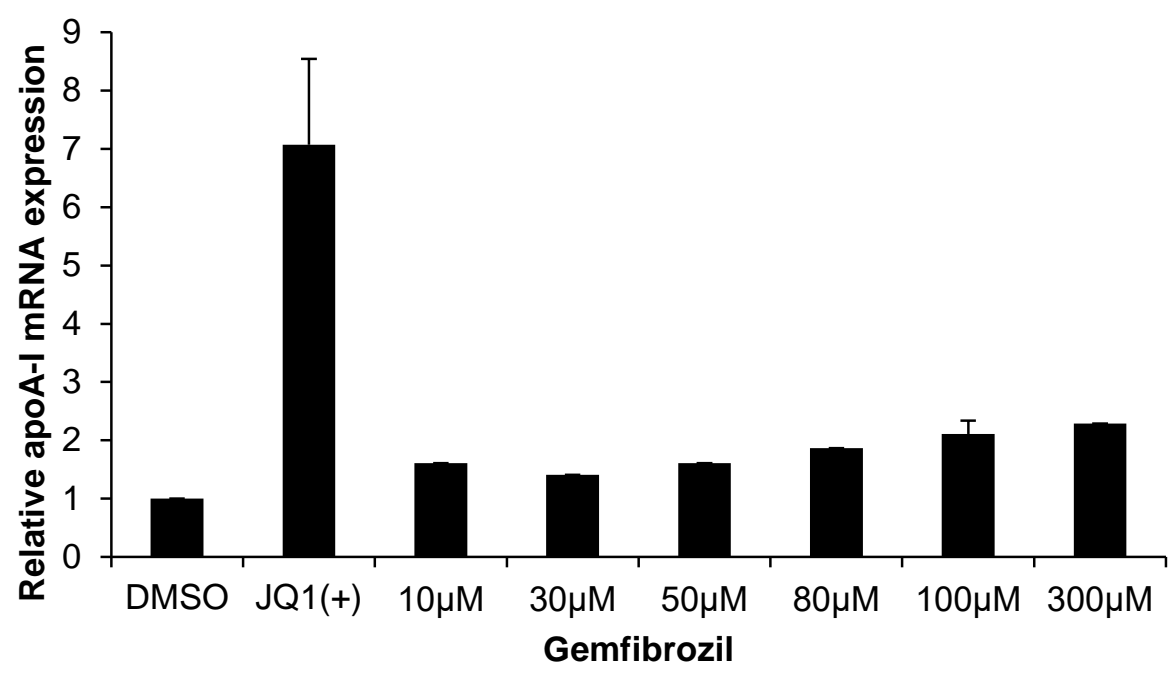

Figure 4. The effect of known apoA-I inducer gemfibrozil on apoA-I transcription in HepG2 cells.

\section{Summary of most important findings and conclusions}

In summary, this dissertation has contributed to an improved understanding of factors and processes involved in apoA-I transcription. We confirmed that PPAR $\alpha$ is certainly important, but is not the only factor involved in apoA-I transcription. Other factors (or processes), which are indicated with the question mark in figure 5, may be involved as well. To investigate which factors may be responsible for differences in apoA-I transcription between two known PPAR activators: fenofibric acid and GW7647, the genetic expression profiles of fenofibric acid or GW7647 treated HepG2 cells were compared. Although this analysis pointed towards a role for the C/EBP- $\beta$ gene in apoA-I production, no link was found between apoA-I production and C/EBP- $\beta$ silencing or overexpression, in (non-) inflammatory or ERstressed conditions. Clearly, ER-stress was more pronounced in the fenofibric acid condition, which directed us towards the effect of ER-stress on apoA-I transcription. We found that ER-stress reduced PPARa transcription and activity in our HepG2 cell model. This suggests that the ER-stress mediated reduction in apoA-I transcription could be partly mediated via inhibition of PPARa mRNA expression and activity. When we provided HepG2 cells with PPARa agonist GW7647 in a situation of present ER-stress, clearly ER-stress was decreased, which showed that ER-stress could be attenuated by PPAR $\alpha$ activation.

Our studies confirmed that BRD4 inhibition is a promising therapy to increase apoA-I transcription, as BET inhibitor JQ1(+) reduced the level of ER-stress in HepG2 cells that were pre-treated with ER-stress inducer thapsigargin. Furthermore, BET inhibitor JQ1(+) increased apoA-I transcription in a PPARa independent manner. 


\section{CHAPTER 8}

Additionally, we searched for a common substructure in BRD4 binding compounds and looked for compounds with this substructure in Dictionary of Natural Products (DNP).

Literature research and in silico structural comparisons to natural databases (DMP and DSM) led to the discovery of the compounds equilenin, 9(S)-HOTrE, cymarin, emicymarin, eriodictyol being apoA-I mRNA increasers.

More information on the goal of each study, the methods, results and corresponding conclusions can be found in table 2 .

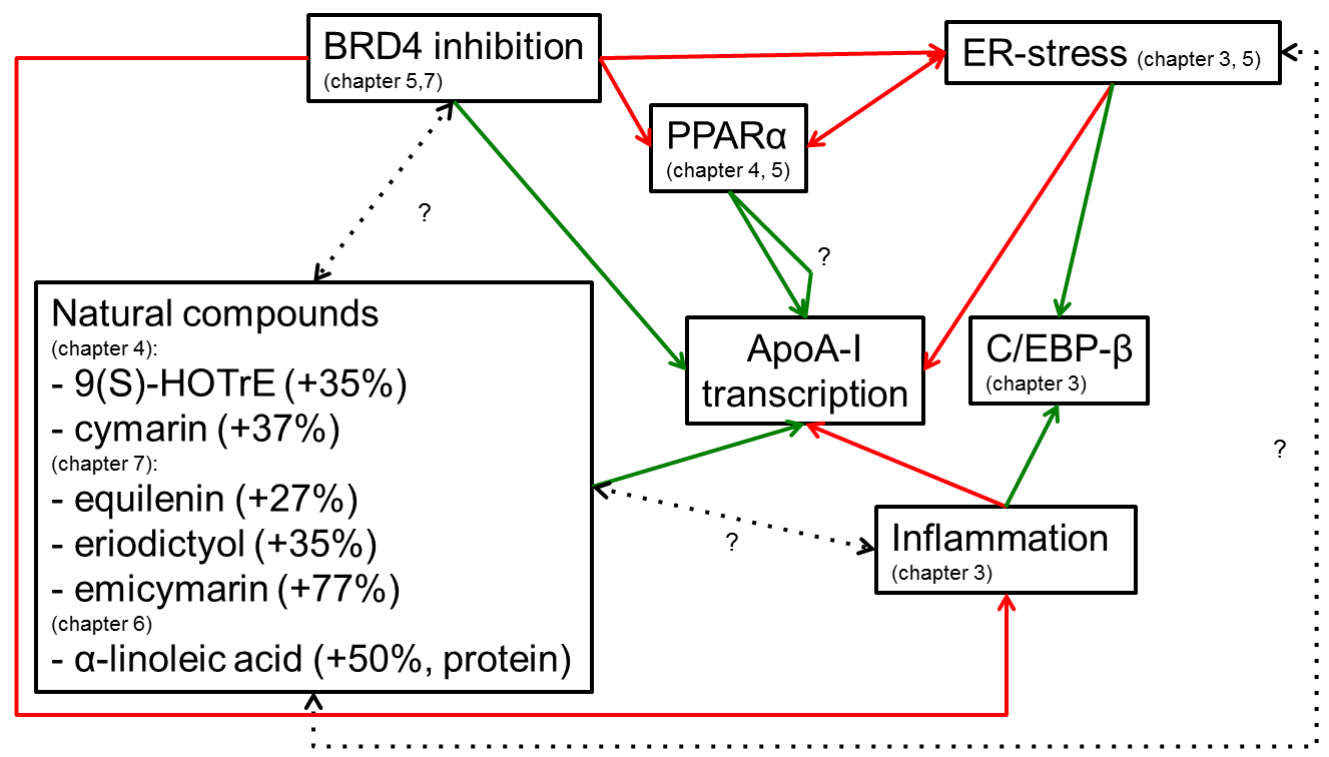

Figure 5. Schematic summary of the natural compounds and processes and their effect on apoA-I transcription (or in the case of $\alpha$-linoleic acid on apoA-I protein production) as mentioned in this dissertation. The red arrows represent a reduction or inhibition, whereas the green arrows symbolize an increase or activation. The dotted lines are unknown links, which could be the focus for future studies. 
Table 2. Table summarizing the most important findings and conclusions of the studies as discussed in chapters 3 to $\mathbf{7}$ of this thesis. Experiments were performed in HepG2 cells, unless stated otherwise.

\begin{tabular}{|c|c|c|c|c|}
\hline & Goal of study & Methods & Main results & Main conclusions \\
\hline $\begin{array}{l}\text { Chapter } \\
3\end{array}$ & $\begin{array}{l}\text { Identify regulatory } \\
\text { factors involved in } \\
\text { apoA-I production }\end{array}$ & $\begin{array}{l}\text { - Microarrays } \\
\text { - Western } \\
\text { blotting } \\
\text { - ELISA: apoA-I } \\
\text {-qPCR: genes } \\
\text { array } \\
\text { - C/EBP- } \beta \\
\text { silencing, } \\
\text { overexpression } \\
\end{array}$ & $\begin{array}{l}\text { - ER-stress related } \\
\text { signature in FeAc } \\
\text { condition } \\
\text { - No effect of C/EBP- } \beta \\
\text { on apoA-I production } \\
\text { (in (non)- inflammatory } \\
\text { or ER-stress } \\
\text { conditions) }\end{array}$ & $\begin{array}{l}\text { C/EBP- } \beta \text { is not a } \\
\text { target for hepatic } \\
\text { apoA-I production }\end{array}$ \\
\hline $\begin{array}{l}\text { Chapter } \\
4\end{array}$ & $\begin{array}{l}\text { I) Discover novel } \\
\text { natural PPARa } \\
\text { transactivating } \\
\text { compounds in } \\
\text { HEK293 (kidney) } \\
\text { cells } \\
\text { II) Determine the } \\
\text { effects of the } \\
\text { identified natural } \\
\text { compounds on } \\
\text { apoA-I } \\
\text { transcription }\end{array}$ & $\begin{array}{l}\text { - PPARa } \\
\text { transactivation } \\
\text { assay in } \\
\text { HEK293 cells } \\
\text { - dose } \\
\text { responses with } \\
\text { compounds of } \\
\text { interest } \\
\text { - qPCR apoA-I }\end{array}$ & $\begin{array}{l}\text { - PPARa } \\
\text { transactivating } \\
\text { compounds increased } \\
\text { CPT1a mRNA } \\
\text { - No significant } \\
\text { correlation between } \\
\text { PPARa transactivation } \\
\text { and CPT1 } 1 \text { mRNA } \\
\text { - 9(S)-HOTrE and } \\
\text { cymarin increased } \\
\text { apoA-I (+35\%, +37\%) } \\
\text { - Cymarin decreased } \\
\text { KEAP1 mRNA }\end{array}$ & $\begin{array}{l}\text { - Activating PPARa } \\
\text { only is not sufficient } \\
\text { to identify } \\
\text { compounds that } \\
\text { elevate apoA-I } \\
\text { transcription } \\
\text { - 9(S)-HOTrE and } \\
\text { cymarin increase } \\
\text { apoA-I transcription } \\
\text { - Cymarin may be a } \\
\text { BRD4 inhibitor }\end{array}$ \\
\hline $\begin{array}{l}\text { Chapter } \\
5\end{array}$ & $\begin{array}{l}\text { Discover possible } \\
\text { links between ER- } \\
\text { stress, PPARa } \\
\text { activation and BET } \\
\text { inhibition in relation } \\
\text { to apoA-I } \\
\text { transcription }\end{array}$ & $\begin{array}{l}\text { - Induce ER- } \\
\text { stress: } \\
\text { thapsigargin } \\
\text { - Induce PPARa } \\
\text { activation: } \\
\text { GW7647 } \\
\text { - Induce BET } \\
\text { inhibition: JQ1(+) } \\
\text { - Western } \\
\text { blotting: ER- } \\
\text { stress markers } \\
\text { - qPCR: PPARa, } \\
\text { KEAP1 and } \\
\text { apoA-I }\end{array}$ & $\begin{array}{l}\text { - ER-stress and BET } \\
\text { inhibition decreased } \\
\text { PPARa (expression } \\
\text { and activity) } \\
\text { - PPARa activation and } \\
\text { BET-inhibition } \\
\text { diminished ER-stress } \\
\text { marker production and } \\
\text { rescued apoA-I } \\
\text { transcription during } \\
\text { existing ER-stress }\end{array}$ & $\begin{array}{l}\text { - ER-stress mediated } \\
\text { reduction in apoA-I } \\
\text { transcription could } \\
\text { be partly mediated } \\
\text { via the inhibition of } \\
\text { PPARa mRNA } \\
\text { expression and } \\
\text { activity } \\
\text { - BET inhibition } \\
\text { increases apoA-I } \\
\text { transcription, even if } \\
\text { PPARa production } \\
\text { and activity are } \\
\text { decreased } \\
\text { - BET inhibition is a } \\
\text { promising strategy to } \\
\text { increase apoA-I }\end{array}$ \\
\hline $\begin{array}{l}\text { Chapter } \\
6\end{array}$ & $\begin{array}{l}\text { Determine dose } \\
\text { response } \\
\text { relationships } \\
\text { between fatty acids } \\
\text { and PPARa } \\
\text { transactivation }\end{array}$ & $\begin{array}{l}\text { - PPARa and } \\
\text { PPAR } \\
\text { response } \\
\text { element } \\
\text { luciferase } \\
\text { reporter } \\
\text { transfection } \\
\text { - Dose } \\
\text { responses with } \\
\text { fatty acids of } \\
\text { interest } \\
\text { - qPCR: PPARa, } \\
\text { ACO, CPT1a } \\
\text { - ELISA: apoA-I }\end{array}$ & $\begin{array}{l}\text { - Except for linoleic } \\
\text { and } \text {-linolenic acid, all } \\
\text { fatty acids studied } \\
\text { dose dependently } \\
\text { changed PPARa } \\
\text { transactivation } \\
\text { - Fatty acids, reported } \\
\text { to bind strongly to } \\
\text { PPARa, could even } \\
\text { repress PPARa } \\
\text { transactivation }\end{array}$ & $\begin{array}{l}\text { - Fatty acid chain } \\
\text { length and saturation } \\
\text { influences } \\
\text { transcriptional } \\
\text { activation and } \\
\text { repression } \\
\text { - Fatty acid binding } \\
\text { can activate or } \\
\text { repress a target } \\
\text { gene }\end{array}$ \\
\hline
\end{tabular}




\section{CHAPTER 8}

\begin{tabular}{|c|c|c|c|c|}
\hline $\begin{array}{l}\text { Chapter } \\
7\end{array}$ & $\begin{array}{l}\text { Discover natural } \\
\text { compounds that } \\
\text { increase apoA-I } \\
\text { transcription. } \\
\text { Focus on BRD4 } \\
\text { inhibitors and other } \\
\text { apoA-I increasers } \\
\text { from literature }\end{array}$ & $\begin{array}{l}\text { - literature } \\
\text { review } \\
\text { - virtual } \\
\text { screening } \\
\text { - dose } \\
\text { responses with } \\
\text { compounds of } \\
\text { interest } \\
\text { - gPCR apoA-I }\end{array}$ & $\begin{array}{l}-60 \% \text { of BRD4 } \\
\text { binding compounds } \\
\text { have the ethylbenzene } \\
\text { substructure in } \\
\text { common } \\
\text { - Literature hits } \\
\text { hesperetin, and } \\
\text { equilenin found in } \\
\text { natural databases } \\
\text { - Effect of compounds } \\
\text { on apoA-I transcription: } \\
\text { Hesperetin: }=/- \\
\text { Equilenin: }+27 \% \\
\text { - Effect of respective } \\
\text { structural variations on } \\
\text { apoA-I transcription: } \\
\text { Eriodictyol: }+35 \% \\
\text { Hordenine: }= \\
5(\mathrm{~S}), 15(\mathrm{~S})-\mathrm{DiHETE}:- \\
\text { Emicymarin: }+77 \%\end{array}$ & $\begin{array}{l}\text { - Natural } \\
\text { compounds } \\
\text { equilenin, eriodictyol } \\
\text { and emicymarin } \\
\text { increase apoA-I } \\
\text { transcription }\end{array}$ \\
\hline
\end{tabular}

\section{Future directions}

The research on apoA-I transcription that was presented in this thesis was performed mostly in HepG2 cells. For future research it is necessary to use additional cell lines or other set ups such as human precision cut liver slices (HPCLS), or the CaCo-2 - HepG2 cell co-cultures in a transwell system using the SHIME protocol, which may reflect more the in vivo situation. Additionally, future research should focus on the effects of the identified compounds, and their look a like structures, on apoA-I under normal, ER-stressed or inflammatory conditions. Possibly, the natural compounds that were found to increase apoA-I transcription (equilenin, 9(S)-HOTrE, cymarin, eriodictyol and emicymarin) reduce the negative effects of metabolic syndrome related disturbances, such as ER-stress and inflammation.

Since BRD4 inhibition is a promising strategy for increasing apoA-I, it would be interesting to confirm if the discovered natural compounds are BRD4 inhibitors. Until now, we have tested two apoA-I increasing compounds for BRD4 inhibition by determining their ability to lower KEAP1 mRNA transcription. Another way to assess BRD4 inhibitor capacity is the use of BRD4 (BD1 or BD2) Inhibitor assays. Future studies could also focus on the effect of the natural compounds that contain the BRD4 common substructure - ethylbenzene - that we identified on apoA-I transcription, protein production and cholesterol efflux capacity. 


\section{References}

1. World Health Organization WHO (June 2016) Cardiovascular diseases (CVDs) fact sheet Available from: http://wwwwhoint/mediacentre/factsheets/fs317/en/.

2. Mathers CD, Loncar D (2006) Projections of global mortality and burden of disease from 2002 to 2030. PLoS Med 3: e442.

3. Federation IID (2006) The IDF consensus worldwide definition of the METABOLIC SYNDROME. obtained from: https://wwwidforg/webdata/docs/IDF_Meta_def_finalpdf.

4. Wing RR, Lang W, Wadden TA, Safford M, Knowler WC, et al. (2011) Benefits of modest weight loss in improving cardiovascular risk factors in overweight and obese individuals with type 2 diabetes. Diabetes Care 34: 1481-1486.

5. Bullen C (2008) Impact of tobacco smoking and smoking cessation on cardiovascular risk and disease. Expert Rev Cardiovasc Ther 6: 883-895.

6. Owen N, Healy GN, Matthews CE, Dunstan DW (2010) Too much sitting: the population health science of sedentary behavior. Exerc Sport Sci Rev 38: 105-113.

7. Stubbs RJ, Whybrow S (2004) Energy density, diet composition and palatability: influences on overall food energy intake in humans. Physiol Behav 81: 755-764.

8. Rohrl C, Eigner K, Winter K, Korbelius M, Obrowsky S, et al. (2014) Endoplasmic reticulum stress impairs cholesterol efflux and synthesis in hepatic cells. J Lipid Res 55: 94-103.

9. Naem E, Haas MJ, Wong NC, Mooradian AD (2013) Endoplasmic reticulum stress in HepG2 cells inhibits apolipoprotein A-I secretion. Life Sci 92: 72-80.

10. Back SH, Kang SW, Han J, Chung HT (2012) Endoplasmic reticulum stress in the beta-cell pathogenesis of type 2 diabetes. Exp Diabetes Res 2012: 618396.

11. Crichton GE, Alkerwi A (2015) Physical activity, sedentary behavior time and lipid levels in the Observation of Cardiovascular Risk Factors in Luxembourg study. Lipids Health Dis 14: 87.

12. Behre C, Bergstrom G, Schmidt C (2010) Moderate physical activity is associated with lower ApoB/ApoA-I ratios independently of other risk factors in healthy, middle-aged men. Angiology 61: 775-779.

13. Dullens SP, Plat J, Mensink RP (2007) Increasing apoA-I production as a target for CHD risk reduction. Nutr Metab Cardiovasc Dis 17: 616-628.

14. Smits LP, Kootte RS, Stroes ES (2014) Reversal of atherosclerosis with apolipoprotein A1: back to basics. Atherosclerosis 232: 217-219.

15. Wink (2009) Mode of action and toxicology of plant toxins and poisonous plants. Mitt Julius KühnInst 421.

16. Pyle LE, Sviridov D, Fidge NH (2001) Characterization of the maturation of human proapolipoprotein A-I in an in vitro model. Biochemistry 40: 3101-3108.

17. Zannis VI, Karathanasis SK, Keutmann HT, Goldberger G, Breslow JL (1983) Intracellular and extracellular processing of human apolipoprotein A-I: secreted apolipoprotein A-I isoprotein 2 is a propeptide. Proc Natl Acad Sci U S A 80: 2574-2578.

18. Chau P, Fielding PE, Fielding CJ (2007) Bone morphogenetic protein-1 (BMP-1) cleaves human proapolipoprotein $A 1$ and regulates its activation for lipid binding. Biochemistry 46: 84458450.

19. Zhu J, Gardner J, Pullinger CR, Kane JP, Thompson JF, et al. (2009) Regulation of apoAl processing by procollagen C-proteinase enhancer-2 and bone morphogenetic protein-1. J Lipid Res 50: 1330-1339.

20. Zannis VI, Kan HY, Kritis A, Zanni EE, Kardassis D (2001) Transcriptional regulatory mechanisms of the human apolipoprotein genes in vitro and in vivo. Curr Opin Lipidol 12: 181-207.

21. Duez H, Lefebvre B, Poulain P, Torra IP, Percevault F, et al. (2005) Regulation of human apoA-I by gemfibrozil and fenofibrate through selective peroxisome proliferator-activated receptor alpha modulation. Arterioscler Thromb Vasc Biol 25: 585-591.

22. Jahangiri A, de Beer MC, Noffsinger V, Tannock LR, Ramaiah C, et al. (2009) HDL remodeling during the acute phase response. Arterioscler Thromb Vasc Biol 29: 261-267.

23. Carpintero R, Pineiro M, Andres M, Iturralde M, Alava MA, et al. (2005) The concentration of apolipoprotein A-I decreases during experimentally induced acute-phase processes in pigs. Infect Immun 73: 3184-3187.

24. Ozcan L, Tabas I (2012) Role of endoplasmic reticulum stress in metabolic disease and other disorders. Annu Rev Med 63: 317-328.

25. Zhou H, Liu R (2014) ER stress and hepatic lipid metabolism. Front Genet 5: 112.

26. Tabas I (2010) The role of endoplasmic reticulum stress in the progression of atherosclerosis. Circ Res 107: 839-850. 


\section{CHAPTER 8}

27. Ivanova EA, Orekhov AN (2016) The Role of Endoplasmic Reticulum Stress and Unfolded Protein Response in Atherosclerosis. Int J Mol Sci 17.

28. Chistiakov DA, Sobenin IA, Orekhov AN, Bobryshev YV (2014) Role of endoplasmic reticulum stress in atherosclerosis and diabetic macrovascular complications. Biomed Res Int 2014: 610140.

29. Bjorkerud S, Bjorkerud B (1996) Apoptosis is abundant in human atherosclerotic lesions, especially in inflammatory cells (macrophages and T cells), and may contribute to the accumulation of gruel and plaque instability. Am J Pathol 149: 367-380.

30. Myoishi M, Hao H, Minamino T, Watanabe K, Nishihira K, et al. (2007) Increased endoplasmic reticulum stress in atherosclerotic plaques associated with acute coronary syndrome. Circulation 116: 1226-1233.

31. Papa FR (2012) Endoplasmic reticulum stress, pancreatic beta-cell degeneration, and diabetes. Cold Spring Harb Perspect Med 2: a007666.

32. Gosmini R, Nguyen VL, Toum J, Simon C, Brusq JM, et al. (2014) The discovery of I-BET726 (GSK1324726A), a potent tetrahydroquinoline ApoA1 up-regulator and selective BET bromodomain inhibitor. J Med Chem 57: 8111-8131.

33. Gilham D, Wasiak S, Tsujikawa LM, Halliday C, Norek K, et al. (2016) RVX-208, a BET-inhibitor for treating atherosclerotic cardiovascular disease, raises $A p 0 A-1 / \mathrm{HDL}$ and represses pathways that contribute to cardiovascular disease. Atherosclerosis 247: 48-57.

34. Mirguet O, Lamotte Y, Donche F, Toum J, Gellibert F, et al. (2012) From ApoA1 upregulation to BET family bromodomain inhibition: discovery of I-BET151. Bioorg Med Chem Lett 22: 2963-2967.

35. Kempen HJ, Bellus D, Fedorov O, Nicklisch S, Filippakopoulos P, et al. (2013) Stimulation of Hepatic Apolipoprotein A-I Production by Novel Thieno-Triazolodiazepines: Roles of the Classical Benzodiazepine Receptor, PAF Receptor, and Bromodomain Binding. Lipid Insights 6: 47-54.

36. Chung $\mathrm{CW}$, Coste $\mathrm{H}$, White $\mathrm{JH}$, Mirguet $\mathrm{O}$, Wilde J, et al. (2011) Discovery and characterization of small molecule inhibitors of the BET family bromodomains. J Med Chem 54: 3827-3838.

37. Bartholomeeusen K, Xiang Y, Fujinaga K, Peterlin BM (2012) Bromodomain and extra-terminal (BET) bromodomain inhibition activate transcription via transient release of positive transcription elongation factor $\mathrm{b}(\mathrm{P}-\mathrm{TEFb})$ from $7 \mathrm{SK}$ small nuclear ribonucleoprotein. $\mathrm{J}$ Biol Chem 287: 36609-36616.

38. Denis GV, Nikolajczyk BS, Schnitzler GR (2010) An emerging role for bromodomain-containing proteins in chromatin regulation and transcriptional control of adipogenesis. FEBS Lett 584: 3260-3268.

39. Wang F, Liu H, Blanton WP, Belkina A, Lebrasseur NK, et al. (2010) Brd2 disruption in mice causes severe obesity without Type 2 diabetes. Biochem J 425: 71-83.

40. Shang E, Nickerson HD, Wen D, Wang X, Wolgemuth DJ (2007) The first bromodomain of Brdt, a testis-specific member of the BET sub-family of double-bromodomain-containing proteins, is essential for male germ cell differentiation. Development 134: 3507-3515.

41. Matzuk MM, McKeown MR, Filippakopoulos P, Li Q, Ma L, et al. (2012) Small-molecule inhibition of BRDT for male contraception. Cell 150: 673-684.

42. Kokkola T, Suuronen T, Pesonen M, Filippakopoulos P, Salminen A, et al. (2015) BET Inhibition Upregulates SIRT1 and Alleviates Inflammatory Responses. Chembiochem 16: 1997-2001.

43. Belkina AC, Nikolajczyk BS, Denis GV (2013) BET protein function is required for inflammation: Brd2 genetic disruption and BET inhibitor JQ1 impair mouse macrophage inflammatory responses. J Immunol 190: 3670-3678.

44. Dawson MA, Prinjha RK, Dittmann A, Giotopoulos G, Bantscheff M, et al. (2011) Inhibition of BET recruitment to chromatin as an effective treatment for MLL-fusion leukaemia. Nature 478: 529-533.

45. Delmore JE, Issa GC, Lemieux ME, Rahl PB, Shi J, et al. (2011) BET bromodomain inhibition as a therapeutic strategy to target c-Myc. Cell 146: 904-917.

46. Shi J, Vakoc CR (2014) The mechanisms behind the therapeutic activity of BET bromodomain inhibition. Mol Cell 54: 728-736.

47. Muller S, Filippakopoulos P, Knapp S (2011) Bromodomains as therapeutic targets. Expert Rev Mol Med 13: e29.

48. Jang MK, Mochizuki K, Zhou M, Jeong HS, Brady JN, et al. (2005) The bromodomain protein Brd4 is a positive regulatory component of P-TEFb and stimulates RNA polymerase II-dependent transcription. Mol Cell 19: 523-534. 
49. Lin L, Wen SH, Guo SZ, Su XY, Wu HJ, et al. (2014) Role of SIRT1 in Streptococcus pneumoniaeinduced human beta-defensin-2 and interleukin-8 expression in A549 cell. Mol Cell Biochem 394: 199-208.

50. Li Y, Wang P, Yang X, Wang W, Zhang J, et al. (2016) SIRT1 inhibits inflammatory response partly through regulation of NLRP3 inflammasome in vascular endothelial cells. Mol Immunol 77: 148-156.

51. Picaud S, Wells C, Felletar I, Brotherton D, Martin S, et al. (2013) RVX-208, an inhibitor of BET transcriptional regulators with selectivity for the second bromodomain. Proc Natl Acad Sci U S A 110: 19754-19759.

52. Etcheverry P, Grusak MA, Fleige LE (2012) Application of in vitro bioaccessibility and bioavailability methods for calcium, carotenoids, folate, iron, magnesium, polyphenols, zinc, and vitamins $B(6), B(12), D$, and E. Front Physiol 3: 317.

53. Wienk KJ, Marx JJ, Beynen AC (1999) The concept of iron bioavailability and its assessment. Eur J Nutr 38: 51-75.

54. Molly K, Vande Woestyne M, Verstraete W (1993) Development of a 5-step multi-chamber reactor as a simulation of the human intestinal microbial ecosystem. Appl Microbiol Biotechnol 39: 254-258.

55. Fang X, Neyrinck AP, Matthay MA, Lee JW (2010) Allogeneic human mesenchymal stem cells restore epithelial protein permeability in cultured human alveolar type II cells by secretion of angiopoietin-1. J Biol Chem 285: 26211-26222.

56. Chang TK, Chen J, Pillay V, Ho JY, Bandiera SM (2003) Real-time polymerase chain reaction analysis of CYP1B1 gene expression in human liver. Toxicol Sci 71: 11-19.

57. Guengerich FP (2008) Cytochrome p450 and chemical toxicology. Chem Res Toxicol 21: 70-83.

58. Rodriguez-Antona C, Donato MT, Pareja E, Gomez-Lechon MJ, Castell JV (2001) Cytochrome P450 mRNA expression in human liver and its relationship with enzyme activity. Arch Biochem Biophys 393: 308-315.

59. Rodriguez-Antona C, Donato MT, Boobis A, Edwards RJ, Watts PS, et al. (2002) Cytochrome P450 expression in human hepatocytes and hepatoma cell lines: molecular mechanisms that determine lower expression in cultured cells. Xenobiotica 32: 505-520.

60. Wilkening S, Stahl F, Bader A (2003) Comparison of primary human hepatocytes and hepatoma cell line Hepg2 with regard to their biotransformation properties. Drug Metab Dispos 31: 10351042.

61. Hewitt NJ, Hewitt P (2004) Phase I and II enzyme characterization of two sources of HepG2 cell lines. Xenobiotica 34: 243-256.

62. O'Brien PJ, Irwin W, Diaz D, Howard-Cofield E, Krejsa CM, et al. (2006) High concordance of druginduced human hepatotoxicity with in vitro cytotoxicity measured in a novel cell-based model using high content screening. Arch Toxicol 80: 580-604.

63. Neele DM, Kaptein A, Huisman H, de Wit EC, Princen HM (1998) No effect of fibrates on synthesis of apolipoprotein(a) in primary cultures of cynomolgus monkey and human hepatocytes: apolipoprotein A-I synthesis increased. Biochem Biophys Res Commun 244: 374-378.

64. Costantini S, Di Bernardo G, Cammarota M, Castello G, Colonna G (2013) Gene expression signature of human HepG2 cell line. Gene 518: 335-345. 
Summary 


\section{SUMMARY}

Cardiovascular diseases (CVDs) are the most frequent cause of morbidity and mortality worldwide. CVDs can be classified as coronary heart diseases (CHDs), cerebrovascular diseases and peripheral arterial diseases. The primary process underlying CHD development is atherosclerosis, which is caused by dyslipidemia. Dyslipidemia, or a disturbed lipid profile, is a key characteristic of the metabolic syndrome. Several in vitro and in vivo studies have shown that increasing apolipoprotein A-I (apoA-I) production, the main protein of the High Density Lipoprotein $(\mathrm{HDL})$ particle, is a promising approach to reduce CVD risk.

In this dissertation we focused on the effects of several (natural) compounds and cellular metabolic syndrome related pathways, such as endoplasmic reticulum (ER) -stress and inflammation, on apoA-I transcription in human hepatocellular carcinoma (HepG2) cells. Additionally, insight into new possibilities to increase apoA-I transcription using natural compounds was provided.

Peroxisome-proliferator-activated-receptor-alpha (PPARa) is involved in apoA-I production, as the apoA-I promoter contains a PPAR binding site. Interestingly, preliminary data showed that PPAR $\alpha$ agonists fenofibric acid and GW7647 exerted different effects on apoA-I production in HepG2 and CaCo-2 cells. To unravel why these agonists differently affected apoA-I production, their gene-expression profiles were compared. Microarray analyses suggested that CCAAT/enhancer-bindingprotein-beta (C/EBP- $\beta$ ) might be responsible for the lower apoA-I production in the fenofibric acid condition. Therefore, the involvement of the C/EBP- $\beta$ gene in disturbances within the metabolic syndrome was reviewed in chapter 2 . The key message was that C/EBP- $\beta$ is involved the differentiation and maturation of adipocytes, with a higher expression during ER- stress and pro-inflammatory conditions. In chapter 3 , the effect of the C/EBP- $\beta$ gene on apoA-I production using C/EBP- $\beta$ silencing and isoform-specific overexpression experiments was evaluated. This role of C/EBP- $\beta$ was investigated in ER-stressed, inflammatory and non-inflammatory conditions. Although a C/EBP binding consensus sequence is present in the apoA-I promoter, C/EBP- $\beta$ silencing or isoform-specific overexpression affected apoA-I production in neither of the tested conditions (normal, inflammation and ER-stress). Therefore, we concluded that C/EBP- $\beta$ was not a regulatory factor to influence hepatic apoA-I production.

Because PPAR $\alpha$ is involved in apoA-I production, in chapter 4 we searched for natural compounds with the ability to increase apoA-I transcription via increasing PPARa transactivation. We showed that 28 out of 2500 natural compounds increased PPARa transactivation by minimally 2 -fold. Dose-response experiments in HepG2 cells using these identified compounds confirmed PPARa activity, as was illustrated by a PPAR a target gene CPT1 $\alpha$. Furthermore, experiments resulted in the discovery of two compounds, 9(S)-HOTrE and cymarin that increased apoA-I transcription in HepG2 cells by $35 \%$ and $37 \%$ respectively. However, these results also illustrate that apoA-I transcription involves multiple regulatory players and PPAR a activation alone is not sufficient.

As endoplasmic reticulum ER stress, bromodomain and extra terminal (BET) protein inhibition and PPARa activation all influence apoA-I transcription, the link between these processes was studied in chapter 5 . We found no link between ERstress and BET inhibition, but both processes decreased PPARa mRNA expression and activity. Interestingly, both BET inhibition and PPARa activation ameliorated the apoA-I lowering effect of ER-stress, which showed that BET inhibition and PPARa activation are interesting targets to elevate apoA-I 
transcription. As BET inhibition increased apoA-I transcription despite of decreased PPARa production and activity, this highlighted the importance of BET inhibition as a promising therapy to increase apoA-I transcription.

Previous studies evaluated binding of fatty acids to the PPARa promoter. However, we found that binding to PPAR $\alpha$ does not necessarily lead to PPAR transactivation. In chapter 6 we examined dose-response relationships between several fatty acids and PPARa transactivation in HepG2 cells. Lauric acid (C12:0) and lower doses of myristic acid (C14:0) increased PPAR $\alpha$ transactivation. Palmitic (C16:0) and stearic acid (C18:0) inhibited, whereas their monounsaturated counterparts palmitoleic (C16:1(n-7)) and oleic acid (C18:1(n-9)) increased PPAR $\alpha$ transactivation. Linoleic $(\mathrm{C} 18: 2(n-6))$ and $y$-linolenic acid $(C 18: 3(n-6))$ did not influence PPAR $\alpha$ transactivation, while $\alpha$-linolenic $(\mathrm{C} 18: 3(\mathrm{n}-3))$ acid strongly increased transactivation. Arachidonic $(C 20: 4(n-6))$, eicosapentaenoic (EPA, C20:5(n-3)), and docosahexaenoic (DHA, C22:6(n-3)) acid all activated PPAR $\alpha$ transactivation at lower doses, but acted at higher concentrations as PPAR $\alpha$ repressors. In line with these results, a-linolenic acid increased and DHA decreased apoA-I protein secretion and PPAR $\alpha$ mRNA expression.

Finally, in chapter 7 we aimed to discover natural compounds to elevate apoA-I transcription in HepG2 cells. Since evidence points towards a role for BRD4 inhibitors in increasing apoA-I transcription, we particularly focused on natural compounds with the ability to bind to BRD4. After a literature search for compounds that could increase apoA-I or HDL concentrations, we generated three lists: list $A$, containing apoA-I increasing compounds with unknown BRD4 proteinbinding capacity (including the compounds that were found to increase apoA-I in chapter 4: 9(S)-HOTrE and cymarin); list $B$ with known BRD4 inhibitors that increased apoA-I production; and list $C$ with reported BRD4 binding function, but with unknown effects on apoA-I production. By in silico comparison, the structures of the compounds on each list were compared to each other and to two natural compound databases. Comparing lists $A$ and $B$ to a natural in house DSM database resulted in the recognition of four compounds: hesperetin, equilenin, 9(S)-HOTrE and cymarin. In list C, a common substructure was discovered in $60 \%$ of all BRD4-inhibitor compounds. This substructure was found in 179 compounds from the Dictionary of Natural Products (DNP). Obviously, it would be interesting to test the effect of these compounds or the ethylbenzene substructure itself on apoAI production in future studies. Experiments in HepG2 cells revealed that equilenin, $9(\mathrm{~S})$-HOTrE and cymarin increased apoA-I transcription respectively by $27 \%, 35 \%$ and $37 \%$ whereas hesperetin did not. For each of these compounds also a structural look a like compound was selected. For hesperetin this look a like was eriodictyol, for equilenin it was hordenine, for 9(S)-HOTrE it was 5(S),15(S)DiHETE and for cymarin we chose emicymarin. Of the structural look a likes, eriodictyol and emicymarin increased apoA-I transcription by $35 \%$ and $77 \%$. Based on these findings, we concluded that next to equilenin, 9(S)-HOTrE and cymarin, which were found in literature and in the study presented in chapter 4, the two natural compounds eriodictyol and emicymarin may be interesting targets for further studies to increase apoA-I production.

In conclusion, the present dissertation contributes to an improved understanding of processes involved in apoA-I transcription. Additionally, new natural compounds were identified that have the potency to increase hepatic apoA-I transcription. 
SUMMARY 


\section{Samenvatting}




\section{SAMENVATTING}

Hart- en vaatziekten (H\&VZ) zijn wereldwijd de belangrijkste oorzaak van ziekte en sterfte. H\&VZ kunnen worden geclassificeerd als coronaire hart ziekten $(\mathrm{CHZ})$, cerebrovasculaire ziekten en perifere vaatziekten en zijn sterk gerelateerd aan een verstoord vetprofiel (dyslipidemie) in het bloed. De primaire oorzaak van het ontwikkelen van $\mathrm{CHZ}$ is atherosclerose, een ontstekingsproces in de vaatwand veroorzaakt door dyslipidemie. Dyslipidemie en atherosclerose zijn sterk geassocieerd met het metabool syndroom. Verschillende in vitro en in vivo studies hebben aangetoond dat het verhogen van apolipoproteine A-I (apoA-I), het hoofdbestanddeel van het Hoge Dichtheid Lipoproteïne (HDL) deeltje, een veelbelovende methode is om het risico op $\mathrm{H} \& \mathrm{VZ}$ te verkleinen.

In dit proefschrift hebben we gefocust op de effecten van verschillende (natuurlijke) stoffen en cellulaire en metabole pathways, waaronder ER-stress en inflammatie, op apoA-I transcriptie in humane levercarcinoma cellen (HepG2). Hiernaast is inzicht verkregen in nieuwe mogelijkheden om de apoA-I transcriptie met behulp van natuurlijke stoffen te verhogen.

Vanuit eerdere studies is bekend dat de transcriptiefactor peroxisome-proliferatoractivated-receptor-alpha (PPAR $\alpha$ ) betrokken is in de productie van apoA-I. De promotor van apoA-I bevat een bindingsplaats voor PPARs. Interessant is dat eerdere data van onze groep heeft aangetoond dat twee PPAR a agonisten fenofibric acid en GW7647 beiden een ander effect hadden op de apoA-I productie in humane carcinoma lever en darm cellen (HepG2 en CaCo-2). Om te achterhalen welke transcriptie- of co-factoren van invloed waren op het ontstaan van deze effecten van deze agonisten op de apoA-I productie is met behulp van de microarray techniek de genexpressie van met fenofibric acid en GW7647 behandelde HepG2 en CaCo-2 cellen vergeleken. Dit resulteerde in de hypothese dat CCAAT/enhancer-binding-protein-beta (C/EBP- $\beta$ ) verantwoordelijk zou zijn voor het de lagere apoA-I productie gezien na behandeling met fenofibric acid. Literatuuronderzoek uit hoofdstuk 2 heeft aangetoond dat het C/EBP- $\beta$ gen betrokken is bij verschillende processen waaronder de differentiatie en maturatie van adipocyten, maar ook bij processen als ER-stress en inflammatie.

Om te onderzoeken of C/EBP- $\beta$ inderdaad een rol speelt in apoA-I productie werd het C/EBP- $\beta$ gen gesilenced of tot overexpressie gebracht in HepG2 cellen, onder normale, inflammatoire en ER-stress geïnduceerde omstandigheden (hoofdstuk 3). Hoewel de promotor van apoA-I ook een bindingsplaats bevat voor C/EBP, zorgde isovorm specifieke overexpressie en silencing van het gehele C/EBP- $\beta$ gen niet voor een verandering in apoA-I productie, ook niet tijdens inflammatie of ERstress. Om deze reden kan men concluderen dat C/EBP- $\beta$ niet betrokken is in apoA-I productie en dus niet bruikbaar is om de productie van apoA-I in levercellen te beïnvloeden.

Aangezien het bekend is dat PPARa betrokken is in de productie van apoA-I, is in hoofdstuk 4 gezocht naar PPARa activerende stoffen. Uiteindelijk zijn uit een lijst van 2500 natuurlijke stoffen 28 PPARa activerende stoffen gevonden. 24 van deze stoffen waren commercieel beschikbaar en zijn dus getest op hun effect op de apoA-I transcriptie in HepG2 cellen. De experimenten met deze natuurlijke stoffen resulteerde in de ontdekking van 9(S)-HOTrE en cymarin, die apoA-I met respectievelijk $35 \%$ en $37 \%$ verhoogden. Op basis van deze data kon men concluderen dat meerder factoren naast PPAR $\alpha$ betrokken zijn in het verhogen van de apoA-I transcriptie in HepG2 cellen. 
De processen endoplasmatisch reticulum (ER)- stress, bromodomein en extra terminal (BET) eiwit inhibitie en PPARa activatie beinvloeden allen de apoA-I transcriptie. Daarom is in hoofdstuk 5 de link tussen deze drie processen bestudeerd. We vonden geen link tussen ER-stress en BET inhibitie, echter beide processen verlaagden PPAR $\alpha$ mRNA expressie en de activiteit van PPAR $\alpha$. Interessant was dat BET inhibitie en PPARa activatie aanwezige ER-stress verminderen, en de het remmende effect van ER-stress op apoA-I transcriptie verminderen. Deze bevindingen lieten zien dat beide processen interessante targets zijn in apoA-I transcriptie. Het feit dat BET inhibitie de apoA-I transcriptie van apoA-I verhoogde terwijl gelijktijdig PPARa productie en activiteit laag was, geeft aan dat BET inhibtie een veelbelovende therapie is om apoA-I transcriptie te verhogen.

Eerdere studies hebben voornamelijk gefocused op de binding van vetzuren aan de promotor van PPARa. In hoofdstuk 6 zijn dosis respons relaties getest van verschillende vetzuren en hun effect op PPARa transactivatie in HepG2 cellen. Uit deze experimenten bleek dat binding aan de promotor van PPARa niet noodzakelijkerwijs tot PPARa transactivatie leidt. Laurinezuur (C12:0) en lagere dosissen myristinezuur (C14:0) verhoogden PPARa transactivatie. Palmitinezuur (C16:0) en stearinezuur (C18:0) remden, terwijl hun enkelvoudig onverzadigde tegenhangers palmitoleïnezuur $(\mathrm{C} 16: 1(\mathrm{n}-7))$ en oliezuur (C18:1(n-9)) PPARa transactivatie verhoogden. Linolzuur (C18:2(n-6)) en gammalinoleenzuur $(C 18: 3(n-6))$ zorgde niet voor een toename van de PPARa transactivatie, terwijl $\alpha$-linoleenzuur (C18:3(n-3)) de transactivatie van PPAR $\alpha$ sterk liet toenemen. Arachidonzuur (C20:4(n-6)), eicosapentaeenzuur (EPA, C20:5(n-3)) en docosahexaeenzuur (DHA, C22:6(n-3)) zorgde voor een verhoging van de PPAR $\alpha$ transactivatie bij lage dosissen, echter bij hogere concentraties gedroegen deze vetzuren zich als repressor van de transactivatie. In lijn met deze resultaten, verhoogde $\alpha$-linoleenzuur en verlaagde DHA de apoA-I protein excretie en PPAR $\alpha$ mRNA expressie.

In hoofdstuk 7 van deze dissertatie is gezocht naar natuurlijke stoffen die de apoA-I transcriptie in HepG2 cellen verhogen. Omdat studies hebben aangetoond dat BET inhibitie, en specifiek de inhibitie van BRD4, tot een verhoging van de apoA-I transcriptie leidt, is in deze studie ook de binding van natuurlijke stoffen aan BRD4 onderzocht. Literatuur onderzoek resulteerde in een lijst $A$ met stoffen die apoA-I verhogen (waaronder 9(S)-HOTrE en cymarin), lijst $B$ met apoA-I verhogende BET inhibitors, en lijst $C$ met BRD4 bindende stoffen (IC50<500nM). Met behulp van in silico vergelijkingen zijn de molecuulstructuren van alle lijsten met elkaar en met twee natuurlijke stoffen databases vergeleken. Het vergelijken van lijst $A$ en $B$ met de natuurlijke databases resulteerde in de bevestiging van vier stoffen die inderdaad natuurlijk bleken te zijn: hesperetin, equilenin, 9(S)-HOTrE en cymarin. In lijst C werd in 60\% van alle stoffen een substructuur gevonden. Deze substructuur is teruggevonden in 179 natuurlijke stoffen uit de database Dictionary of Natural Products (DNP). Het zou interessant zijn om te testen wat het effect van deze ethylbenzeen structuur is op apoA-I transcriptie in toekomstige studies. De experimenten in HepG2 cellen lieten zien dat equilenin, 9(S)-HOTrE en cymarin apoA-I transcriptie verhoogden met respectievelijk $27 \%$, 35\% en $37 \%$. Hesperetin verhoogde apoA-I transcriptie niet. Voor elk van de vier geteste stoffen werd een andere commercieel beschikbare structuur met een zo hoog mogelijke gelijkenis getest. Voor hespeterin was dit eriodictyol. Voor equilenin werd 


\section{SAMENVATTING}

hordenine gekozen, voor 9(S)-HOTrE was dit 5(S),15(S)-DiHETE en voor cymarin werd het effect van emicymarin op apoA-I transcriptie getest. Van de compounds met de hoge structuur gelijkenis zorgde eriodictyol en emicymarin voor een toename in apoA-I van $35 \%$ en $77 \%$. Gebaseerd op deze bevindingen concludeerden we dat, naast 9(S)-HOTrE and cymarin, de compounds eriodictyol and emicymarin interessante nieuwe natuurlijke targets zijn voor toekomstig onderzoek naar het verhogen van de apoA-I productie. In deze dissertatie is een bijdrage geleverd aan een beter begrip van de factoren en processen die betrokken zijn in de apoA-I transcriptie in HepG2 cellen. 
Valorisation 


\section{VALORISATION}

\section{Valorisation}

Atherosclerosis, a chronic inflammatory disease of the artery wall, is the main underlying pathology in cardiovascular disease (CVD) development and is initiated by a disturbed lipid and lipoprotein profile (dyslipidemia). Despite remarkable improvements in therapy and prevention, CVDs still remain the leading cause of mortality worldwide [1]. On a yearly basis, CVDs account for more than 17.3 million deaths and expectations are that this number will grow to more than 23.6 million within the year 2030 [2]. In the United States (U.S.), about 85.6 million people are currently living with some form of CVD or with CVD-related after-effects. Clearly, this goes hand in hand with high CVD-related health costs. In fact, from 2011 to 2012 the direct CVD-related costs in the U.S, which reflect e.g. hospital services, prescribed medications and home health care, were estimated on 193.1 billion dollars. Other CVD-related indirect costs, such as the loss of future productivity, were estimated to be about 123.5 billion dollars. Together this adds up to 316.6 billion dollars in one year [3]. In attempt to reduce the CVD related mortality and the related healthcare costs, extensive research on ways to decrease CVD risk factors is needed. In order to develop interventions that could reduce CVD risk, it is essential to increase our knowledge on underlying pathways that lead to atherosclerosis. Furthermore, research is needed to create new possibilities to target prevention or treatment programs for this pathology.

It is well accepted that increased Low Density Lipoprotein cholesterol (LDL-C) is a major risk for CVD development. This is why therapies aiming to reduce LDL-C have already been successfully developed. However, after effective LDL-C lowering treatment, there often remains a residual risk for CVD development. Clearly, there is a need to discover additional therapies to further reduce the risk for CVD development. Nowadays, there is a wealth of evidence from in vitro and in vivo studies using pharmaceuticals to increase the production of apolipoprotein A-I (apoA-I). Increasing apoA-I, the main protein of High Density Lipoprotein (HDL) particles, is a promising strategy to protect against CVD development [4]. For example, the intravenous infusion of recombinant apoA-I Milano reduced atheroma size in humans [5] and using apoA-I mimetics [6,7], cholesterol efflux capacity is clearly increased. By increasing cholesterol efflux capacity from macrophages in the vessel wall to HDL particles, cholesterol can be transported back to the liver, where it can be used for the production of amongst others bile acids. Moreover, recent evidence suggests that increased cholesterol-efflux capacity protects against development of CVD [8,9] and recurrence of CVD [10].

While there already are some natural products available on the market that decrease the "atherogenic" LDL-C concentrations, such as margarines containing plant sterols or plant stanols, natural dietary products that aim to increase functional HDL particles, in order to increase reverse cholesterol transport and cholesterol-efflux capacity, are not available yet. Development of functional foods that increase functional HDL particle production could help consumers that are looking for a solution to maintain a healthy lipid and lipoprotein profile. Natural BET inhibitors could eventually also be used as a functional food product to reduce the risk for development of other types of diseases, as BET family members are involved in many biological processes. ApoA-I increaser JQ1(+), for example, is also used as a male anti-fertility in mice [11], because it inhibits testes specific 
BRDT. In addition, BET inhibitors possess anti-inflammatory effects [12] and are involved in the suppression of proto-oncogenes [13]. The finding that BET inhibition is beneficial for treatment of many types of disease highlights the importance of research related to this topic.

\section{Societal and economic relevance}

From a scientific point of view, the research described in this dissertation contributed to the fundamental understanding of metabolic disturbed processes and regulatory factors involved in apoA-I transcription and ways to target apoA-I transcription by natural means. After performing safety assessments, the natural compounds that were discovered using both the PPARa screening (chapter 4) and the in silico screening (chapter 7), could be tested in human studies. Moreover, our research provides leads for future in vivo studies, not only within the field of BRD4 inhibition, but also within the field of functional food production. If the discovered natural compounds appear to be safe to use in human subjects, and if they appear to be effective in increasing apoA-I and thereby in inducing cholesterol efflux capacity, this will be of high societal and economic relevance.

Valorisation is described by the National Valorisation Commission as "the process of creating value from knowledge by making knowledge suitable and/or available for societal and/or economic use, and by translating that knowledge into competitive products, services, processes and commercial activities". As discussed earlier, the costs for treatment of CVD related diseases could decline when an additional therapy to increase functional HDL or apoA-I production is available.

The future production of functional food products is a nice example of the translation of obtained knowledge into practice, and from an economical perspective, the production of functional foods contributes to development of the food industry. The Dutch Technology Foundation STW, which is part of the Netherlands Organization for Scientific Research (NWO), and which is partly funded by the Ministry of Economic Affairs, supported the research that was presented in this dissertation. Within this STW project there is close collaboration between scientific researchers, industry and the government. Where researchers contribute to the development of fundamental knowledge, the collaboration with these partners could facilitate a translation of the obtained results into commercially available products.

\section{References}

1. World Health organisation (WHO) (2016) Cardiovascular diseases (CVDs) fact sheet Available from: http://wwwwhoint/mediacentre/factsheets/fs317/en/.

2. Writing Group M, Mozaffarian D, Benjamin EJ, Go AS, Arnett DK, et al. (2016) Heart Disease and Stroke Statistics-2016 Update: A Report From the American Heart Association. Circulation 133: e38-360.

3. Writing Group M, Mozaffarian D, Benjamin EJ, Go AS, Arnett DK, et al. (2016) Executive Summary: Heart Disease and Stroke Statistics--2016 Update: A Report From the American Heart Association. Circulation 133: 447-454.

4. Smits LP, Kootte RS, Stroes ES (2014) Reversal of atherosclerosis with apolipoprotein A1: back to basics. 


\section{VALORISATION}

5. Nissen SE, Tsunoda T, Tuzcu EM, Schoenhagen P, Cooper CJ, et al. (2003) Effect of recombinant ApoA-I Milano on coronary atherosclerosis in patients with acute coronary syndromes: a randomized controlled trial. JAMA 290: 2292-2300.

6. Leman LJ, Maryanoff BE, Ghadiri MR (2014) Molecules that mimic apolipoprotein A-I: potential agents for treating atherosclerosis. J Med Chem 57: 2169-2196.

7. Michael Gibson C, Korjian S, Tricoci P, Daaboul Y, Yee M, et al. (2016) Safety and Tolerability of CSL112, a Reconstituted, Infusible, Plasma-Derived Apolipoprotein A-I, After Acute Myocardial Infarction: The AEGIS-I Trial (ApoA-I Event Reducing in Ischemic Syndromes I). Circulation 134: 1918-1930.

8. Rohatgi A, de Lemos JA, Shaul PW (2015) HDL cholesterol efflux capacity and cardiovascular events. N Engl J Med 372: 1871-1872.

9. Borja MS, Ng KF, Irwin A, Hong J, Wu X, et al. (2015) HDL-apolipoprotein A-I exchange is independently associated with cholesterol efflux capacity. J Lipid Res 56: 2002-2009.

10. Ishikawa T, Ayaori M, Uto-Kondo H, Nakajima T, Mutoh M, et al. (2015) High-density lipoprotein cholesterol efflux capacity as a relevant predictor of atherosclerotic coronary disease. Atherosclerosis 242: 318-322.

11. Matzuk MM, McKeown MR, Filippakopoulos P, Li Q, Ma L, et al. (2012) Small-molecule inhibition of BRDT for male contraception. Cell 150: 673-684.

12. Kokkola T, Suuronen T, Pesonen M, Filippakopoulos P, Salminen A, et al. (2015) BET Inhibition Upregulates SIRT1 and Alleviates Inflammatory Responses. Chembiochem 16: 1997-2001.

13. Dawson MA, Prinjha RK, Dittmann A, Giotopoulos G, Bantscheff M, et al. (2011) Inhibition of BET recruitment to chromatin as an effective treatment for MLL-fusion leukaemia. Nature 478: 529-533. 
Dankwoord 


\section{DANKWOORD}

\section{Dankwoord}

Het is zover, mijn proefschrift is af. Wat voelt dat goed! Aangezien vele mensen aan dit succes hebben bijgedragen is nu is het moment aangebroken om die personen hartelijk te bedanken.

Allereerst wil ik mijn promotoren Prof. dr. Jogchum Plat en Prof. dr. Ronald P. Mensink en co-promotor Dr. Ing. Herman Popeijus bedanken. Terugblikkend op de afgelopen vier jaar heb ik zowel op wetenschappelijk als op persoonlijk niveau ontzettend veel van jullie mogen leren.

Beste Jogchum, bedankt voor jouw aanstekelijke enthousiasme. Ik kan me nog goed herinneren dat ik na onze bijeenkomsten mijn kantoor binnen liep met allerlei nieuwe wetenschappelijke vragen en ideeën. Ik heb veel respect voor de manier waarop jij ondanks je drukke schema altijd voldoende tijd wist vrij te maken voor $\mathrm{mij}$ en je andere promovendi. Dankje voor alle kansen die ik heb gekregen.

Beste Ronald, bedankt voor jouw kritische blik op de manuscripten, je humor en je logische manier van redeneren. Ik heb onze samenwerking de afgelopen vier jaar als prettig ervaren. Het was mooi om met jou te discussiëren over onderzoeksresultaten. Vaak wist jij natuurlijk al lang hoe de vork in de steel zat, maar wilde je het mij horen verdedigen.

Beste Herman, jij was degene die mij introduceerde in de wereld van DNA, transfecties, luciferase assays, RNA isolaties en qPCRs. Toen ik stage bij je kwam lopen heb ik je de oren van je hoofd af gevraagd, zo interessant vond ik het. We hebben samen veel gelachen op het lab. Bedankt voor je hulp bij het maken van prachtige figuren en voor je oneindige betrokkenheid. Ik heb je altijd een hele toegankelijke persoon gevonden en ik vind dat een hele mooie eigenschap.

De leden van de beoordelingscommissie, Prof. dr. E.C.M. Mariman, Prof. dr. A.K. Groen, Prof. dr. S.A.H. Kersten, Dr. S. Rensen en Prof. dr. R. Shiri-Sverdlov wil ik bedanken voor het kritisch beoordelen van dit proefschrift.

Natuurlijk wil ik alle collega's bedanken! Charlotte, Lotte, Bibi, Resy, Dorien, Sabine, Kylie, José, Merel, Daisy, Els, Florence, Nadine en Martine het was fijn om met jullie te discussiëren over data, koetjes en kalfjes en andere zeer belangrijke zaken. Ook Maud en Maurice bedankt voor jullie samenwerking en voor het vakkundig uitvoeren van analyses. Verder heb ik genoten van al onze uitjes, zoals de Efteling, Phantasialand, de kookworkshop en HB/BW-day away.

ledereen van sectie $A$ en sectie $B$ wil ik bedanken voor de mooie herinneringen aan de weekendjes weg naar de Ardennen. Ik geloof dat ik geen enkel weekendje heb overgeslagen. En niet te vergeten het Limburgse Carnaval, het kerstdiner, de borrels en de andere feestjes. In het bijzonder wil ik Jos bedanken, Jos je beschikt over de gave om mensen bijeen te brengen, bedankt hiervoor, zonder jou zou het een stukje minder gezellig zijn op de afdeling!

Silvie, jij hebt mij enthousiast gemaakt voor het onderzoek tijdens jouw studie naar Resveratrol "de rode wijn studie". Je hebt meerdere personen uit mijn familie blij gemaakt met de uitkomst van je studie: "Proost!". Ik ben blij dat we nog steeds contact hebben en wens jou, Jan-Willem, Jolien en niet te vergeten Henkie een mooie toekomst samen. 
Stefan Dullens, hoewel je geen directe collega van mij was, wil ik je bedanken voor de resultaten die je genereerde tijdens jouw promotieonderzoek. Het is dit onderzoek geweest waar ik op verder ben gegaan en gelukkig heeft dit geresulteerd in de publicatie van ons C/EBP- $\beta$ artikel in JCB.

Alle betrokkenen binnen het STW project van DSM en Unilever, bedankt voor de vruchtbare samenwerking en de discussies die we hadden tijdens onze meetings en congressen.

Sander, Steven, Frank, Kim, Junfang en Cathy bedankt voor de samenwerking die we hebben opgezet binnen het leverplakjes project Heelkunde. Het was erg interessant om de kans te krijgen bij de leverchirurgie aanwezig te zijn en de humane lever te verwerken met de tissue slicer. Cathy, Junfang en Kim, wat hebben we die slicer vaak vervloekt samen, als hij weer eens oververhit was of om andere raadselachtige redenen niet werkte. Maar we hebben ook erg veel gelachen. Veel succes gewenst met het afronden van jullie promotie en vervolg carrière.

Wanneer ik zin had in wat vermaak gedurende mijn dagelijkse treinreis op het traject Maastricht- Eindhoven, kon ik bovenin de voorste coupé van de intercity plaatsnemen. Hier trof ik de "trein homies": Birgitta, Marije, Boris en architect Nik (die ik via jullie heb leren kennen. Ook mooi dat ik af en toe alleen met hem in de trein zat en we ook dan hele gesprekken hadden). Met behulp van de groepsapp "trein drama" was iedereen op tijd op de hoogte van alle NS-perikelen. Bedankt voor jullie gezelschap.

Mijn paranimfen verdienen natuurlijk een aparte vermelding in dit meest gelezen hoofdstuk van mijn proefschrift. Lieve Cara en Peter, jullie hebben me gedurende mijn promotietraject altijd gesteund en geholpen waar nodig. Ik kon altijd bij jullie terecht voor een "tas" koffie, een "babbel" en een "schijfke" van Peter op z'n tijd (meestal vrijdag rond 16:00). Leuk trouwens Peter dat we samen naar Above and Beyond zijn geweest. Jij en Cara waren beiden mijn kamergenootjes en in die tijd hebben we elkaar goed leren kennen. Hilarisch vond ik het wanneer we elkaar niet begrepen vanwege de taal barrière (Belgisch vs. Brabants). Ik heb veel nieuwe Belgische woorden van jullie geleerd. Ik wens jullie veel succes met jullie carrière bij $\mathrm{HB} / \mathrm{BW}$ en ik heb goesting om jullie ook na mijn promotie nog vaak te zullen zien. Cara, Peter, bedankt dat je aan mijn zijde wilt staan bij mijn verdediging.

Aan alle leden van o.d.d. Qui Vive zou ik willen zeggen: Prosit senior, prosit corona, ad fundum! Alle leden bedankt voor het leuke contact wat er nog steeds is na alle jaren van studie. Hopelijk blijven we elkaar nog lang ontmoeten.

Dan wil ik me nu richten aan mijn lieve (schoon)familie en vrienden. Bedankt voor jullie oneindige interesse en voor jullie vriendschap. Hoewel voor sommigen lastig te bevatten was wat ik nu precies deed op de Universiteit, ben ik blij dat ik nu eindelijk de vraag "Is je boekje al af?" met een volmondig JA kan beantwoorden. 


\section{DANKWOORD}

Lieve opa en oma, tot op de verdediging! Ik ben blij dat jullie weer aan de beterende hand zijn want onze familie heeft jullie nog heeeel lang nodig.

Lieve pap en mam, bedankt voor alle steun, jullie begrip en alle kansen die jullie me gegeven hebben, niet alleen tijdens dit promotietraject, maar gedurende mijn hele leven. Alles wat ik tot nu toe bereikt heb, heb ik aan jullie te danken! Jullie zijn de beste ouders die iemand zich maar kan wensen en ik hou van jullie.

En mijn grote broer Thomas. Wat vind ik jou toch geweldig. Je bent zo goed in wat je doet en je beschikt over eigenschappen waar ik nog veel van zou kunnen leren. Ik vind het heel fijn dat ik jou de laatste tijd zo veel zie en ik kijk uit naar onze toekomstige familie. Ik wens jou en Meike veel geluk en dat jullie maar goed mogen "ritsen", aldus je vader.

Lieve Sjors, bedankt voor al jouw steun en liefde, voor je nuchtere advies, je logica en die armen waarin ik me zo graag laat vallen! Wij zijn echt een goed team samen. Ik kan niet wachten op alle dingen die wij in de toekomst gaan meemaken. En het maakt mij niet uit, als het maar met jou is. Ik hou van jou! 
Curriculum Vitae 


\section{CURRICULUM VITAE}

Sophie Elise van der Krieken was born on April $8^{\text {th }}, 1989$ in Eindhoven, the Netherlands. She completed secondary school at Rythovius College in Eersel in 2007. From 2007 until 2010 she studied Health Sciences with specializations Bioregulation and Health and Physical Activity and Health, at Maastricht University. Under supervision of prof. dr. Patrick Schrauwen and dr. Silvie Timmers she studied the effects of Resveratrol on mitochondrial function in healthy obese men. In 2012 she graduated for the Research Master in Nutrition and Metabolism (NUTRIM): Fundamental and Clinical aspects. Her master internships were on optimizing transfection efficiency of histon-GFP in HepG2 and CaCo-2 cells and research on molecular pathways in apolipoprotein A-I (apoA-I) production. From 2012 until 2016 she worked on her PhD project "Identification of natural components to elevate HDL cholesterol concentrations through increasing apoA-I production", at the department of Human Biology \& Human Movement Sciences at Maastricht University, under supervision of prof. dr. Jogchum Plat, prof. dr. ir. Ronald P. Mensink and co-promoter dr. ing. Herman Popeijus. Her PhD project was supported by the Dutch Technology Foundation STW, which is part of the Netherlands Organisation for Scientific Research (NWO) and partly funded by the Ministry of Economic Affairs. The research that was performed during this $\mathrm{PhD}$ project is described in this dissertation, entitled "Interventions to increase apolipoprotein A-I transcription in HepG2 cells". Sophie has presented her project results at several national and international congresses. 


\section{List of publications}




\section{Published manuscripts}

Van der Krieken SE, Popeijus HE, Mensink RP, Plat J. Link between ER-stress, PPARa activation and BET Inhibition with Apolipoprotein A-I Transcription in HepG2 cells. Journal of cellular Biochemistry. 2016

Van der Krieken SE, Popeijus HE, Konings M, Dullens SPJ, Mensink RP, Plat J. C/EBP- $\beta$ is differentially affected by PPARa agonists Fenofibric acid and GW7647, but does not change apolipoprotein A-I production during ER-stress and inflammation. Journal of cellular Biochemistry. 2016

Van der Krieken SE, Popeijus HE, Konings M, Mensink RP, Plat J.Review: CCAAT/enhancer binding protein $\beta$ in relation to inflammation, ER-stress and metabolic disturbances in the metabolic syndrome. BioMed Research Int. 2015.

Popeijus HE, van Otterdijk SD, Van der Krieken SE, Konings M, Serbonij K, Plat J, Mensink RP.

Fatty acid chain length and saturation influences PPARa transcriptional activation and repression in HepG2 cells. Mol Nutr Food Res. 2014.

Timmers S, Konings E, Bilet L, Houtkooper RH, van de Weijer T, Goossens GH, Hoeks J, van der Krieken SE, Ryu D, Kersten S, Moonen-Kornips E, Hesselink MK, Kunz I, Schrauwen-Hinderling VB, Blaak EE, Auwerx J, Schrauwen P. Calorie Restriction-like Effects of 30 Days of Resveratrol Supplementation on Energy Metabolism and Metabolic Profile in Obese Humans. Cell Metabolism 2011;14:612-622.

\section{Book chapter}

Popeijus HE, Van der Krieken SE. C/EBP- $\beta$, CCAAT/enhancer binding protein B. Encyclopedia of Signaling Molecules, 2nd Edition. 2016. Accepted.

\section{Submitted or in preparation:}

Van der Krieken SE, Popeijus HE, Mensink RP, Plat J. Identification of natural PPAR $\alpha$ transactivating compounds and their effect on apolipoprotein A-I transcription in human liver cells. Submitted.

Van der Krieken SE, Popeijus HE, Mensink RP, Plat J. Search strategy for natural compounds that increase apolipoprotein A-I transcription in human liver cells. A focus on BRD4 inhibition. In preparation. 